\title{
Assessing the Role of Human Rights Protections for

\author{
Sexual Minorities in HIV Prevention in Asia:
}

\author{
A Meta-Analysis
}

by

JAMES EDWARD ANDERSON, B.P.A.P.M.

\author{
A thesis submitted to \\ The Faculty of Graduate Studies and Research \\ in partial fulfilment of \\ the requirements for the degree of
}

Master of Arts

The Norman Paterson School of International Affairs

Carleton University

Ottawa, Ontario

March 1, 2012

(C) 2012, James Edward Anderson 
Library and Archives

Canada

Published Heritage

Branch

395 Wellington Street

Ottawa ON K1A ON4

Canada
Bibliothèque et

Archives Canada

Direction du

Patrimoine de l'édition

395 , rue Wellington

Ottawa ON K1A ON4

Canada
Your file Votre référence

ISBN: 978-0-494-91560-8

Our file Notre référence

ISBN: $978-0-494-91560-8$
NOTICE:

The author has granted a nonexclusive license allowing Library and Archives Canada to reproduce, publish, archive, preserve, conserve, communicate to the public by telecommunication or on the Internet, loan, distrbute and sell theses worldwide, for commercial or noncommercial purposes, in microform, paper, electronic and/or any other formats.

The author retains copyright ownership and moral rights in this thesis. Neither the thesis nor substantial extracts from it may be printed or otherwise reproduced without the author's permission.
AVIS:

L'auteur a accordé une licence non exclusive permettant à la Bibliothèque et Archives Canada de reproduire, publier, archiver, sauvegarder, conserver, transmettre au public par télécommunication ou par l'Internet, prêter, distribuer et vendre des thèses partout dans le monde, à des fins commerciales ou autres, sur support microforme, papier, électronique et/ou autres formats.

L'auteur conserve la propriété du droit d'auteur et des droits moraux qui protege cette thèse. $\mathrm{Ni}$ la thèse ni des extraits substantiels de celle-ci ne doivent être imprimés ou autrement reproduits sans son autorisation.
In compliance with the Canadian Privacy Act some supporting forms may have been removed from this thesis.

While these forms may be included in the document page count, their removal does not represent any loss of content from the thesis.
Conformément à la loi canadienne sur la protection de la vie privée, quelques formulaires secondaires ont été enlevés de cette thèse.

Bien que ces formulaires aient inclus dans la pagination, il n'y aura aucun contenu manquant. 


\section{Abstract}

The notion of human rights being critical for HIV prevention is omnipresent within HIV discourse. In a world divided between States that criminalize homosexuality and those that protect sexual minorities, there is a need to better understand the relationship between human rights for sexual minorities and HIV prevention among men who have sex with men. To quantitatively measure this relationship, this study constructed an original instrument (the Sexual Orientation and Gender Identity Human Rights Index) to compare the legal environments for sexual minorities. Next, this study performed a meta-analysis on epidemiological and behavioural studies from 22 Asian countries in order to find national averages for HIV prevalence, inconsistent condom use, recent HIV testing, adequate HIV knowledge, and exposure to HIV prevention services. Although the relationships were mostly weak, the results do support the argument that greater human rights protections for sexual minorities is related to improved indicators of $\mathrm{HIV}$ prevention. 
I would like to thank the University of Ottawa for awarding me a 2009 Summer Social Justice Fellowship, which gave me the opportunity to intern at the United Nations Educational, Scientific and Cultural Organization (UNESCO) in Bangkok, Thailand. That experience formed the inspiration and driving force behind conducting this study.

I am grateful to the support provided to be me by my academic advisors, Prof. Valerie Percival (Carleton University), Prof. Penelope Simons (University of Ottawa), Prof. Edward Mills (University of Ottawa/University of British Columbia), and my supervisor, Prof. Yiagadeesen Samy (Carleton University). Also, the assistance with data analysis by Steve Kanters (Simon Fraser University, Center for Clinical Epidemiology and Evaluation) was invaluable.

Lastly, I would like to thank those who helped me translate studies; my uncle James W. Anderson, who helped edit this thesis; Tanya Brunet, who has been a constant source of strength and encouragement; and my friends, family and colleagues who have supported me throughout the past four years.

$\sim$ For my mother 


\section{Contents}

Abstract ii

Acknowledgments iii

Contents iv

List of Figures and Tables. $v$

Abbreviations $v i$

Terminology vii

1 Introduction

1.1 Overview of the global HIV epidemic among MSM 1

2 Theoretical Framework

2.1 Overview of public international law and human rights 13

The human right to health 13 Human rights protection for sexual minorities

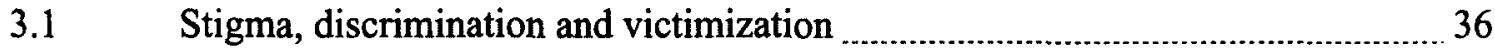

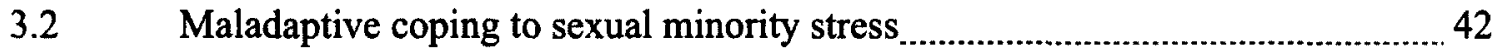

3.3 Mobilizing civil society and relationship recognition

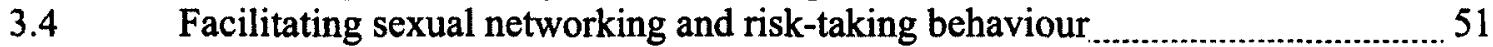

3.5 Conclusions from the literature review

4 Methodology

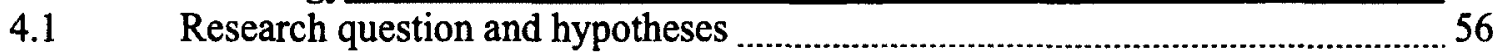

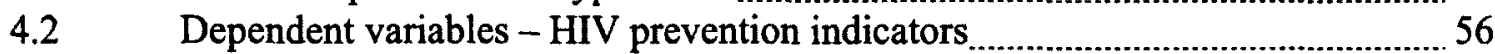

4.3 Independent variable - The SOGI Human Rights Index $\ldots$

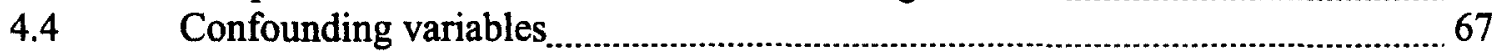

4.5 Data collection

5 Data Analysis 73

$5.1 \quad$ Summary of findings

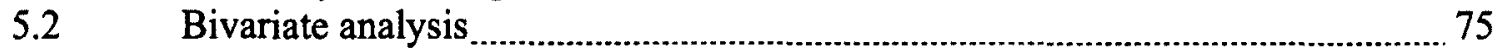

$5.3 \quad$ Multiple-regression analysis

6 Conclusions and Policy Recommendations 85

$6.1 \quad$ General conclusions 85

$6.2 \quad$ Policy recommendations

$7 \quad$ Appendix — 93

8 Bibliography _ 147

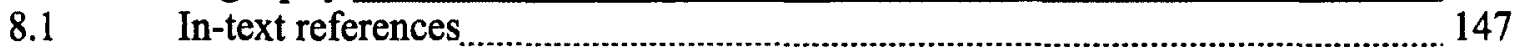

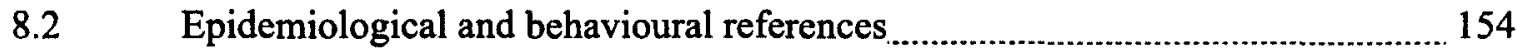

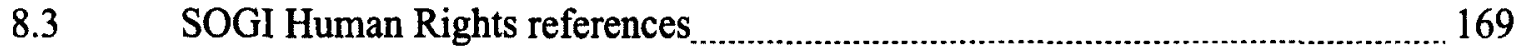


Figure 1: "Sexual minorities" constituting GLBT and MSM/WSW .................................... vii

Figure 2: Projected annual new HIV infections in Asia (status quo model) ............................ 3

Figure 3: Condom use among MSM ......................................................................... 7

Figure 4: HIV testing among MSM

Figure 5: HIV knowledge among MSM

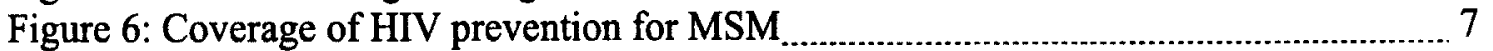

Figure 7: UN statement on sexual orientation, gender identity and human rights .................. 30

Figure 8: Pathways between MSM and HIV risk, mediated by human rights ....................... 35

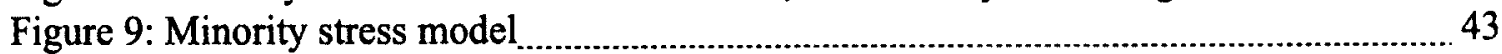

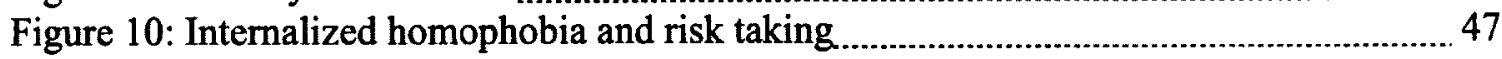

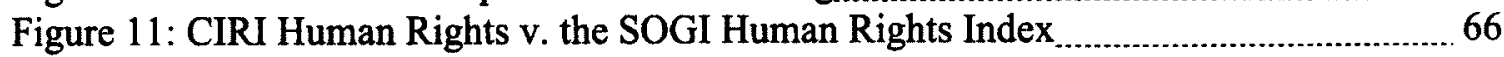

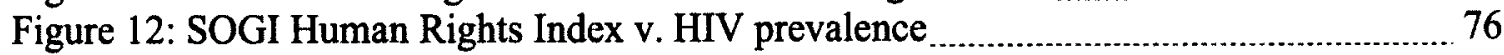

Figure 13: SOGI Human Rights Index v. inconsistent condom use ..................................... 77

Figure 14: SOGI Human Rights Index v. recent HIV testing ................................................ 78

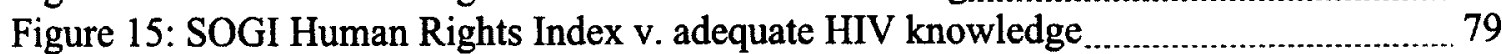

Figure 16: SOGI Human Rights Index v. exposure to HIV prevention ................................... 80

Figure 17: SOGI Human Rights Index v. HIV prevention indicators (combined) .................. 83

Figure 18: Projected annual new HIV infections in Asia (best practices model) ...................92

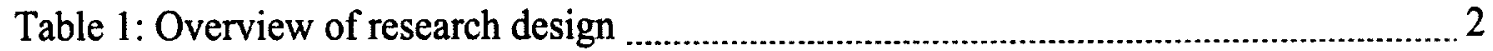

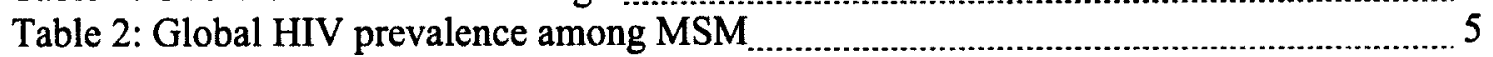

Table 3: Countries reporting on the four MSN-related indicators to UNGASS ..................... 6

Table 4: Estimates of lifetime and recent MSM behaviour in LMIC

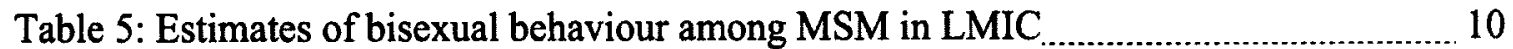

Table 6: Distribution of LMIC legal regimes with respect to sexual minorities ................... 12

Table 7: Principle 17 - The right to the highest attainable standard of health .......................... 32

Table 8: Existing and missing data from the UNGASS biannual reports................................ 57

Table 9: SOGI Human Rights Index template

Table 10: Confounding variables $\ldots$

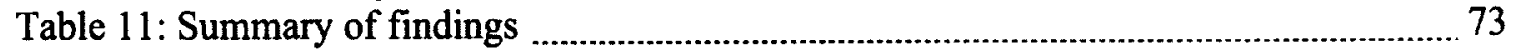

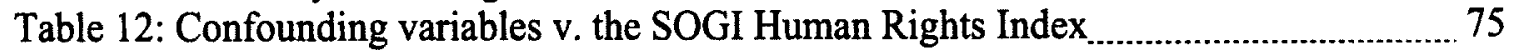

Table 13: Confounding variables v. HIV prevalence............................................................... 76

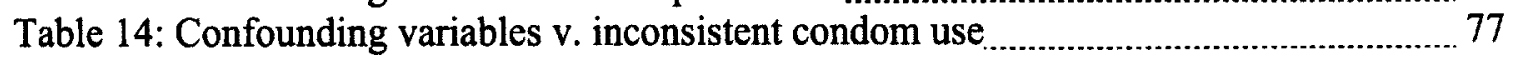

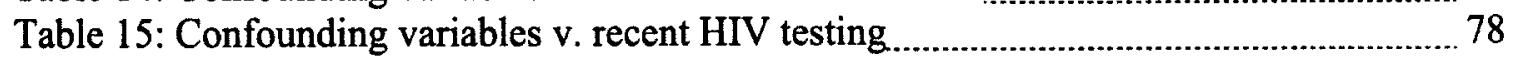

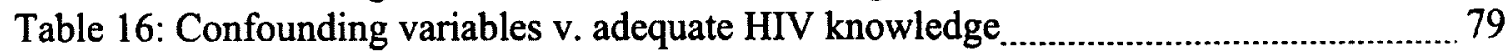

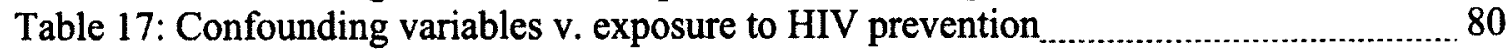

Table 18: Multiple-regression analysis of HIV prevention indicators each separately $\ldots . . . . . . .82$

Table 19: Multiple-regression analysis of HIV prevention indicators all combined .............. 83

Table 20: Comparison of HIV prevention indicators by legal regimes ................................90 90

Table 21: Inclusion of MSM in national strategic plans and surveillance in Asia .................. 91 


\begin{tabular}{|c|c|}
\hline AICHR & ASEAN Intergovernmental Commission on Human Rights \\
\hline AIDS & Acquired Immune Deficiency Syndrome \\
\hline ART & Anti-Retroviral Therapy (or Treatment) \\
\hline ASEAN & Association of Southeast Asian Nations \\
\hline $\mathrm{AU}$ & African Union \\
\hline BSS & Behavioural Sentinel Survey (or Surveillance) \\
\hline CAT & Convention Against Torture \\
\hline CBO & Community-Based Organization \\
\hline CEDAW & Convention on the Elimination of All forms of Discrimination Against Women \\
\hline CESCR & Committee on Economic, Social and Cultural Rights \\
\hline CRC & Convention on the Rights of the Child \\
\hline $\mathrm{CI}$ & Confidence Interval \\
\hline CIRI & Cingranelli-Richards (Human Rights Dada Project) \\
\hline ECtHR & European Court of Human Rights \\
\hline EU & European Union \\
\hline GLBT & Gay, Lesbian, Bisexual and Transgender \\
\hline HDI & Human Development Index \\
\hline HIV & Human Immunodeficiency Virus \\
\hline IDU & Injecting Drug Users/ Injection Drug Use \\
\hline IACHR & Inter-American Commission on Human Rights \\
\hline IBBS & Integrated Bio-Behavioural Surveillance \\
\hline ICCPR & International Covenant on Civil and Political Rights \\
\hline ICESCR & International Covenant on Economic, Social and Cultural Rights \\
\hline IGLHRC & International Gay and Lesbian Human Rights Commission \\
\hline ILGA & International Lesbian, Gay, Bisexual, Trans and Intersex Association \\
\hline IQR & Interquartile Range \\
\hline LMIC & Low- and Middle-Income Country \\
\hline MARP & Most At Risk Population \\
\hline MSM & Men who have Sex with Men \\
\hline MTF & Male-To-Female \\
\hline NCPI & National Composite Policy Index \\
\hline NGO & Non-Governmental Organization \\
\hline OAS & Organization of American States \\
\hline OIC & Organisation of Islamic Cooperation \\
\hline OR & Odds Ratio \\
\hline PDR & People's Democratic Republic (of Laos) \\
\hline PLWHA & People Living With HIV/AIDS \\
\hline SOGI & Sexual Orientation and Gender Identity \\
\hline UAI & Unprotected Anal Intercourse \\
\hline UDHR & Universal Declaration of Human Rights \\
\hline UN & United Nations \\
\hline UNAIDS & United Nations Joint Programme on HIV/AIDS \\
\hline UNESCO & United Nations Educational, Scientific and Cultural Organization \\
\hline UNGASS & United Nations General Assembly Special Session on HIV/AIDS \\
\hline WSW & Women how have Sex with Women \\
\hline
\end{tabular}


According to the Yogyakarta Principles:

"Sexual orientation" is understood to refer to each person's capacity for profound emotional, affectional and sexual attraction to, and intimate and sexual relations with, individuals of a different gender or the same gender or more than one gender.

"Gender identity" is understood to refer to each person's deeply felt internal and individual experience of gender, which may or may not correspond with the sex assigned at birth, including the personal sense of the body (which may involve, if freely chosen, modification of bodily appearance or function by medical, surgical or other means) and other expressions of gender including dress, speech and mannerisms. ${ }^{1}$

When discussing sexual orientation and gender identity (SOGI), the literature uses three related but not necessarily interchangeable concepts: GLBT, MSM and sexual minorities.

GLBT/LGBT: Identity-based approaches tend to use GLBT (gay, lesbian, bisexual, transgender) to refer to people who identify with a particular sexual orientation and/or gender identity. GLBT is used in an affirmative way as an expression of one's identity. However, the term excludes those who have GLBT-behaviours, but identify as "straight".

MSM/WSW: Behavioural-based approaches, common in health discourse, use MSM (men who have sex with men) to avoid labelling people based on their presumed identities and focus strictly on their behaviour. Male-to-female (MTF) transgender persons are sometimes included as MSM. As for women, the use of WSW (women who have sex with women) appears in the literature, but has not gained currency yet.

Sexual Minorities: Rights-based approaches use the term "sexual minorities" when referring to people whose sexual orientation or practices differ from the dominant heteronormative paradigm. This term, as illustrated in Figure 1 below, is intended to be comprehensive and includes those who identify as GLBT or behave as MSM/WSW.

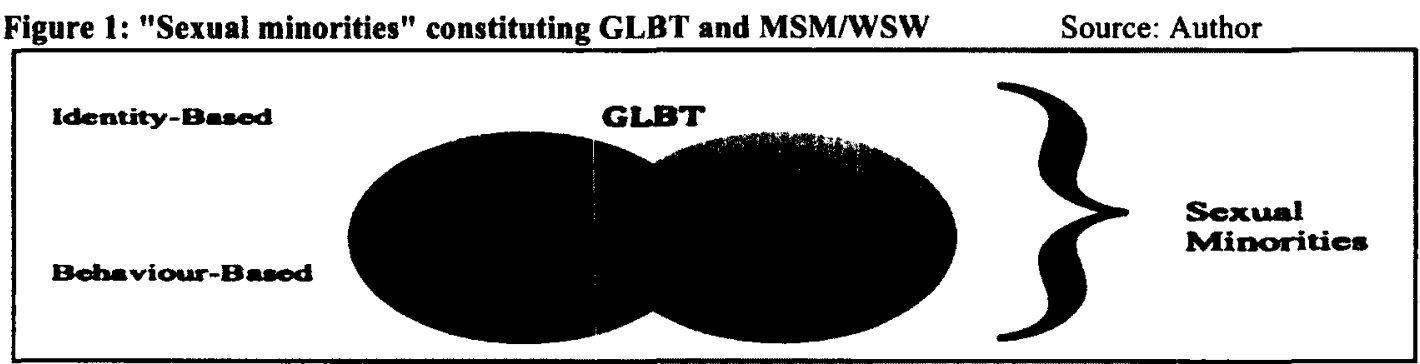

1 International Panel of Experts in International Human Rights Law and on Sexual Orientation and Gender Identity, The Yogyakarta Principles: Principles on the Application of International Human Rights Law in Relation to Sexual Orientation and Gender Identity, March 2007, at 6, online: $<w w w . y o g y a k a r t a p r i n c i p l e s . o r g />$. 


\section{Introduction}

Jonathan Mann was one of the earliest proponents of the view that human rights play a critical role in the HIV epidemic. During his time as head of the World Health Organization's HIV programme (the predecessor of UNAIDS), he observed that "HIV had the capacity to exploit the fault lines in an already unequal world", 2 and that "HIV is now becoming a problem mainly for les exclus, the 'excluded ones', living at the margin of society."3 This relationship between human rights, HIV, and marginalization has been analysed extensively over the years in the context of economic status, gender, and race.

Sexual minorities form another marginalized group that is disproportionately affected by HIV - especially homosexual men, bisexual men, and transgender male-tofemale individuals, grouped together as "men who have sex with men" (MSM). Due to the high risk of HIV transmission associated with unprotected anal intercourse (UAI), MSM are considered one of the most at risk populations (MARPs), along with sex workers and injecting drug users. Furthermore, information about MSM is hard to obtain because they are a hard to reach population due in large part to the stigmatization and discrimination that sexual minorities face nearly everywhere in the world.

"Even as the language of 'HIV and human rights' remains omnipresent, a gap in understanding exists as to what role human rights legitimately play in HIV [prevention] efforts." There are perhaps two main reasons for the knowledge-gap with respect to the role of human rights in HIV prevention among sexual minorities. First, countries that are homophobic and criminalize homosexual behaviour tend to have little or no data on the

2 Caceres, et al, "Sexual diversity, social inclusion and HIV/AIDS" (2008a) 22: Sup 2 AIDS s45 at s47. 3 Csete, "HIV/AIDS and human rights: we've only just begun" (2005) 10:1 HIV/AIDS Pol'y \& L. Rev. 7.

4 Gruskin, et al, "Beyond the numbers: using rights-based perspectives to enhance antiretroviral treatment scale-up" (2007) 21: Sup 5 AIDS s13 at s15. 
HIV epidemic among their MSM. Second, evidence from countries with progressive rights for sexual minorities also tend to have concentrated HIV epidemics among their MSM, which would seem to undermine the argument that human rights are critical to HIV prevention. ${ }^{5}$ Consequently, this data could be used as evidence supporting the need to criminalize homosexual behaviour in order to stop the spread of HIV.

This study endeavors to uncover, quantitatively, the relationship between human rights protection for sexual minorities and HIV prevention among MSM and transgender people in Asia. Table 1 below has an overview of the research design of this study.

Table 1: Overview of research design

\footnotetext{
Research Question:

How does variation in human rights protections for sexual minorities influence variation in indicators of HIV prevention among MSM and transgender people in Asia?

Hypothesis:

Greater human rights protection for sexual minorities is correlated with better indicators of HIV prevention among MSM and transgender people.

Independent Variable:

This study designed an original Sexual Orientation and Gender Identity Human Rights Index, which was used to measure and compare, quantitatively, the human rights environments for sexual minorities in 22 Asian countries.

Dependent Variables:

A meta-analysis (i.e., a synthesis of studies) was performed on HIV prevention data from 22 Asian countries. The 5 indicators of HIV prevention are: HIV prevalence, inconsistent condom use during the past 6 months, HIV testing with the past 12 months, adequate HIV knowledge, and exposure to HIV prevention services within the past 12 months.
}

Even though the implications for this study may very well extend to all regions, including developed countries, there are three main reasons why the focus of this project is on Asia. First, Asia has the second largest number of people living with HIV/AIDS after sub-Saharan Africa. Second, male-to-male transmission of HIV has been identified as one of the three main modes of transmission in the region and, if trends continue, MSM could account for nearly half of all new infections by 2020 (see Figure 2). Third, MSM behaviour is widely stigmatized and criminalized in many countries in the region, making it very difficult to openly discuss the health risks of MSM behaviour.

5 Wohfeiler, "Structural and environmental HIV prevention for gay and bisexual men" (2000) 14:Sup 1 AIDS s52 at s55. 
Figure 2: Projected annual new HIV infections in Asia (status quo model) Source: Commission on AIDS in Asia, at 57

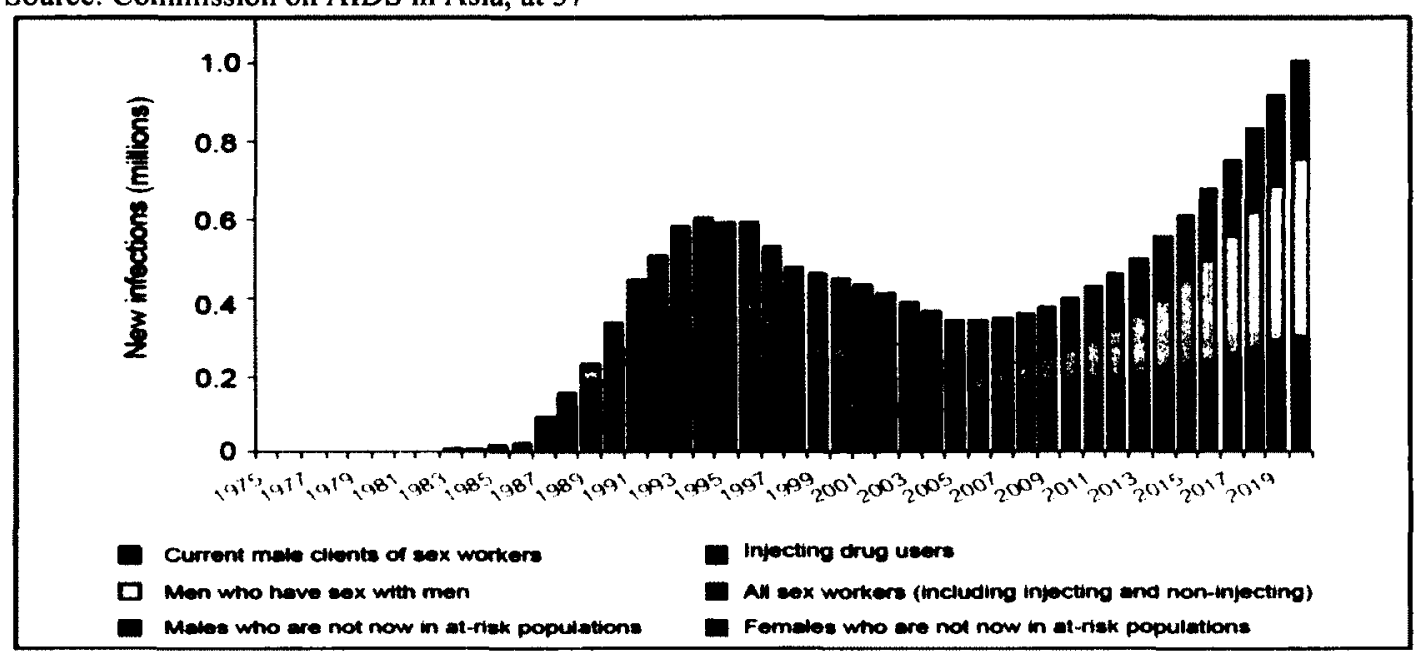

The balance of this Chapter reviews current global data related to HIV and MSM.

Chapter 2 examines the international legal obligation to respect, protect, and fulfil the highest attainable standard of health without discrimination based on sexual orientation. This human rights approach to preventing HIV among MSM serves as the theoretical framework for this study. Chapter 3 reviews the literature related to human rights for sexual minorities and HIV prevention among MSM. It explores four general pathways in which the existence or absence of human rights may affect indicators of HIV prevention.

Chapter 4 reviews the methodology used in this study. The research question, hypotheses, operationalization of variables, and the inclusion/exclusion criteria for data collection are presented. Of particular importance, this study's original Sexual Orientation and Gender Identity Human Rights Index is clearly presented in hopes that it can be refined and expanded for future use.

Finally, Chapter 5 presents the data analysis and Chapter 6 offers conclusions and policy recommendations. The Appendix contains the complete epidemiological and behavioural data and the sexual minority rights sources for each country under review. 
1.1 Overview of the global HIV epidemic among MSM

"A lack of data means a lack of action."

Before delving into the substantive part of this study, it is important to have a global picture of the HIV epidemic among MSM. The first section presents recent data on HIV prevalence and indicators related to HIV prevention among MSM. The next section explores important aspects of male sexuality: the prevalence of MSM behaviour (which is important for estimating the HIV burden of a country) and the prevalence of bisexuality among MSM (which can bridge HIV transmission from MSM to the general female population). The final section provides a global overview of laws persecuting and protecting sexual minorities, which depicts the structural context within which MSM live and HIV prevention efforts targeting MSN take place.

\section{A) Global HIV epidemiological and prevention trends among MSM}

In a systematic review of epidemiological studies of HIV, Baral, et al found that "in Latin America, MSM were 33 times more likely to have HIV [than the general adult population]; in Asia, more than 18 times; and in Africa, 3.8 times more likely." Other studies have also documented the alarmingly disproportionate HIV prevalence between MSM and the general adult population. ${ }^{8}$ One such study, by Griensven, et al, ${ }^{9}$ reviewed

6 Roehr, "The invisible epidemic" (2008) 337 British Medical Journal 1262 at 1263.

7 Baral, et al, "Elevated risk for HIV infection among men who have sex with men in low- and middle-income countries 2000-2006: a systematic review" (2007) 4:12 PLoS Med. e339 cited in Saavedra, et al, "Sex between men in the context of HIV: The AIDS 2008 Jonathan Mann Memorial Lecture in health and human rights" (2008) 11:9 J. Int'l AIDS Society at 2.

8 See e.g.,: Beyrer, "Hidden yet happening: the epidemics of sexually transmitted infections and HIV among men who have sex with men in developing countries" (2008) 84:6 Sex. Transm. Infect. 410; Beyrer, et al, "The Expanding Epidemic of HIV Type 1 Among Men Who Have Sex With Men in Low- and Middle-Income Countries: Diversity and Consistency" (2010) 32:1 Epidemiological Rev. 137; and Griensven and Wijngaarden, "A review of the epidemiology of HIV infection and prevention responses among MSM in Asia" (2010) 24: Sup 3 AIDS s30 at s32.

9 Griensven, et al, "The global epidemic of HIV infection among men who have sex with men" (2009) 4 Current Opinion in HIV \& AIDS 300 at 302 . It should be noted that missing data does not imply 
recent global prevalence and incidence data of HIV among MSM. Table 2 below, summarizes some of their key findings. Notably absent from their report is data from the

Middle East, where homosexuality is still very stigmatized.

Table 2: Global HIV prevalence among MSM

Source: Griensven, et al (2009) [Table compiled from data in report; Toronto data from a separate source]

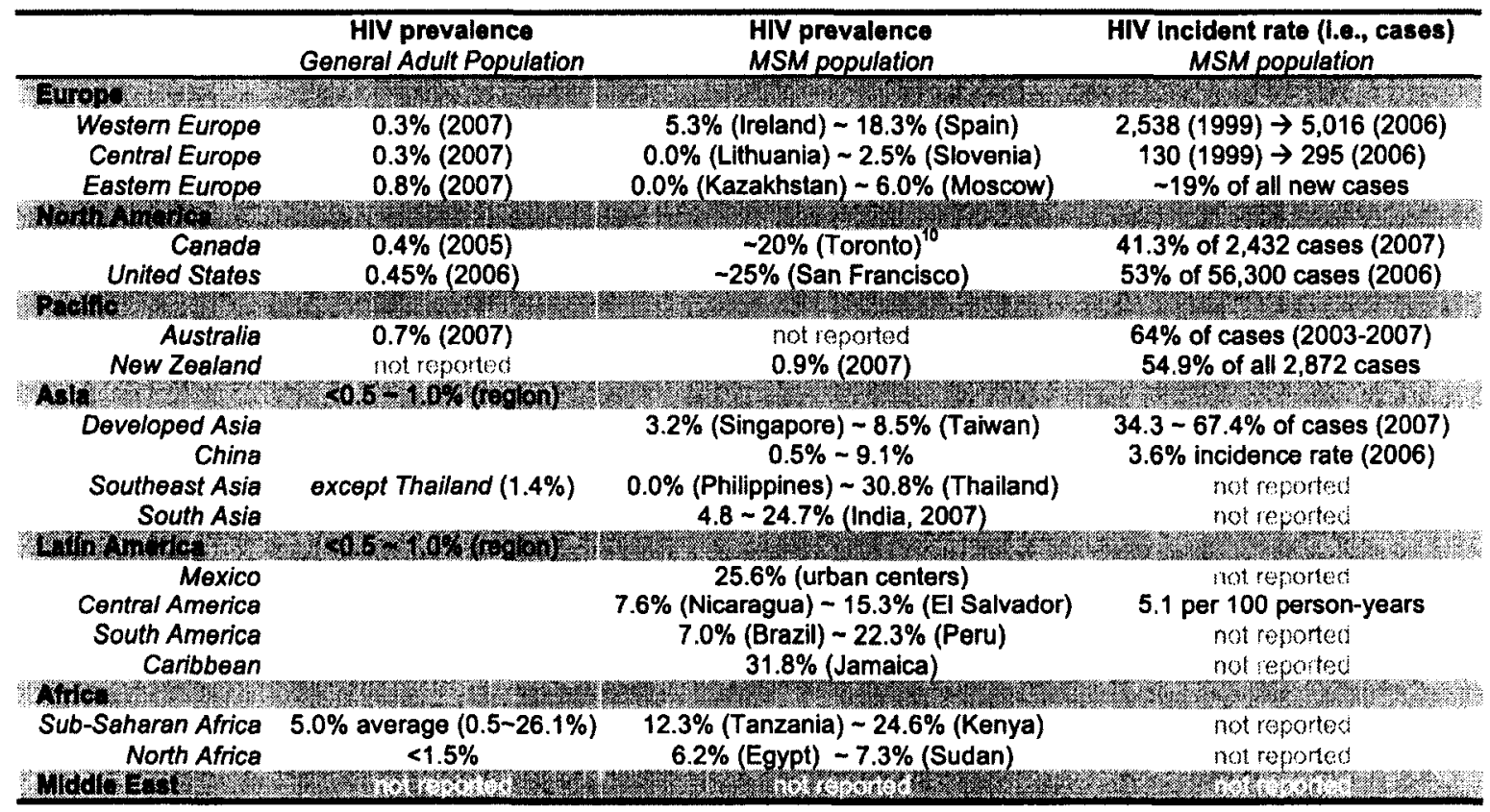

Since 2006, UN Member States have been encouraged to include data on HIV prevalence among MSM in their biannual reports to the UN General Assembly Special Session on HIV/AIDS (UNGASS). ${ }^{11}$ However, not all governments include MSM in their national HIV surveillance. Sometimes MSM are intentionally ignored in HIV surveillance, but other times they are ignored unintentionally by relying solely on antenatal testing to estimate their country's HIV burden. ${ }^{12}$ Thus, for the most part, data

that there is no data; rather, it only indicates that such data was not reported in their study.

10 Remis and Liu, "The Epidemiology of HIV infection among Men who have sex with other men in Ontario: The situation in 2005" in Ontario Gay Men's HIV Prevention Strategy: Gay, Bi, MSM Situation Report (Toronto: Ontario Ministry of Health and Long-Term Care, 2006) 107 at 132.

11 The 2001 Declaration of Commitment on HIV/AIDS (UN Doc A/Res/S-26/2) encourages UN Member States to report on their progress fighting HIV/AIDS (see paras 94-96). This is a political commitment and not an international legal commitment.

12 McFarland and Caceres, "HIV surveillance among men who have sex with men" (2001) 15: Sup 3 
on HIV prevalence among MSM is researched by non-governmental epidemiologists and usually limited to a few cities.

Three decades into the epidemic, HIV among MSM remains "under-studied, under-funded and frequently ignored or denied by governments." ${ }^{3}$ Epidemiological models suggest that, if HIV prevention coverage reached at least $80 \%$ of targeted at-risk populations (MSM in this case) and interventions induced behaviour change in at least $60 \%$ of the population, then the epidemic's upward trend could be reversed. ${ }^{14}$ In 2006 , a review of 38 countries with disaggregated financial data showed that only $\$ 3$ million was spent on MSM, while an estimated $\$ 29$ million of funding was needed to reach $80 \%$ of targeted MSM. ${ }^{15}$

In addition to HIV prevalence among MSM, UN Member States are also encouraged to report on four indicators of HIV prevention related to MSM in their biannual reports to UNGASS: condom use, HIV testing, HIV knowledge, and coverage of HIV prevention services. Unfortunately, many countries did report on these four MSM related indicators during the 2006, 2008, and 2010 UNGASS reporting years, evidenced in Table 3, leaving a knowledge gap for policy makers.

Table 3: Countries reporting on the four MSM-related indicators to UNGASS Source: UNAIDS $(2010)^{16}[\mathrm{~N}=$ total countries reporting in a given year/192 members of the UN]

\begin{tabular}{|c|c|c|c|}
\hline & $2006(N=143 / 192)$ & $2008(N=153 / 192)$ & $2010(N=182 / 192)$ \\
\hline $\begin{array}{l}\text { Condom use between MSM } \\
\text { HIV testing among MSM } \\
\text { HIV knowledge among MSM } \\
\text { Coverage of HIV prevention services for MSM }\end{array}$ & $\begin{array}{l}29 \\
22 \\
16 \\
18\end{array}$ & $\begin{array}{l}68 \\
70 \\
47 \\
43\end{array}$ & $\begin{array}{l}82 \\
83 \\
54 \\
53\end{array}$ \\
\hline
\end{tabular}

AIDS s23 at s24.

13 Saavedra, et al, supra note 7 at 2.

14 Commission on AIDS in Asia, Redefining AIDS in Asia: Crafting an Effective Response, (Oxford University Press: New Delhi, India, 2008) at 98.

15 Saavedra, et al, supra note 7 at 5 . The total HIV expenditure for the 38 countries was not reported.

16 Joint United Nations Programme on HIV/AIDS (UNAIDS), Global Report: UNAIDS Report on the Global AIDS Epidemic 2010, (Geneva: UNAIDS, 2010) at 209 and 224-225. Table compiled from data on various pages in the report; actual countries were not listed in the report. 
In a study of data submitted by low- and middle-income countries (LMIC) to UNGASS in 2008 concerning these four indicators, Adams, et al found that only 66 out of 147 LMIC reported on at least one of the four indicators. ${ }^{17}$ Their study found that "Globally weighted estimates indicate that on average, 31\% of MSM in LMIC were tested for HIV; $33 \%$ were reached by HIV prevention programs; $44 \%$ had correct HIV knowledge; and 54\% used condoms the last time they had anal sex with a man."18 Excluding North Africa and the Middle East (due to insufficient data), the lowest regional figures came from South and Southeast Asia, as indicated by following graphs:

Figure 3: Condom use among MSM

Source: Adams, et al, (2009) at s 148

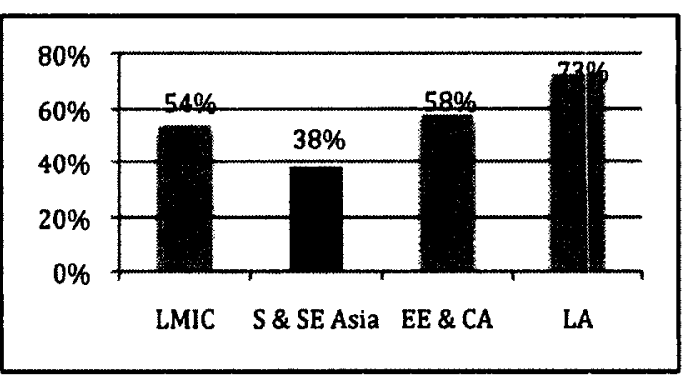

Figure 5: HIV knowledge among MSM Source: Adams, et al, (2009) at s146

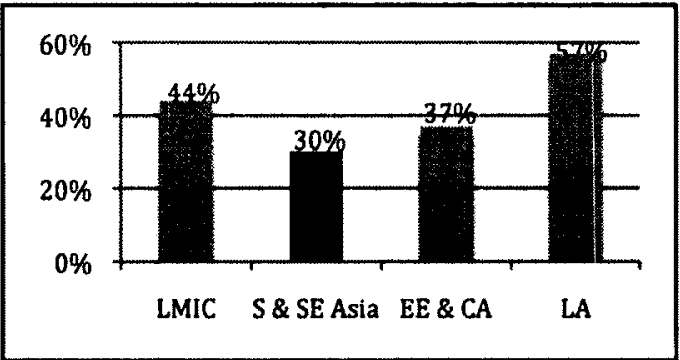

LMIC $=$ Low-Middle-Income Countries $E E \& C A=$ Eastern Europe and Central Asia
Figure 4: HIV testing among MSM

Source: Adams, et al, (2009) at s146

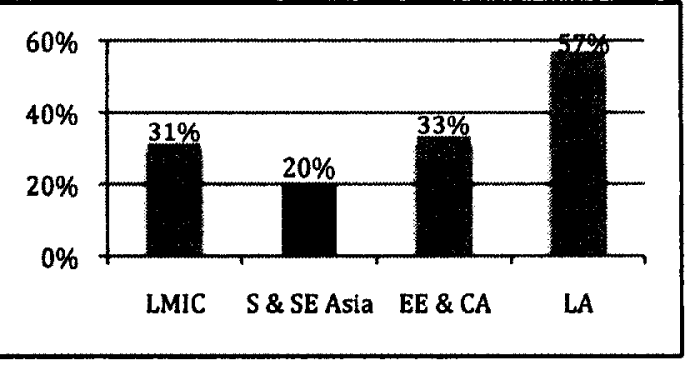

Figure 6: Coverage of HIV prevention for MSM Source: Adams, et al, (2009) at s 146

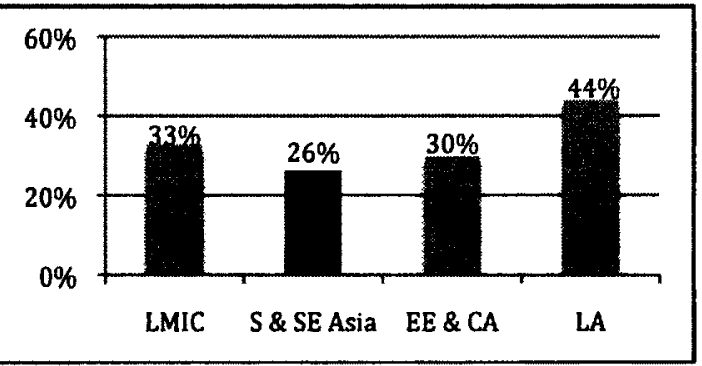

$S \& S E$ Asia $=$ South and Southeast Asia

$L A=$ Latin America

17 Adams, et al, "Estimating Levels of HIV Testing, HIV Prevention Coverage, HIV Knowledge, and Condom Use Among Men Who Have Sex With Men (MSM) in Low-Income and Middle-Income Countries" (2009) 52: Sup $2 J . A I D S$ s143. Depending on the indicator in question, additional countries were removed from the data set for inconsistent reporting style or that the sample size was too small (i.e., $\mathrm{n}<100$ ). 
Their study concluded that,

the HIV epidemics and prevention needs among MSM in [LMIC] have been relatively neglected. Compounded by limited resources, the quality and coverage of services and programs for MSM in (most) LMIC remain low, especially in contexts where the social stigma attached to male-tomale sex and the criminalization of this behavior is widespread. ${ }^{19}$

This is especially the case in the Middle East and North Africa. However, Caceres, et al emphasized that "this region is an example of the urgent need to address the social and political context before more meaningful data can even start to be collected that do not put research participants at risk of state violence in the first place."20

\section{B) The prevalence of MSM behaviour and bisexuality among MSM}

One of the reoccurring messages from UNAIDS is "know your epidemic". Yet, there is a knowledge gap in knowing the number of MSM in a country. Estimating the number of MSM is important to understanding the HIV burden in a country and to inform evidence-based policy making. ${ }^{21}$ Aside from respondents being dishonest while answering questions relating to same-sex sexual experience, there is usually no precise definition of "sex", which can take on a range of meanings depending on the cultural context. As Caceres, et al noted in their systematic review of studies reporting on samesexual behaviour, "[m]ost surveys reported [ever had sex with a man] without stating how sex had been defined in their survey, so that this could include anything from anal sex to mutual masturbation." 22 The best available estimates of global MSM behaviour comes from their systematic review of 561 epidemiological studies between 1990 and 2004 from

19 Ibid.

20 Caceres, et al, "Epidemiology of male same-sex behaviour and associated sexual health indicators in low- and middle-income countries: 2003-2007 estimates" (2008b) 84: Sup 1 Sex. Transm. Infect. i49 at i53.

$21 \quad$ Ibid at i50.

22 Caceres, et al, "Estimating the number of men who have sex with men in low and middle income countries" (2006) 82: Sup 3 Sex. Transm. Infect. iii3. 
LMIC, $^{23}$ of which only 67 reported data on MSM behaviour in the general population. In 2008 they updated their findings with studies from 2003-2007 (see Table 4).

Table 4: Estimates of lifetime and recent MSM behaviour among LMIC

Sources: Caceres, et al (2006) at iii5; and Caceres, et al (2008b) at i52 [Adapted: Combined both studies]

\begin{tabular}{|c|c|c|c|c|}
\hline & \multicolumn{2}{|c|}{ Lifetime MSM behaviour } & \multicolumn{2}{|c|}{ Recent MSM behaviour (past 12 months) } \\
\hline & $1990-2004$ & $2003-2007$ & $1990-2004$ & $2003-2007$ \\
\hline Africa, East-South & nidd & $1-4 \%$ & $n d t$ & nid \\
\hline Asia, East & $4 \%$ & $4-19 \%$ & not & nid \\
\hline Asia, Southeast & $7-12 \%$ & nid & $4 \%$ & $7 \%$ \\
\hline Asia, South & $6-8 \%$ & $8-34 \%$ & $7-8 \%$ & ned \\
\hline Caribbean & $1-3 \%$ & no & nid & nid \\
\hline Eastern Europe and Central Asia & $6-27 \%$ & $3 \%$ & nid & $n i d$ \\
\hline Latin America & $2-25 \%$ & $3-15 \%$ & $1-8 \%$ & $1-14 \%$ \\
\hline Middle East and rest of Africa & nid & nidi & $n / \alpha$ & $n i d$ \\
\hline
\end{tabular}

The denial of the existence of homosexuality or MSM behaviour in some countries continues to be a problem for developing appropriate public health policies. For example, a research team was told by "Togo government officials not to bother with their proposal to research MSM because they did not exist. The team persisted with a community-based ethnographic approach that identified 122 MSM and discovered key gaps in their knowledge of HIV risk." 24 In fact, the WHO has noted that "[h]igh HIV prevalence among MSM and transgender people is being reported from countries that had previously ignored or denied the existence of MSM in their populations."25 Ultimately, the social denial and criminalization of homosexuality makes it difficult for governments and community organizations to meet the health needs of MSM.

Another key aspect about "knowing your epidemic", is recognizing the potential bridging effect between HIV among MSM and the general female population through MSM bisexual behaviour. Many homosexual men feel compelled to hide their sexuality

23 lbid. Only studies quality-coded as "excellent" or "best data in the region" were included in their weighted regional estimates. Note: LMIC, by definition, exclude developed countries.

24 Mykhalovskiy, et al, "XVII International AIDS Conference: From Evidence to Action - Social, behavioural and economic science and policy and political science" (2009) 12: Sup 1 J. Intl. AIDS Society s5.

25 World Health Organization (WHO), Prevention and Treatment of HIV and other Sexually Transmitted Infections Among Men Who Have Sex with men and Transgender Populations: Report of a technical consultation, (Geneva, Switzerland: WHO, 15-17 September 2008) at 7. 
by having female sexual partners or even marrying. Thus, countries with sodomy laws not only force MSM to hide from the police and healthcare workers, but also force their wives and female partners to hide with them, creating "a dance of disaster". ${ }^{26}$ According

to Caceres, et al, recent bisexual activity as well as marriage are quite prevalent among MSM. Estimates of MSM from LMIC having had a recent female sexual partner and MSM who are married, based on studies collected between 2003-2007, are in Table 5. ${ }^{27}$

Table 5: Estimates of bisexual behaviour among MSM in LMIC Source: Caceres, et al (2008a) at i52.

\begin{tabular}{lcc}
\hline & Recent female sexual partner (past 12 months) & Married \\
\hline Africa, East-South & $50-69 \%$ & $n d$ \\
Africa, West-Central & $n d$ & $8-15 \%$ \\
Asia, East & $11-52 \%$ & $7-29 \%$ \\
Asia, Southeast & $40-70 \%$ & $3-13 \%$ \\
Asia, South & $20-98 \%$ & $21-42 \%$ \\
Caribbean & $11 d$ & $41 \%$ \\
Eastern Europe and Central Asia & $n \ell t$ & $7 \%$ \\
Latin America & $8-30 \%$ & $5 \%$ \\
Middle East and North Africa & $n i d$ & $16 \%$ \\
\hline
\end{tabular}

These rates of bisexual behaviour, coupled with high-risk behaviour common among MSM, could create a dangerous situation for the general female population. For instance, in a study of 491 MSM in Thailand, Griensven, et al documented high rates of both recent bisexual activity among MSM (22.3\%) and HIV prevalence (17.3\%), with none of the 491 men in their sample aware of their HIV status. ${ }^{28}$

A final area of concern is that many transgender people sell sex to heterosexualidentified men. The high rates of HIV "among transgender people can have a 'booster effect' on the spread of HIV through heterosexual commercial sex networks.,"29

26 Cary Alan Johnson, "Diverse sexualities/Disparate laws: Sexual minorities, the State and International Law" (April 3, 2010), Keynote address at the Harvard Law School.

27 Caceres, et al (2008b), supra note 20 at i52. Studies were collected through database searches, internet searches, and key reference people were contacted to acquire unpublished manuscripts. Only studies quality-coded as "excellent" or "best data in the region" were included.

28 Celentano, "Undocumented epidemics of HIV continue to persist in the twenty-first century" (2005) 19:5 AIDS 527; and Griensven, et al, "Evidence of a previously undocumented epidemic of HIV infection among men who have sex with men in Bangkok, Thailand" (2005) 19:5 J. AIDS 521. Monitoring the AIDS Pandemic (MAP) Network, Male-Male Sex and HIV/AIDS in Asia (2005) at 8. 


\section{C) Overview of laws affecting sexual minorities around the world}

According to the International Lesbian, Gay, Bisexual, Trans and Intersex Association (ILGA)'s 2010 annual report, State Sponsored Homophobia, at the end of 2009, five countries (Iran, Saudi Arabia, Mauritania, Yemen, and Sudan) along with parts of Nigeria and Somalia continue to enforce the death penalty for homosexuality. Globally, 76 countries criminalize homosexuality, which is one fewer than the previous year, since the High Court of Delhi read down the anti-sodomy law on July 2, 2009, "thus freeing one sixth of the [sexual minority] world population from legal persecution." ${ }^{30}$

In a report on legal environments and HIV among MSM in Asia and the Pacific, Godwin found that "in all countries in this region, MSM and transgender people face stigma and violence, but with few exceptions, there is no protective legislation in place to protect from or mitigate the effect of discrimination and violence." ${ }^{31}$ A similar study is currently underway at the global-level; in 2010, the UN launched the Global Commission on HIV and the Law, which will discuss the criminalization of homosexuality, sex work and HIV transmission, among other topics. ${ }^{32}$

Caceres, et $a l^{33}$ conducted a survey of repressive ${ }^{34}$ and protective ${ }^{35}$ legal regimes for sexual minorities in LMICs and their association with different legal traditions. More repressive legal regimes were correlated with common law and Islamic traditions,

30 Ottosson, "State-Sponsored Homophobia: A world survey of laws prohibiting same sex activity between consenting adults, an ILGA report" (May 2010) at 4.

31 Godwin, Legal environments, human rights and HIV responses among men who have sex with men and transgender people in Asia and the Pacific: An agenda for action, (Bangkok: APCOM-UNDP, 2010) at 110.

32 See: "Global Commission on HIV and the Law", online: <http://www.hivlawcommission.org/>.

33 Caceres, et al, "Review of Legal Frameworks and the Situation of Human Rights related to Sexual Diversity in Low and Middle Income Countries", (2008c) Commissioned by UNAIDS.

34 Repressive - countries whose laws prohibit sexual intercourse between people of the same sex, and impose penalties such as death, heavy labour, imprisonment or fines (ibid at 8).

35 Protective - countries whose laws prohibit discrimination against sexual diversity, and/or laws that recognize same-sex marriage/civil union, and transgender rights recognition (ibid at 8). 
whereas more protective legal regimes were correlated with civil law traditions. ${ }^{36}$ Table 6 captures the distribution of LMIC's legal regimes regarding sexual minority rights.

Table 6: Distribution of LMIC legal regimes with respect to sexual minorities

Source: Caceres, et $a l,(2008 \mathrm{~b})$ at 7 [Adapted: rows and columns switched and "totals" omitted]

\begin{tabular}{|c|c|c|c|c|c|}
\hline \multirow[b]{2}{*}{ Regions: } & \multicolumn{5}{|c|}{ Legal Regimes } \\
\hline & $\begin{array}{c}\text { Highly } \\
\text { Repressive }\end{array}$ & $\begin{array}{l}\text { Moderately } \\
\text { Repressive }\end{array}$ & Neutral & $\begin{array}{l}\text { Protection } \\
\text { Measures }\end{array}$ & $\begin{array}{l}\text { Recognition } \\
\text { Measures }\end{array}$ \\
\hline Sub-Saharan Africa & 18 & 12 & 15 & 1 & 1 \\
\hline Latin America & 0 & 3 & 5 & 3 & 6 \\
\hline Caribbean & 11 & 0 & 5 & 5 & 0 \\
\hline Middle East \& North Africa & 6 & 7 & 1 & 0 & 0 \\
\hline South Asia & 6 & 2 & 0 & 0 & 0 \\
\hline East Asia \& the Pacific & 8 & 5 & 9 & 2 & 0 \\
\hline Eastern Europe \& Central Asia & 0 & 2 & 11 & 6 & 8 \\
\hline
\end{tabular}

According to ILGA, "there is a directionally indicative correlation between higher expenditures from in-country resources [e.g., governmental funding] and MSM supportive policies. Expenditures are lower or not reported in countries classified as having homophobic policy environments." ${ }^{37}$ Others have even suggested that "[t]he success or failure of HIV programming is highly dependent on the legal and social environments of a country." ${ }^{38}$ However, there have been no quantitative studies to support or refute that assertion, at least none were found while conducting the literature review presented in Chapter 3. Therefore, this current study endavours to contribute to this body of research through a quantitative analysis of the role variations in the legal environment for sexual minorities has on MSM-related HIV prevention indicators.

$36 \quad$ Ibid.

37 Saavedra, et al, supra note 7 at 6.

38 Senior, "HIV, human rights, and men who have sex with men" (2010) 10: 7 Lancet 448 at 449. 


\section{Theoretical Framework}

The human rights approach to HIV prevention among MSM presented in this study relies on two key features of our current international human rights regime. First, States have a legal obligation to respect, protect, and fulfil their citizens' right to health, including sexual health. Second, international human rights provisions related to nondiscrimination have expanded over the past three decades prohibiting discrimination based on sexual orientation. ${ }^{39}$ Before delving into these two areas of human rights law, a brief overview of the sources of public international law and general structure of the human rights regime is presented.

\subsection{Overview of public international law and human rights}

In public international law, most of the rules governing State behaviour have been consented to through a treaty. With respect to human rights, the international community negotiated three primary documents, which together are commonly referred to as the International Bill of Rights: The Universal Declaration of Human Rights (UDHR), adopted in 1948; the International Covenant on Civil and Political Rights (ICCPR), adopted in 1966 and entered into force on March 23, 1976; and the International Covenant on Economic, Social and Cultural Rights (ICESCR), adopted in 1966 and entered into force on January 3, 1976. The latter two transformed the enumerated rights in the UDHR into legally binding rights with correlating duties on States to respect, protect and fulfil such rights. Since treaty law is consent-based, States are allowed (depending on the actual treaty provisions) to make "reservations" or interpretative

39 Protection from gender identity-based discrimination has been developing recently; however, currently such protection is lagging behind that of sexual orientation. 
"declarations", which can alter the application of certain treaty provisions internally to the State, or between States, again depending on the actual reservation.

Parallel to this body of law is "customary international law", which includes rules that have developed, usually over a period of time, based on the twin-requirements of repeated State behaviour and a belief that such behaviour is obligatory (opinio juris). Unfortunately, this area of international law is difficult to pinpoint with certainty, but the UN Human Rights Committee has listed the following rights and freedoms of the ICCPR as having become customary international law:

freedom from slavery; freedom from torture and cruel, inhumane, or degrading treatment or punishment; freedom from arbitrary arrest and detention; right to life and liberty; freedom of thought, conscience, and religion; the right to be presumed innocent until proven guilty; freedom from execution for pregnant women and children; freedom from advocacy of hatred based on nationality, race, or religion; freedom to marry; and the right of minorities to enjoy their own culture, religion, or use their own language. ${ }^{40}$

Unlike with treaty law, States cannot make a "reservation" to customary international law or a rule of $j u s$ cogens (a peremptory norm of international law where no derogation is permissible, such as the prohibition against genocide). However, if a State objects from the genesis of the formation of a customary norm, and continues to object, it could be considered a "persistent objector", which would relieve the State from that particular customary international legal obligation unless the norm is also a rule of $j u s$ cogens.

Treaty-based law and customary international law are by far the two most dominant sources of public international law. That said, according to Article 38 of the Statute of the International Court of Justice, other recognized sources of international law

40 Commission on Human Rights, General Comment 24(52), on issues relating to reservations made upon ratification or accession to the Covenant or the Optional Protocols thereto, or in relation to declarations under article 41 or the Covenant, UN Doc CCPR/C/21/Rev.1/Add.6 (1994) at para 8. 
include general principles of law, judicial decisions and the teachings of the most highly qualified publicists. $^{41}$ The latter two are very helpful in interpreting the meaning of treaty-based law, customary international law, and general principles of law, and have been used in developing the concept of the human right to health and non-discrimination based on sexual orientation.

Human rights law is in many ways a special type of public international law (i.e., sui generis). While all States have a legal interest in State compliance to human rights treaties, they may not have a political, social, or economic interest in monitoring compliance in the same way that they would in trade and investment treaties. That is not to say that there is no monitoring. The $\mathrm{UN}$ and various regional human rights regimes have developed a complex system of monitoring treaty compliance, including hearing complaints made by individuals against their own State. For instance, the UN Human Rights Committee, which oversees the ICCPR, can hear "communications" (not cases) to which the Committee will express their "view" (not decision). ${ }^{42}$ These "views" are not legally binding, unlike traditional judicial decisions such as those made by the European Court of Human Rights. However, the views of these quasi-judicial bodies serve a critical role in shaming a State into treaty compliance, as well as providing an authoritative interpretation of the human rights treaty obligation in question, which all parties to the treaty should follow. Most of the other UN human rights committees have the same authority to hear individual complaints. ${ }^{43}$

41 Charter of the United Nations and Statute of the International Court of Justice, June 26, 1945, 59 Stat. 1031, TS No. 993, 3 Bevans 1153 at art 38(1)(c)-(d).

42 Rehman, International Human Rights Law: A Practical Approach, (Harlow: Pearson Education Limited, 2003) at 91.

43 The Committee on the Elimination of Discrimination Against Women, the Committee against Torture, the Committee on the Rights of Persons with Disabilities, and the Committee on the Elimination of Racial Discrimination can all hear individual complaints as per their constitutive 
These committees also have the authority and mandate to issue General Comments or Recommendations, which can have the effect of clarifying a treaty obligation or giving broad application to decisions that had been made vis-à-vis individual States. They also engage with States in their mandatory periodic reporting. Ultimately, exercising these functions provide authoritative interpretations of their respective treaties, and have been used in the context of the right to health and in expanding anti-discrimination protection to sexual minorities.

United Nations Special Rapporteurs are another example of how the UN tries to ensure treaty compliance. The history of the UN Special Rapporteurs can be traced back to 1967 where Resolution 1235 of the Economic and Social Council authorized the Commission on Human Rights (now the Human Rights Council) to create "Special Procedures", where Working Groups (i.e., a group of human rights experts) or Special Rapporteurs (i.e., an individual human rights expert) are tasked with examining information on gross violations of human rights and/or making a thorough study of situations that reveal a consistent pattern of human rights violations. ${ }^{44}$ Currently, Special Rapporteurs examine discrete areas of human rights law and report thematically or on country-by-country basis, which again serves to name and shame States into compliance.

treaty or an optional protocol. The Committee on Economic, Social and Cultural Rights will have the authority to hear complains after 10 more States ratify the optional protocol to the ICESCR. On December 19, 2011 the UN General Assembly adopted a third protocol to the Convention on the Rights of the Child, which would give its monitoring committee the authority to hear individual complaints. Finally, the Committee on Migrant Workers will also be able to hear complaints after 10 States Parties have made a declaration accepting the committee's authority to hear such complaints.

44 UN Economic and Social Council, "Communications concerning human rights", Resolution 1235 (XLII) of the Economic and Social Council, UN Doc E/4393 (1967) at paras 2 and 3. 


\subsection{The human right to health}

Early international law considered health a domestic issue. The first few treaties were to protect the citizens of powerful States through notifications and quarantines. Since the adoption of the UDHR, the notion of a "right to health" began appearing in multilateral human rights treaties, the most important being the ICESCR. According to Article 12(1) of the ICESCR: "The States Parties to the present Covenant recognize the right of everyone to the enjoyment of the highest attainable standard of physical and mental health."45

Unlike the rights enumerated in the ICCPR, the right to health is considered a "progressively realized" right - meaning it does not have to be fulfilled immediately. The Committee on Economic, Social and Cultural Rights (CESCR), which oversees the ICESCR, has stated that the notion of progressive realization:

imposes an obligation to move as expeditiously and effectively as possible towards that goal. Moreover, any deliberately retrogressive measures in that regard would require the most careful consideration and would need to be fully justified by reference to the totality of the rights provided for in the Covenant and in the context of the full use of the maximum available resources. ${ }^{46}$

Furthermore, there is "a minimum core obligation to ensure the satisfaction of, at the very least, minimum essential levels of each of the rights." ${ }^{, 47}$ In the context of the right to health, the minimum core obligation would be to provide essential primary healthcare.

The right to health is also not a right to be healthy, but to the highest attainable standard, which depends on the resources of a State as well as supportive legislation and

International Covenant on Economic, Social and Cultural Rights, 16 December 1966, 993 UNTS 3, at art 12(1).

46 UN Committee on Economic, Social and Cultural Rights (CESCR), General Comment No. 3 (1990): The nature of States parties' obligations (Art 2, Para.1, of the Covenant), December 14, 1990, UN Doc E/1991/23, at para 9. 
policies. Thus, education and information play a important role in resource-scarce countries in fulfilling the right to health.

\section{A) The right to health in the context of HIV}

The CESCR has elaborated on the right to health in its General Comment No. 14. It highlighted the interconnectedness of the right to health with, inter alia, the right to work, education, life, non-discrimination, equality, privacy, access to information, and freedoms of associations, assembly, and movement. ${ }^{48}$ Especially relevant to the topic of this study, the CESCR recognized that the right to health extends beyond a right to healthcare and requires action on underlying determinants of health, such as "access to health-related education and information, including on sexual and reproductive health., 49 The notion of "accessibility" refers to not only physical health facilities, but also to issues of non-discrimination based on "sexual orientation", 50 and information accessibility such as "the right to seek, receive and impart information and ideas concerning health issues", 51 which has clear implications for HIV/AIDS related information.

States have three concurrent obligations under international human rights law: respect human rights, protect human rights, and fulfil human rights.

The obligation to respect means that States must refrain from interfering with or curtailing the enjoyment of human rights. The obligation to protect requires States to protect individuals and groups against human rights abuses. The obligation to fulfill means that States must take positive action to facilitate the enjoyment of basic human rights. ${ }^{52}$

In General Comment No. 14, the CESCR also illustrates how these three concurrent

48 UN CESCR, General Comment No. 14 (2000): The right to the highest attainable standard of health (article 12 of the International Covenant on Economic, Social and Cultural Rights), August 11, 2000, UN Doc E/ C.12/2000/4, at para 3.

49 Ibid at paras 11 and 14.

$50 \quad$ Ibid at para 18.

51 Ibid at para 12(b)(iv).

52 Office of the High Commissioner of Human Rights, "International Human Rights", online: $<\mathrm{http}$ ://www.ohchr.org/en/professionalinterest/Pages/InternationalLaw.aspx >. 
obligations apply to the right to health. Extracting only the references that relate to HIV, the obligation to respect requires States to refrain from "limiting access to contraceptives and other means of maintaining sexual and reproductive health, from censoring, withholding, or intentionally misrepresenting health-related information, including sexual education and information, as well as from preventing people's participation in healthrelated matters." $\$ 33$ The obligation to protect requires that a State Party exercise due diligence to ensure private actors do not violate the right to health. For instance, "[ensuring] that medical practitioners and other health professionals meet appropriate standards of education, skill, and ethical codes of conduct." ${ }^{\text {}}$ In many cases, healthcare practitioners may lack sensitivity to the unique health needs of sexual minorities. Finally, the obligation to fulfill the right to health includes providing information campaigns related to HIV/AIDS, providing sexual and reproductive health services, ensuring that healthcare staff are trained to meet the specific needs of vulnerable or marginalized groups, and to support people in making informed choices about their health. ${ }^{55}$ The CESCR also offers examples of violations of the right to health. One example in particular is when a State "adopts laws or policies that interfere with the enjoyment of any of the components of the right to health." ${ }^{.56}$ Laws that criminalize homosexuality would most likely violate the right to health.

The Committee on the Rights of the Child, which monitors the implementation and compliance of the Convention on the Rights of the Child, released two General Comments that have helped interpret the right to health. General Comment No. 4 deals

53 UN CESCR (2000), supra note 49 at para 34.

54 Ibid at para 35. Another relevant example to the discussion of HIV includes: "States should also ensure that third parties do not limit people's access to health-related information and services."

$55 \quad$ Ibid at paras 36-37.

$56 \quad$ lbid at para 50. 
with adolescent health and the rights of the child, specifically Article 6 (right to life, survival, and development) and Article 24 (right to health). In particular, it refers to nondiscrimination based on sexual orientation, ${ }^{57}$ access to correct information on sexuality, sexual behaviour, and risky lifestyles, ${ }^{58}$ attention to mental health concerns (e.g., suicide ideation), ${ }^{59}$ and, regarding HIV and other sexually transmitted infections, requires States "to take measures to remove all barriers hindering the access of adolescents to information, preventive measures such as condoms, and care". ${ }^{60}$ General Comment No. 3 specifically addresses HIV and how it can affect the fulfillment of most of the rights of the child. Emphasis was on education and access to information, and called on States to "refrain from censoring, withholding, or intentionally misrepresenting health-related information, including sexual education and information.",61

\section{B) Special Rapporteurs and the right to sexual health}

Perhaps some of the most relevant work in the area of health and human rights for the purposes of this study is the recent 2010 report by the Special Rapporteur on the Right of Everyone to the Highest Attainable Standard of Physical and Mental Health. The theme of Anand Grover's report was the relationship between the human right to health and "the criminalization of three forms of private, adult, consensual sexual behaviour: same-sex conduct and sexual orientation, sex work, and HIV transmission."62 As discussed in greater detail in Chapter 3, Grover notes the deleterious effects that

57 UN Committee on the Rights of the Child, General Comment No. 4 (2003): Adolescent health and development in the context of the Convention on the Rights of the Child, July 1, 2004, UN Doc CRC/ $\mathrm{GC} / 2003 / 4$, at para 6.

$58 \quad$ Ibid at para 16.

$59 \quad$ lbid at para 22.

$60 \quad$ Ibid at para 30.

61 UN Committee on the Rights of the Child, General Comment No 3 (2002): HIV/AIDS and the Rights of the Child, March 17, 2003, UN Doc CRC/GC/2003/3, at para 16.

62 Human Rights Council, Report of the Rapporteur on the right of everyone to the highest attainable standard of physical and mental health, Anand Grover, UN Doc A/HRC/13/20, April 27, 2010, at 1. 
criminalization has on the mental health of sexual minorities (evidenced by high rates of suicide); the refusals by healthcare practitioners to treat sexual minorities; that fear is a predominant factor in preventing sexual minorities from seeking HIV testing, prevention services, treatment or care; and finally, criminal laws "legitimize" existing prejudices, community violence and police brutality towards sexual minorities. ${ }^{63}$ His report concludes that "[c]riminalization is not only a breach of a State's duty to prevent discrimination; it also creates an atmosphere wherein affected individuals are significantly disempowered and cannot achieve full realization of their human rights."64

Paul Hunt, the former Special Rapporteur on the Right of Everyone to the Highest Attainable Standard of Physical and Mental Health, focused his 2004 report on the right to sexual and reproductive health. Hunt defined "sexual and reproductive health rights" as,

a state of physical, emotional, mental and social well-being related to sexuality, not merely the absence of disease, dysfunction or infirmity; sexual health requires a positive and respectful approach to sexuality and sexual relationships, as well as the possibility of having pleasurable and safe sexual experiences, free of coercion, discrimination and violence. ${ }^{65}$

Examples of sexual rights include: the right to seek, receive, and impart information related to sexuality; the right to choose their partner; the right to decide whether or not to be sexually active; and the right to pursue a satisfying, safe and pleasurable sexual life. ${ }^{66}$

Realizing some of these sexual health rights for adolescents can be critical to HIV

63 Ibid at paras $17-20$.

$64 \quad$ lbid at para 25.

65 Commission on Human Rights, Report of the Rapporteur on the right of everyone to the highest attainable standard of physical and mental health, Paul Hunt, UN Doc E/CN.4/2004/49, February 16, 2004 at para 53. The concept of "sexual and reproductive health" first appeared at the International Conference on Population and Development in 1994. Subsequently, sexual and reproductive health rights have appeared in the context of women's rights, children's rights, the Millennium Development Goals, and of course, the 2001 Declaration of Commitment on HIV/AIDS, and the 2006 and 2011 Political Statements of Commitment on HIV/AIDS.

66 Glasier, et al, "Sexual and Reproductive Health: a matter of life and death" (2006) 368:9547 Lancet 1595 at 1596. 
prevention programs, since these are the formative years where safer sex practices can be learned.

Although sexual and reproductive health rights are usually discussed in the context of women, pre- and post-natal care, childbirth, and rights to family planning, Hunt goes beyond these issues and flags a few that are especially relevant to this study. "Some traditional views about sexuality are obstacles to the provision of sexual and reproductive health services, including reliable information, and these views have an especially damaging impact upon adolescents." ${ }^{.67}$ Stigma and discrimination "pose a serious threat to sexual and reproductive health for many groups [including] sexual minorities." ${ }^{, 68}$ The stigma and discrimination related to HIV

may also reinforce other prejudices, discriminations and inequalities related to gender and sexuality. The result is that those affected may be reluctant to seek health and social services information, education and counseling, even when those services are available. This in turn, contributes to the vulnerability of others to HIV infections. ${ }^{69}$

Finally, Hunt refers to the prohibition in international law to discriminate on the grounds of sexual orientation (explored in greater detail in section 2.3 below), and recommends that States "should ensure that sexual and other health services are available for men who have sex with men, lesbians and transsexual and bisexual people."70

\subsection{Human rights protection for sexual minorities}

In the wake of the Second World War, the modern international human rights movement was born. Unfortunately, despite the fact that Nazi Germany targeted

67 Commission on Human Rights (2004), supra note 65 at para 14.

68 Ibid at para 33.

69 Ibid at para 35.

$70 \quad$ Ibid at para 39. 
homosexuals in their efforts to purify their nation, ${ }^{71}$ the international community did not include sexual orientation as one of the enumerated grounds of non-discrimination and equality. According to professor Douglas Sanders, ${ }^{72}$ there are at least four factors that could explain the omission of sexual orientation in the early international human rights instruments. First, the extent of the holocaust (i.e., the atrocities committed against homosexuals) was not fully known during the treaty negotiations. Second, homosexuality was considered a mental illness and remained on the International Classification of Diseases list until 1990. Third, homosexuality was criminalized throughout much of the world. Fourth, a "gay rights movement" did not begin to develop until after the treaties were concluded. Thus, gay rights activists have had to make creative arguments under the enumerated grounds of "sex" or "other status", to fight for sexual minorities' rights to privacy and equality.

\section{A) The treatment of "sexual orientation" by regional organizations}

Advances in human rights protections for sexual minority began in the European human rights regime. In Dudgeon v. The United Kingdom (1981), ${ }^{73}$ Norris v. Republic of Ireland (1988), ${ }^{74}$ and Modinos v. Cyprus (1993), ${ }^{75}$ the European Court of Human Rights

(ECtHR) held that the criminalization of homosexual conduct violated the right to

71 "The Nazi campaign against homosexuality targeted the more than one million German men who, the state asserted, carried a 'degeneracy' that threatened the 'disciplined masculinity' of Germany. Denounced as 'antisocial parasites' and as 'enemies of the state,' more than 100,000 men were arrested under a broadly interpreted law against homosexuality. Approximately 50,000 men served prison terms as convicted homosexuals, while an unknown number were institutionalized in mental hospitals. Others-perhaps hundreds-were castrated under court order or coercion. Analyses of fragmentary records suggest that between 5,000 and 15,000 homosexual men were imprisoned in concentration camps, where many died from starvation, disease, exhaustion, beatings, and murder." United States Holocaust Memorial Museum, "Nazi Persecution of Homosexuals 1933-1945" online: $<$ http://www.ushmm.org/museum/exhibit/online/hsx/>.

72 Personal communication from Douglas Sanders, professor emeritus, Faculty of Law, University of British Columbia, and professor, Chulalongkorn University, Bangkok, Thailand (February 27, 2012).

73 Dudgeon $v$ The United Kingdom, 4 Eur HR Rep 149 (1981).

$74 \quad$ Norris $v$ Republic of Ireland, 13 Eur HR Rep 186 (1989).

75 Modinos v Cyprus, 16 Eur HR Rep 485 (1993). 
privacy, which includes one's sexual life. The ECtHR also held that even a consistent policy to not prosecute sodomy was no substitute for full repeal. ${ }^{76}$ In Lustig-Prean $v$. United Kingdom (1999), ${ }^{77}$ the ECtHR ruled that the ban on homosexuals from military service was discriminatory. With respect to treaty-based law, the Treaty of Amsterdam, which amended the European Union, is the first and only international treaty that explicitly mentions "sexual orientation". The Treaty of Amsterdam, which entered into force in 1999, requires EU Member States to combat discrimination based on sexual orientation. $^{78}$

The Organization of American States (OAS), the only other regional organization that has commented on sexual orientation, has passed three recent resolutions ${ }^{79}$ on human rights, sexual orientation, and gender identity. These resolutions condemn violence against sexual minorities and encourage States to enact protections from violence and discrimination. The only case heard by the Inter-American Commission on Human Rights (IACHR) was Marta Alvarez v. Colombia (1998). ${ }^{80}$ Marta Alvarez was denied conjugal visits from her same-sex partner in the same prison. Heterosexual couples within the same prison, however, were granted this right. In Marta Alvarez, the IACHR found the case to be "admissible", citing that all local remedies had been exhausted and decided to continue analyzing the merits of the complaint. ${ }^{81}$ The IACHR never released a decision on the merits because, "[a]fter years of litigation, in November of 2002, a local

$76 \quad$ Norris $v$ Republic of Ireland, supra note 74, at para 33; and Modinos v Cyprus, ibid, at para 18.

77 Lustig-Prean v United Kingdom, 29 Eur HR Rep 548 (1999).

78 Treaty of Amsterdam amending the Treaty on European Union, the Treaties establishing the European Communities and certain related acts, October 2, 1997, entered into force May 1, 1999, at art 5(2)(7).

79 AG/RES. 2600 (XL-O/10), AG/RES. 2504 (XXXIX-O/09), and AG/RES. 2435 (XXXVIII-O/08).

80 Colombia: Report $N^{\circ} 71 / 99$ Marta Lucia Alvarez Giraldo, Admissibility, Case 11.656, May 4, 1999.

$81 \mathrm{Ibid}$ at paras 15 and 23. 
Colombian judge granted visitation rights to Alvarez." 82

So far the Organisation of Islamic Cooperation (OIC), the African Commission on Human and People Rights, and the Association of South East Asian Nations (ASEAN) have not addressed sexual orientation or gender identity. The OIC adopted the Cairo Declaration of Human Rights in Islam in 1990, which states, "[a]ll the rights and freedoms stipulated in this Declaration are subject to the Islamic Shariah."83 Since Sharia law condemns homosexuality, this declaration could never be interpreted to protect sexual orientation and gender identity. The African Commission on Human and People Rights oversees the African Charter of Human and Peoples' Rights, which may address issues of sexual orientation and gender identity in the future. ${ }^{84}$ Finally, ASEAN has just recently launched the ASEAN Intergovernmental Commission on Human Rights (AICHR) in 2009. One of AICHR's first goals is to develop an ASEAN human rights treaty giving AICHR a mandate to investigate human rights violations.

\section{B) "Asian Values" as a potential threat to sexual minority rights}

Although most Western countries blindly accept the notion that human rights are "universal", there is debate in other regions about the universality of what are often seen as "Western" human rights. In Asia, for instance, the "Asian Values" debate continues to

82 Rothschild, Written Out: How sexuality is used to attack women's organizing, (New York: International Gay and Lesbian Human Rights Commission and the Center for Women's Global Leadership, 2005) at 60, footnote 146.

83 Cairo Declaration of Human Rights in Islam, adopted by and proclaimed by Organization of Islamic Conference resolution 217 A (III) on 5 August 1990.

84 Evans and Murray, eds, The African Charter on Human and Peoples' Rights: The System in Practice, 1986-2006, 2d ed, (Cambridge: Cambridge University Press, 2008) at 184: "The only communication brought to the Commission regarding discrimination on the grounds of sexual orientation - challenging Zimbabwe's criminalisation of same-sex behaviour - was withdrawn by the complainant before it could be considered, leaving this vexed question unexamined by the premier African human rights institution. Commissioners have, however, ask questions of both Cameroon and Namibia during the examination of State reports in relation to the States' attitude to same-sex behaviour; and of South Africa from the other perspective, by Commissioner El Hassan of Sudan, who questioned South Africa in 2005 about the possibility of same-sex marriage seen in the light of article $18(3)$ of the African charter relating to the family as the 'natural unit and basis of society'." 
have a significant impact on how human rights are perceived and practiced. Three dichotomies inform the "Asian Values" debate: first, individual rights must yield to community and family rights; ${ }^{85}$ second, Asian societies are "structured around duties, not rights, and any rights held by individuals, families, or communities were largely dependent on the discharge of duties"; ${ }^{86}$ and third, adopting Western human rights would come at the cost of both security and economic development. As a result, "many Asian governments do not accept international human rights standards or the universality of human rights absolutely, but claim that such universality may have to bend, and at times be subjected, to national and regional 'particularities' ."87

The Bangkok Declaration (1993), adopted by Asia-Pacific States in preparation for the World Conference on Human Rights in Vienna, is perhaps the most public and international articulation of the "Asian Values" concept. The Bangkok Declaration stipulated that:

While human rights are universal in nature, they must be considered in the context of a dynamic and evolving process of international norm-setting, bearing in mind the significance of national and regional particularities and various historical, cultural and religious backgrounds. ${ }^{88}$

This articulation of "Asian Values" can still be seen today, as evidenced in the Terms of Reference for the ASEAN Intergovernmental Commission on Human Rights (2009). Although Article 2.2 of the Terms of Reference recognizes that human rights are universal, indivisible, interdependent, and interrelated, Article 1.4 requires that the

85 Chew, "Human Rights in Singapore: Perceptions and Problems" (1994) 34:11 Asian Survey 933 at 935.

86 Donnelly, "Human Rights and Asian Values: A Defense of "Western" Universalism", in Joanne R. Bauer and Daniel A. Bell, eds, The East Asian Challenge for Human Rights (Cambridge: Cambridge University Press, 1999) 60 at 78.

87 Muntarbhorn, "Asia, Human Rights and the New Millennium: Time for a Regional Human Rights Charter?" (1998) 8 Transn'l L. \& Contemp. Prob. 408 at 409.

88 The Bangkok Declaration, March 29-April 3, 1993, reprinted in Muntarbhorn, Ibid at 410. 
Commission be mindful of national and regional particularities and mutual respect for different historical, cultural, and religious backgrounds. ${ }^{89}$ The persistence of "Asian Values" in ASEAN human rights discourse will be a challenge to the realization of sexual minorities' right to health. Professor Sanders, an expert on sexual minority rights in Asia, cautioned that "the shift of Asian governments towards supporting human rights in general does not automatically mean a shift in favor of homosexual rights." ${ }^{.90}$

\section{C) The treatment of "sexual orientation" by the United Nations}

Even though no international human rights treaty explicitly mentions "sexual orientation" or "gender identity", over the years the UN treaty monitoring bodies have all interpreted their respective treaties to include protection from discrimination on such grounds. ${ }^{91}$ One of the most important developments in international human rights for sexual minorities was the UN Human Rights Committee's decision in Toonen v. Australia (1994). ${ }^{92}$ Australia, by 1994, had decriminalized sodomy in every state except Tasmania. Mr. Toonen, a resident of Tasmania, argued that his right to privacy under the ICCPR was being violated. Tasmania argued that the criminalization of homosexuality was part of their HIV/AIDS prevention strategy. In rejecting Tasmania's position, the UN Human Rights Committee said:

The Australian Government observes that statutes criminalizing homosexual activity tend to impede public health programmes "by driving underground many of the people at the risk of infection". Criminalization of homosexual activity thus would appear to run counter to the implementation of effective education programmes in respect of the HIV/AIDS prevention. Secondly, the Committee notes that no link

89 Terms of References for the ASEAN Intergovernmental Commission on Human Rights, adopted at the 42nd ASEAN Foreign Ministers Meeting on July 20, 2009, held in Phuket, Thailand.

90 Godwin, supra note 31 at 14.

91 Lau, "Sexual Orientation: Testing the Universality of International Human Rights Law" (2004) 71 U. Chicago L. Rev. 1689, at 1702, footnote 84.

92 Toonen v Australia, Communication No 488/1992, UN Doc CCPR/C/50/D/488/1992 (1994). 
has been shown between the continued criminalization of homosexual activity and the effective control of the spread of the HIV/AIDS virus. ${ }^{93}$

The effect of the decision in Toonen was finally realized in 1996, when a Tasmanian court struck down the anti-sodomy law, which was officially repealed a year later.

In this landmark decision for sexual orientation rights, the UN Human Rights Committee decided that discrimination based on "sexual orientation" is included under the term "sex" in Article 2 of the ICCPR. After Toonen, legal scholars, reflecting on the developments of international human rights law protecting sexual minorities, contend that "[as] a matter of international law, sexual orientation discrimination is a form of sex discrimination. Indeed, the former is not possible without reference to the sex of the individual." 94

The only other cases involving sexual orientation heard by the UN Human Rights Committee were Joslin v. New Zealand $(1999)^{95}$ and Young v. Australia (2000). ${ }^{96}$ In Joslin, the Committee rejected the claim that New Zealand's definition of marriage violates the ICCPR. However, in Young, the Committee agreed with the claim that Australia was violating the anti-discrimination provisions in the ICCPR by allowing survivor benefits only for unmarried opposite-sex partners. The distinction in these cases was that in Joslin the Committee found no positive obligation on States to extend marriage to same-sex couples, whereas, in Young, once the State had turned its mind to extending survivor benefits to unmarried couples, it must do so without discrimination.

The UN Human Rights Committee's decisions are authoritative interpretations of

$93 \quad$ Ibid at 8.5 .

94 International Commission of Jurists, Submission to the Supreme Court of the State of Nepal, Providing the Basis in International Human Rights Law for the Prohibition of Discrimination Based on Sexual Orientation and Gender Identity and Other Connected Matters, January 9, 2008 at 5.

95 Joslin v New Zealand, Communication No 902/1999, UN Doc CCPR/C/75/D/902/1999 (1999).

96 Young $v$ Australia, Communication No 941/2000, UN Doc CCPR/C/78/D/941/2000 (2003). 
the rights and obligations of the ICCPR. As such, the decision in Toonen has been referred to in many cases (both domestic and international), and has helped interpret the international obligations under the ICCPR as well as other human rights treaties. For instance, in 1999 the Committee on the Elimination of Discrimination against Women recommended that "lesbianism be reconceptualized as a sexual orientation and that penalties for its practice be abolished."97 In 2000, the CESCR interpreted "other status" to include "sexual orientation" as a prohibited ground of discrimination. ${ }^{98}$ This was reiterated in the CESCR's General Comment No. 20 (2009), which listed recognized groups that are to be included under "other status", and referred to the Yogyakarta Principles for defining the sexual orientation and gender identity. ${ }^{99}$ In 2004 , the Committee on the Rights of the Child expanded the enumerated grounds for protection against discrimination in Article 2 to "cover adolescent's sexual orientation and health status (including HIV/AIDS and mental health)."100

Over the past decade, the UN Special Rapporteurs and Special Representatives ${ }^{101}$

97 UN Committee on the Elimination of Discrimination against Women, Concluding Observations of the Committee on the Elimination of Discrimination Against Women: Kyrgyzstan, January 27, 1999, UN Doc CEDAW/A/54/38, at paras 127-128.

98 UN CESCR, General Comment No. 14: The right to the highest attainable standard of health, August 11, 2000, UN Doc E/C.12/2000/4, at para 18.

99 UN CESCR, General Comment No. 20: Non-Discrimination in Economic, Social and Cultural Rights (art. 2, para. 2), June 10, 2009, UN Doc E/C.12/2GC/20, at para 32.

100 UN Committee on the Rights of the Child, General Comment No. 4 (2003): Adolescent health and development in the context of the Convention on the Rights of the Child, July 1, 2004, UN Doc $\mathrm{CRC} / \mathrm{GC} / 2003 / 4$, at para 6 .

101 The following list of documents prepared by Special Rapporteurs have made explicit reference to sexual orientation and/or gender identity: Special Rapporteur on extrajudicial, summary or arbitrary executions, UN Doc A/HRC/4/20/Add.2 (2007); Special Rapporteur on the promotion and protection of the right to freedom of opinion and expression, UN Doc E/CN.4/2001/64 (2001); Special Representative of the Secretary-General on the situation of human rights defenders, UN Doc A/HRC/4/37/Add.2 (2006); Special Rapporteur on contemporary forms of racism, racial discrimination, xenophobia and related intolerance, UN Doc E/CN.4/1999/15/Add.1 (1999); Special Rapporteur on torture and other cruel, inhuman or degrading treatment or punishment, UN Doc E/CN.4/2000/9 (2000); Special Rapporteur on violence against women, its causes and consequences, UN Doc E/CN.4/2002/83 (2002), UN Doc E/CN.4/2005/72 (2005), and UN Doc A/HRC/4/34/Add.1 (2007); and Special Rapporteur on the right of everyone to the highest attainable standard of 
have been growing increasingly concerned about human rights violations against sexual minorities. Their important work helps with norm building through monitoring, reporting, praising, and shaming UN Member States.

On December 18, 2008, Argentina, on behalf of the 65 other Member States, delivered an historic statement on sexual orientation, gender identity, and human rights to the UN General Assembly. ${ }^{102}$ The statement reaffirms that the principle of universality of human rights applies to every human being regardless of sexual orientation or gender identity. The statement also calls on States to decriminalize homosexual acts. In May 2009 , with the change in administration, the United States added their support to Argentina's statement, bringing the total number of supporters to 67 . Syria, however, delivered an opposing statement on behalf of 56 other like-minded States.

Figure 7: UN statement on sexual orientation, gender identity and human rights Source: <http://en.wikipedia.org/wiki/UN_declaration_on_LGBT_rights>

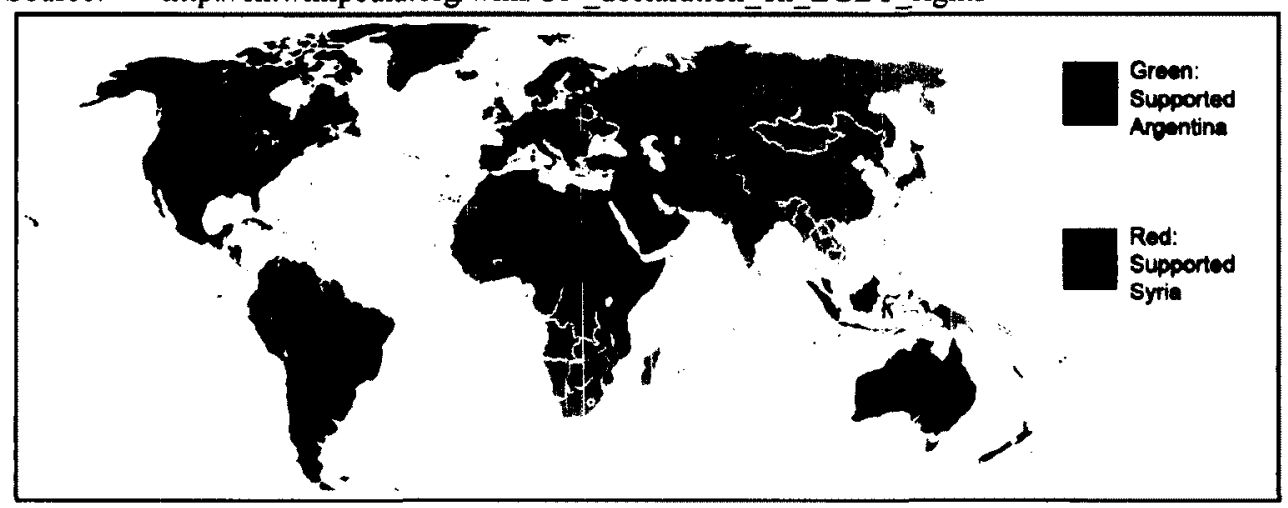

Since the $2008 \mathrm{UN}$ statement, there have been two noteworthy votes at the UN.

First, with only 23 in favour, 13 against, and 13 abstentions, the International Gay and

physical and mental health UN Doc A/HRC/13/20 (2010), and UN Doc E/CN.4/2004/49 (2004).

102 United Nations General Assembly, Annex to the letter dated 18 December 2008 from the Permanent Representatives of Argentina, Brazil, Croatia, France, Gabon, Japan, the Netherlands and Norway to the United Nations addressed to the President of the General, UN Doc A/63/635 (22 December 2008). A "statement" is distinct from a "resolution" (which is adopted by an official vote); it functions more as an example of soft law, or norm building, essentially capturing a growing consensus around a topic without carrying any binding authority. 
Lesbian Human Rights Commission (IGLHRC) was given "consultative status" at the UN Economic and Social Council in July 2010. ${ }^{103}$ Second, in December 2010, the UN General Assembly voted (93 votes in favour, 55 against, and 27 abstentions) to reinsert the reference to sexual orientation in the resolution on extra-judicial executions that had been removed the month before by the Social, Humanitarian Cultural Affairs Committee (the Third Committee of the UN General Assembly). ${ }^{104}$

Hypothetically, if non-discrimination protection on the basis of sexual orientation was becoming customary international law, then States that supported Syria's statement or voting against sexual minority rights at the UN could be characterized as "persistent objectors". However, there is probably still too much diversity in State practice on this issue to consider it an emerging customary norm at this time.

\section{D) The Yogyakarta Principles}

One of the most recent and significant developments in international human rights for sexual minorities was the Yogyakarta Principles. ${ }^{105}$ In 2006, a high-level conference of leading human rights experts and judges from around the world met in Yogyakarta, Indonesia. Recalling the sources of international law, professor Sanders explained, "the idea of a high-level conclave fit with a particular pattern in international law. One of the recognized sources of international law lies in the work of prominent scholars and

103 International Gay and Lesbian Human Rights Commission (IGLHRC), "United Nations Grants Official Status to U.S.-based International LGBT Rights Group" (July 19, 2010) online: $<$ http://www.iglhrc.org/cgi-bin/iowa/article/pressroom/pressrelease/1169.html>.

104 IGLHRC, "Civil Society Pressures Governments to Successfully Reverse Discriminatory Vote at UN" (December 12, 2010) online: <http:/www.iglhrc.org/cgi-bin/iowa/article/pressroom/ pressrelease/1291.html .

105 For the complete list of Yogyakarta Principles, see: <http://www.yogyakartaprinciples.org/>. For an extremely detailed analysis of the jurisprudence and related international legal sources that support the Yogyakarta Principles, please see: Williams, Jurisprudential Annotations to the Yogyakarta Principles (November 2007) online: <http://www.yogyakartaprinciples.org/yogyakartaprinciples-jurisprudential-annotations.pdfs. 
judges." 106 The resulting consensus document is a set of 29 principles that state the current international human rights law in relations to sexual minorities. Thus, the Yogyakarta Principles is not an aspirational document, nor does it attempt to create "new" rights and obligation. It simply interprets existing international human rights instruments and jurisprudence, and rephrases it in a language that is clear and precise regarding sexual minorities. "Each [principle] comprises a statement of international human rights law, its application to a given situation and an indication of the nature of the State's duty to implement the legal obligation." 107 The right to health, as expressed in the Yogyakarta Principles, is an appropriate example and is reproduced in Table 7 below.

Table 7: Principle 17 - The right to the highest attainable standard of health Source: Yogyakarta Principles (2006) <http://www.yogyakartaprinciples.org/>

Everyone has the right to the highest attainable standard of physical and mental health, without discrimination on the basis of sexual orientation or gender Identity. Sexual and reproductive health is a fundamental aspect of this right.

States shall:

A. Take all necessary legislative, administrative and other measures to ensure enjoyment of the right to the highest attainable standard of health, without discrimination on the basis of sexual orientation or gender identity;

B. Take all necessary legislative, administrative and other measures to ensure that all persons have access to healthcare facilities, goods and services, including in relation to sexual and reproductive health, and to their own medical records, without discrimination on the basis of sexual orientation or gender identity;

C. Ensure that healthcare facilities, goods and services are designed to improve the health status of, and respond to the needs of, all persons without discrimination on the basis of, and taking into account, sexual orientation and gender identity, and that medical records in this respect are treated with confidentiality:

D. Develop and implement programmes to address discrimination, prejudice and other social factors which undermine the health of persons because of their sexual orientation or gender identity;

E. Ensure that all persons are informed and empowered to make their own decisions regarding medical treatment and care, on the basis of genuinely informed consent, without discrimination on the basis of sexual orientation or gender identity;

F. Ensure that all sexual and reproductive health, education, prevention, care and treatment programmes and services respect the diversity of sexual orientations and gender identities, and are equally available to all without discrimination;

G. Facilitate access by those seeking body modifications related to gender reassignment to competent, nondiscriminatory treatment, care and support;

H. Ensure that all health service providers treat clients and their partners without discrimination on the basis of sexual orientation or gender identity, including with regard to recognition as next of kin;

I. Adopt the policies, and programmes of education and training, necessary to enable persons working in the healthcare sector to deliver the highest attainable standard of healthcare to all persons, with full respect for each person's sexual orientation and gender identity.

106 Sanders, The Role of the Yogyakarta Principles, February 8, 2009, at 4, online: <http://sxpolitics.org/wp-content/uploads/2009/03/yogyakarta-principles-2-douglas-sanders.pdfs.

107 O'Flaherty and Fisher, "Sexual Orientation, Gender Identity and International Human Rights Law: Contextualising the Yogyakarta Principles" (2008) 8:2 Human Rights L. Rev. 207 at 234. 


\subsection{A human rights approach to HIV prevention among MSM}

Since some States are not party to the ICCPR and/or the ICESCR, ${ }^{108}$ and therefore are not legally bound to them, it would be incorrect to say that they are "in violation" of international human rights law. However, there may be an argument that aspects of the right to health have attained customary international law status, as well as the general principle of non-discrimination (though as previously stated, expanding nondiscrimination to include sexual orientation would probably not meet the threshold for customary international law status). Regardless, this study does not endeavour to adjudicate any particular country's compliance with international human rights law. Rather, the previous analysis of international law provides an international standard on which comparisons can be made. It also allows the identification of best practices and impediments to HIV prevention - in terms of both the human right to health as well as the human rights protection for sexual minorities.

Human behaviour may ultimately be unrelated to human rights; however, the role that the State plays in providing at-risk individuals with the knowledge and resources to make life-saving decisions at a critical moment of pleasure seeking is very much related to this international standard of human rights. Examples of best practices in HIV prevention include: access to voluntary, confidential HIV testing; access to appropriate information on how HIV is transmitted and how to prevent infection; access to condoms and lubricant; access to care, treatment, and support for people living with HIV; and freedom to disseminate information and protection.

108 Among the countries under review in this study, Malaysia, Myanmar, and Singapore are not parties to either the ICCPR or ICESCR, and China has signed but not ratified the ICCPR. Indonesia, Laos, Maldives, Pakistan, and Taiwan became parties to these treaties during the decade under review (2000-2010), which limits the applicability of these treaties for this study. All countries under review in this study are parties to the CRC and CEDAW (although the status of Taiwan among these treaties is "complicated" due to the UN's one-China policy). 
These best practices flow from the obligations to respect, protect, and fulfill the human right to health. However, the efficacy of these best practices will be impeded so long as sexual minorities continue to face discrimination. Thus, a human rights approach to HIV prevention among MSM must also endeavour to respect, protect, and fulfill the right of sexual minorities to non-discrimination.

"Human rights" in this study are broadly interpreted to include an array of laws that can affect the daily life of sexual minorities. Protective legal environments would have a range of human rights protections, such as non-discrimination protection, relationship recognition, the right to privacy, equal legal protection from sexual offences (e.g., exploitation, trafficking, and assault), and freedoms of assembly and speech. Punitive legal environments, on the other hand, would have none of these freedoms, and would impose penalties on sexual minorities and gender identity minorities, including penal sanctions and discriminatory practices.

This human rights approach to HIV prevention among MSM frames the remainder of this study. For instance, the underlying question to revisit throughout the literature review in Chapter 3 is what impact does "this" have on the human rights approach to HIV prevention among MSM? The answer will vary depending on the example under discussion, for example: criminalizing homosexual behaviour fails to respect sexual minorities' right to health by limiting their access to health services, correct information on HIV, and dissuades them from seeking regular HIV testing; on the other hand, the realization of the freedoms of speech and assembly facilitates fulfilling sexual minorities' right to health by allowing them to mobilize an effective response to the HIV epidemic facing the MSM community. 


\section{Literature Review}

"Not only does the spread of HIV/AIDS impede the realization of a range of human rights, but human rights violations and state failure to fulfill human rights obligations negatively impact health and thwart the fight against HIV/AIDS. "I09

In an effort to fully understand this relationship between human rights for sexual minorities and HIV prevention an extensive literature review was completed. ${ }^{110}$ This literature review identified four broad pathways between being a sexual minority and HIV risk mediated by the existence or absence of human rights protection for sexual minorities:

Figure 8: Pathways between MSM and HIV risk, mediated by human rights Source: Author

\begin{tabular}{|c|c|c|c|}
\hline & \multicolumn{2}{|c|}{$\begin{array}{l}\text { Lack of human rights } \\
\text { protection for sexual } \\
\text { minorities }\end{array}$} & Higher ri \\
\hline & \multirow{2}{*}{$\begin{array}{l}\text { Existence of human } \\
\text { rights protection for } \\
\text { sexual minorities }\end{array}$} & & \\
\hline & & & \\
\hline
\end{tabular}

The first two pathways are common in situations where there is a lack of human rights protection for sexual minorities, epitomized by the criminalization of homosexuality. First, stigma, discrimination, and the victimization of sexual minorities

109 Stemple, "Health and human rights in today's fight against HIV/AIDS" (2008) 22: Sup $2 \mathrm{~J}$. AIDS s113 at s115.

110 Sources were gathered from database searches, bibliographies, joumals, the MSM-Asia ListServ, web searches, and resources forwarded to me by colleagues. The types of sources include peerreviewed articles, conferences reports, news articles, and speeches from various academic disciplines, epidemiological studies, and documents from international organizations and NGOs.

Databases included Ovid - EMBASE, HAPI, HealthSTAR, Ovid MEDLINE(R), Scopus, Scholar's Portal, Journals@Ovid Full Text, and PubMed. Search criteria included combinations of [HIV or AIDS], [MSM or "men who have sex with men" or "men having sex with men" or "sex between men"] and ["human rights"] and ["sexual minorities" or "sexual orientation" or homosexual or homosexuality or gay]. Results from these searches uncovered other topics that required additional searches. Search terms included "homophobia", ["risking taking" or "substance abuse" and MSM].

Publication dates for inclusion were open to anything published since the discovery of AIDS in the early 1980s. Most sources, however, are from 1995 onwards. Sources were limited to those published in English. Some sources were immediately excluded based on reading the title and abstract, and if necessary, skimming the article. Sources that were peripheral to the issues of interest, were redundant, or were not relevant were subsequently excluded. 
can directly lead to opportunities for HIV infection, as well as the interruption of HIV prevention efforts. Second, sexual minorities living in such unfriendly environments can suffer from poor mental health, leading to increased sexual risk taking behaviour.

The next two pathways are common in countries that have human rights protection for sexual minorities. First, in addition to undoing much of the harm associated with a lack of human rights, strong human rights can help the gay-community mobilize and respond more effectively to the HIV epidemic, and same-sex marriage rights may help promote longer relationships which could isolate same-sex couples from the spread of HIV. Second, policymakers must be mindful that the existence of human rights may also create an environment that is actually conducive to HIV transmission by facilitating sexual networking and other risk taking behaviour.

\subsection{Stigma, discrimination and victimization}

\section{"Discrimination and inequality are driving the epidemic. Wherever it strikes, HIV/AIDS exacerbates existing inequalities and creates a fatal combination of stigma and neglect."}

Countries that criminalize homosexuality create an environment that fuels stigma and discrimination, and can increase the risk of HIV infection while interfering with HIV prevention efforts. Even where sodomy is not criminalized, or where anti-sodomy laws are not actively enforced, police can arbitrarily use other criminal provisions, such as loitering or vagrancy laws, to harass sexual minorities. "The practical effects can be to drive these individuals underground, denying them access to public health or healthcare services and contributing to increased HIV/AIDS morbidity and mortality."112 Sexual

111 Khan, "Bangkok 2004: A human rights crisis in need of a human rights response" (2004) 9:3 HIV/AIDS Pol'y \& L. Rev. 75 at 76.

112 Gabel, et al, "A global assessment of the role of law in the HIV/AIDS pandemic" (2009) 123:2 
minorities may fear disclosing their sexual history to their healthcare provider, because they fear being harassed, humiliated, or "outed" to the police. Consequently, many some MSM may avoid getting tested for HIV.

Sexual interaction between the police and MSM is another issue of concern. In a sample of 240 MSM from India and Bangladesh collected between 2003-2005, a shocking $42 \%$ reported being sexually assaulted by the police, and $70 \%$ reported being harassed, blackmailed, and/or physically assaulted by police. ${ }^{113}$ Similar cases of police physical and sexual victimization of sexual minorities were reported in India, ${ }^{114} \mathrm{Nepal}^{115}$ Malaysia, ${ }^{116}$ Indonesia, ${ }^{117}$ and Pakistan. ${ }^{118}$

Enforcement of criminal laws against homosexual acts also affect the health of sexual minorities by interrupting, harassing, and even arresting HIV prevention workers. Police have used the possession of condoms, safe-sex literature, and condom-use demonstration equipment as evidence of promoting a criminalized behaviour. This was clearly documented in India, where HIV prevention workers used a penis replica to

Public Health 260 at 262.

113 Godwin, supra note 31 at 30.

114 Csete, "Indian NGO challenges penal code prohibition of 'unnatural offences"' (2002) 7:1 HIV/AIDS Pol'y \& L. Rev. 58; Ramasubban, "Political intersections between HIV/AIDS, sexuality and human rights: A history of resistance to the anti-sodomy law in India" (2008) 3: Sup 2 Global Public Health 22 at 26; and Pappas, et al, "Males Who Have Sex with Males (MSM) and HIV/AIDS in India: The Hidden Epidemic" (2001) 16:1-2 AIDS \& Pub. Pol'y J. 1 at 6-7. In a study of 301 kothi, 48\% reported being harassed by police. Reports even included some kothi being picked up by police and gang-raped in police barracks.

115 Godwin, supra note 31 at 33. In 2004, a policeman in Nepal forced a meti (transgender) to perform oral sex on him and then slit her throat.

116 Immigration and Refugee Board of Canada, "Malaysia: Treatment of sexual minorities (August 2004 - August 2005)" August 30, 2005, MYS100434.E. A survey of 507 mak nyahs (transgender) in Malaysia found that $70 \%$ of the respondents who had been arrested were forced to strip before other people in lock-up and $20 \%$ were forced to expose their breasts and genitalia.

117 Amnesty International, "Indonesia (Aceh): Torture of gay men by the Banda Raya police", 20 June 2007. Two gay men were tortured and humiliated by the Banda Raya police January 22-23, 2007. The police allegedly forced them to strip naked, perform oral sex and other sexual acts in front of them, sprayed them with a hose with cold water for about 15 minutes wearing only their underwear, forced one man to urinate on the head of his partner, and physically beat them.

118 Godwin, supra note 31 at 33. In 2002, a study reported police abuses of zenanas (transgender people) in Lahore, Pakistan was both "common and frequent". 
demonstrate how to properly use a condom. Visual demonstration is critical in countries where illiteracy rates remain high. Unfortunately, the police claimed that the penis replica was a "sex toy" when they arrested four HIV prevention workers in Lucknow, India. ${ }^{119}$ If HIV prevention programs fail to reach those at greatest risk of infection, they may have inaccurate information about the risks they face while engaging in different forms of sexual activities. In fact, many MSM are unaware of the risk of unprotected anal intercourse, mistakenly thinking it is safer than having other unprotected sex with a sex worker. ${ }^{120}$ Similar scenarios of police interference in HIV outreach work were reported in Bangalore, India, ${ }^{121}$ and in Nepal, ${ }^{122}$ Uganda, ${ }^{123}$ Sri Lanka, ${ }^{124}$ Thailand, ${ }^{125}$ China, ${ }^{126}$ and the Philippines. ${ }^{127}$

HIV outreach workers have seen a "chilling effect" on accessing HIV prevention services following the arrests of homosexual men. For example, after a police crackdown on homosexuals in India, HIV outreach workers noticed the number of "kothi" (feminized

119 Mistra, "Decriminalising homosexuality in India" (2009) 17:34 Reproductive Health Matters 20 at 22; Hergest, "India: UNAIDS claims law criminalizing homosexuality hinders HIV prevention" (2006) 11:1 HIV/AIDS Pol'y \& L. Rev. 35; Agoramoorthy and Hsu, "Can India abolish the anachronistic homosexuality law to battle HIV/AIDS?" (2006) 20:10 AIDS 1469; and Ramasubban, supra note 114 at 31 .

120 After direct blood-to-blood contact, unprotected anal intercourse is the second most high-risk activity, significantly more risky than penile-vaginal intercourse.

121 Mistra supra note 119 at 22. Police barred sexual minorities from seeking health services offered by Sangama (an NGO working with sexual minorities in Bangalore), forcing outreach workers to hold their meetings outside the city.

122 Saavedra, et al, supra note 7 at 3 . The police have beaten peer outreach workers for attempting to distribute condoms. The Blue Diamond Society (an NGO working with MSM in Nepal) reported having some of their outreach workers raped and severely beaten by the police.

123 Ibid at 3. Three GLBT activists were arrested and charged while peacefully demonstrating for access to HIV services for MSM.

124 Godwin, supra note 31 at 35 . Outreach workers in Sri Lanka were arrested in 2005 for distributing condoms.

125 Ibid at 74. While sex between men is legal in Thailand, sex work is illegal. Police routinely use condoms as evidence of sex work in gay venues.

126 Ibid at 56. The police detained MSM found socializing in parks in Guangzhou (2008) and Beijing (2009), among them were HIV outreach workers.

127 Ibid at 72. Police in the Philippines use condoms (used or unused) as evidence of sex work to charge MSM. Business owners find it difficult to support safe-sex services if condoms are involved. 
men) hanging out in their usual spots dropped by half, clearly impacting their ability to reach this at-risk population. ${ }^{128}$ This chilling effect was also reported in Senegal, ${ }^{129}$ Malawi, Kenya, and Uganda. ${ }^{130}$ Beyrer, reporting on these African cases, suggests that "[m]en can hardly be expected to participate in prevention programs if they fear blackmail, arrest, social stigma, and police violence."131

Governments that criminalize homosexuality send a clear message to their citizens that it is permissible to stigmatize and discriminate against sexual minorities. Prejudice and gay bashing essentially becomes "sanctioned" by the State, commonly referred to as State-sponsored homophobia. Widespread homophobia can lead to all sorts of tragedies, as recently seen in Uganda with the murder of gay rights activist David Kato in $2011 .^{132}$ There are countless cases of vigilante attacks against sexual minorities. They are physically and sexually victimized, creating opportunities for HIV infection to both the victims and to the perpetrators, and these acts go unstopped and unpunished by the police. Institutionalized discrimination can also come from within the healthcare profession. Healthcare providers often lack specialized knowledge needed to adequately address the health concerns of MSM, and they "can intentionally or unintentionally express disapproval and prejudice, driving MSM away from healthcare settings." ${ }^{\text {"133 }}$ In a

128 Chatterjee, "AIDS in India: police power and public health" (2006) 367 Lancet 805 at 805.

129 Moody, "Ensuring human and sexual rights for men who have sex with men living with HIV" (2009) 87:11 Bull. of the WHO 875; Garmaise, "Senegal: Growing intolerance towards gay men" (2009) 14:1 HIV/AIDS Pol'y \& L. Rev. 31; and Senior, supra note 38 at 448. After the arrest of 9 members of AIDES Senegal (an HIV NGO) for being "homosexuals", healthcare workers noted that HIV and STD services dropped significantly among MSM due to fear of being prosecuted.

130 Senior, supra note 38 at 448.

131 Beyrer, "Global Prevention of HIV Infection for Neglected Populations: Men Who Have Sex with Men" (2010) 50: Sup 3 Clinical Infect. Dis. s108 at s111.

132 Office of the High Commission for Human Rights, "Laws criminalizing homosexuality are incompatible with international human rights standards and fuel homophobia", online: <http://www.ohchr.org/EN/NewsEvents/Pages/Homophobia.aspx>.

133 Ayala, et al, "Social Discrimination Against Men who have sex with Men (MSM): Implications for HIV Policy and Programs" (2010) The Global Forum on MSM and HIV at 3. 
study of HIV among MSM in Malawi, Namibia, and Botswana, Baral, et al found that, "having disclosed sexual orientation to a health care provider was significantly associated with having been denied health care."134 While the actual denial of health services was low (mean=5.1\%), the authors found that $17.59 \%$ (Malawi), $18.3 \%$ (Namibia), and $20.5 \%$ (Botswana) were afraid to seek health services because of their sexual orientation. ${ }^{135}$ Similar observations were also recorded in Nepal, ${ }^{136}$ India, $^{137}$ and in the 2010 NGO delegation annual report to the UNAIDS board. ${ }^{138}$ Ultimately, perceived or actual discrimination of MSM by health providers can be a serious obstacle to the full realization of the right to health for sexual minorities.

After an outbreak of HIV in India's largest prison (Tihar Jail), the superintendent refused to supply inmates with condoms, claiming that, "it would be tantamount to legalising homosexuality." "139 A similar case was reported in Namibia, where HIV prevalence among inmates is nearly $10 \% .^{140}$ Although the HIV prevalence among nonprison MSM in Namibia is higher $(12.4 \%),{ }^{141}$ proper safe sex education and condom distribution is crucial in prison situations where the limitation on choices of sex partners

134 Baral et al, "HIV Prevalence, Risks for HIV Infection, and Human Rights among Men Who Have Sex with Men (MSM) in Malawi, Namibia, Botswana" (2009) 4:3 PloS ONE 1 at 7. Their sample size was 537 MSM recruited by respondent-driven sampling.

135 Ibid at 4.

136 Pant, "Vulnerable populations in Nepal face hostile environment" (2006) 11:2-3 HIV/AIDS Pol'y \& L. Rev. 87 at 88. In a sample of 148 HIV-positive MSM and transgender people surveyed in Nepal, nearly $20 \%$ reported both physical abuse and service refusal in healthcare.

137 Godwin, supra note 31 at 38. In a sample of 421 HIV-positive MSM and transgender people in India, nearly a third had been refused healthcare services and $4.8 \%$ reported assaults by healthcare staff.

138 "Stigma and Discrimination: Hindering Effective HIV Responses", NGO Delegation Annual Report to the UNAIDS Board, Presented at the 26th UNAIDS Board Meeting, Geneva, Switzerland, 22-24 June 2010 at 9 and 11 . More than a third of 1,021 respondents reported being afraid to access or denied access to HIV prevention services and HIV care and support services, mostly due to working with or belonging to a stigmatized group.

139 Ramasubban, supra note 114 at 25; and Mistra, supra note 119 at 22.

140 Herget, "Namibia: Anti-homosexuality law undermines HIV prevention in prisons", (2006) 11:1 HIV/AIDS Pol'y \& L. Rev. 34; and Weidlich, "AIDS taking toll among prison inmates and staff" (April 20, 2007), The Namibian, online: <http://www.namibian.com.na/index.php?id=28\&tx_ttnews [tt_news] $=31217 \&$ no_cache $=1>$.

141 Baral, et al, supra note 134 at 5. 
could accelerate the spread of HIV. Furthermore, "[m]ale prisons are hyper-masculine environments where sexual violence is used by staff and inmates for punishment, intimidation and discrimination. Homosexual and transgender prisoners face the highest rates of victimization."142

Sexual minorities also face severe stigma and discrimination from their communities. One particular form of this discrimination is called social exclusion, which Caceres, et al describe as:

the alienation or disenfranchisement that certain individuals or groups experience within society. [...] Those who are socially excluded are ascribed little social value, they may be marginalized economically, politically and socially, and they cannot enjoy the economic and social opportunities available to others including access to good health. ${ }^{143}$

Social exclusion can be difficult to recognize when studying a foreign culture, requiring researchers to be very attentive. One such example was uncovered in a 2009 study of MSM from Chennai, India, where HIV prevalence was associated with lower education and not living with parents - both indicators of disenfranchisement in a traditional society. ${ }^{144}$ This type of familial and societal rejection can increase internalized homophobia, which appears to be associated with high-risk behaviour, especially when substance abuse is used as a coping strategy. ${ }^{145}$ Moreover, "[s]ocial marginalization can have the multiple effects of ghettoizing people into small sexual networks, allowing high HIV infection rates to remain high and undetected for years."146

142 International Coalition on AIDS and Development, "Gender Based Violence and HIV \& AIDS: Affecting Everyone" (May 2008) at 2.

143 Caceres, et al (2008a), supra note 2 at s46.

144 Mayer, et al, "Out of the Closet and Into Public Health Focus: HIV and STDs in Men Who Have Sex With Men in Middle Income and Resource-Limited Countries" (2010) 37:4 Sex. Transm. Dis. 205 at 205.

$145 \mathrm{Ibid}$ at 206.

146 The Global Fund to Fight AIDS, TB, and Malaria. The Global Fund Strategy in Relation to Sexual Orientation and Gender Identities (SOGI), proceedings of the 19th Board Meeting of the Global 
3.2 Maladaptive coping to sexual minority stress

"When your whole understanding is self-stigmatisation, self-hatred,
you take more risks." 147

The next major pathway looks at increased sexual risk-taking as a consequence of maladaptive coping with sexual minority stress. While sexual minority stress can exist everywhere, regimes that have no human rights protection for sexual minorities and promote homophobia tend to have higher rates of maladaptive coping and poor mental health among MSM.

The literature on sexual minority stress often mentions "social comparison theory" - a process of comparing oneself to peers resulting in being socialized into learning what is considered right or wrong. For instance: what is masculine and what sexual orientation is right, among other things. Often the standard in this social comparison process is heterosexist and homophobic. Consequently, when members of a sexual minority have successfully concealed their sexual orientation, their peers might speak freely, expressing their honest views about "fags", "queers", and "homos". These negative messages incorporate into one's own identity and personality, commonly referred to as internalized homophobia.

Meyer developed a "minority stress model" to explore the impact of social stress on the mental health of sexual minorities. In psychological literature, stress is broadly described as "any condition having the potential to arouse the adaptive machinery of the individual." ${ }^{148}$ Traditionally, psychologists looked at personal events such as the passing of a loved-one. The notion of "social stress" expands this traditional understanding to

Fund to Fight AIDS, TB, and Malaria (Geneva) May 5-6, 2009, at 3. 
include conditions in the social environment. Minority stress is a form of social stress derived from prejudice and discrimination related to low socio-economic status, race, gender, or sexual orientation, among others, that induces changes that require adaptation and therefore can be considered stressors. ${ }^{149}$ Meyer identified four main ways in which stressors affect the psychological processes of minorities: first, external events, such as violence and discrimination; second, constantly expecting such events; third, concealing one's minority status in an attempt to avoid such events; and fourth, the internalization of society's anti-minorities views. Figure 9, illustrates Meyer's minority stress model:

Figure 9: Minority stress model

Source: Meyer (2003) at 679 [simplified]

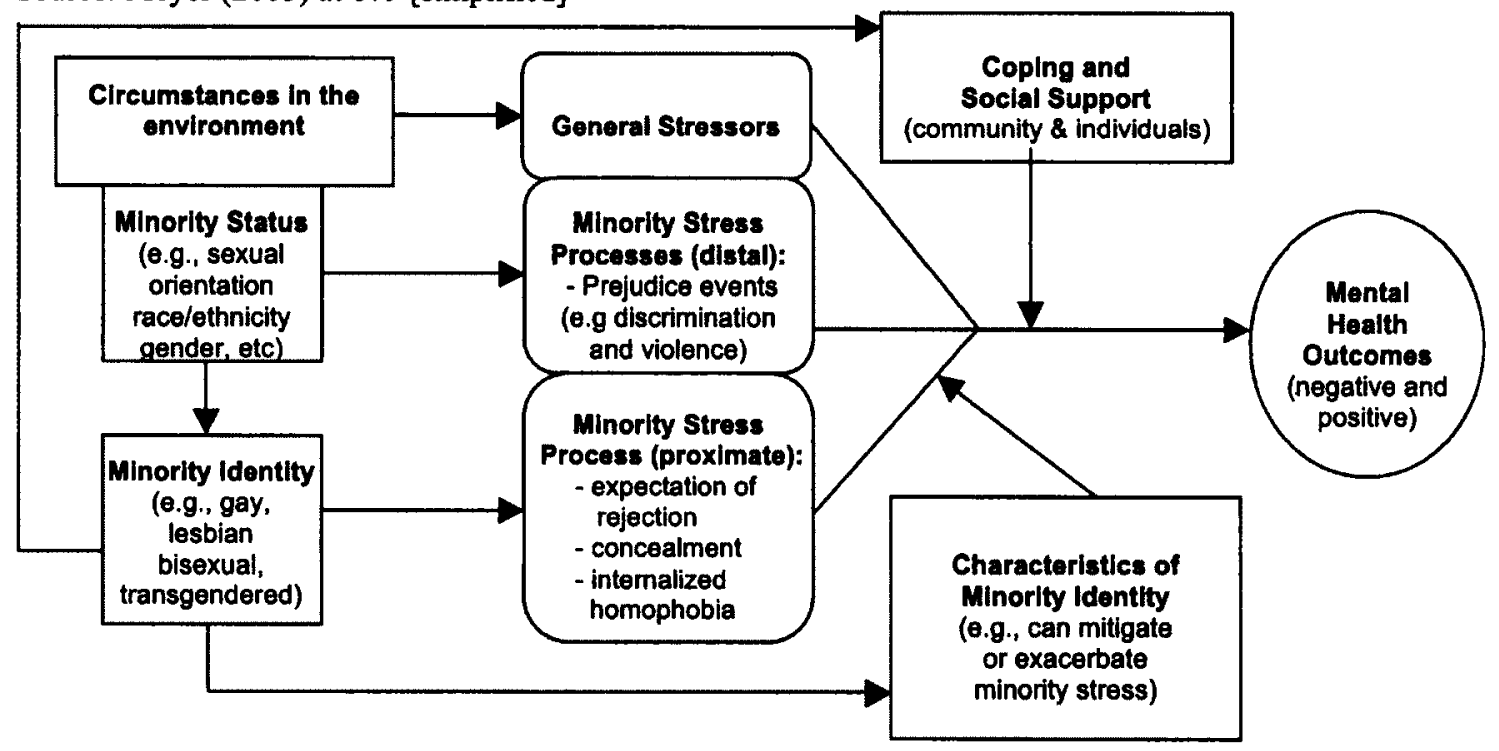

The minority stress model begins with the general circumstances in the environment - common to everyone - producing the general stressors. Since minority stress is additional to general stress, an important element of a person's circumstances is their minority status. Minorities, however, can have overlapping statuses, such as racial and socio-economic status, which may provide advantages or disadvantages. External

149 Ibid at 675. 
minority stressors in this model are called "prejudice events", which are forms of violence and discrimination targeting minorities. These minority stressors can be either State-led (e.g., police arrests or harassment) or from private actors in the form of hate-crimes and discrimination. Experiencing a prejudice event would inevitably induce stress, which potentially has negative consequences for mental health.

Minority identity is related to, but distinct from, minority status. The latter is a societal classification, whereas the former is the product of internalizing one's minority status (i.e., self-acceptance). The process and final outcome of developing one's minority identity could mitigate or exacerbate minority stress. Regardless of this synthesis process, minorities are often faced with a series of internal minority stress processes. First, constantly worrying that prejudice events may occur can lead to sub-optimal mental health conditions, including anxiety and depression. The literature also refers to this as "vigilance":

Like other minority group members, [GLBT] people learn to anticipate - indeed, expect - negative regard from members of the dominant culture. To ward off potential negative regard, discrimination, and violence they must maintain vigilance. The greater one's perceived stigma, the greater the need for vigilance in interactions with dominant group members. ${ }^{150}$

Second, minorities also often try to conceal their minority status. Since sexual orientation can be considered an "invisible" minority status (although this is probably debatable), hiding one's sexual orientation has been one of the primary means to avoid stigmatization for centuries. "Paradoxically, concealing one's stigma is often used as a coping strategy, but it is a coping strategy that can backfire and become stressful."151 Third, internalizing society's anti-minorities views is another possible negative consequence of having a 
sexual minority identity. Essentially, directing society's negative views of homosexuality on oneself leads to self-devaluation, poor self-regard, and internal conflict where one essentially denies the existence of a key aspect on one's identity.

Embracing one's minority identity, on the other hand, can lead to positive coping responses to minority stress. For instance, gay, lesbian, bisexual and transgender (GLBT) social groups provide an environment where sexual minorities can be relatively free from stigma and discrimination. Social comparison theory suggests that "negative evaluation by others - such as stereotypes and prejudice directed at minority persons in society may lead to adverse psychological outcomes." ${ }^{\text {,152 }}$ Relying more on GLBT group members for comparison will allow minority group members to avoid self devaluation on the grounds of their sexual orientation. Thus, "group solidarity and cohesiveness helps protect minorities from the adverse mental health effects of minority stress."

In testing this model, Meyer found that homosexuals were more likely to have mental disorders than their heterosexual counterparts with a weighted odds ratio (OR) of $2.41 .{ }^{154}$ "The studies have concluded that minority stress processes are related to an array of mental health problems including depressive symptoms, substance use, and suicide ideation." 155 Similar findings were also reported in Ehlers, et als study of the well-being of sexual minorities in Botswana, ${ }^{156}$ and by Chakrapani, et al, who found that "the importance of gay-affirmative community-based organizations [...] cannot be

152 Ibid at 675-6.

153 Ibid at 677.

154 Ibid at 684. The meta-analysis included 10 studies and did not account for cohort effects. According to the author, younger generations have unparalleled ease with sexuality (at 690).

155 Ibid at 679.

156 Ehlers, et al, "The well-being of gays, lesbians and bisexuals in Botswana" (2001) 35:6 J. Adv. Nursing 848 at 852 . Fourteen considered suicide in the past, and another 14 still consider it $(\mathrm{N}=47)$. The authors attribute some of these psychological issues to internalized homophobia, which accords with the findings that most of the respondents had at least two drinks per day. Alcohol functions as a "social lubricant" and is a way of "coping with feelings of shame". 
overstated," ${ }^{157}$ since they help mitigate depression and low self-esteem.

Internalized homophobia ${ }^{158}$ is a process in which "societal negative attitudes towards homosexuality are incorporated into self-image, creating various psychological distortions and reactions." 159 Some of the theories that link internalized homophobia to high-risk behaviour include increased substance abuse to cope with the negative effects of internalized homophobia, such as depression and low self-esteem, or as a method to "lower sexual inhibitions related to [internalized homophobia] and thereby allow the fulfillment of sexual urges that are otherwise stigmatized and avoided."160 Another avenue by which internalized homophobia leads to high-risk behaviour is "the development of less secure interpersonal attachments, social isolation, avoidance of gay venues and resources, and increased sexual impulsivity and risk.",161

As previously mentioned, during psychological development there is a synthesis of different aspects which will form the individual's complete identity. This process differs for sexual minorities compared to racial minorities due to the late awareness of one's sexual orientation. As Meyer points out, "[sexual minority] individuals are distinct from Blacks in that they are not born into their minority identity but acquire it later in life. Because of this, [sexual minority] individuals do not have the benefit of growing up in a self-enhancing social environment similar to that provided to Blacks in the process of socialization."162 Thus, unlike internalized racism, "it is unlikely that [internalized homophobia] completely abates even when the person has accepted his or her

157 Chakrapani, et al, "Structural violence against Kothi-identified Men who have Sex with Men in Chennai, India: A Qualitative Investigation" (2007) 19:4 AIDS Ed. \& Prev. 346 at 361.

158 Also appears in the literature as "internalized homonegativity" and "internalized heterosexism".

159 Johnson, et al, "Internalized Heterosexism Among HIV-Positive, Gay-Identified Men: Implications for HIV Prevention and Care" (2008) 76:5 J. Consulting \& Clinical Psych. 829 at 830.

$160 \quad$ Ibid at 830.

161 Ibid.

162 Meyer, supra note 148 at 690. 
homosexuality. Because of the strength of early socialization experiences and because of continued exposure to antigay attitudes, [internalized homophobia] remains an important factor in the gay person's psychological adjustment throughout life."163

Building on these earlier theoretical links, Johnson, et al developed a model using internalized homophobia to explain increases in high-risk sexual behaviour and nonadherence to anti-retroviral therapy (ART) among HIV positive gay men:

Figure 10: Internalized homophobia and risk taking

Source: Johnson, et al (2008) at 832 [adapted= "internalized homophobia" was "IH" in the original

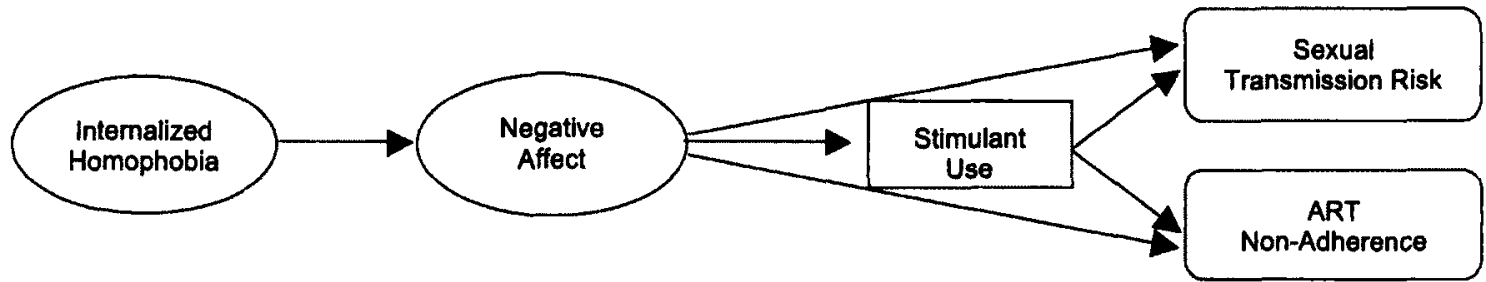

According to the authors, there is a direct correlation between gay men who internalize societal anti-homosexual attitudes and what the authors call a "negative affect", which includes anger, anxiety, sadness, disgust, contempt, and stress. Substance abuse is added to the model as a coping mechanism for these negative affects, which can increase the chances of unprotected anal intercourse (UAI) and non-adherence to ART. Their model could account for $15 \%$ of the variance in UAI and $17 \%$ in non-adherence to ART. ${ }^{164}$

\subsection{Mobilizing civil society and relationship-recognition}

In the third pathway, the existence of human rights protection for sexual minorities can not only undo much of the harm discussed in the first two pathways, but it can also improve sexual minority health in a couple of other notable ways. A supportive human rights environment allows for the creation of safe-spaces for sexual minorities,

163 Ibid at 682.

164 Johnson, et al, supra note 159. 
helps mobilize the gay-community's ability to response effectively to the HIV epidemic, and encourages the formation of longer relationships through relationship recognition (e.g., same-sex marriage), which could begin to isolate them from HIV exposure.

Laws have the power to endow individuals with rights that can help them avoid disease. Burris, in his examination of law as a structural factor in the spread of communicable disease, points out that, "few 'factors in the social, economic and political environment' are unrelated to law, and it is inevitable that law would play some role in any effort to change how society operates." 165 He suggests that human rights law, in particular, has the potential to allow individuals or communities to learn about and act upon risks to their health. ${ }^{166}$

Vulnerability to HIV increases when people are denied the right to information; when restrictions are put on freedom of expression. [...] When communities or workers are deprived of their right to organize and mobilize, it makes them less able to respond appropriately to HIV/AIDS and more vulnerable to it. ${ }^{167}$

Gruskin and Ferguson also found that "[1]aws and policies that prohibit discrimination on the grounds of sexual orientation have been found to help promote access to HIV-related information and services for men engaged in same-sex sexual activity."168

The right to free association is important in developing safe spaces where sexual minorities can openly discuss issues of shared concern, such as men's sexual health Creating these safe spaces in schools can be critical for instilling life-saving skills early on among sexual minority youth. In a study of public high school students in Massachusetts, Blake, et al found that "teachers who receive appropriate training,

165 Burris, "Law as a Structural Factor in the Spread of Communicable Disease" (1999) 36 Hous. $L$. Rev. 1755 at 1770.

166 Ibid at 1775.

167 Khan, supra note 111 at 76.

168 Gruskin and Ferguson, "Government regulation of sex and sexuality in their own words" (2009)17:34 Reproductive Health Matters 108 at 110. 
curricula, and material to provide gay-sensitive instruction in schools can make a difference in the lives of GLB youths." ${ }^{169}$ Specifically, sexual minority youths in schools with gay-sensitive HIV instruction reported significantly lower sexual risk taking behaviour, suicide, and victimization than sexual minority students in schools without gay-sensitive instruction. ${ }^{170}$ Pride Centers in universities and Gay-Straight Alliances in high schools can help combat homophobia, support psychological development, and are also excellent resources for sexual health needs, such as free safe-sex kits and the locations of confidential and anonymous HIV testing centers. ${ }^{171}$

Sexual minorities in large urban cities also tend to live in and/or socialize in "gay villages". This increases the visibility of sexual diversity, which has been known to help reduce homophobia in society. In fact, one theory of homophobia mitigation is the contact hypothesis, which argues that intergroup exposure "helps to undermine negative stereotypes, thus minimizing prejudice and maximizing intergroup cooperation."172 Similarly, Ross, et al mention that social interaction is a moderator of homophobia. However, those with higher levels of internalized homophobia tend to avoid associating with GLBT groups, and thus, would not benefit from such moderation. ${ }^{173}$ Higher concentration of sexual minorities in urban centers also increase availability of specialized health services for MSM, such as Ottawa's gay Zone gaie. ${ }^{174}$

169 Ibid.

170 Blake, et al, "Preventing Sexual Risk Behaviors Among Gay, Lesbian, and Bisexual Adolescents: The Benefits of Gay-Sensitive HIV Instruction in Schools" (2001) 91:6 American J. Public Health 940 at 944.

171 See e.g.: Pride Center of the Student Federation of the University of Ottawa, online: $<$ http://sfuo.ca/services/pride/en/index.htm>.

172 Bernstein, "Paths to Homophobia" (2004) 1:2 Sexuality Research \& Social Policy 41 at 42.

173 Ross, et al, "The relationship of internalized homonegativity to unsafe sexual behavior in HIV seropositive men who have sex with men"(2008) 20:6 AIDS Ed. \& Prev. 547 at 548.

174 See: "gay ZONE gay" online: <http://www.aco-cso.ca/gayzonegaie/english.html>. 
The freedom to mobilize, to assemble, and to speak openly about important lifethreatening issues has been instrumental in the fight against HIV. Civil society played a critical role in the early years of the HIV epidemic, especially among sexual minorities who are often serviced first and only by GLBT-friendly NGOs. In fact, scholars have pointed out that the emergence of civil-society movements and the right to assemble and protest preceded any formal governmental response to the HIV epidemic. ${ }^{175}$ Piot, et al noted that emerging civil society movements coincided with HIV prevention movements in Brazil, Uganda, South Africa, Thailand, and Cambodia. ${ }^{176}$ In Peru, the government supported efforts to develop a gay community by reigning in official repression (such as police raids) and providing funds for HIV prevention to the gay community in order to help fight HIV. ${ }^{177}$ The importance of establishing peer-based responses to HIV was highlighted in a report by Monitoring the AFDS Pandemic Network that suggests "[p]eer networks have the potential to influence group norms regarding safe sex and other HIV risk reduction strategies." 178 They cite India as an example of higher condom use among MSM in cities with active peer distribution networks compared to those without.

In looking back on the AIDS epidemic in North America and Western Europe, Wright made two important observations. First, "[t]he strong connection between [gay] sub-cultural institutions in Western countries not only provided international networks in which HIV could spread, but also ready-made structures, which could be utilized for prevention activities." 179 This observation resonates with the idea that realization of

175 Piot, et al, "Coming to terms with complexity: a call to action for HIV prevention" (2008) 372 Lancet 845 at 852; and Roehr, supra note 6 at 1264.

176 Piot, et al, ibid.

177 Roehr, supra note 6 at 1264.

178 Monitoring the AIDS Pandemic (MAP) Network, supra note 29 at 12.

179 Wright, "Homosexuality and HIV/AIDS prevention: the challenge of transferring lessons learned from Western European to Central and Eastern European Countries" (2005) 20:1 Health Promotion 
human rights for sexual minorities may increase the pathways of HIV transmission by facilitating social interactions (see section 3.4 below). However, as Wright correctly noted, it was these same social networks that responded aggressively to HIV/AIDS during the early years of the epidemic, long before governments began to respond. Wright's second observation is "the gay liberation movement does not yet have the level of infrastructure and general social support in Central and Eastern Europe as in the West."180 The absence of these networks limits the gay community's ability to respond adequately, essentially leaving the HIV prevention mandate to governments.

With respect to relationship-recognition, "[a] huge array of legal rules and social practices provide incentives to heterosexuals to form relationships that are intended to be permanent and monogamous. Through the civil status of marriage, heterosexual couples acquire tangible economic benefits ranging from favorable rules of property ownership and inheritance, to insurance benefits, to parental rights." ${ }^{81}$ Same-sex couples, until recently, have never had these same governmental incentives to form long-lasting and monogamous relationships. Given the health risks associates with having multiple sexual partners, some experts believe that "HIV among gay men would arguably decline significantly if more gay men were in long-term monogamous relationships."182

\subsection{Facilitating sexual networking and risk-taking behaviour}

The final pathway is the possibility that human rights can create an environment that is favourable for HIV transmission. The main concern of open and liberal societies, with full human rights for sexual minorities such as Canada, is that it will facilitate sexual

\footnotetext{
International 91 at 92.

180 Ibid at 93.

181 Burris, supra note 165 at 1780

182 Ibid at 1779.
} 
encounters, which can increase the risk of HIV transmission. Urban migration of sexual minorities from rural communities to gay-friendly large urban centers has led to larger concentrations of sexual minorities and thus, more opportunities for sexual connections. "Cities provide MSM and other sexual minorities adequate numbers of potential sex and life partners and more tolerant social polices where behaviors and identities that are stigmatized elsewhere may be enacted with less fear and more comfort."

The concentration of sexual minorities in urban centers also creates incentives for business entrepreneurs to open venues that cater to a gay clientele, like gay bars and clubs. These venues, as noted by Frye, et $a l$, can help facilitate sexual networking: "MSM who live in neighborhoods characterized by low levels of homophobia and large numbers of MSM; these men may tend to have more sex partners and sex in high-risk venues due to proximity and ease of access."184 Whereas, countries that criminalize homosexuality tend to prohibit gay bars and clubs, let alone bathhouses, saunas, or other similar sex venues, which are common in all major urban centers in North America, Western Europe and developed Asia.

Although the Internet has also been used as tool to educate people about HIV, it is also often used to facilitate sexual encounters. MSM all over the world rely heavily on the Internet to find relationships and sexual partners. Countries that have strict censorship laws can easily block gay-related websites. This is a growing issue, now that the Internet Corporation for Assigned Names and Numbers (a private-public entity that is responsible for allocating internet domain names), has been considering creating a new top-level

183 Frye, et al, "The Urban Environment and Sexual Risk Behavior among Men who have Sex with Men" (2006) 83:2 J. Urban Health 308 at 309.

184 Ibid at 314. 
domain name extension <.gay>. ${ }^{185}$ Currently countries do censor websites, but this requires searching for keywords and individually blocking websites, which can be done using software like China's new Green Dam. However, with a new top-level domain name extension like <.gay>, a country could simply block the entire domain.

Finally, there are some concerns that greater understanding of HIV has led to the development of strategies by MSM to continue having unprotected sex, while trying to reduce their exposure to HIV. These strategies include sero-sorting, strategic position, negotiated safety, and withdrawal. ${ }^{186}$ Sero-sorting is where men have unprotected sex with men of the same sero-status (i.e., the same HIV status). ${ }^{187}$ A new development that complicates the sero-sorting strategy is the HIV positive individuals that respond well to anti-retro viral therapy can have an "undetectable viral load", which some argue is noninfectious. Strategic-positioning is where a man decides that he will always use a condom if he is receiving anal intercourse but will forgo condom use if he is the inserting partner. This strategy is based on the premise that receptive UAI is substantially more risky than insertive UAI. Negotiated safety is where boyfriends or sex-friends agree to have unprotected sex between themselves, but promise to use condoms when they have sex with other people. Finally, withdrawal simply involves ejaculating outside the body, which is used not only to reduce exposure to HIV but also commonly used to avoid unplanned pregnancies.

185 For more information, see: "dotGay", online: <http://dotgay.com>.

186 For a more complete discussion of these strategies, see: Australian Federation of AIDS Organisations, "HIV risk reduction strategies among gay men", April 2011, online: $<$ http://www.afao.org.au/_data/assets/pdf_file/0012/5601/LR_APril11_risk_reduction.pdf $>$.

187 The risk reduction in HIV sero-negative pairings is rather evident; however, it is also common for HIV sero-positive MSM to seek out other HIV sero-positive men for unprotected sexual encounters. Although in HIV sero-positive pairings there is no risk of a "new" infection, either partner is at risk of contract the other's strand of HIV, which could be resistant to ART. Multiple HIV strand infections limit the effectiveness of medication and can lead to premature morbidity and mortality. 
In a recent study from six US cities, Phillips, et al found a small yet significant correlation between sero-sorting and a decreased risk of becoming HIV positive ( $O R=$ $0.88,95 \%$ Confidence Interval $(\mathrm{CI}), 0.81-0.95)$, but no statistically significant effect for strategic positioning $(\mathrm{OR}=1.02,95 \% \mathrm{CI}, 0.92-1.14) .^{188}$ However, little is known about the use of these techniques outside of developed countries. In fact, MSM in developing countries generally lack the basic HIV knowledge to employ Western style risk-reduction strategies. $^{189}$

\subsection{Conclusions from the literature review}

According to this literature review, punitive legal environments, such as those that criminalize homosexuality, have several consequences that have an impact on HIV prevalence among MSM and their access to HIV prevention services. These regimes can affect MSM risk-taking behaviour by: increasing stigma and discrimination, which sexual minorities may respond to with maladaptive coping strategies (e.g., increased substance abuse and suicide ideation); increasing internalized homophobia, which is associated with avoiding gay-affirmative community groups; and increasing the number and frequency of short-term relationships (i.e., less monogamy). Both police and private actors may also directly increase the risk of HIV transmission through sexual violence, such as rape.

Furthermore, punitive legal environments may interrupt HIV prevention by: increasing the harassment of HIV outreach workers (e.g., by arrest and blackmail); decreasing governmental funding for MSM-targeted HIV prevention services; decreasing the visibility of MSM, making them harder to find for the purposes of HIV testing and

188 Phillips, et al, "Serosorting is Associated with a Decreased Risk of HIV Seroconversion in the EXPLORE Study Cohort" (2010) 5:9 PLOS ONE el2662. 
other prevention services; preventing MSM from accessing correct information on HIV transmission and prevention; and decreasing the willingness of MSM to participate in these services, due to fear of being "outted", blackmailed, or worse.

On the other hand, protective legal environments, especially those with antidiscrimination protection for sexual minorities, can help mobilize civil society's response to the HIV epidemic by providing safe spaces for sexual minorities to socialize and access age-appropriate sexual health information, and by creating a larger gay constituency that can attract more governmental and international funding to support their HIV prevention efforts. Moreover, same-sex relationship recognition might begin to isolate MSM from exposure to HIV through forming longer and monogamous relationships. However, these same protective legal environments could also increase the spread of HIV through facilitating sexual networking, providing more MSM-related venues (such as bars, clubs, and bathhouses), and increasing the use of risk-reduction strategies used to continue having unprotected sex. 


\section{Methodology}

\subsection{Research question and hypotheses}

The research question is: how does variation in human rights protections for sexual minorities influence variation in indicators of HIV prevention among MSM and transgender people in Asia? Based on the literature review findings and theoretical framework, the following hypotheses can be derived:

Increasingly protective human rights environments for sexual minorities will:

i. decrease HIV prevalence among MSM

ii. decrease inconsistent condom use between MSM

iii. increase recent HIV testing among MSM

iv. increase adequate HIV knowledge among MSM

v. increase the exposure to HIV prevention services for MSM

With respect to the regional focus of the study, data was collected for 22 countries: Bangladesh, Cambodia, China, Hong Kong, India, Indonesia, Japan, Korea (the Republic of), Lao People's Democratic Republic (PDR), Malaysia, Maldives, Mongolia, Myanmar, Nepal, Pakistan, Philippines, Singapore, Sri Lanka, Taiwan, Thailand, TimorLeste, and Vietnam. Data from Afghanistan, Bhutan, Brunei Darussalam, and North Korea were also sought, but none were found. Therefore, these four were excluded.

\subsection{Dependent variables - HIV prevention indicators}

The objective of this study is to measure variation in indicators of HIV prevention among MSM. There are five HIV prevention indicators related to MSM that every country is requested to report biannually to the UN General Assembly Special Session on 
HIV/AIDS (UNGASS). These five indicators, which form the basis of this study's dependent variables, include: (a) HIV prevalence among MSM; (b) condom use between MSM; (c) recent HIV testing among MSM; (d) adequate HIV knowledge among MSM; and (e) exposure of HIV prevention services for MSM. Therefore, using the data contained in the UNGASS reports would have been ideal. However, as Table 8 shows, most of the Asian countries under review did not submit a report, did not have data on one or more of these indicators, or submitted a report that was in the wrong format. Consequently, this study undertook an extensive collection of epidemiological and behavioural studies in an effort to fill in the missing data.

Table 8 - Existing and missing data from the UNGASS biannual reports

Source: Author

\begin{tabular}{|c|c|c|c|c|c|c|c|c|c|c|}
\hline & \multicolumn{2}{|c|}{$\begin{array}{l}\text { Indlcator } 8 \\
\text { HIV testing }\end{array}$} & \multicolumn{2}{|c|}{$\begin{array}{c}\text { Indlcator } 9 \\
\text { Prevention } \\
\text { Coverage }\end{array}$} & \multicolumn{2}{|c|}{$\begin{array}{l}\text { Indlcator } 14 \\
\text { HIV knowledge }\end{array}$} & \multicolumn{2}{|c|}{$\begin{array}{l}\text { Indlcator } 19 \\
\text { Condom use }\end{array}$} & \multicolumn{2}{|c|}{$\begin{array}{l}\text { Indlcator } 23 \\
\text { HIV prevalence }\end{array}$} \\
\hline & 2008 & 2010 & 2008 & 2010 & 2008 & 2010 & 2008 & 2010 & 2008 & 2010 \\
\hline Bangladesh & Yes & Yes & Yes & Yes & Yes & Yes & Yes & Yes & Yes & Yes \\
\hline Cambodia & Yes & $\begin{array}{l}2008 \\
\text { data }\end{array}$ & No data & $\begin{array}{l}2008 \\
\text { Data }\end{array}$ & No data & $\begin{array}{l}2008 \\
\text { Data }\end{array}$ & Yes & $\begin{array}{l}20093 \\
\text { Datá }\end{array}$ & Yes & $\begin{array}{l}2008 \\
\text { Dataz }\end{array}$ \\
\hline $\begin{array}{l}\text { China \& } \\
\text { Hong Kong }\end{array}$ & $\begin{array}{l}\text { Wrong } \\
\text { format }\end{array}$ & Yes & $\begin{array}{l}\text { Wrong } \\
\text { format }\end{array}$ & Yes & $\begin{array}{l}\text { Wrong } \\
\text { format }\end{array}$ & Yes & $\begin{array}{l}\text { Wrong } \\
\text { format }\end{array}$ & Yes & $\begin{array}{l}\text { Wrong } \\
\text { format }\end{array}$ & Yes \\
\hline India & Yes & Yes & Yes & Yes & Yes & Yes & Yes & Yos & Yes & Yes \\
\hline Indonesia & Yes & $\begin{array}{l}2008 \\
\text { data }\end{array}$ & No data & $\begin{array}{l}2008 \\
\text { Data }\end{array}$ & No data & $\begin{array}{l}2008 \\
\text { Data }\end{array}$ & Yes & $\begin{array}{l}2008 \\
\text { Data }\end{array}$ & Yes & $\begin{array}{l}2008 \\
\text { Datas }\end{array}$ \\
\hline Japan & $\begin{array}{l}\text { Wrong } \\
\text { forthat }\end{array}$ & $\begin{array}{l}\text { Wrongs } \\
\text { fornat }\end{array}$ & $\begin{array}{l}\text { Wrong } \\
\text { forniat }\end{array}$ & $\begin{array}{l}\text { Wrong } \\
\text { format }\end{array}$ & $\begin{array}{l}\text { Wrong } \\
\text { formal }\end{array}$ & $\begin{array}{l}\text { Wrong } \\
\text { format }\end{array}$ & $\begin{array}{l}\text { Wrong } \\
\text { format }\end{array}$ & $\begin{array}{l}\text { Wrong } \\
\text { tormat }\end{array}$ & $\begin{array}{l}\text { Wrons! } \\
\text { forma! }\end{array}$ & $\begin{array}{l}\text { Wroms } \\
\text { forma: }\end{array}$ \\
\hline Korea, Republic & $\begin{array}{l}\text { Wrong } \\
\text { tomat }\end{array}$ & $\begin{array}{l}\text { No } \\
\text { report }\end{array}$ & $\begin{array}{l}\text { Wrong } \\
\text { format }\end{array}$ & $\begin{array}{l}\text { No } \\
\text { report }\end{array}$ & $\begin{array}{l}\text { Wrong } \\
\text { tormal }\end{array}$ & $\begin{array}{c}\text { No } \\
\text { report }\end{array}$ & $\begin{array}{l}\text { Wrong } \\
\text { format }\end{array}$ & $\begin{array}{c}\text { No } \\
\text { report }\end{array}$ & $\begin{array}{l}\text { Wrong } \\
\text { format }\end{array}$ & $\begin{array}{c}\text { No } \\
\text { romot }\end{array}$ \\
\hline Laos, PDR & Yes & Yes & No data & No data & Yes & No data & Yes & No data & Yes & Yes \\
\hline Malaysia & No data & No data & No data & No data & No data & No data & No data & Yes & Yes & Yes \\
\hline Maldives & $\begin{array}{c}\text { No } \\
\text { moont }\end{array}$ & $\begin{array}{l}\text { No } \\
\text { report }\end{array}$ & $\begin{array}{l}\text { No } \\
\text { report }\end{array}$ & $\begin{array}{l}\text { No } \\
\text { report }\end{array}$ & $\begin{array}{c}\text { No } \\
\text { repot }\end{array}$ & $\begin{array}{c}\text { No } \\
\text { report }\end{array}$ & $\begin{array}{c}\text { No } \\
\text { report }\end{array}$ & $\begin{array}{c}\text { No } \\
\text { report }\end{array}$ & $\begin{array}{c}\text { No } \\
\text { repont }\end{array}$ & $\begin{array}{c}\text { No } \\
\text { report }\end{array}$ \\
\hline Mongolia & Yes & Yes & Yes & Yes & Yes & Yes & Yes & Yes & Yes & Yes \\
\hline Myanmar & $\begin{array}{c}\text { No } \\
\text { report }\end{array}$ & Yes & $\begin{array}{l}\text { No } \\
\text { report }\end{array}$ & Yes & $\begin{array}{l}\text { No } \\
\text { report }\end{array}$ & Yes & $\begin{array}{c}\text { No } \\
\text { report }\end{array}$ & Yes & $\begin{array}{c}\text { No } \\
\text { report }\end{array}$ & Yes \\
\hline Nepal & Yes & Yes & Yes & Yes & Yes & Yes & Yes & Yes & Yes & Yes \\
\hline Pakistan & Yes & Yes & Yes & Yes & Yes & Yes & Yes & No data & Yes & Yes \\
\hline Philippines & Yes & Yes & Yes & Yes & Yes & Yes & Yes & Yes & Yes & Yes \\
\hline Singapore & $\begin{array}{l}\text { Wrong } \\
\text { format }\end{array}$ & $\begin{array}{l}\text { Wrong } \\
\text { format }\end{array}$ & $\begin{array}{l}\text { Wrong } \\
\text { format }\end{array}$ & $\begin{array}{l}\text { Wrong } \\
\text { format }\end{array}$ & $\begin{array}{l}\text { Wrong } \\
\text { format }\end{array}$ & $\begin{array}{l}\text { Wrong } \\
\text { format }\end{array}$ & $\begin{array}{l}\text { Wrong } \\
\text { format }\end{array}$ & $\begin{array}{l}\text { Wrong } \\
\text { format }\end{array}$ & $\begin{array}{l}\text { Wrong } \\
\text { format }\end{array}$ & $\begin{array}{l}\text { Wrong } \\
\text { fomat }\end{array}$ \\
\hline Sri Lanka & Yes & Yes & No data & No data & Yes & No data & Yes & Yes & No data & Yes \\
\hline $\begin{array}{l}\text { Taiwan (UN's } \\
\text { 1-Chine Polloy) }\end{array}$ & $\begin{array}{l}\text { No } \\
\text { report }\end{array}$ & $\begin{array}{c}\text { No } \\
\text { report }\end{array}$ & $\begin{array}{c}\text { No } \\
\text { repori }\end{array}$ & $\begin{array}{c}\text { No } \\
\text { report }\end{array}$ & $\begin{array}{c}\text { No } \\
\text { report }\end{array}$ & $\begin{array}{c}\text { No } \\
\text { report }\end{array}$ & $\begin{array}{c}\text { No } \\
\text { report }\end{array}$ & $\begin{array}{c}\text { No } \\
\text { report }\end{array}$ & $\begin{array}{c}\text { No } \\
\text { repolt }\end{array}$ & $\begin{array}{c}\text { No } \\
\text { report }\end{array}$ \\
\hline Thailand & Yes & Yes & No data & No clata & Yes & Yes & Yes & No data & Yes & Yes \\
\hline Timor-Leste & $\begin{array}{c}\text { No } \\
\text { report }\end{array}$ & $\begin{array}{l}\text { Wrong } \\
\text { formal }\end{array}$ & $\begin{array}{c}\text { No } \\
\text { report }\end{array}$ & $\begin{array}{l}\text { Wong } \\
\text { formal }\end{array}$ & $\begin{array}{l}\text { No } \\
\text { report }\end{array}$ & $\begin{array}{l}\text { Wrong } \\
\text { format }\end{array}$ & $\begin{array}{c}\text { No } \\
\text { report }\end{array}$ & $\begin{array}{l}\text { Wrong } \\
\text { format } \\
\end{array}$ & $\begin{array}{c}\text { No } \\
\text { report }\end{array}$ & $\begin{array}{l}\text { Wrong } \\
\text { format }\end{array}$ \\
\hline Vietnam & Yes & Yes & Yes & Yes & Yes & Yes & Yes & Yes & Yes & Yes \\
\hline TOTAL $(\mathrm{N}=21)$ & 12 & 12 & 7 & 9 & 10 & 10 & 12 & 10 & 12 & 13 \\
\hline
\end{tabular}


Meta-analysis $^{190}$ was chosen as the statistical technique to calculate national averages for each dependent variable for each country under review. A meta-analysis synthesizes existing research by combining multiple studies into a single measure. One of the criticisms of meta-analysis is that it compares apples and oranges. However, this criticism was mitigated by carefully designing the inclusion criteria so that all of the studies that are being combined attempt to measure the same thing.

In meta-analysis, there are two types of models: "fixed effect" and "random effect". Fixed effect model is used when there is an expectation of homogeneity, or one true effect (where each study measures data in the same manner). In a fixed effect metaanalysis, weight is assigned based on the quantity of information in a particular study (i.e., a larger sample size is given a larger weight). Random-effect model is used when heterogeneity is expected. The weight assigned to each study in a random effect metaanalysis is more evenly distributed, thereby removing some of the bias that studies with large sample-sizes would otherwise have. When the conditions for a fixed effect model are met, both fixed and random effects will lead to the same model. Therefore, a randomeffect model can be seen as a more robust approach.

A random-effect model was used because the data in this analysis combines studies from different cities within a country and thus heterogeneity was expected. For the purposes of this study, a meta-analysis of proportions was run using StatsDirect, ${ }^{191}$ which required numeric proportions (i.e., a numerator and denominator). If a study presented its findings in percentages and one could calculate the numerators based on a

190 See e.g.: Borenstein, et al, Introduction to Meta-Analysis, (Chichester, UK: John Wiley \& Sons, Ltd., 2009).

191 StatsDirect Ltd., StatsDirect statistical software, (England: StatsDirect Ltd., 2008), online: $<$ http://www.statsdirect.com>. 
known sample size (i.e., the denominator), then the study would be included. The metaanalysis was also performed separately for the data collected before and after a change in sexual minorities rights.

\section{A) HIV prevalence among $M S M$}

Indicator $23^{192}$ for the purposes of reporting to UNGASS requires HIV prevalence data for most at risk populations (MARPs), which includes MSM. While incidence data (i.e., rate of new infections) is more policy-relevant, there is very little incidence data in the published literature. In fact, most epidemiological studies only report on HIV prevalence among a sample. Therefore, only studies that report on HIV prevalence rates among a sample of MSM will be included in this study.

\section{B) Inconsistent condom use between MSM}

Perhaps the most challenging indicator to assess is condom use between MSM. Epidemiological and behavioural sentinel surveys (BSS) have nearly no consistency from one to another. Some studies ask policy-irrelevant questions such as: "Have you ever used a condom?". The answer "no" is actually useful since it measures the prevalence of having only unprotected anal intercourse (UAI) within a sample. The answer "yes", on the other hand, is meaningless, since it could signify a single use of a condom or condom use with every sexual act. Policy-relevant questions on condom use include: "Do you always, usually, sometimes or never use condoms?" or "In the past 6-months, did you always use condoms?" However, indicator 19 for the purposes of reporting to UNGASS

192 It should be noted that the indicator numbers in this study correspond to the 2008 and 2010 UNGASS reporting periods. For the 2012 reporting period, the guidelines for UNGASS reporting have changed to reflect the new objectives in the 2011 Political Declaration on HIV/AIDS (UN Doc A/Res/65/277). The method of measuring each indicator has not changed, only the indicator number has changed. This indicator will be 1.14 for the 2012 reporting period. 
asks: "Did you use a condom during your last sexual experience?"193

Some studies dichotomize condom use in several ways, such as the frequency of receptive or insertive $\mathrm{UAI}$, or the frequency of $\mathrm{UAI}$ with casual partners, with sex workers, or with regular partners. Though surely useful for their intended purposes, these types of studies are challenging to synthesize. If the consistency of condom use among the full sample of a study is not discernable, then the higher risk activities are logically the most relevant to policy makers as well as for this current study.

For the purposes of establishing inclusion criteria, a study will be included if it reports both recent sexual activity (e.g., in the last six-months) and frequency of inconsistent condom use within that time frame (e.g., the proportion of respondents who did not "always" use condoms). If the study segregates the data, the higher risk activities will be included (e.g., casual sex and receptive UAI). Similarly, studies that report no condom use at last sex will also be included. If a study reports both condom use at last sex and consistent condom use over a time period, the latter will be included.

\section{C) HIV testing among MSM in the past 12 months}

The questions with respect to HIV testing data vary in epidemiological studies and BSS between, "Have you ever had an HIV test" and "Have you had an HIV test within the last 12 months?". The former question is not policy-relevant. It suggests awareness of testing, but does not capture testing frequency or contemporaneity. The latter question is policy-relevant, since it includes a timeframe. Indicator 8 for the purposes of reporting to UNGASS seeks to ascertain the percentage of MARPs who received an HIV test in the

193 UNAIDS, Monitoring the Declaration of Commitment on HIV/AIDS : guidelines on construction of core indicators: 2010 reporting, (2009) UN Doc UNAIDS/09.10E at 61 . This indicator is renumbered 1.12 for the 2012 reporting period. 
last 12 months and who know their results. ${ }^{194}$ Therefore, for the purposes of establishing inclusion criteria, studies that report HIV testing within a timeframe of up to the previous 12 months will be included.

\section{D) Adequate HIV knowledge among MSM}

Indicator 14 for the purposes of reporting to UNGASS asks five questions, three related to HIV prevention and two related to rejecting misconceptions. ${ }^{195}$ However, few studies actually ask the questions necessary to satisfy the UNGASS requirement. By far the most common question asked on surveys is whether or not using condoms can prevent the transmission of HIV. Other common questions asked on surveys include: name three out of four modes of HIV transmission (i.e., unprotected sex, intravenous injections, mother-to-child, and blood-to-blood contact); and name three ways to prevent the transmission of HIV (e.g., $A$ bstinence, Being faithful, and Condom use, commonly known as the $A B C s$ of HIV prevention). Many studies ask a series of questions and report how many respondents "correctly answered $8 / 10$ or better", for example. Sometimes studies try to draw attention to the fact that misconceptions are still held and report the respondents who believe that, "You can get HIV from holding hands".

194 Ibid at 40 . Indicator 12 is measured by asking: Have you been tested for HIV in the last 12 months? If yes, I don't want to know the results, but did you receive the results of that test? This indicator is renumbered 1.13 for the 2012 reporting period.

$195 \mathrm{Ibid}$ at 54 . Indicator 14 is measured by asking:

1. Can having sex with only one faithful, uninfected partner reduce the risk of HIV transmission?

2. Can using condoms reduce the risk of HIV transmission?

3. Can a healthy-looking person have HIV?

4. Can a person get HIV from mosquito bites?

5. Can a person get HIV by sharing a meal with someone who is infected?

The first three questions should never be changed, but the last two can be replaced with common misconceptions in the country. Data should be reported as the number of respondents who correctly answered all five in the numerator and all respondents (including those who didn't answer or have never heard of HIV) on the denominator.

Note: This indicator has been removed from the 2012 reporting period. The new guideline only asks about HIV knowledge among young people aged 15-24. 
A final way to measure knowledge in studies is by asking, "Have you heard of HIV?", “Is HIV curable?", and "Can you prevent HIV transmission?”. These yes/no questions fail to inquire into modes of transmission or prevention, and focus instead on a general awareness of the disease. Since they are not very informative, studies that only report general awareness of HIV will be excluded.

For the purpose of this study, having "adequate" HIV knowledge will include any of the following: (1) studies that report the number of respondents who know condoms can prevent the transmission of HIV; (2) studies that report the number of people who can correctly identify three out of four modes of HIV transmission; or (3) studies that report the number of people who can correctly identify HIV prevention techniques. If a study includes data on one or more of these options, the proportion of respondents that know condoms can prevent the transmission of HIV will be included.

\section{E) Exposure to HIV prevention services for MSM}

Data on exposure to HIV prevention services is the least measured indicator among epidemiological studies and BSS. Indicator 9 for the purposes of reporting to UNGASS asks two questions: "Do you know where you can go if you wish to receive an HIV test?"; and "In the last twelve months, have you been given condoms (e.g., through an outreach service, drop-in centre or sexual health clinic)?". ${ }^{196}$ Questions regarding receiving condoms or receiving information from an outreach worker are the most common among epidemiological studies and BSS. Other studies report the average number of prevention service types attended, which is less policy-relevant since it fails to convey to proportion of MSM being reached by HIV prevention efforts. Although there

$196 \mathrm{Ibid}$ at 42 . The numerator is the number of respondents who answered yes to both questions. This indicator is renumbered 1.11 for the 2012 reporting period. 
is little data available on this variable, studies that report either receiving condoms, receiving information, or attending a safe-sex meeting/information session will be included in this study.

\subsection{Independent variable - SOGI Human Rights Index}

A country's human rights environment for sexual minorities is more nuanced than a simple legal versus illegal dichotomy. In an effort to capture this variation between punitive regimes and protective regimes, a quantitative measure of a State's legal environment for sexual minorities was sought. By way of comparison, the CingranelliRichards (CIRI) Human Rights data project tracks the human rights records of 195 countries each year since $1981 .{ }^{197}$ Although this instrument is well respected and would be ideal in other projects, it does not focus on sexual minorities. While a country might enjoy strong human rights in general, its policies and laws related to sexual orientation may very well be less tolerant. Thus, the CIRI human rights data project was not appropriate for this study.

The social sciences have developed several indices and scales that try to measure sexual orientation-based stigma and discrimination and the attitudes that heterosexuals hold towards sexual minorities. ${ }^{198}$ These instruments have all been developed to measure attitudes and perceptions within a sample of respondents. Therefore, none of these instruments captures a State's legal environment for sexual minorities.

There are two extremely helpful and important global projects, though they are

197 "CIRI Human Rights Data Project", online: <http://ciri.binghamton.edu>.

198 See, e.g.,: the Index of Homophobia (Hudson and Ricketts, "A strategy for the measurement of homophobia" (1980) 5:4 J. Homosexuality 357); the Attitudes Towards Gays and Lesbians Scale (Herek, "Heterosexuals' Attitudes towards Lesbians and Gay Men: Correlates and Gender Differences" (1988) 25:4 J. Sex Research 451); and the Modern Homophobia Scale (Raja and Stokes, "Assessing Attitudes Toward Lesbians and Gay Men: The Modem Homophobia Scale" (1998) 3:2 J. Gay, Lesbian, and Bisexual Identity 113). 
both qualitative. First, there is IGLA's annual State Sponsored Homophobia report, which surveys both punitive and protective laws around the world. ${ }^{199}$ Second, there is the recently released Transrespect $v$. Transphobia ${ }^{200}$ worldwide mapping project focusing on transgender rights issues. Though neither provide a quantitative measure, both were very helpful in providing references to the sexual minority rights in countries under review.

Despite extensive research, a quantitative scale or index that measures the legal environment of a State with respect to sexual minorities was not found. Therefore, this study proposes a new instrument, entitled the Sexual Orientation and Gender Identity (SOGI) Human Rights Index. The SOGI Human Rights Index includes nine punitive items (each worth -1 point) and nine protective items (each worth +1 point). The formulae used to calculate the SOGI Human Rights score for a country is: $0.5+$ Total Points /18. See Table 9 (on the following page) for a template used throughout the Appendix to calculate the SOGI Human Rights score for each country under review in this study.

Most of the fields in the SOGI Human Rights Index have a clear Yes/No answer to whether the item exists or not. However, "discriminatory laws and practices" and "supportive laws and practices" do require some degree of judgement. Generally, a single, reasonably substantial piece of evidence would be sufficient, but often several examples are listed in the Appendix. For any field where no evidence was found to authoritatively say that an item exists or does not exist, "no data" was used. In these situations, zero is awarded, which has a neutral effect on the SOGI Human Rights score.

199 International Lesbian, Gay, Bisexual, Trans and Intersex Association (IGLA), online: $<$ http://ilga.org/>.

200 "Transrespect versus Transphobia Worldwide" online: <http://www.transrespect-transphobia.org/>. First phase released December 23, 2011. 
Table 9 - SOGI Human Rights Index Template

Source: Author

\section{SeXual OrIEntation \& Gender Identity Human Rights IndeX}

\begin{tabular}{|c|c|}
\hline Penalty for homosexuality (death penalty) & $-1 \square 0 \square$ \\
\hline Penalty for homosexuality (lashings) & $-1 \square 0 \square$ \\
\hline Penalty for homosexuality ( $>10$ years in jail) & $-1 \square 0 \square$ \\
\hline Penalty for homosexuality (2-10 years in jail) & $-1 \square 0 \square$ \\
\hline Penalty for homosexuality ( $<2$ years in jail) & $-1 \square 0 \square$ \\
\hline Penalty for homosexuality (fines) & $-1 \square 0 \square$ \\
\hline Gender non-conformity sanctions & $-1 \square 0 \square$ \\
\hline 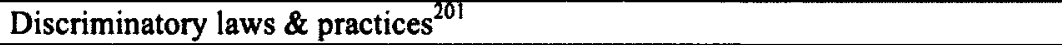 & $-1 \square 0 \square$ \\
\hline Reservations / not party to ICCPR \& ICESCR & $-1 \square 0 \square$ \\
\hline Punitive Points $=$ & $\#$ \\
\hline Ratified ICCPR \& ICESCR & $0 \square+1 \square$ \\
\hline Gender-neutral sexual offences protection ${ }^{202}$ & $0 \square+1 \square$ \\
\hline Equal age of consent & $0 \square+1 \square$ \\
\hline Supportive laws \& policies ${ }^{203}$ & $0 \square+1 \square$ \\
\hline Anti-discrimination protection & $0 \square+1 \square$ \\
\hline Sex reassignment options available ${ }^{204}$ & $0 \square+1 \square$ \\
\hline Recognizes new or third gender (e.g., ID) & $0 \square+1 \square$ \\
\hline Right to marry/civil unions for Transgender & $0 \square+1 \square$ \\
\hline Same-sex marriage/civil unions & $0 \square+1 \square$ \\
\hline Protective Points $=$ & \# \\
\hline TOTAL POINTS = & $\#$ \\
\hline
\end{tabular}

\begin{tabular}{|c|c|c|c|c|c|}
\hline \multicolumn{5}{|c|}{ SEXUAL ORIENTATION \& GENDER IDENTITY HUMAN RIGHTS SCORE: } \\
\hline neutral & + & Total Points divided by 18 & $=$ & SOGI HR Score \\
\hline 0.5 & + & $\#$ & 18 & $=$ & \\
\hline
\end{tabular}

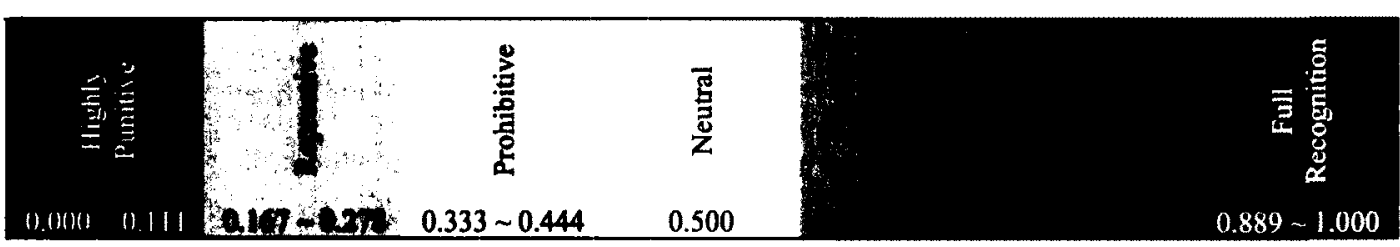

201 Discriminatory laws and practices include any one of the following: institutionalized homophobic practices (e.g., military ban on sexual minorities), deportation for sexual minorities, restrictions on civil liberties (e.g., censorship of sexual orientation related material), and the pathologization of homosexuality.

202 Sexual offences include rape, sexual assault, and sexual exploitation (i.e. human trafficking in sex work) for both adults and minors.

203 Supportive laws and practices include any one of the following: realized freedoms of assembly and speech (supported by the presence of gay bars, gay publications, pride festivals, and gay organization), asylum protection for sexual minorities, and family formation rights (including adoption and/or assisted reproduction).

204 Sex reassignment options include any one of the following: hormone therapy, chest reconstruction surgery, and genital reconstruction surgery.

205 SOGI Human Rights scores range from perfect persecution (with a score of 0.0 ) and perfect protection (with a score of 1.0 ). Thus, 0.5 represents a neutral environment, or one that has punitive provisions offset with protective provisions, making it analogous to being neutral. 
After constructing the SOGI Human Rights Index, and calculating the individual scores for each of the 22 countries $^{206}$ under review, the results were tested against the CIRI human rights data for the same countries during the same time period. This was done in order to test the previously stated hypothesis that countries with strong overall human rights might not necessarily have strong human rights for sexual minorities. The two main indicators of human rights in the CIRI project are physical integrity rights index $^{207}$ and empowerment rights index. ${ }^{208}$ Figure 11 below, depicts the relationship between CIRI human rights scores and the SOGI human rights scores.

Figure 11 - CIRI Human Rights v. the SOGI Human Rights Index

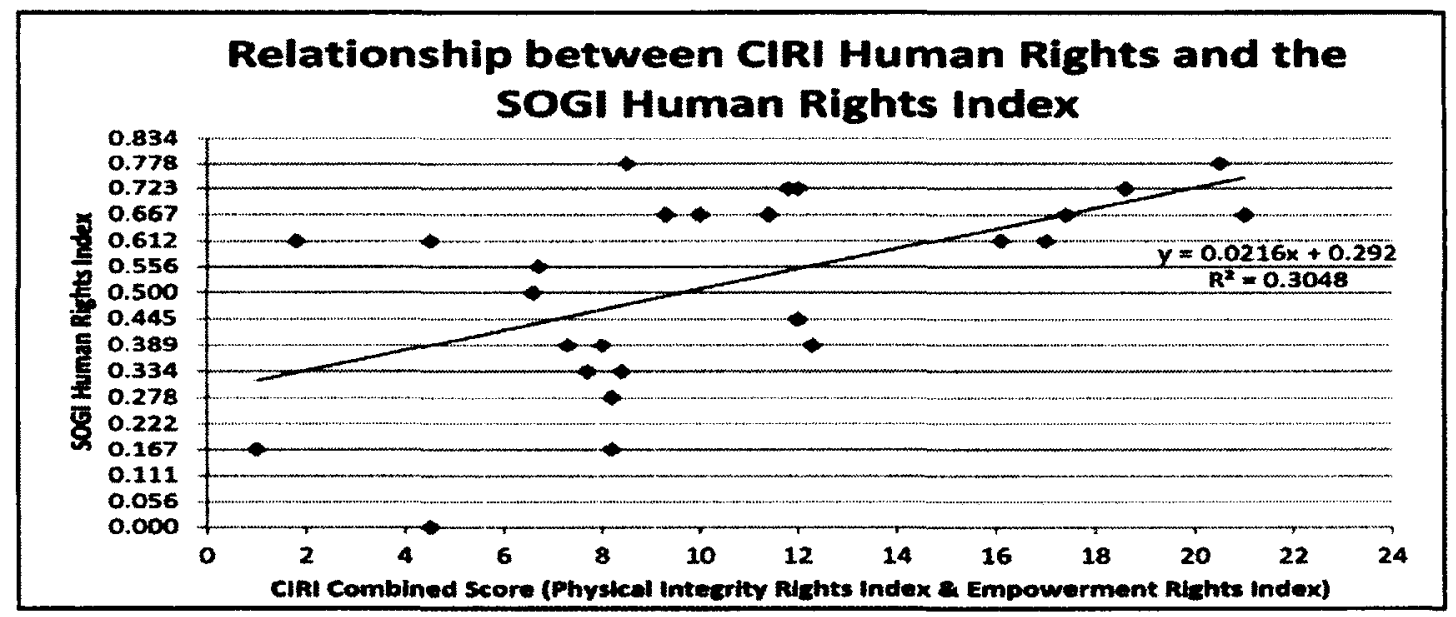

With an $\mathrm{R}^{2}$ of 0.3048 , the CIRI and SOGI Human Rights scores are only moderately correlated. Thus, using CIRI human rights scores for the countries under review would miss the nuanced legal environment faced by sexual minorities, which can differ from that of their sexual majority counterparts. This reinforces the pressing need to have an instrument that targets sexual and gender identity minorities.

206 Bangladesh, Cambodia, China, Hong Kong, India, Indonesia, Japan, Korea (the Republic of), Laos, Malaysia, Maldives, Mongolia, Myanmar, Nepal, Pakistan, Philippines, Singapore, Sri Lanka, Taiwan, Thailand, Timor-Leste, and Vietnam.

207 Comprising indicators of torture, extrajudicial killing, political imprisonment, and disappearance.

208 Comprising indicators of foreign movement, domestic movement, freedom of speech, freedom of assembly and association, workers' rights, electoral self-determination, and freedom of religion. 


\subsection{Confounding Variables}

There is always a possibility that the relationship being examined may be spurious if all possible extraneous variables are not controlled. In an effort to minimize this risk, four key confounding variables were chosen based on the literature review and common sense (see Table 10 on the next page). First, Islam, as the dominant religion of the State, was chosen because the overwhelming evidence suggests that Islamic countries tend to not only criminalize homosexual behaviour but also actively campaign internationally to stop or slow the progressive development of international human rights protection for sexual minorities. ${ }^{209}$ Furthermore, Islam was singled out over other religions due to the general tolerance shown in other religions. ${ }^{210}$ Countries with Islam as their dominant religion are coded 1 , and the rest are coded 0 . Five countries in this study have Islam as their dominant religion.

Second, having a British colonial legacy was selected since continental European imperial powers did not export sodomy laws to their colonies. Only former British colonies still criminalize homosexuality in Asia. Former British colonies are coded 1, and the rest are coded 0 . Ten countries in this study have a British colonial legacy.

Third, the Human Development Index (HDI) was selected because wealth, health and education have been clearly identified as social determinants of health. Countries with high HDI are theorized to have stronger human rights, even for sexual minorities, and they would also tend to have a lower disease burden, including HIV. Thus, countries

209 Syria on behalf the Organization of the Islamic Council, delivered an opposing statement to Argentina's statement on sexual orientaiton, gender identity and human right on December 18, 2008.

210 A notable example includes the Holy See's statement during the 2008 UN General Assembly debate on sexual orientation, gender identity and human rights. The Vatican opposed the actual UN Statement, largely due to fears that it would lead to same-sex marriage, but urged countries to decriminalize homosexual behaviour. Father Bené, on behalf of the Holy See said: "The Holy See continues to advocate that every sign of unjust discrimination towards homosexual persons should be avoided and urges States to do away with criminal penalties against them." (UN Doc A/63/PV.71). 
with an HDI score of 0.677 or greater are coded 1 , and the rest are coded 0 . Six countries in this study had a high or very high HDI score.

Finally, the Polity IV Project was used to determine the political regime of each country. Democratic States would likely have better human rights protections for sexual minorities, whereas autocratic regimes would likely be more repressive towards sexual minorities. Democratic countries are coded 1, and the rest are coded 0 . Fifteen countries were coded as democratic. It should be noted that during the decade under review several countries slipped in and out of democracy. Therefore, a country would be coded based on whether the majority of the decade was democratic or autocratic.

Table 10 - Confounding variables

Source: Author

\begin{tabular}{|c|c|c|c|c|}
\hline & $\begin{array}{c}\text { Dominant Rellgion } \\
(\text { Islam }=1)\end{array}$ & $\begin{array}{c}\text { Colonial Legacy } \\
(\text { British }=1)\end{array}$ & $\begin{array}{c}\mathrm{HDI}^{2 / 3} \\
(>0.677=1)\end{array}$ & $\begin{array}{l}\text { Pollty IV Score } \\
\text { (Democratic }=1 \text { ) }\end{array}$ \\
\hline Bangladesh & 1 & 1 & 0 & 1 \\
\hline Cambodia & 0 & 0 & 0 & 1 \\
\hline China & 0 & 0 & 0 & 0 \\
\hline Hong Kong & 0 & 1 & 1 & 1 \\
\hline India & 0 & 1 & 0 & 1 \\
\hline Korea, Republic of & 0 & 0 & 1 & 1 \\
\hline Laos, PDR & 0 & 0 & 0 & 0 \\
\hline Malaysia & 1 & 1 & 1 & 1 \\
\hline Maldives & 1 & 1 & 0 & No data \\
\hline Mongolia & 0 & 0 & 0 & 1 \\
\hline Singapore & 0 & 1 & 1 & 0 \\
\hline Sri Lanka & 0 & 1 & 0 & 1 \\
\hline Taiwan & 0 & 0 & 1 & 1 \\
\hline Thailand & 0 & 0 & 0 & 1 \\
\hline Timor-Leste & 0 & 0 & 0 & 1 \\
\hline Vietnam & 0 & 0 & 0 & 0 \\
\hline
\end{tabular}

211 "Organisation of Islamic Cooperation", online: <http://www.oic-oci.org/member_states.asp>.

212 "Commonwealth Secretariat - Member States", online: <http://www.thecommonwealth.org/Internal/ $191086 / 142227 / m e m b e r s />$. It is common knowledge that Hong Kong was a former British colony, though it is not a member of the Commonwealth. "CIA - The World Factbook : Burma", online: <https://www.cia.gov/library/publications/the-world-factbook/geos/bm.html>.

213 UNDP, 2010 Report: HDI Trends 1980-2010, online: <http://hdr.undp.org/en/media/HDI-trends1980-2010.xls>. The Taiwanese government calculated their own HDI, since the UN includes Taiwan as part of China, see Wikipedia, "List of country by Human Development Index", online: <http://en.wikipedia.org/wiki/List_of_countries_by_Human_Development_Index>.

214 Polity IV Project, Political Regime Characteristics and Transitions, 1800-2010, online: <http://www.systemicpeace.org/inscr/p4v2010.x1s>. 


\section{A) Indicators of HIV prevention data collection}

Epidemiological and behavioural studies were collected between May 2009 and August 2011. A mixed method search strategy was used, beginning with general Internet queries and journal database searches. ${ }^{215}$ Other search strategies included consulting: personal acquaintances that work in the field of HIV prevention, bibliographies from studies; ListServes, ${ }^{216}$ the UNAIDS Data Hub, ${ }^{217}$ websites of various HIV related organizations in $\mathrm{Asia}^{218}$ and abstracts from international HIV conferences. ${ }^{219}$ Approximate 340 studies from 22 countries were initially identified.

In order to be included, studies had to report data between 2000-2010. In some cases, exceptions were made for data reported in 1999 (usually when there was little or no data since 2000). Studies did not have to be in English in order to be included. Although the vast majority of studies were in English, studies in Traditional and Simplified Chinese, ${ }^{220}$ Japanese, ${ }^{221}$ Korean, ${ }^{222}$ and Thai ${ }^{223}$ were found and translated. Since

215 Search terms included combinations of country specific terms (e.g., "Japan" or "Japanese"), HIV, MSM-related terms (e.g., "MSM", "men who have sex with men", "men having sex with men", "male to male sex", "sex between men", "homosexual/ity", "gay", and "transgender"), and HIV prevention-related terms (e.g., "unprotected anal intercourse", "condom use/usage", "HIV testing", "HIV prevention", etc).

216 Global Forum on MSM and HIV ListServ <English@forum.msmgf.org> and MSM-Asia ListServ <msm-asia@googlegroups.com>.

217 UNAIDS, "HIV and AIDS Data Hub for Asia-Pacific", online: <http://www.aidsdatahub.org/>.

218 These included NGO wesbites, such as: Naz Foundation International <http://www.nfi.net $>$; the Family Health Initiative <www.fhi.org>; Population Services International (PSI) <www.psi.org/>; and MSM-Japan <www.msm-japan.jp/>.

It also included various national departmental HIV prevention websites, such as: Bangladesh's National AIDS/STD Program (NASP) <www.bdnasp.net>; India's National Aids Control Organisation (NACO) <http://www.nacoonline.org>; among others.

219 Such as the International Congress of AIDS in Asia and the Pacific <http://www.icaap9.org > and the International AIDS Society <http://www.iasociety.org/AbstractSearch.aspx>.

220 Traditional and Simplified Chinese translated by Cory Wong (Ottawa).

221 Japanese translated by Author (Ottawa), Jordan Bernick (Ottawa), Yoshikazu Kono (Ottawa) and Minako Yashiro (Tokyo).

222 Tables within the Korean document were in English, the rest of the document was not translated. 
searching in foreign languages was impractical, there is high probability that other useful studies were missed. However, this problem was minimized through the use of the Asia MSM ListServ (where a request for data was distributed), contacting experts from the various countries, and reviewing the available data against the UNGASS biannual reports, as well as other regional reports on HIV and MSM.

The following additional exclusion criteria were applied after collecting all of the studies and reviewing them carefully. Studies were excluded if they were qualitative, if they had a very small sample (generally $\mathrm{N}<100$, however, exceptions were made if there was little or no other data for a country), and if the study had conflicting/erroneous data that could not be resolved by contacting the lead author. Studies were also excluded if they did not report on any of the five indicators of HIV prevention. If there were two or more studies that reported on the same sample, they would be treated as "one" study. If they conflicted, and the author(s) could not offer an explanation, the most peer-reviewed version (e.g., as opposed to a conference abstract version) would be included. Finally, studies by the same author(s) from different cities, but conducted in the same year, were combined. In other words, the numeric proportions from several cities (e.g., Nagoya, Osaka, and Tokyo) are pooled for a given year, so long as the author(s) and studies' methodology are consistent.

\section{B) SOGI human rights data collection}

Comparative legal research is a complex task, especially when one is unfamiliar with the nuances of foreign jurisdictions, let alone the language barrier. Despite these difficulties, the data collection objective for calculating the SOGI Human Rights score for

223 The one study in Thai that was translated by "Aum" Ekkaluck Jamparsri (Bangkok) was not relevant to this current study. 
each country under review sought out primary sources of legislation, official policies, and case law. This was supplemented with reliable secondary sources, and occasionally less reliable sources (e.g., wikipedia) were used. Recognizing the unreliability of some sources, ideally more than one less reliable source stating substantially the same information would be needed before assigning punitive or protective points to the SOGI Human Rights score of a country.

Locating authoritative sources for the SOGI Human Rights Index usually began with a search of secondary material, especially material produced by regional or local experts that have specialized knowledge of a country's legal system. This strategy often uncovered the primary sources (i.e., legislation, policies, or case law), which were then sought though websites such as <www.worldlii.org>, as well as the legislative websites for each country. If the title of a particular legislation was known, a simple search on Google was usually successful at locating a digital copy.

Various secondary sources were especially helpful in providing the bulk of data for the SOGI Human Rights scores for most of the countries under review. ${ }^{224}$ Local experts were contacted where there were gaps in identifying the existence or absence of a particular field in the SOGI Human Rights score template. Examples included the Bandhu Social Welfare Society (Bangladesh), the Cambodian Center for Human Rights, the Hong Kong Refugee Advice Center, and the Gay Vietnam Alliance.

224 See e.g.,: Asylum Law: <http://www.asylumlaw.org/>; Canadian Immigration and Refugee Board's responses to information requests: <http://www.irb.gc.ca/>; Australian Refugee Review Tribunal's country advice: <http://www.mrt-rrt.gov.au/>; IGLA's State Sponsored Homophobia Reports (20092011): <www.igla.org>; GayLawNet: <http://www.gaylawnet.com/laws/laws.htm>; IGLHRC: <http://www.iglhrc.org/cgi-bin/iowa/home/index.html>; INTERPOL's Sexual Offences Laws: $<$ https://www.interpol.int/Public/Children/SexualAbuse/NationalLaws/Default.asp>; UN Treaty Collections: <http://treaties.un.org/>; "Transrespect versus Transphobia Worldwide": $<$ http://www.transrespect-transphobia.org/>; and Wikipedia, "LGBT rights by country or territory": $<$ http://en.wikipedia.org/wiki/LGBT_rights_by_country_or_territory $>$. 
Finally, the SOGI Human Rights score for a country reflects only the period of years for which epidemiological and behavioural data were available. For example, if a country has had some progressive developments in 2007, but data on HIV prevention is only available up to 2005 , then the recent legal changes would not alter the SOGI Human Rights score for the country. Likewise, if there was HIV prevention data before and after a change in the legal environment, then the new SOGI Human Rights score would be applicable only to the HIV prevention data from the legislative change onwards. All recent developments are clearly documented in the Appendix. 


\section{Data Analysis}

\subsection{Summary of findings}

After completing the data collection phase and excluding studies that did not meet the inclusion criteria for this study, a meta-analysis was performed on approximately 230 studies to find national averages for each State under review. For the six countries that had progressive developments in their human rights protections for sexual minorities, the meta-analysis of the HIV-related data was analyzed separately for the years before and after the change in the legal environment. The findings from this preliminary analysis are presented in Table 11 below; for a more detailed account of these figures, please consult the Appendix.

Table 11 - Summary of findings

\begin{tabular}{|c|c|c|c|c|c|c|c|}
\hline \multirow{2}{*}{\multicolumn{3}{|c|}{$\begin{array}{r}\text { Independent Variable } \\
\text { SOGI Human } \\
\text { Rlghts Score }\end{array}$}} & \multicolumn{5}{|c|}{ Dependent Variables } \\
\hline & & & $\begin{array}{c}\text { HIV } \\
\text { Prevalence }\end{array}$ & $\begin{array}{l}\text { Inconslstent } \\
\text { condom use }\end{array}$ & $\begin{array}{c}\text { Recent HIV } \\
\text { testing }\end{array}$ & $\begin{array}{l}\text { Adequate HN } \\
\text { knowledge }\end{array}$ & $\begin{array}{l}\text { Exposure to } \\
\text { HIV prevention }\end{array}$ \\
\hline Bangladesh & & 0.278 & $0.25 \%$ & $89 \%$ & $3.1 \%$ & $65 \%$ & $48 \%$ \\
\hline Cambodia & & 0.722 & $9 \%$ & $45 \%$ & $40 \%$ & $88 \%$ & $68 \%$ \\
\hline China & & 0.611 & $3.25 \%$ & $52 \%$ & $27 \%$ & $79 \%$ & $59 \%$ \\
\hline \multirow[t]{2}{*}{ Hong Kong } & $<2006$ & 0.722 & $1.85 \%$ & $54 \%$ & $42 \%$ & $73 \%$ & $6 \%$ \\
\hline & $>2006$ & 0.889 & $2.7 \%$ & $35 \%$ & $30 \%$ & $76 \%$ & $52 \%$ \\
\hline \multirow[t]{2}{*}{ India } & $<2005$ & 0.333 & $15 \%$ & $62 \%$ & No foula & $75 \%$ & $26 \%$ \\
\hline & $>2005$ & 0.389 & $11.35 \%$ & $55 \%$ & No dela & $93 \%$ & $45 \%$ \\
\hline \multirow[t]{2}{*}{ Indonesia } & $<2006$ & 0.556 & $9 \%$ & $70 \%$ & No dista & $86 \%$ & $41 \%$ \\
\hline & $>2006$ & 0.667 & $13.3 \%$ & $72 \%$ & $42 \%$ & $81 \%$ & $70 \%$ \\
\hline \multirow[t]{2}{*}{ Japan } & $<2004$ & 0.667 & $2.6 \%$ & $50 \%$ & $26 \%$ & $93 \%$ & voden \\
\hline & $>2004$ & 0.778 & $3.5 \%$ & $48 \%$ & $39 \%$ & $61 \%$ & $38 \%$ \\
\hline \multicolumn{2}{|c|}{ Korea, Republic of } & 0.611 & Notatia & $74 \%$ & $44 \%$ & Nodata & $3 \%$ \\
\hline \multicolumn{2}{|c|}{ Laos, PDR } & 0.500 & $1.80 \%$ & $68 \%$ & $16 \%$ & $88 \%$ & $38 \%$ \\
\hline \multicolumn{2}{|l|}{ Malaysia } & 0.167 & $4 \%$ & $45 \%$ & Aosatg & $80 \%$ & ved dot \\
\hline \multicolumn{2}{|l|}{ Maldives } & 0.389 & $0.00 \%$ & $71 \%$ & Nowas & $48 \%$ & $68 \%$ \\
\hline \multicolumn{2}{|l|}{ Mongolia } & 0.611 & $0.85 \%$ & $53 \%$ & $71 \%$ & $99 \%$ & $69 \%$ \\
\hline \multicolumn{2}{|l|}{ Myanmar } & 0.167 & $29 \%$ & Nodata & No bla & $\sqrt{3000}$ & Moua \\
\hline \multirow[t]{2}{*}{ Nepal } & $<2008$ & 0.389 & $3.68 \%$ & $42 \%$ & $17 \%$ & $84 \%$ & $56 \%$ \\
\hline & $>2008$ & 0.667 & $3.75 \%$ & $35 \%$ & $43 \%$ & $83 \%$ & $79 \%$ \\
\hline \multicolumn{2}{|l|}{ Pakistan } & 0.000 & $1.80 \%$ & $76 \%$ & No hata & $41 \%$ & $4.7 \%$ \\
\hline \multicolumn{2}{|l|}{ Phillippines } & 0.722 & $0.22 \%$ & $68 \%$ & $11 \%$ & No ara & $24 \%$ \\
\hline \multicolumn{2}{|l|}{ Singapore } & 0.444 & $3.98 \%$ & $42 \%$ & $49 \%$ & No dalo & Modat? \\
\hline \multicolumn{2}{|l|}{ Sri Lanka } & 0.333 & $0.48 \%$ & $74 \%$ & $11 \%$ & $80 \%$ & $33 \%$ \\
\hline \multicolumn{2}{|l|}{ Taiwan } & 0.722 & $7 \%$ & $49 \%$ & Nodrta & $96 \%$ & $68 \%$ \\
\hline \multirow[t]{2}{*}{ Thailand } & $<2007$ & 0.667 & $19 \%$ & $42 \%$ & Nodata & $82 \%$ & $54 \%$ \\
\hline & $>2007$ & 0.778 & $24 \%$ & $57 \%$ & $35 \%$ & $83 \%$ & Nodata \\
\hline \multicolumn{2}{|c|}{ Timor-Leste } & 0.667 & $0.91 \%$ & $88 \%$ & No tinta & $80 \%$ & $76 \%$ \\
\hline \multicolumn{2}{|l|}{ Vietnam } & 0.611 & $6 \%$ & $54 \%$ & $26 \%$ & $69 \%$ & $57 \%$ \\
\hline
\end{tabular}


Despite efforts to fill in all of the missing data from the recent UNGASS report, there was still a relative large area of "no data" in Table 11. While HIV prevalence data was widely collected, it is unfortunate that only the Republic of Korea failed to collect prevalence data. ${ }^{225}$ The least reported indicator of HIV prevention was the proportion of MSM that have had a recent HIV test. Although, there were studies from India, Malaysia, Maldives, Pakistan, Taiwan, and Timor-Leste that asked about lifetime HIV testing, these studies were excluded. Finally, six countries had only one or two studies available for the meta-analysis. ${ }^{226}$ These limitations undoubtedly impact the generalizability of the analysis presented below. However, these very same limitations reinforce the notion that MSM remain greatly understudied, and so policy makers have inadequate quantitative data to make informed decisions.

The remainder of this Chapter is divided into two parts: bivariate analyses and multiple-regression analyses. The bivariate analyses examine the relationship between each dependent variable (i.e., indicators of HIV prevention) and the independent variable (i.e., sexual minority rights). It also identifies the impact and significance of the confounding variables (i.e., Islamic countries, former British colonies, countries with high HDI, and democratic countries). The multiple-regression analyses control for the effect of the significant confounding variables for each dependant variable separately and for all five HIV prevention indicators combined.

225 According to the available research on HIV and MSM from the Republic of Korea, there is some strong suggestion that male-to-male transmission accounts for a relatively large percentage of the HIV incidence (36.6\%), and the HIV prevalence rate among MSM in the Republic of Korea is estimated to be $4.5 \sim 5.5 \%$. However, there were no peer-reviewed epidemiological studies found to substantiate this figure. (Shin Surin, "Republic of Korea," in Tadashi Yamamoto and Satoko Itoh, eds, Fighting a Rising Tide: The Response to AIDS in East Asia, (Tokyo: Japan Center for International Exchange, 2006) 156 at 158).

226 The Republic of Korea, Malaysia, Maldives, Myanmar, Singapore, and Timor-Leste 


\subsection{Bivariate analysis}

Confounding variables are thought to interact with both the explanatory variable (i.e., sexual minority rights) and the outcome variables (i.e., indicators of HIV prevention). Therefore, a Wilcoxon Rank Sum test was performed to evaluate whether such relationships exist. ${ }^{227}$ The relationship between the SOGI Human Rights scores and three out of the four confounding variables was found to be statistically significant: Islam as the dominant religion, having been a former British colony, and having democratic institutions (Table 12). These findings are not surprising since the prevailing view among Islamic countries and Sharia law can be characterized as homophobic. Similarly, only former British colonies in Asia criminalize homosexual behaviour. Finally, democratic institutions would logically have greater support for the rule of law, human rights and civil liberties than autocratic regimes.

Table 12: Confounding variables v. the SOGI Human Rights Index

\begin{tabular}{l|ll|ll|l|l}
\hline Confoundlng Variables & \multicolumn{3}{|c|}{ Medlan SOGI Human Rights Scores (IQR) } & P-value \\
\hline Dominant Religion: & $\begin{array}{l}\text { Islam } \\
n=6\end{array}$ & $0.334(0.167-0.556)$ & $\begin{array}{l}\text { Other } \\
n=22\end{array}$ & $0.639(0.444-0.722)$ & $0.0240^{*}$ \\
\hline Colonial Legacy: & $\begin{array}{l}\text { British } \\
n=12\end{array}$ & $0.389(0.306-0.556)$ & $\begin{array}{l}\text { Other } \\
n=16\end{array}$ & $0.667(0.611-0.722)$ & $0.0193^{*}$ \\
\hline Human Development Index: & $\begin{array}{l}\mathrm{HDI}>0.677 \\
n=6\end{array}$ & $0.639(0.444-0.722)$ & $\begin{array}{l}\text { Other } \\
n=22\end{array}$ & $0.611(0.389-0.667)$ & 0.7138 \\
\hline Polity IV Score: & $\begin{array}{l}\text { Democratic } \\
n=20\end{array}$ & $0.667(0.473-0.722)$ & $\begin{array}{l}\text { Other } \\
n=5\end{array}$ & $0.500(0.444-0.611)$ & $0.0862^{* *}$ \\
\hline
\end{tabular}

\section{A) Sexual minority rights and HIV prevalence among MSM}

Data on HIV prevalence among MSM were among the most complete in this study. Among the countries under review, only the Republic of Korea had no HIV prevalence data. The linear regression in Figure 12 suggests that there is no relationship

227 The Wilcoxon Rank Sum test is a non-parametric test, requiring no assumptions about the underlying distribution of the data, used to determine the association between a quantitative variable and a categorical variable: Wilcoxon, "Individual comparisons by ranking methods" (1945) 1:6 Biometrics Bulletin 80. 
between HIV prevalence and human rights for sexual minorities $\left(\mathrm{R}^{2}=0.0013\right.$, $\mathrm{p}$-value $=0.2966) .{ }^{228}$ Even after removing Thailand and Myanmar from the data set, due to their extreme values, the relationship remains statistically insignificant.

Figure 12 - SOGI Human Rights Index v. HIV prevalence

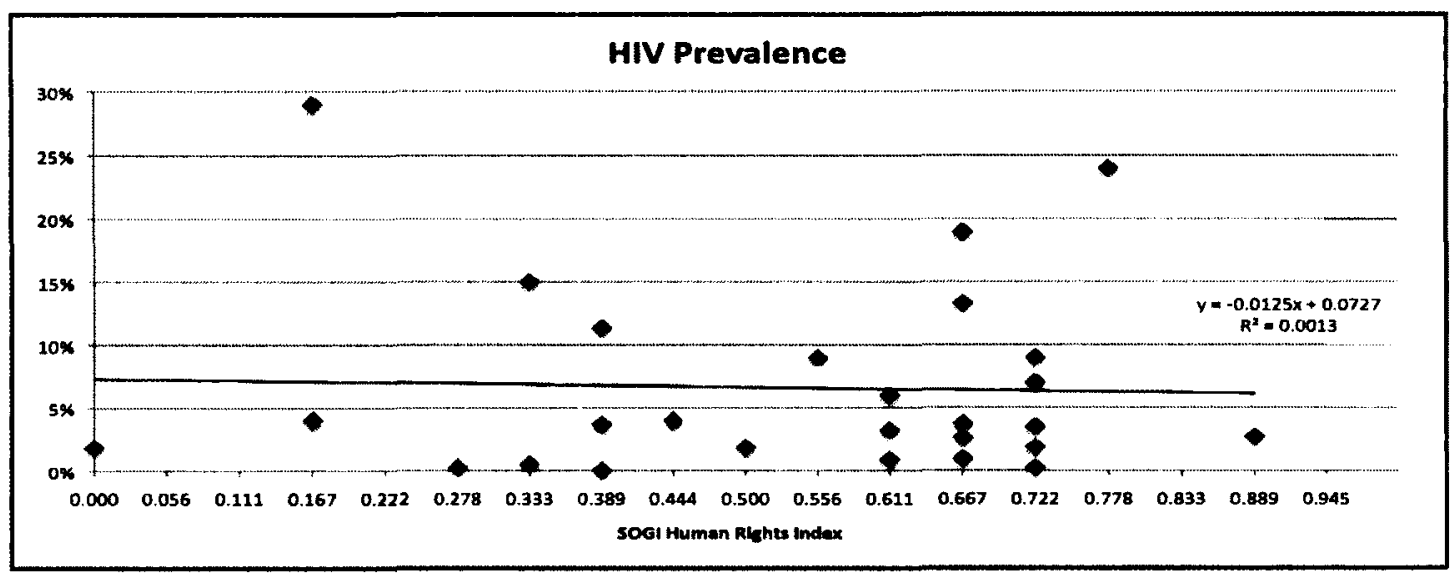

An examination of the effect of the confounding variables revealed that all four (i.e., Islamic traditions, British colonial legacies, high HDI, and democratic institutions) do not interact with HIV prevalence among MSM (Table 13).

Table 13: Confounding variables v. HIV prevalence

\begin{tabular}{|c|c|c|c|c|c|}
\hline \multirow{2}{*}{$\begin{array}{l}\text { Confounding Varlables } \\
\text { Dominant Religion: }\end{array}$} & \multicolumn{4}{|c|}{ Medlan Percentages of HIV Prevalence (IQR) } & \multirow{2}{*}{$\begin{array}{l}\text { P-value } \\
0.5023\end{array}$} \\
\hline & $\begin{array}{l}\text { Islam } \\
n=6\end{array}$ & $2.90 \%(0.25-9.00 \%)$ & $\begin{array}{l}\text { Other } \\
n=21\end{array}$ & $3.68 \%(1.85 \sim 9.00 \%)$ & \\
\hline Colonial Legacy: & $\begin{array}{l}\text { British } \\
n=12\end{array}$ & $3.19 \%(1.14 \sim 3.99 \%)$ & $\begin{array}{l}\text { Other } \\
n=15\end{array}$ & $6.00 \%(1.80 \sim 13.30 \%)$ & 0.2414 \\
\hline Human Development Index: & $\begin{array}{l}\mathrm{HDI}>0.677 \\
n=5\end{array}$ & $3.98 \%(3.50-4.00 \%)$ & $\begin{array}{l}\text { Other } \\
n=22\end{array}$ & $3.46 \%(0.91-11.35 \%)$ & 0.7787 \\
\hline Polity IV Score: & $\begin{array}{l}\text { Democratic } \\
n=19\end{array}$ & $3.75 \%(0.91-11.35 \%)$ & $\begin{array}{l}\text { Other } \\
n=5\end{array}$ & $3.98 \%(3.25 \sim 6.00 \%)$ & 0.7222 \\
\hline
\end{tabular}

$228 \mathbf{R}^{2}$ : If the relationship were perfect, then the coefficient of determination $\left(\mathbf{R}^{2}\right)$ would be 1.0 (indicating $100 \%$ of the variance in one variable is accounted for by a variance in the other variable). In such cases, all observed points would fall on the predicted line. Likewise, if there was no relationship, $\mathrm{R}^{2}$ would be 0.0 , where the observed points appear scattered around the predicted line. In between, $R^{2}$ indicates the strength of the relationships, with $0.25-0.50$ indicating a moderate association and 0.50 or greater indicating a strong association.

p-value: The probability statistic most commonly used for testing a null hypothesis is the p-value, which measures the likelihood that the observed result would be observed in another representative random sample. The p-value ranges from 0.0 to 1.0, and the null hypothesis (i.e., the absence of an association) is rejected if the $p$-value is below a pre-determined value, which is usually 0.05 . Some studies relax this cut off by including $p$-values up to 0.1 as "marginally statistically significant". 


\section{B) Sexual minority rights and inconsistent condom use between MSM}

Data on condom use was also among the most complete in this study. Only Myanmar among the countries under review did not have data on inconsistent condom use. The linear regression in Figure 13 suggests that $12 \%$ of the variation in condom use is accounted for by variation in human rights for sexual minorities. This is a weak relationship $\left(\mathrm{R}^{2}=0.1214\right)$ that is marginally significant $(\mathrm{p}$-value $=0.0748)$.

Figure 13 - SOGI Human Rights Index v. inconsistent condom use

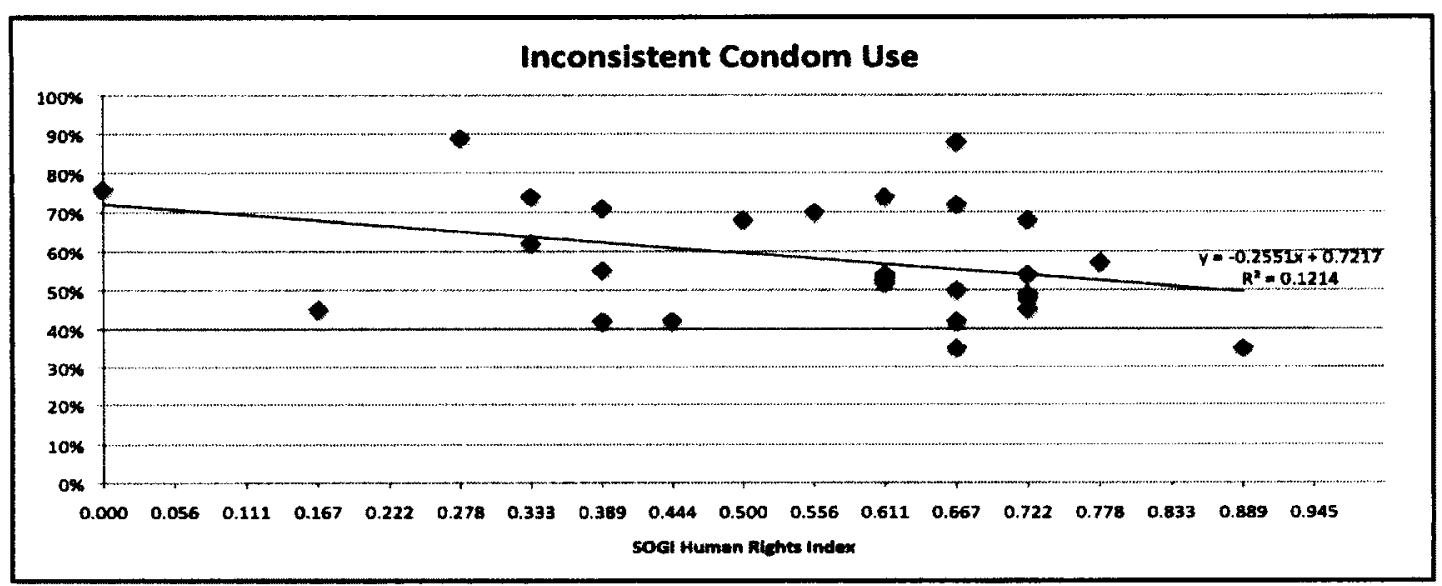

An examination of the effect of the four identified confounding variables revealed that Islam as the dominant religion was statistically significant, while the other three were not (Table 14). Inconsistent condom use between MSM was higher among Islamic countries than non-Islamic countries.

Table 14: Confounding variables v. inconsistent condom use

\begin{tabular}{|c|c|c|c|c|c|}
\hline Confounding Variables & \multicolumn{4}{|c|}{ Median Percentages of Inconsistent Condom Use (IQR) } & P.value \\
\hline Dominant Religion: & $\begin{array}{l}\text { Islam } \\
n=6\end{array}$ & $71.5 \%(70.0 \sim 76.0 \%)$ & $\begin{array}{l}\text { Other } \\
n=21\end{array}$ & $53 \%(45.0-62.0 \%)$ & $0.0307^{*}$ \\
\hline Colonial Legacy: & $\begin{array}{l}\text { British } \\
n=12\end{array}$ & $54.5 \%(42.0 \sim 72.5 \%)$ & $\begin{array}{l}\text { Other } \\
n=15\end{array}$ & $54.0 \%(49.0-70.0 \%)$ & 0.6959 \\
\hline Human Development Index: & $\begin{array}{l}H D \mid>0.677 \\
n=6\end{array}$ & $48.5 \%(45.0-50.0 \%)$ & $\begin{array}{l}\text { Other } \\
n=21\end{array}$ & $57.0 \%(52.0-71.0 \%)$ & 0.1888 \\
\hline Polity IV Score: & $\begin{array}{l}\text { Democratic } \\
\mathrm{n}=20\end{array}$ & $54.5 \%(46.5 \sim 71.0 \%)$ & $\begin{array}{l}\text { Other } \\
n=4\end{array}$ & $53.0 \%(47.0-61.0 \%)$ & 0.6417 \\
\hline
\end{tabular}




\section{C) Sexual minority rights and recent HIV testing among MSM}

The data set on recent HIV testing was missing in $35.7 \%$ of the cases under review. This is problematic for analysis as well as for developing HIV prevention policies founded on evidence-based research. Nevertheless, the linear regression in Figure 14 suggests that $17 \%$ of the variation in recent HIV testing is accounted for by variation in human rights for sexual minorities. This is a moderate relationship $\left(\mathrm{R}^{2}=0.1732\right)$ that is statistically significant $(\mathrm{p}$-value $=0.0106)$.

Figure 14 - SOGI Human Rights Index v. recent HIV testing

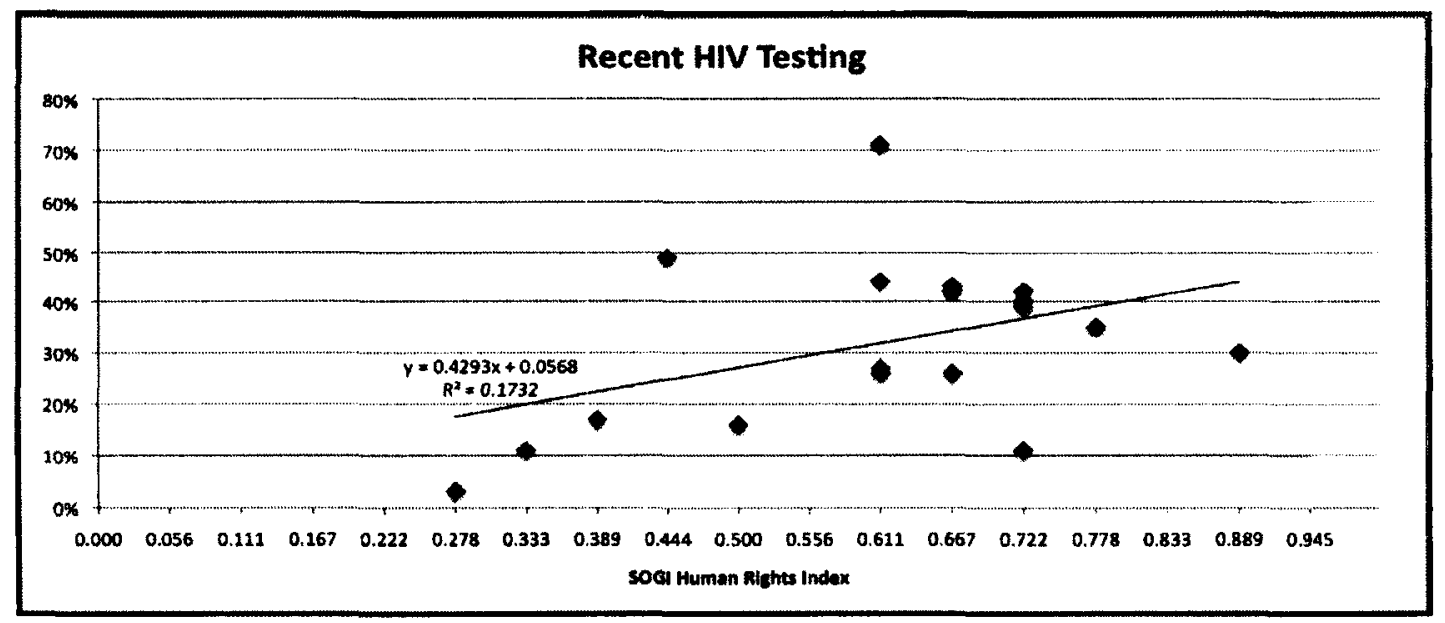

An examination of the effect of the four confounding variables revealed that none had a statistically significant interaction with HIV testing among MSM (Table 15).

Table 15: Confounding variables v. recent HIV testing

\begin{tabular}{|c|c|c|c|c|c|}
\hline \multirow{2}{*}{$\begin{array}{l}\text { Confounding Variables } \\
\text { Dominant Religion: }\end{array}$} & \multicolumn{4}{|c|}{ Medlan Percentages of Recent HIV Testing (IQR) } & \multirow{2}{*}{$\begin{array}{l}\text { P-value } \\
0.5736\end{array}$} \\
\hline & $\begin{array}{l}\text { Islam } \\
n=2\end{array}$ & $22.5 \%(3.1-42.0 \%)$ & $\begin{array}{l}\text { Other } \\
n=16\end{array}$ & $32.5 \%(21.5-42.5 \%)$ & \\
\hline Colonial Legacy: & $\begin{array}{l}\text { British } \\
n=7\end{array}$ & $30.0 \%(11.0 \sim 43.0 \%)$ & $\begin{array}{l}\text { Other } \\
n=11\end{array}$ & $35.0 \%(26.0-42.0 \%)$ & 0.7855 \\
\hline Human Development Index: & $\begin{array}{l}\mathrm{HDI}>0.677 \\
n=4\end{array}$ & $41.5 \%(32.5 \sim 46.5 \%)$ & $\begin{array}{l}\text { Other } \\
n=14\end{array}$ & $28.5 \%(16.0 \sim 42.0 \%)$ & 0.2018 \\
\hline Polity IV Score: & $\begin{array}{l}\text { Democratic } \\
n=13\end{array}$ & $39.0 \%(26.0 \sim 42.0 \%)$ & $\begin{array}{l}\text { Other } \\
n=4\end{array}$ & $26.5 \%(21.0-38.0 \%)$ & 0.7336 \\
\hline
\end{tabular}




\section{D) Sexual minority rights and adequate HIV knowledge among MSM}

Data on adequate HIV knowledge was only missing from four countries: the Republic of Korea, Myanmar, the Philippines, and Singapore. The linear regression in Figure 15 suggests that $19 \%$ of the variation in HIV knowledge is accounted for by variation in human rights for sexual minorities. This is a moderate relationship $\left(\mathrm{R}^{2}=0.1908\right)$ that is statistically significant $(\mathrm{p}$-value $=0.0323)$.

Figure 15 - SOGI Human Rights Index v. adequate HIV knowledge

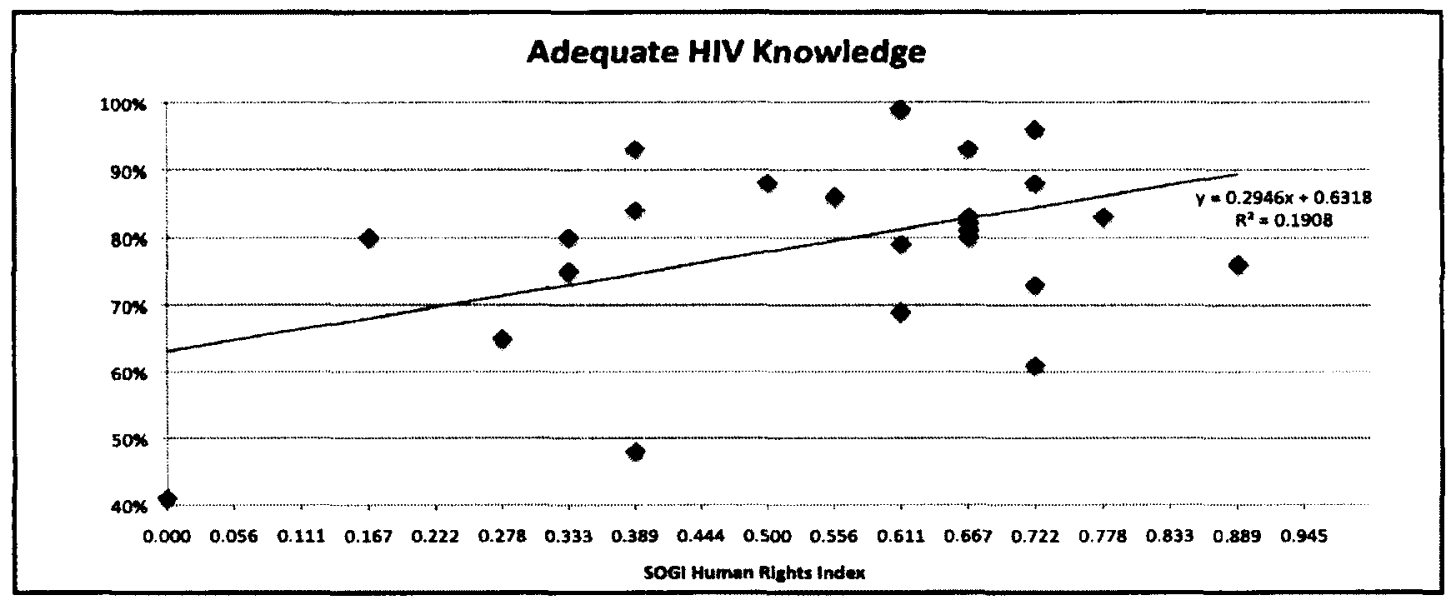

An examination of the effect of the four confounding variables revealed that Islam as the dominant religion and having a British colonial legacy were marginally significant, while the other two were not (Table 16). The data suggests that HIV knowledge was less adequate among Islamic countries and former British colonies.

Table 16: Confounding variables v. adequate HIV knowledge

\begin{tabular}{|c|c|c|c|c|c|}
\hline \multirow{2}{*}{$\begin{array}{l}\text { Confounding Variables } \\
\text { Dominant Religion: }\end{array}$} & \multicolumn{4}{|c|}{ Medlan Percentages of Adequate HIV Knowledge (IQR) } & \multirow{2}{*}{$\begin{array}{l}\text { P-value } \\
0.0886^{\star *}\end{array}$} \\
\hline & $\begin{array}{l}\text { Islam } \\
\mathrm{n}=6\end{array}$ & $72.5 \%(48.0 \sim 81.0 \%)$ & $\begin{array}{l}\text { Other } \\
n=18\end{array}$ & $82.5 \%(76.0-88.0 \%)$ & \\
\hline Colonial Legacy: & $\begin{array}{l}\text { British } \\
n=11\end{array}$ & $76.0 \%(65.0 \sim 83.0 \%)$ & $\begin{array}{l}\text { Other } \\
n=13\end{array}$ & $83.0 \%(80.0-88.0 \%)$ & $0.0555^{* *}$ \\
\hline Human Development Index: & $\begin{array}{l}H D \mid>0.677 \\
n=4\end{array}$ & $86.5 \%(70.5 \sim 94.5 \%)$ & $\begin{array}{l}\text { Other } \\
n=20\end{array}$ & $80.5 \%(74.0 \sim 85.0 \%)$ & 0.5348 \\
\hline Polity IV Score: & $\begin{array}{l}\text { Democratic } \\
n=18\end{array}$ & $81.5 \%(76.0 \sim 88.0 \%)$ & $\begin{array}{l}\text { Other } \\
n=3\end{array}$ & $79.0 \%(69.0 \sim 88.0 \%)$ & 0.5456 \\
\hline
\end{tabular}




\section{E) Sexual minority rights and exposure to HIV prevention services for MSM}

Data on exposure to HIV prevention services was missing from five countries: Japan (<2004), Malaysia, Myanmar, Singapore, and Thailand (>2007). The linear regression in Figure 16 suggests that $11 \%$ of the variation in exposure to HIV prevention services is accounted for by variation in human rights for sexual minorities. This is a weak relationship $\left(R^{2}=0.1117\right)$ that is marginally significant $(p$-value $=0.1190)$.

Figure 16 - SOGI Human Rights Index v. exposure to HIV prevention

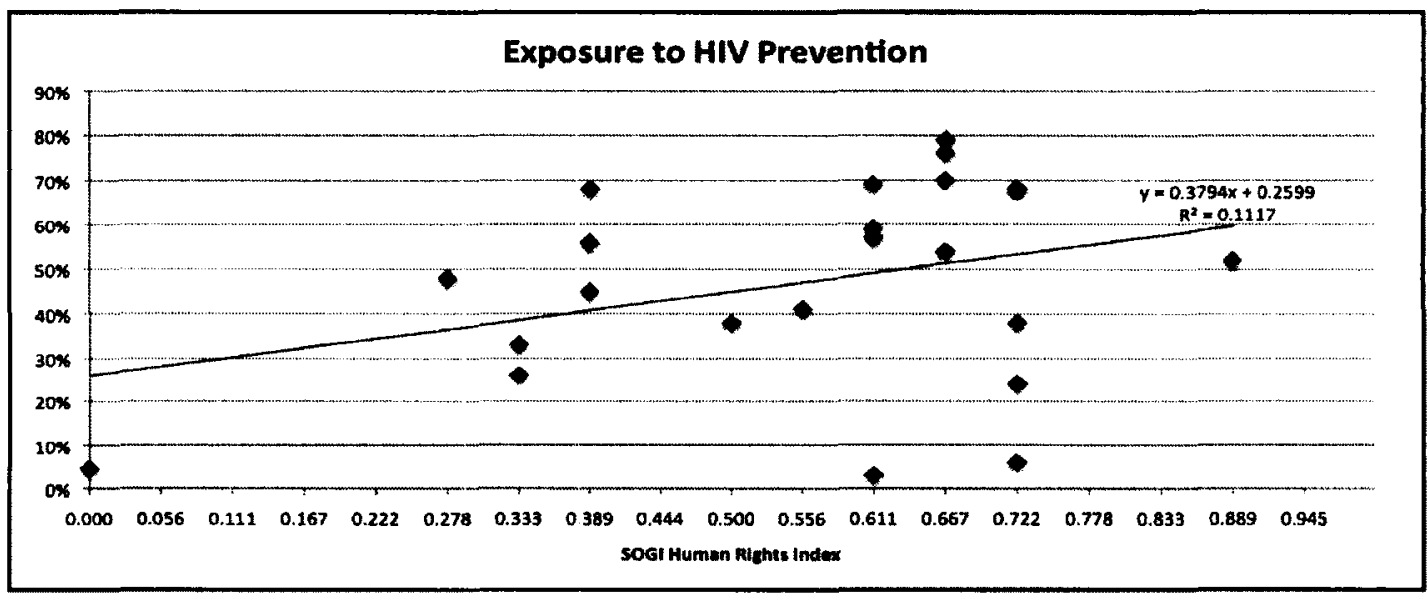

An examination of the effect of the four identified confounding variables revealed no effect on the results (Table 17). This indicates that Islamic-based countries, British colonial legacy, high $\mathrm{HDI}$, and democratic institution do not interact with exposure to HIV prevention services.

Table 17: Confounding variables v. exposure to HIV prevention

\begin{tabular}{|c|c|c|c|c|c|}
\hline Confounding Variables & Median Pe & Entages of Exposure & IIV Pre & tlon Services (IQR) & P-value \\
\hline Dominant Religion: & $\begin{array}{l}\text { Islam } \\
n=5\end{array}$ & $48.0 \%(41.0-68.0 \%)$ & $\begin{array}{l}\text { Other } \\
n=18\end{array}$ & $53.0 \%(33.0-68.0 \%)$ & 0.9702 \\
\hline Colonial Legacy: & $\begin{array}{l}\text { British } \\
n=10\end{array}$ & $46.5 \%(26.0-56.0 \%)$ & $\begin{array}{l}\text { Other } \\
n=13\end{array}$ & $57.0 \%(38.0 \sim 68.0 \%)$ & 0.3358 \\
\hline Human Development Index: & $\begin{array}{l}H D I>0.677 \\
n=3\end{array}$ & $38.0 \%(3.0-68.0 \%)$ & $\begin{array}{l}\text { Other } \\
n=20\end{array}$ & $53.0 \%(35.5-68.0 \%)$ & 0.4107 \\
\hline Polity IV Score: & $\begin{array}{l}\text { Democratic } \\
\mathrm{n}=17\end{array}$ & $48.0 \%(33.0 \sim 68.0 \%)$ & $\begin{array}{l}\text { Other } \\
n=3\end{array}$ & $57.0 \%(38.0 \sim 59.0 \%)$ & 0.8738 \\
\hline
\end{tabular}




\subsection{Multiple-Regression Analysis}

In multiple-regression there are several explanatory variables (i.e., independent variables) for a single outcome. Since the confounding variables of HDI and Polity IV were not statistically associated with any of the dependent variables, they were excluded from the multiple-regression analysis. The remaining confounding variable, i.e., dominant religion and colonial legacy, were included in the multiple-regression in order to remove their effect on the relationship between sexual minority rights and HIV prevention indicators. Table 18 lists five multiple-regression models one for each dependent variable controlled for dominant religion and colonial legacy.

In multiple-regression missing data is a problem. Unlike bivariate analysis where case deletion is generally acceptable, case deletion in multiple-regression introduces a bias that overstates the precision of estimated effects in the multiple-regression model. In this multiple-regression analysis, Myanmar was eliminated (since four out of the five indicators were missing). Multiple imputation ${ }^{229}$ was then used to fill in the missing data for each dependent variable except for inconsistent condom use, which had no missing data once Myanmar was deleted. All multiple imputation analyses for the purpose of this study were run using 200 imputations, using SAS, version 9.2 software, ${ }^{230}$ to ensure stability in both the estimates and the standard errors.

229 Single imputation of estimates in place of missing values reduces this bias, but in turn artificially reduce the standard error (i.e., making the data distribution 'bell curve' taller and narrower), giving the erroneous impression of a precise estimate. To ensure the removal of bias without an overprecise error bound, multiple imputation creates a series of data sets of estimated means (average) along with additional data points falling within a standard distribution. Data sets are then aggregated and included with the observed data. One of the assumptions in multiple imputation is that the missing data is "missing at random", which permits the mathematical fiction that the missing data can be predicted or guessed based on the real observed data. For additional information, see: Schafer, "Multiple Imputation: a primer" (1999) 8 Statistical Methods in Medical Research 3; and Rubin, Multiple imputation for nonresponse in surveys, (New York: John Wiley, 1987). 
Table 18: Multiple-regression analysis of HIV prevention indicators each separately [Data in percentages with $95 \% \mathrm{CI}$ ]

\begin{tabular}{l|c|c|c}
\hline & SOGI Human Rights & Domlnant Rellgion: Islam & Colonial Legacy: British \\
\hline HIV Prevalence & $7.64(-4.86,20.14)$ & $1.01(-4.95,6.97)$ & $-0.94(-5.23,3.36)$ \\
\hline Inconsistent condom use ${ }^{\prime}$ & $-29.98(-47.63,-12.33)^{*}$ & $10.92(-1.62,23.46)$ & $-12.30(-21.20,-3.41)^{*}$ \\
\hline Recent HIV testing & $33.41(-27.50,94.32)$ & $8.44(-26.45,43.33)$ & $-2.75(-19.85,14.35)$ \\
\hline Adequate HIV knowledge & $2.67(-29.25,34.60)$ & $-11.26(-27.02,4.50)$ & $-4.54(-13.87,4.79)$ \\
\hline Exposure to HIV prevention & $81.93(-73,237.67)$ & $20.27(-25.03,65.57)$ & $6.01(-33.19,45.20)$ \\
\hline 1 No Imputation needed & &
\end{tabular}

After controlling for the effects of dominant religion and colonial legacy, as the SOGI Human Rights scores change from 0.0 (perfect persecution) to 1.0 (perfect protection), on average we expect to see a 7.64 percentage point increase in HIV prevalence, a 29.98 percentage point decrease in inconsistent condom use, a 33.41 percentage point increase in HIV testing, a 2.67 percentage point increase in adequate HIV knowledge, and a 81.93 percentage point increase in exposure to HIV prevention services. Unfortunately, only inconsistent condom use was statistically significant among these multiple-regression models. ${ }^{231}$

Initially, combining the five indicators into a single measure out of $500 \%$ was not possible, since there was too much missing data. However, after performing multiple imputation in order to conduct the above multiple-regression analysis, it was possible to combine the results from all five indicators of HIV prevention. HIV prevalence and inconsistent condom use were reversed so that all five indicators were ranked in the same direction (i.e., percentage that are HIV negative and the percentage that have consistent condom use). Myanmar was deleted as well for this analysis. Figure 17 depicts the observed and imputed data from 21 countries, six of which had changes in their SOGI

231 If the $95 \%$ confidence interval crosses zero (i.e., having negative and positive bounds), then it is not considered statistically significant at the 0.05 level. 
Human Rights scores.

Figure 17 - SOGI Human Rights Index v. HIV prevention indicators (combined)

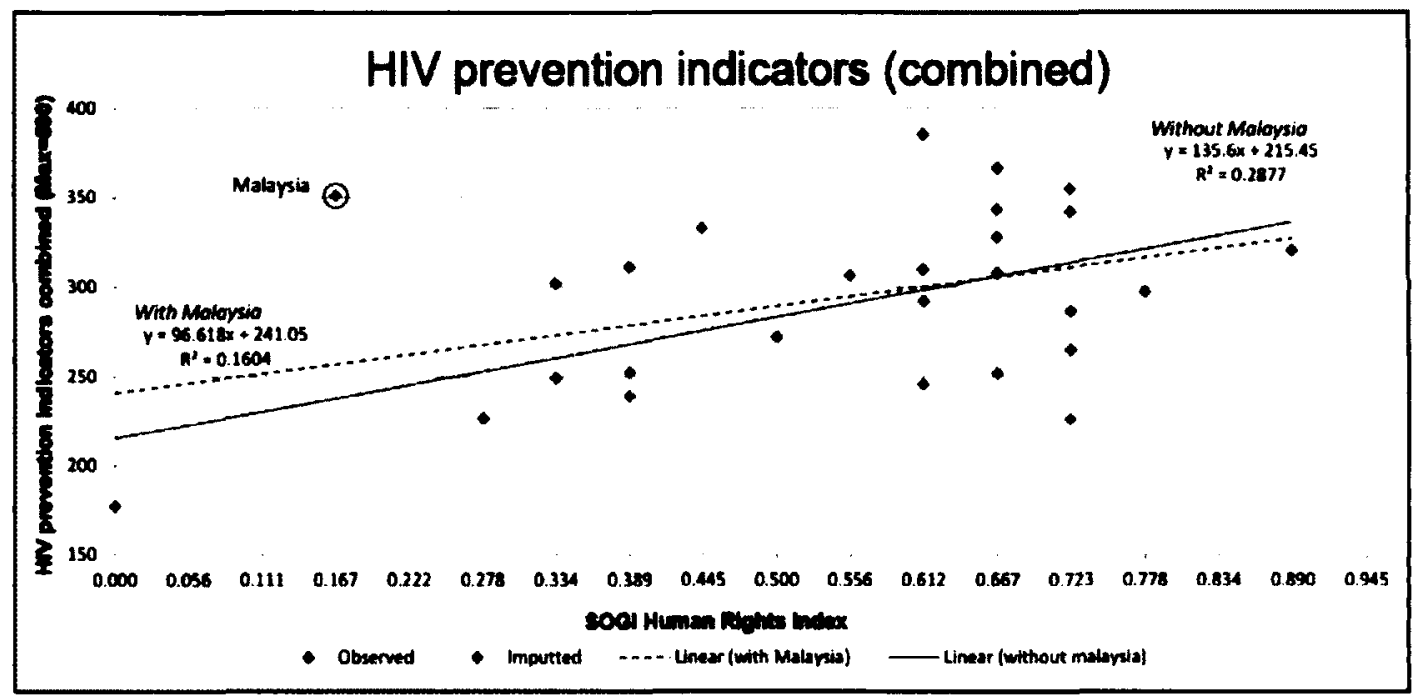

A quick look at the scatter plot in Figure 17 identifies Malaysia as an outlier, due to its low SOGI Human Rights Score and very high combined HIV prevention score. The linear regression in Figure 17 suggests that $16 \%$ of the variation in HIV prevention is accounted for by variation in human rights for sexual minorities $\left(R^{2}=0.1604\right.$, $p$-value $=$ 0.1706); when Malaysia is excluded, nearly $29 \%$ of the variation is explained by this model $\left(\mathrm{R}^{2}=0.2877\right.$, $\mathrm{p}$-value $\left.<0.0001\right)$. Table 19 has a multiple-regression with and without Malaysia, controlling for the confounding variables of dominant religion and colonial legacy.

Table 19: Multiple-regression analysis of HIV prevention indicators all combined [Data in percentages with $95 \% \mathrm{CI}$ ]

\begin{tabular}{l|c|c}
\cline { 2 - 3 } & \multicolumn{2}{c}{ Combined Score of HIV Prevention Indicators } \\
\cline { 2 - 3 } SOGI Human RIghts & With Malaysia & Without Malaysia \\
\hline Dominant Rellgion: Islam & $109.61(-30.40,249.62)$ & $145.30(17.89 .272 .71)^{*}$ \\
\hline Colonial legacy: British & $-5.11(-52.58,42.36)$ & $-19.45(-64.46,25.56)$ \\
\hline "statistically significant & $6.78(-38.40,51.96)$ & $-8.33(-39.41,56.07)$ \\
\hline
\end{tabular}


In interpreting this model, a change in a SOGI Human Rights score from 0.0 (perfect persecution) to 1.0 (perfect protection) leads to a 109 percentage point increase in HIV prevention on average distributed among the five indicators (i.e., a $21.8 \%$ improvement). However, since the $95 \%$ confidence interval crosses zero in the model with Malaysia, it is considered not statistically significant. When the regression was performed without Malaysia, the change in SOGI Human Rights score had a statistically significant effect on the combined score of HIV prevention indicators, with an expected a 145 percentage point increase distributed among the five indicators (i.e., a $29 \%$ improvement).

It is unclear exactly why Malaysia is an outlier, and this could be the subject of a follow-up study. One possibility is that Malaysia is developing rapidly with a strong economy and relatively high HDI score (rising from 0.691 in 2000 to 0.744 in 2010). ${ }^{232}$ Furthermore, former Prime Minster Mahathir Mohamed of Malaysia, who held office from 1981 to 2003, was an active supporter of the "Asian Values" critique of human rights. ${ }^{233}$ Recalling that the "Asian Values" argument is that human rights might have to wait so that development can progress, this could partially explain why Malaysia has such a low SOGI Human Rights score and relatively strong HIV prevention indicators.

232 UNDP, supra note 213.

233 Kraft, "Human Rights, ASEAN and Constructivism: Revisiting the "Asian Values" Discourse" (2001) 22:45 Philippine Pol. Sci. J. 33. 


\section{Conclusions and Policy Recommendations}

"The ongoing study of how greater social acceptability and increased citizenship rights of MSM affects how STI epidemics operate within MSM communities will be an area of study that will yield very important policy conclusions about how best to support health and wellbeing in marginalised communities. "234

How does variation in human rights for sexual minorities influence variation in indicators of HIV prevention among MSM and transgender people in Asia? The answer to the question remains elusive, even after having completed this study. The correlations between the new SOGI Human Rights Index and HIV prevention indicators would, perhaps, be stronger with a larger data set (i.e. more countries). Nevertheless, there are three general conclusions and two broad policy recommendations that can be drawn from the results of this study.

\subsection{General conclusions}

First, there appears to be little or no statistical correlation between variation in human rights for sexual minorities and HIV prevalence among MSM and transgender people in Asia. This finding, though unsurprising to some, undermines much of the omnipresent "critical role of human rights" language in HIV discourse. The literature review, however, clearly identified the concern that open and liberal societies (i.e., those that could be characterized as gay-friendly) could facilitate sexual networking and increased sexual risk taking behaviour. It is important to note that failing to reject a null hypothesis (e.g., protective regimes have no relationship with HIV prevalence among MSM), does not confirm a null hypothesis as "true". In fact, there could be any number

234 Stall and Hart, "The continuing evolution of research on sexually transmitted infections among men who have sex with men" (2008) 84:6 Sex Transm. Infect. 407 at 409. 
of factors masking this relationship.

One possible explanation is that the improvements in anti-retroviral therapy for HIV are helping those with HIV live longer, which can keep HIV prevalence rates high even if the incidence rate is low. This is one of the theories behind the relatively high HIV prevalence rates among MSM in North America. It could be insightful to re-run this analysis with HIV incidence data, though at present such data are scarce.

Another factor worth exploring is the variation in injection drug use (IDU) across different legal regimes for sexual minorities. For instance, is IDU more prevalent in countries with human rights for sexual minorities or without? The intersection of drug use and sexual minority rights may be an important component in a follow-up study, since IDU is one of the driving forces in the Asian HIV epidemic. Beyrer, et al developed four scenarios to characterize the different types of HIV epidemics among MSM in lowto middle income countries. Scenario four is defined as: "MSM transmission, IDU transmission, and heterosexual transmission all contribute significantly to the HIV epidemic. This is the complex context of much of South, Southeast, and Northeast Asia."235 Thus some of the new HIV infections among MSM were not due to sexual risk taking; rather it could be through sharing unclean injection equipment.

Controlling for differences in "gender identity" among MSM would also be an important follow-up study. This study included transgender individuals as MSM, which may have masked the relationship between sexual minority rights and HIV prevalence.

235 Beyer, et al, (2010), supra note 8 at 142. "In scenario 1, MSM risks are the predominate mode of exposure for HIV infection in the population. This scenario is seen across most of South America and in multiple settings in high-income countries. [...] In scenario 2, MSM risks occur within established HIV epidemics driven by IDU. This is the predominant epidemic context in Eastern Europe and Central Asia. [...] In scenario 3, MSM risks occur in the context of mature and widespread HIV epidemics among heterosexuals. This is the prevailing context across sub-Saharan Africa" (at 142). 
Transgender individuals often face worse social exclusion than gender-conforming MSM, which can limit their employment opportunities to entertainment and sex work. As such, transgender individuals are generally considered at higher risk of HIV infection. Although many studies included a "gender" breakdown in their univariate results, ${ }^{236}$ not every study reported disaggregated data, making it challenging to run a sensitivity analysis on the role gender identity plays in the correlation between SOGI human rights and HIV prevalence.

The second conclusion is that stronger human rights for sexual minorities was correlated with better indicators of HIV prevention efforts. At the bivariate level, HIV testing and HIV knowledge had moderate correlations with the SOGI Human Rights Index, while inconsistent condom use and exposure to HIV prevention had weak correlations. Although only inconsistent condom use remained statistically significant after controlling for dominant religion and colonial legacy, this finding is very reassuring considering the role unsafe sex plays in HIV transmission. Moreover, the effect of going from perfect persecution (0.0) to perfect protection (1.0) on the SOGI Human Rights Index had a substantial impact on the five variables once pooled together (see Figure 17 in Chapter 5). The effect is even more pronounced and statistically significant if Malaysia is excluded.

The proportion of MSM with recent HIV testing, adequate HIV knowledge, and exposure to HIV prevention services all increase as the legal environment for sexual minorities improves. This substantiates some of the anecdotal reports mentioned in the literature review. For instance, the literature review demonstrated that MSM feared being open and honest with their doctors, especially in countries that had hostile socio-legal environments for sexual minorities. This could lead to lower HIV testing uptake. 
Likewise, countries that were supportive had developed niche men's health clinics and services for MSM. Thailand, for example, has developed several sexual health centres specifically for MSM, such as the Chai Rak Chai (Men Love Men) Clinic in Bangkok and the Prevention of Infection in Man (PIMAN) Center in Chiang Mai. ${ }^{237}$

The third general conclusion - high quality comprehensive data on HIV prevalence and prevention among MSM is sorely lacking - is abundantly clear from the results of this study. Ideally, all States would include data on the five MSM-related indicators to the UN General Assembly Special Session on HIV/AIDS (UNGASS). As shown in Table 8 (Chapter 4), more than half of the countries under review failed to adequately report on the MSM-related UNGASS indicators. Even following the extensive data collection process undertaken in this study, there was still an unacceptable amount of missing data on HIV testing, HIV knowledge, and exposure to HIV prevention services. These three indicators constitute the bulk of HIV prevention work: reach targeted at-risk populations; provide them with life-saving skills and knowledge; and encourage changes in behaviour, including condom and lubricant use, fewer sexual partners, regular HIV testing, and avoiding sex while under the influence of substances. Effective policies to reduce HIV transmission among MSM and reverse the upward trend seen across the region require accurate national data on these three indicators.

\subsection{Policy recommendations}

The main policy recommendation that logically follows from the previously discussed conclusions and data analysis is to decriminalize homosexuality and remove

237 Though only one study reported recent HIV testing in Thailand (35\%), there were other studies that reported lifetime HIV testing. Also, this low figure should not undermine the utility and importance of having gay men's health clinics in a Southeast Asia country. 
other discriminatory laws and practice in order to begin to see substantial improvements in indicators of HIV prevention among a country's MSM population. This corresponds with the duty to respect and protect the right to health (including sexual health) of sexual minorities. States violate this duty when their laws, policies, and official acts prevent or, at the very least, dissuade sexual minorities from accessing HIV prevention services, respectful medical care, confidential HIV testing; if they restrict access to accurate information about HIV transmission and methods to prevent HIV exposure; and if they fail to prevent abuses by private actors, such as healthcare workers.

In 2001, UN Member States agreed to "enact, strengthen or enforce, as appropriate, legislation, regulations and other measures to eliminate all forms of discrimination against and to ensure the full enjoyment of all human rights and fundamental freedoms by people living with HIV/AIDS and members of vulnerable groups."238 UNGASS developed a National Composite Policy Index (NCPI) to help evaluate progress towards achieving this commitment. The NCPI is comprised of 53 yes/no questions, "including 15 questions that encapsulate the core components of a rights-based approach and focus on the legal and policy environment, the availability of HIV-related services, and vulnerable subpopulations."239 Gruskin, et al analyzed the NCPI from the 2008 UNGASS reporting period for 133 countries. Their findings indicate that while most countries have laws and policies that further the aims of the Declaration of Commitment on HIV/AIDS, many countries also have laws and policies that impede access to HIV services. South and Southeast Asia, for instance, where $71 \%$ of the

238 UN General Assembly, Declaration of Commitment on HIV/AIDS. "Global crisis - global action", August 2, 2001, UN Doc A/Res/S-25/2 at para. 58.

239 Gruskin, et al, "Human Rights in the Global Response to HIV: Findings From the 2008 United Nations General Assembly Special Session Reports" (2009) 52:Sup 2 J. AIDS s104 at s105. 
countries reported obstacles to full universal access to HIV services for MSM. ${ }^{240}$

A simple comparison of the averages of the five HIV prevention indicators for countries characterized as having a punitive legal environment for sexual minorities (defined as having a SOGI Human Rights score below 0.5 ) to countries with a protective legal environments (defined as having a SOGI Human Rights Index above 0.5), supports this policy recommendation (Table 20).

Table 20: Comparison of HIV prevention indicators by legal regimes [percentages = mean]

\begin{tabular}{lccc}
\hline & $\begin{array}{c}\text { Punitive Reglmes } \\
\text { (SOGI Human Rights Scores <0.5) }\end{array}$ & $\begin{array}{c}\text { Protectlve Regimes } \\
\text { (SOGI Human Rights Scores z0.5) }\end{array}$ & \begin{tabular}{c} 
P-value \\
\hline HIV Prevalence
\end{tabular} \\
Inconsistent Condom Use & $6.95 \%$ & $6.4 \%$ & 0.5991 \\
Recent HIV testing & $62 \%$ & $56 \%$ & 0.1977 \\
Adequate HIV knowledge & $20 \%$ & $35 \%$ & 0.3928 \\
Exposure to HIV prevention services & $71 \%$ & $83 \%$ & $0.0453^{*}$ \\
\hline
\end{tabular}

The differences in averages between punitive and protective regimes presented in Table 20 are abundantly clear. Decriminalize private and consensual sexual acts and behaviour between members of the same sex is a logical first step toward this goal. Removing gender non-conformity sanctions would also be an important step, though only Malaysia and Pakistan, of the countries in this study, had sanctions against gender nonconformity. Taking these initial steps could result in significant improvements in terms of health outcomes for sexual minorities, but ideally legislative changes will continue to progress by adopting anti-discrimination protection and relationship recognition.

A second policy recommendation is that all states, even those with protective legal regimes, need to increase the quality and coverage of MSM serological and behavioural data. This is fundamental if a State plans to use evidence-based policy-making. Only by having high quality empirical evidence can a State begin to fulfill the right to health of sexual minorities. Policy-makers with authoritative data, political will, and the necessary 
financial support will be able to implement effective policies that can facilitate the full enjoyment of the right to sexual health among sexual minorities.

Looking at a recent survey of national strategic plans in Asia reveals a comforting trend towards including MSM in most of the national HIV prevention strategies. However, not all States that have included MSM in their national strategic plans have allocated a budgetary line to meet their policy goals (see Table 21).

Table 21: Inclusion of MSM in national strategic plans and surveillance in Asia Source: APCOM, MSM Country Snapshots (August 2010 version) ${ }^{241}$ [Shading indicates "No"]

\begin{tabular}{|c|c|c|c|c|}
\hline & $\begin{array}{l}\text { Most recent } \\
\text { SoGI Human Rights } \\
\text { classlfication }\end{array}$ & $\begin{array}{l}\text { MSM included in } \\
\text { National HIV } \\
\text { Strategic Plan? }\end{array}$ & $\begin{array}{c}\text { Budget for MSM In } \\
\text { National HIV } \\
\text { Strateglc Plan? }\end{array}$ & $\begin{array}{l}\text { MSM Included in } \\
\text { national serological- } \\
\text { behavloural surveys? }\end{array}$ \\
\hline $\begin{array}{l}\text { Bangladesh } \\
\text { Cambodia } \\
\text { China } \\
\text { Hong Kong } \\
\text { India } \\
\text { Indonesia } \\
\text { Japan } \\
\text { Korea, South } \\
\text { Laos, PDR } \\
\text { Malaysia } \\
\text { Maldives } \\
\text { Mongolia } \\
\text { Myanmar } \\
\text { Nepal } \\
\text { Pakistan } \\
\text { Philippines } \\
\text { Singapore } \\
\text { Sri Lanka } \\
\text { Taiwan } \\
\text { Thailand } \\
\text { Timor-Leste } \\
\text { Vietnam }\end{array}$ & $\begin{array}{c}\text { Repressive } \\
\text { Protective } \\
\text { Supportive } \\
\text { Full Recognition } \\
\text { Prohibitive } \\
\text { Supportive } \\
\text { Protective } \\
\text { Supportive } \\
\text { Neutral } \\
\text { Repressive } \\
\text { Prohibitive } \\
\text { Supportive } \\
\text { Repressive } \\
\text { Supportive } \\
\text { Highly Punitive } \\
\text { Protective } \\
\text { Prohibitive } \\
\text { Prohibitive } \\
\text { Protective } \\
\text { Protective } \\
\text { Supportive } \\
\text { Supportive }\end{array}$ & $\begin{array}{l}\text { No } \\
\text { Yes } \\
\text { No } \\
\text { Yes } \\
\text { Yes } \\
\text { Yes } \\
\text { Yes } \\
\text { No } \\
\text { Yes } \\
\text { Yes } \\
\text { Yes } \\
\text { Yes } \\
\text { Yes } \\
\text { Yes } \\
\text { Yes } \\
\text { Yes } \\
\text { Yes } \\
\text { Yes } \\
\text { No } \\
\text { Yes } \\
\text { Yes } \\
\text { No }\end{array}$ & $\begin{array}{c}\text { No } \\
\text { Yes }(0.61-1.49 \%) \\
\text { No } \\
\text { No } \\
\text { Yes ( } \$ 4 \text { million) } \\
\text { No } \\
\text { No } \\
\text { No } \\
\text { Yes }(1.8 \%) \\
\text { Yes } \\
\text { No } \\
\text { No } \\
\text { Yes }(\$ 5.55 \text { million) } \\
\text { Yes }(6.2 \%) \\
\text { Yes }(2 \%) \\
\text { No } \\
\text { Yes } \\
\text { Yes }(10 \%) \\
\text { No } \\
\text { Yes }(1.3 \%) \\
\text { Yes } \\
\text { No }\end{array}$ & $\begin{array}{c}\text { Yes } \\
\text { Yes (since 2005) } \\
\text { Yes } \\
\text { Yes } \\
\text { Yes } \\
\text { Yes } \\
\text { Yes } \\
\text { No } \\
\text { No } \\
\text { No } \\
\text { Yes (since 2008) } \\
\text { Yes (small samples) } \\
\text { No (except tor HIV) } \\
\text { Yes } \\
\text { Yes } \\
\text { Yes } \\
\text { Yes } \\
\text { Yes } \\
\text { No } \\
\text { Yes (by CDC) } \\
\text { No (trom 2010) } \\
\text { No }\end{array}$ \\
\hline
\end{tabular}

One theory behind this apparent disconnect between punitive regimes having included MSM in the national strategic plans (e.g. Malaysia, Myanmar, and Pakistan) is to attract more international HIV prevention funding. For instance, in 2009 the Global Fund to fight AIDS, Tuberculosis and Malaria adopted the Strategy in Relations to Sexual Orientation and Gender Identity. ${ }^{242}$ It encourages States to consult with vulnerable groups (e.g. the MSM community) in designing national or regional strategy plans. The

241 Information compiled from the series of MSM Country Snapshots, via the AIDS Data Hub, online: <http://www.aidsdatahub.org/en/component/acesearch/search?query=MSM+snapshot>.

242 The Global Fund to Fight AIDS, TB, and Malaria, supra note 146. 
resulting strategies would ideally contain specific programming for MSM that would better reflect the needs of these groups. This could have pressured some countries to adopt MSM-related programming in order to secure funding.

In the first chapter to this study, Figure 2 depicted the Commission on AIDS in Asia's epidemiological projection if the status quo remains - a bleak future, one where MSM accounted for half of all new infections by 2020 . The Commission, however, also offered a projection based on best practices:

Figure 18 - Projected annual new HIV infections in Asia (best practices model)

Source: Commission on AIDS in Asia, at 83

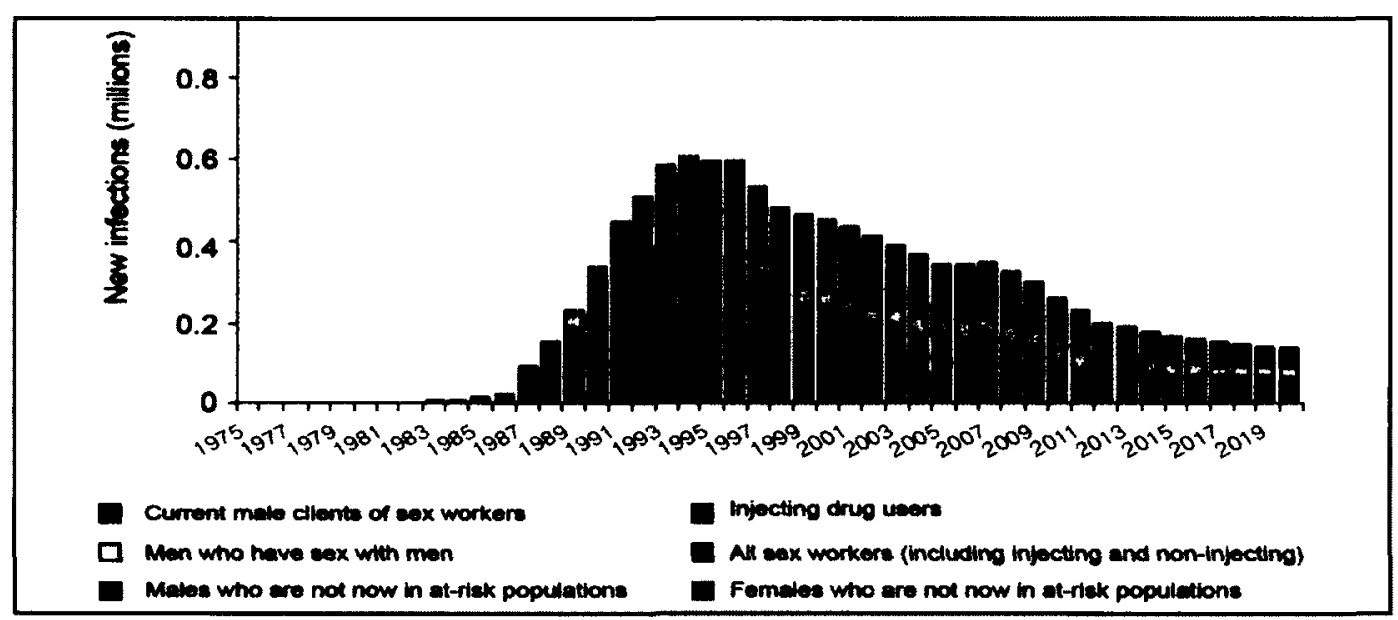

Perhaps this "best practices model" is a best-case scenario. Perhaps it is overly optimistic. Nevertheless, without making the important policy recommendation mentioned above in the near future, the rising HIV infection rates will not likely stabilize or decline, at least not until a viable vaccine and cure are made readily available. Through decriminalization, greater emancipation, stronger human rights protections, and relationship recognition, sexual minorities will be able to better access HIV prevention services and begin to fully realize their human right to health, including sexual health. 


\section{Appendix}

\section{Contents:}

Guide to reading this Appendix ................................................................................. 94

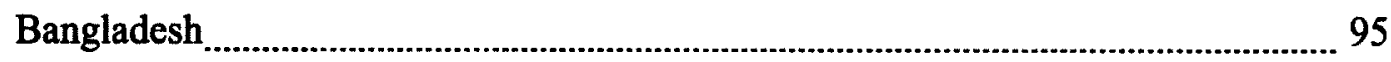

Cambodia

China

Hong Kong $\ldots \ldots \ldots$

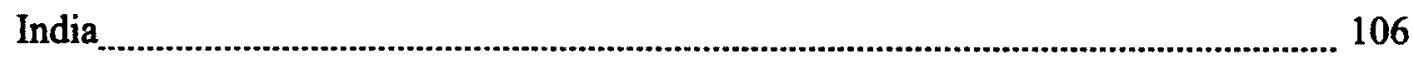

Indonesia

Japan

Korea, Republic of

Laos, PDR

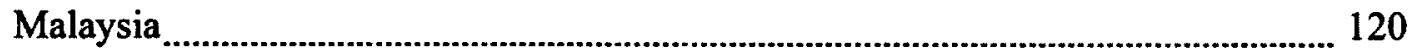

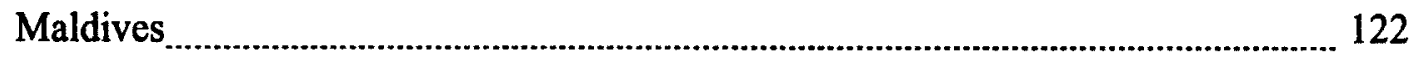

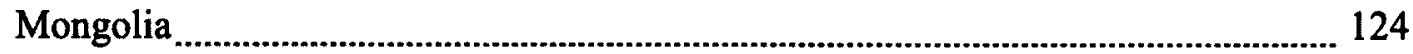

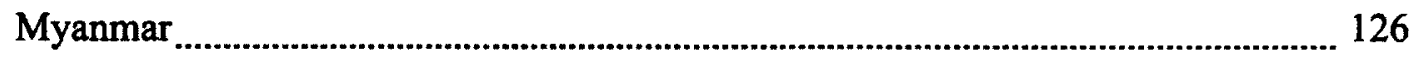

Nepal

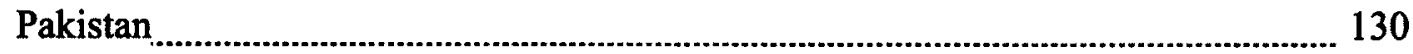

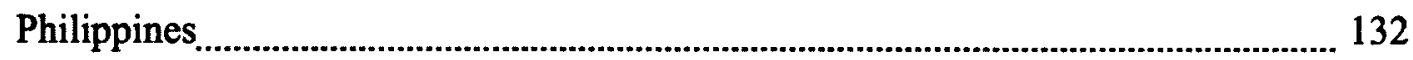

Singapore

Sri Lanka

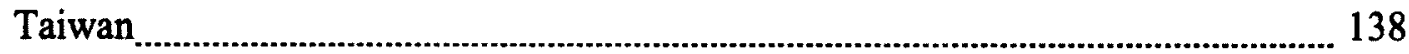

Thailand

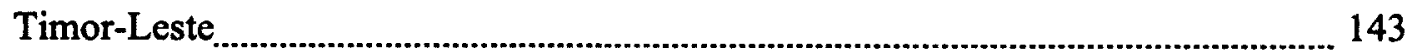

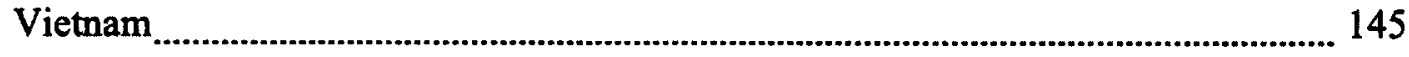


This Appendix contains the meta-analysis of epidemiological and behavioral studies and the SOGI Human Rights score calculations for each country under review.

The meta-analyses of proportions are presented in graphs called forest plots. The figure below will provide an example of how to read a forest plot. The studies included in the meta-analysis are listed on the left and the proportions (written in decimal form rather than as percentages) along with their $95 \% \mathrm{CI}$ are on the right. The squares within the forest plot vary in size proportionate to their sample size, and the horizontal line represents the $95 \% \mathrm{CI}$. Approximately equal weight is assigned to each study using the random-effect model, and the resulting combined average is at the bottom of each figures.

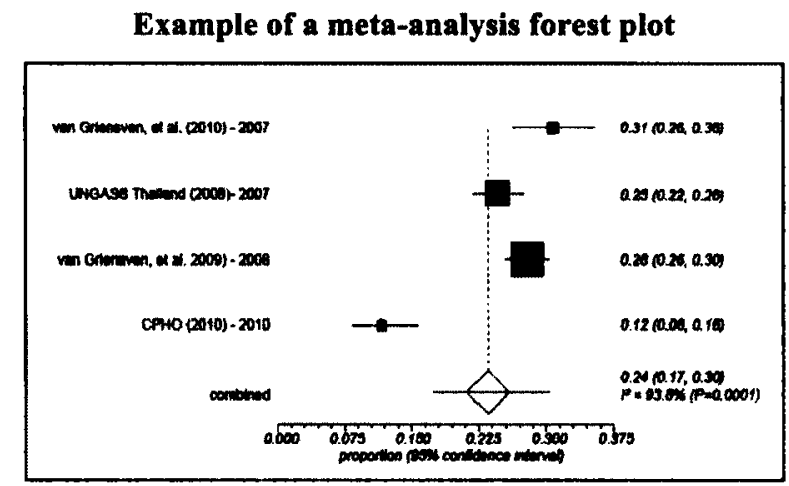

The SOGI Human Rights scores are calculated using the template presented in Chapter 4:

- Punitive items are assigned $-1 \nabla$ if the item exists and $0 \square$ if it does not.

- Protective items are assigned $+1 \nabla$ if the item exists and $0 \nabla$ if it does not.

The column to right contains a number within square brackets, e.g., [1], which refers to one of the references that accompanies the template. The formulae for calculating the SOGI Human Rights score is included on each template along with an assessment of the legal regime. Changes in legislations or policy that occurred during years in which epidemiological and behaviour data are available are indicated with an asterisk (*).

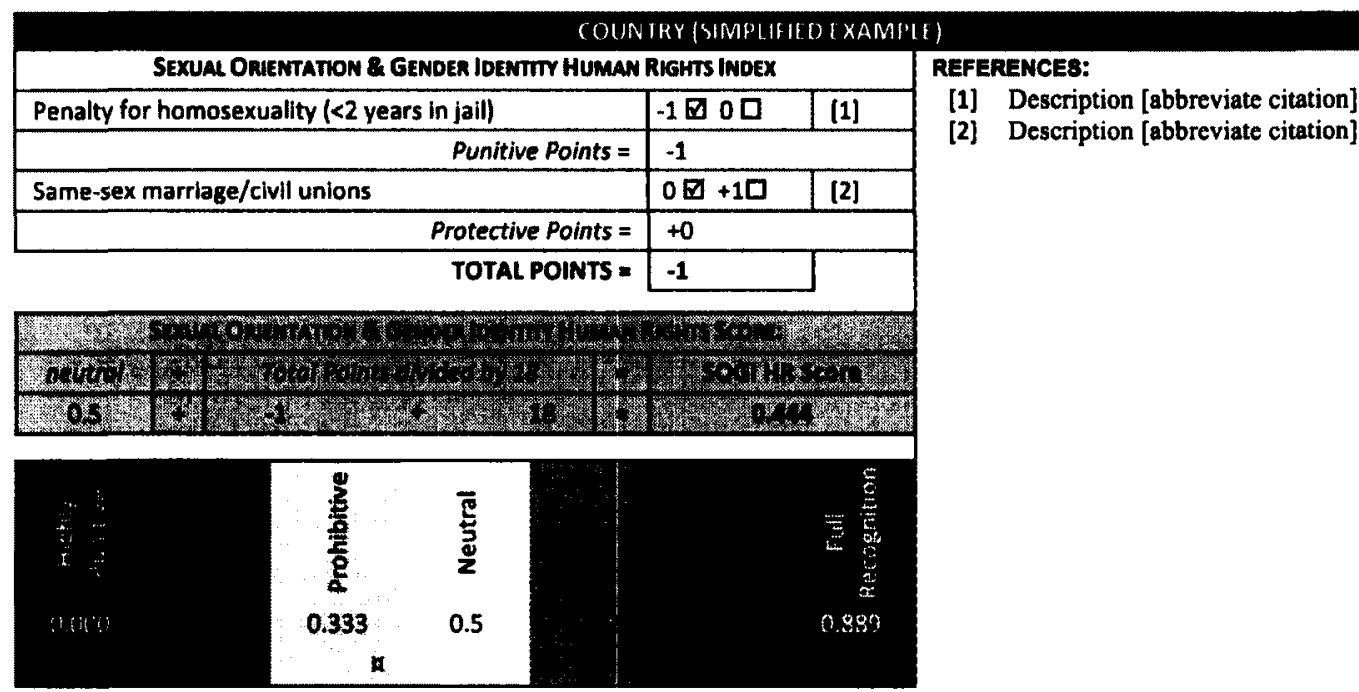


BANGLADESH

\begin{tabular}{|c|c|c|c|c|c|c|}
\hline \multicolumn{2}{|l|}{ BANGLADESH } & \multirow[b]{2}{*}{$\begin{array}{l}\text { HIV } \\
\text { Prevalence }\end{array}$} & \multirow[b]{2}{*}{$\begin{array}{l}\text { Inconsistent } \\
\text { Condom Use }\end{array}$} & \multirow[b]{2}{*}{$\begin{array}{l}\text { HIV Testing } \\
\text { (past year) }\end{array}$} & \multirow[b]{2}{*}{$\begin{array}{l}\text { Adequate HIV } \\
\text { Knowledge }\end{array}$} & \multirow[b]{2}{*}{$\begin{array}{l}\text { Exposure to } \\
\text { HIV Prevention }\end{array}$} \\
\hline Study & Year & & & & & \\
\hline $\mathrm{NFI}(2000)$ & 2000 & No data & $108 / 156$ & Notata & $108 / 200$ & No data \\
\hline NFI (2001) & 2001 & No data & $183 / 198$ & No data & $73 / 195$ & No data \\
\hline NFI (2003) & 2002 & No data & $383 / 399$ & No data & $139 / 400$ & No dats \\
\hline NASP (2003) & 2002 & $4 / 2,399$ & $1,529 / 1,639$ & No data & $1,308 / 1,853$ & $1,182 / 1,853$ \\
\hline NASP (2004) & 2003 & $3 / 2,276$ & $1,588 / 1,783$ & $8 / 1,951$ & $1,426 / 1,950$ & $1,243 / 1,951$ \\
\hline NASP (2005) & 2005 & $5 / 1,531$ & No data & No data & No data & No deta \\
\hline NASP (2007) & 2006 & $5 / 1,038$ & No datat & Nodate & Nodata & No data \\
\hline NASP $(2008 a)$ & 2007 & $3 / 1,481$ & No data & No data & No data & No data \\
\hline NASP (2008b) & 2006 & Nodata & $512 / 631$ & $34 / 799$ & $732 / 799$ & $372 / 799$ \\
\hline NASP (2008b) & 2007 & No data & $1,094 / 1,169$ & $83 / 1,269$ & $1,063 / 1,269$ & $266 / 1,269$ \\
\hline & INED: & $0.25 \%$ & $89 \%$ & $3.1 \%$ & $65 \%$ & $48 \%$ \\
\hline
\end{tabular}

Dependent Variable 1: HIV prevalence

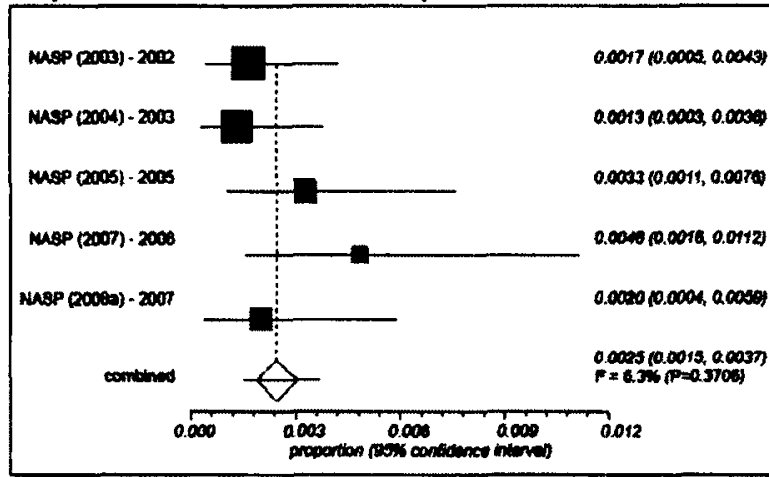

Dependent Variable 2: Inconsistent condom use

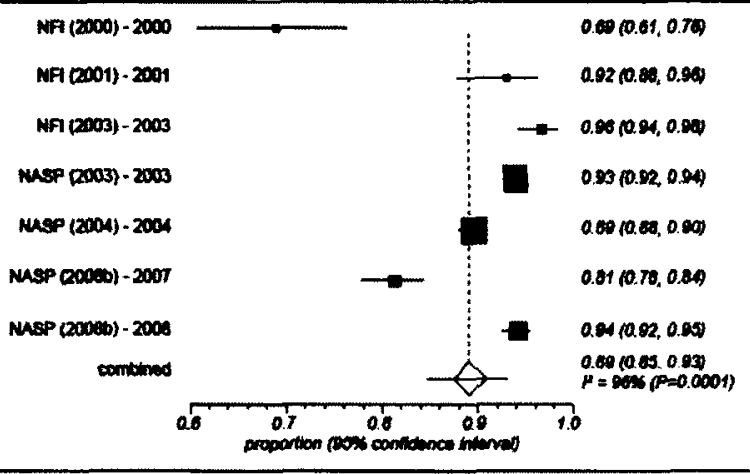

Dependent Variable 3: HIV testing (past year)

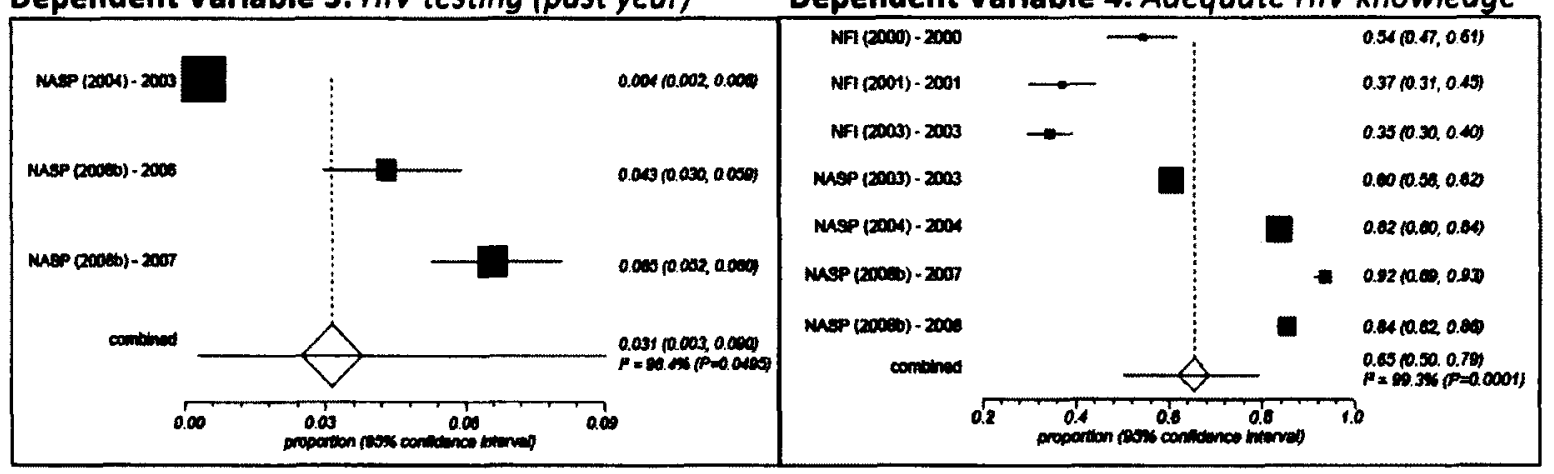

\section{Dependent Variable 5: Exposure to HIV prevention services}

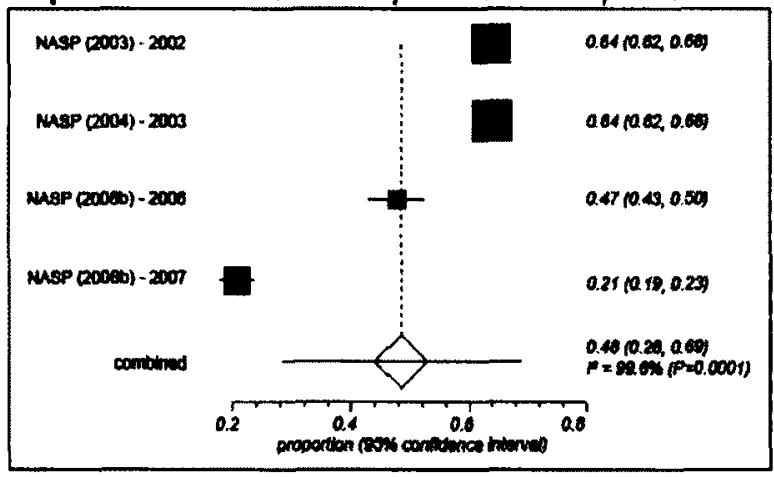


BANGLADESH

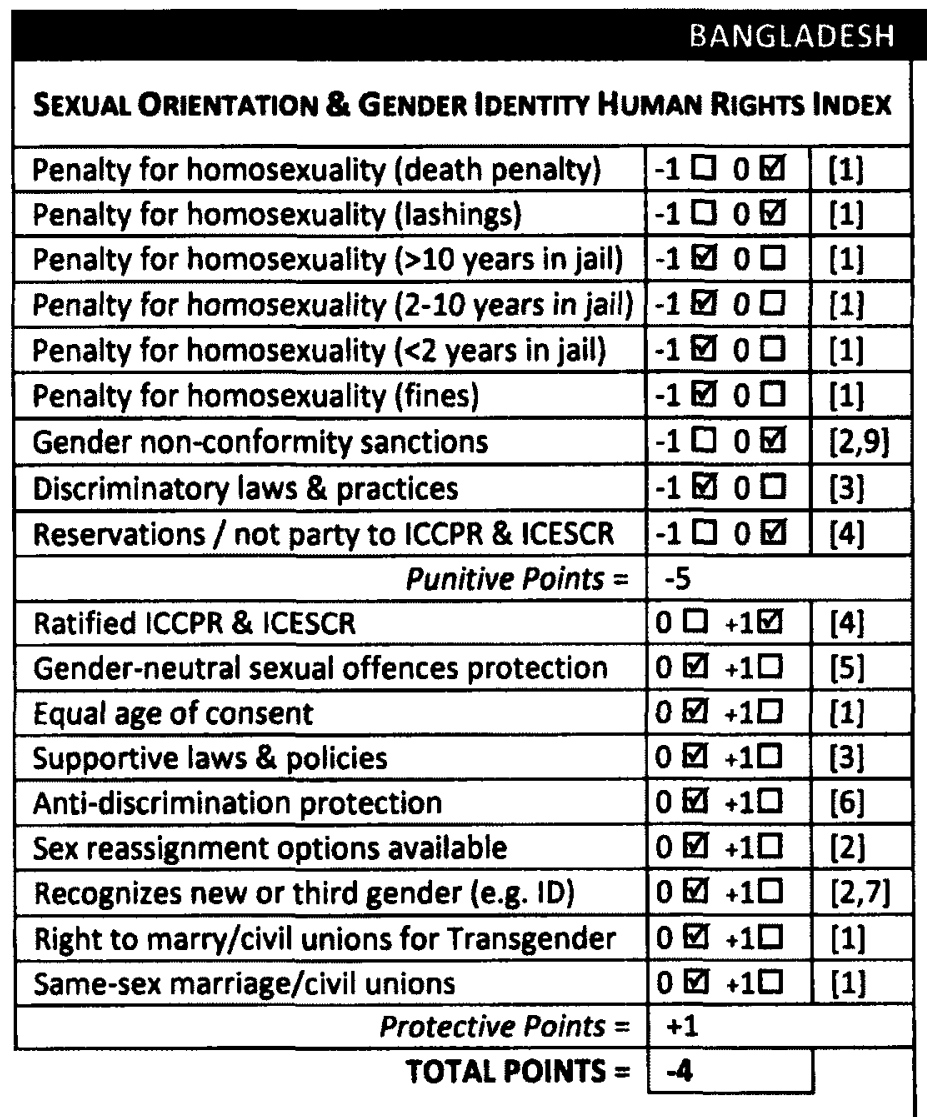

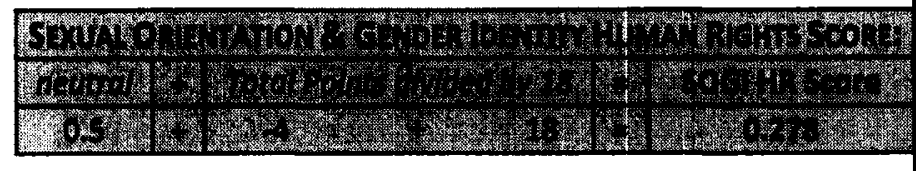

[4] Acceded to the ICCPR (2000) and acceded to the ICESCR (1998): [treaties.un.org]

[5] Only a female person can be victim of rape according to section 375 the Bangladesh Penal Code (1860).

Although sections 372 and 373 of the Bangladesh Penal Code (1860) prohibit the selling and buying of minors for prostitution, which is gender neutral, the explanations use "female person" as an example.

[6] "No laws or regulations in Bangladesh specifically protect most-at risk populations [e.g. MSM] from discrimination. Section 377A of the Bangladesh Penal Code criminalizes and punishes consensual sex between adult men. The law is silent on TG/hijra issues, which creates situations where TG face multiple forms of discrimination.": [WHO (2010) p. 40]

[7] In 2008, a Bangladesh court ruled that transgender people are fully-fledged citizens and have the right to vote. Prior to 2008, transgender people had difficulty voting due to the gender on their ID. However, this change occurred after the years for which epidemiological and behavioural data is available (2000-2007): [GayLawNet "Bangladesh"; and PinkNews (2008)] 


\section{CAMBODIA}

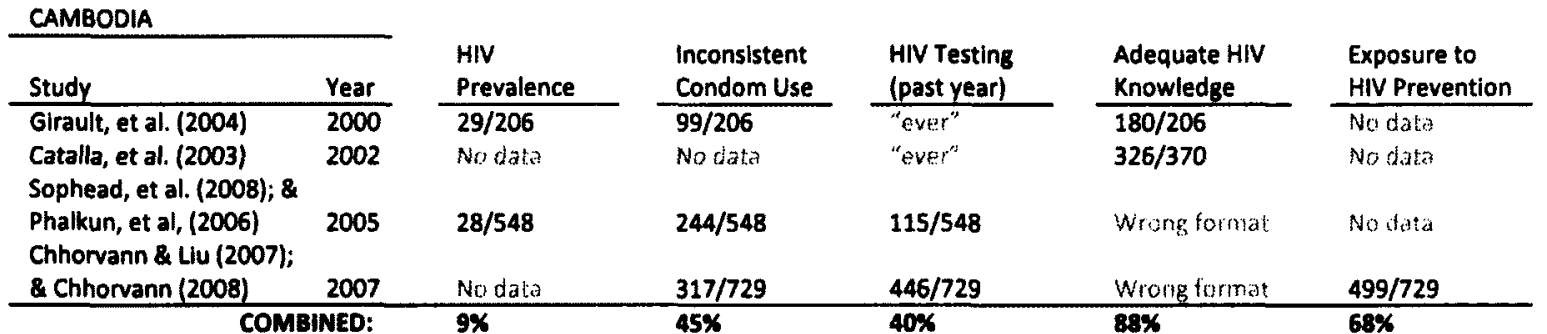

\section{Dependent Variable 1: HIV prevalence}

Dependent Variable 2: Inconsistent condom use

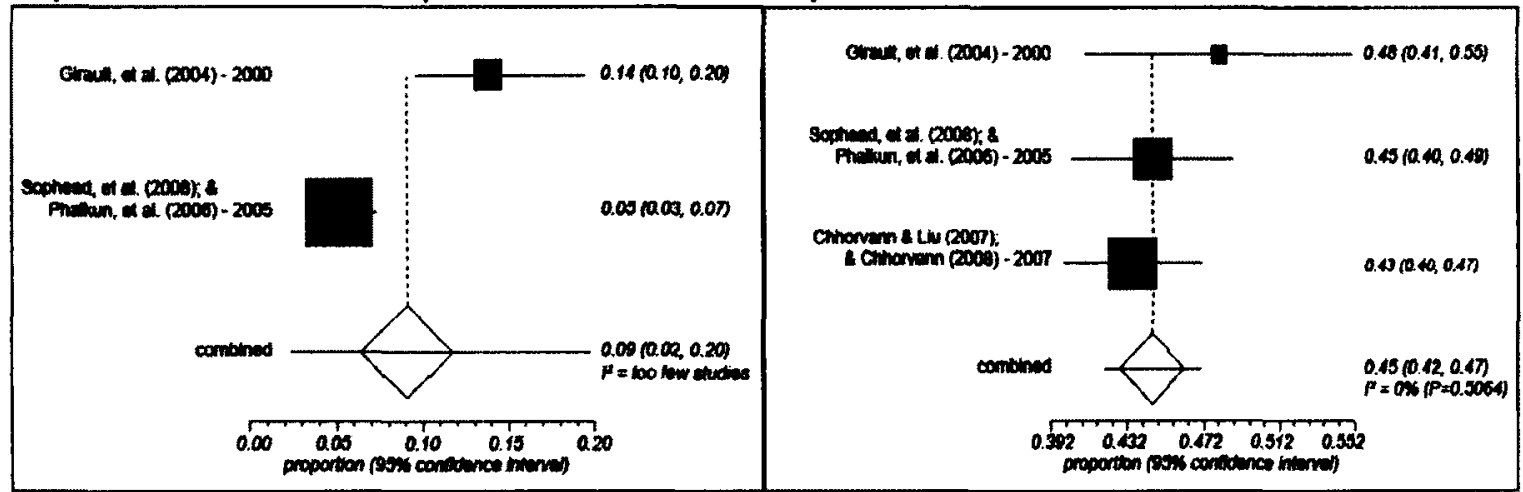

Dependent Variable 3: HIV testing (past year)

Dependent Variable 4: Adequate HIV knowledge
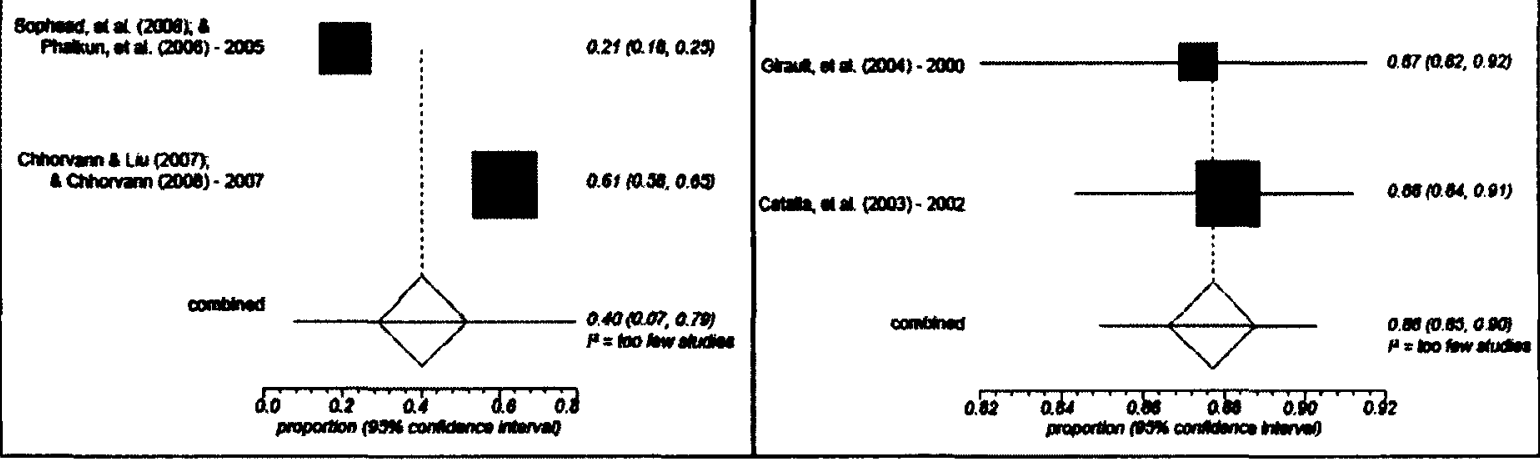

Dependent Variable 5: Exposure to HIV prevention services

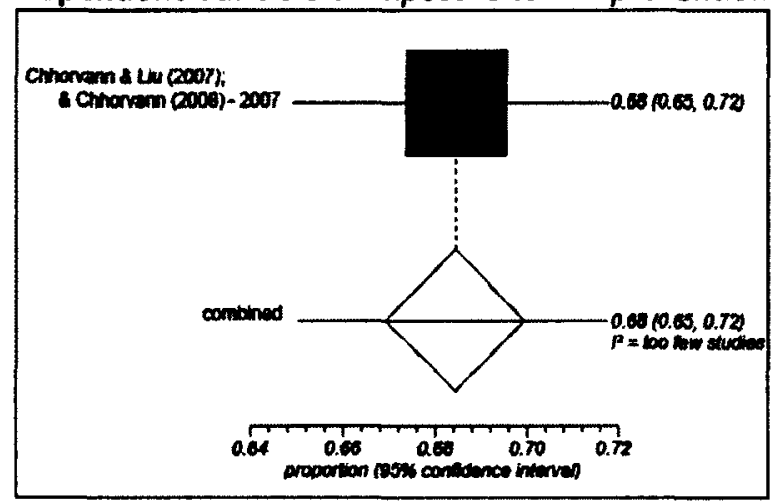


CAMBODIA

SEXUAL ORIENTATION \& GENDER IDENTITY HUMAN RIGHTS INDEX

$\left.\begin{array}{|l|ll|l}\hline \text { Penalty for homosexuality (death penalty) } & -1 & 0 & 0\end{array}\right]$

\begin{tabular}{|l|l|l}
\hline Penalty for homosexuality (lashings) & $-1 \square 0 \square$ & {$[1]$}
\end{tabular}

Penalty for homosexuality (>10 years in jail) $\quad-100 \square[1]$

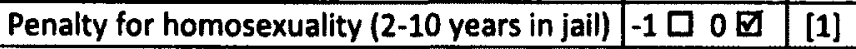

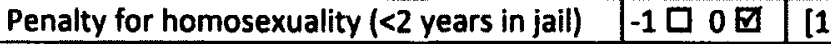

\begin{tabular}{l|l|l}
\hline Penalty for homosexuality (fines) & $-1 \square 0 \square$ & {$[1]$}
\end{tabular}

\begin{tabular}{l|lll}
\hline Gender non-conformity sanctions & $-1 \square 0 \square$ & {$[2]$}
\end{tabular}

\begin{tabular}{l|l|l}
\hline Discriminatory laws \& practices & -1000 & 0
\end{tabular}

\begin{tabular}{ll|l|l}
\hline Reservations / not party to ICCPR \& ICESCR & $-100 \mathrm{O}$ & [4]
\end{tabular}

Punitive Points $=-1$

\begin{tabular}{|l|l|l|}
\hline Ratified ICCPR \& ICESCR & $0 \square+1 区$ & {$[4]$} \\
\hline Gender-neutral sexual offences protection & $0 \square+1 \nabla$ & {$[5]$} \\
\hline
\end{tabular}

\begin{tabular}{l|l|l}
\hline Equal age of consent & $0 \square+10$ & {$[5]$}
\end{tabular}

\begin{tabular}{|l|l|l|}
\hline Supportive laws \& policies & $0 \square+10$ & {$[6]$}
\end{tabular}

\begin{tabular}{l|l|l} 
Anti-discrimination protection & $0 \square+10$ & {$[7]$}
\end{tabular}

\begin{tabular}{l|l|l} 
Sex reassignment options available & $0 \square+10$ & {$[8]$}
\end{tabular}

\begin{tabular}{ll|l|l}
\hline Recognizes new or third gender (e.g. ID) & $0 \square+1 \square$ & [8]
\end{tabular}

Right to marry/civil unions for Transgender $0 \square+1 \square$ [9]

\begin{tabular}{|l|l|l}
\hline Same-sex marriage/civil unions & $0 \nabla+10$ & {$[9]$}
\end{tabular}

Protective Points $=+5$

TOTAL POINTS $=+4$
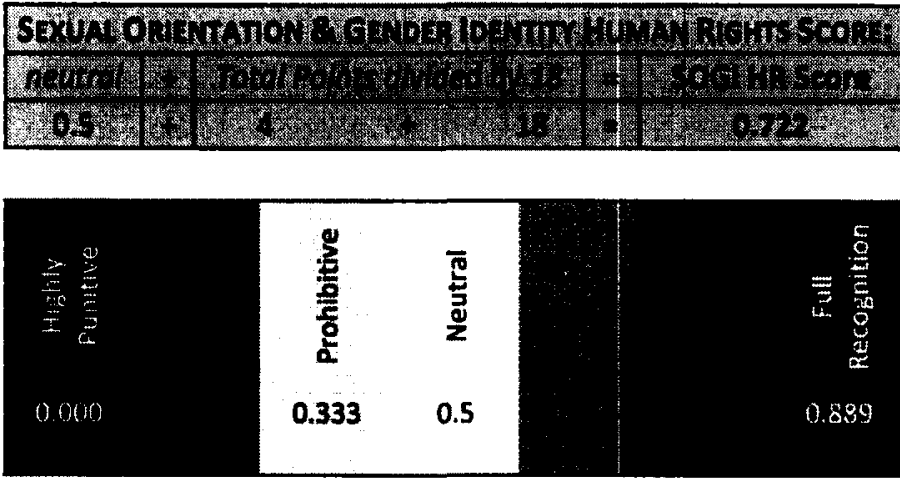

[8] Some sources suggest that sex reassignment is performed in Cambodia. For instance, Popi (the winner of the the 2001 Miss Gay Cambodia beauty contest) had her breasts done in Phnom Penh in 2004, and had genital construction surgery done in Bangkok in 2006: [Phrom Penh Post]

[9] "The Constitution defines marriage to only be between a man and a woman, same-sex marriage can still be officiated over in religious ceremonies.": [CCHR (2010) p. 19; and wikipedia "LGBT rights in Cambodia"]

Although same-sex marriage is not officially recognized, there was one public wedding between two women on March 12, 1995. "The event did not draw negative reactions, only a great curiosity, to the point of 250 people to assist with the Buddhist ceremony, including high officials from the province.": [Laurent (2005) p. 191]

\section{REFERENCES:}

[1] Homosexuality is legal in Cambodia.

[2] Appears to be none. Katoey/Drag Queens exist throughout Cambodia. For instance, in 2001, Cambodia hosted their first and only Transvestite Beauty Contest: [Prom Penh Post]

[3] The Cambodia Center for Human Rights reports that GLBT face discrimination and abuse from employers and State insitutions such as local authoriteis and police: "homosexual males are targed and exploited by police for financial gain. (...) Transgender sex workers have been subject to discrimination and and sometime sbrutal absueby police.": [CCHR (2010) p.16-17]

[4] Acceded to both the ICCPR (1992) and the ICESCR (1992): [treaties.un.org]

[5] Article 8 of the Law on Suppression of the Kidnapping. Trafficking and Exploitation of Human Persons (1996): "Any person who commits debauchery acts onto a minor person of below 15 years old, even if there is consent from the concerned minor person or if upon buying such minor person from somebody else or from a head of the prostitutes, shall be subject to punishment from ten (10) to twenty (20) years in prison ..."

This provision indicates an equal age of consent (15 years old) as well as protection for boys and girls from sexual exploitation.

Article 5 "Rape" of The Law on Aggravating Circumstances of Crimes (2001): "(1) Anyone who rapes or attempts to rape another person of either sex shall be guilty of the rape crime and shall be liable to a punishment of imprisonment from 10 years to 15 years. (2) Rape is an act in all forms of penetration of the genital organ or other means carried out through cruelty, coercion, or surprise."

Article 33 "Rape" and Article 42 "Indecent Assault" of the criminal provisions by the United Nations Transitional Authority in Cambodia (UNTAC) are also gender-inclusive.

[6] Annual pride festivals in Phnom Penh since 2003: [wikipedia "LGBT rights in Cambodia"]. The first gay bar opened in 1999: [IRB, "Cambodia" (2003)] Some sources indicate that same-sex couples can adopt: [Dr. Abbot (2011); and wikipedia "LGBT rights in Cambodia"]

However, the Cambodian Center for Human Rights stated that the government has banned gay foreigners from adopting children, though the law is not yet in effect: [Robert Finch]

There also an increasing number of NGOs working with sexual minorities, such as Rainbow Community of Kampuchea, CCHR, and the Khmere HIV/AIDS NGO Aliance

[7] Appears to be no legal protection from discrimination based on sexual orientation or gender identity. 


\begin{tabular}{|c|c|c|c|c|c|c|}
\hline Study & Year & $\begin{array}{l}\text { HIV } \\
\text { Prevalence }\end{array}$ & $\begin{array}{l}\text { Inconsistent } \\
\text { Condom Use }\end{array}$ & $\begin{array}{l}\text { HIV Testing } \\
\text { (past year) }\end{array}$ & $\begin{array}{l}\text { Adequate HIV } \\
\text { Knowledge }\end{array}$ & $\begin{array}{l}\text { Exposure to } \\
\text { HIV } \\
\text { Prevention }\end{array}$ \\
\hline Li, X. et al (2001) & 1999 & No data & $191 / 310$ & No data & No data & Nodata \\
\hline Qu, et al. (2002) & 2001 & No data & $158 / 187$ & "everp" & $116 / 211$ & Notalo \\
\hline Wang, Q. \& Ross (2002) & 2001 & No data & $169 / 353$ & Notiata & Novata & Notlata \\
\hline \multicolumn{7}{|l|}{ Chol, et al. (2003); Choi, et al. (2004); Choi, et } \\
\hline al. (2006a); \& Liu, et al. (2005) & 2002 & $4 / 481$ & $175 / 284$ & "bver" & $367 / 481$ & Wrong format \\
\hline Zhang, D. et al. (2007) & 2002 & $2 / 154$ & $153 / 215$ & No data & No datat & Na datis \\
\hline Jiang, et al. $(2006)$ & 2003 & $0 / 144$ & $66 / 144$ & "ever" & No datia & Nodata \\
\hline Gu, Y. et al. (2004) & 2003 & $2 / 202$ & $278 / 313$ & "ever" & $192 / 342$ & $162 / 342$ \\
\hline Chu, et al. (2006) & 2004 & No data & $238 / 481$ & No dats & No data & Nociata \\
\hline Ma, X. et al. (2007): \& Ma, X et al. (2006) & 2004 & $5 / 325$ & $152 / 325$ & "evert" & No dota & No dato \\
\hline He, et al. (2006); \& He, et al. (2008) & 2004 & $0 / 320$ & $110 / 201$ & $16 / 201$ & Wrong fomat & No data \\
\hline Zhang, D. et al. (2007) & 2004 & $3 / 320$ & $248 / 397$ & No dìta & Nodata & Nodatat \\
\hline Lau, et al. (2009) & 2005 & No data & $183 / 332$ & $97 / 387$ & $326 / 387$ & $255 / 387$ \\
\hline Liu, et al. (2006) & 2005 & $4 / 250$ & $46 / 115$ & No data & No data & No datia \\
\hline \multicolumn{7}{|l|}{ Li, X. et al (2006); Li, X. et al. (2008); Ruan, Y. } \\
\hline Ma, X. et al. (2007): \& Ma, X et al. (2006) & 2005 & $26 / 427$ & $230 / 427$ & No dato & Notala & Nodita \\
\hline Xu, J. et al. (2007) & 2005 & $4 / 228$ & $117 / 216$ & "ever" & Wrong format & Notata \\
\hline Zhu, et al. (2007) & 2005 & $2 / 121$ & $63 / 100$ & "Evar" & Wrong format & No Gata \\
\hline Xing, et al. (2008) & 2005 & No data & $211 / 372$ & No data & $257 / 372$ & Wromp format \\
\hline Chol, et al. (2006b); \& Choi, et al. (2007) & 2005 & $7 / 477$ & $183 / 332$ & No data & Wrong format & No date \\
\hline Lai, Y, et al (2006) & 2005 & No data & $267 / 477$ & "ever" & $143 / 203$ & No wata \\
\hline Lau, et al. (2008) & 2006 & No diata & $399 / 730$ & "everp" & $776 / 896$ & No data \\
\hline Xu, H. et al. (2006) & 2006 & $13 / 1,384$ & $240 / 1,384$ & No data & No datat & Nouta \\
\hline Xlao, et at. (2010) & 2006 & $146 / 4,983$ & No data & "ever" & $3,627 / 4,983$ & Nodata \\
\hline Ma, X. et al. (2007) & 2006 & $37 / 540$ & $221 / 540$ & "everr" & No dota & No data \\
\hline Ruan, Y. et al. (2009b); \& Wang, C. et al. (2008) & 2006 & $26 / 541$ & $79 / 541$ & "evitr" & No datia & Nodata \\
\hline Zhang, $X$. et al. $(2007)$ & 2006 & $16 / 753$ & $302 / 753$ & Nodata & No data & No data \\
\hline Feng, L. et al. (2009) & 2006 & No dita & $536 / 1,000$ & "ever" & Wrong format & $719 / 1,000$ \\
\hline He, et al. (2009); \& He, et al. (2008) & 2006 & $7 / 423$ & $213 / 423$ & Nodata & Wrong format: & No data \\
\hline Zhang, F. et al. (2008) & 2006 & No data & $99 / 146$ & Nodata & $187 / 212$ & No data \\
\hline Zhang, D. et al. (2007) & 2006 & $15 / 674$ & $405 / 647$ & No data & No data & Nodata \\
\hline Zhang, H. et al. (2010) & 2006 & No data & $34 / 136$ & $33 / 218$ & No data & No data \\
\hline Lau, et al. (2009) & 2006 & No data & $136 / 278$ & $126 / 316$ & $276 / 316$ & $247 / 316$ \\
\hline LI, Y. et al. (2007) & 2006 & $2 / 264$ & $96 / 202$ & "ever" & $224 / 264$ & $142 / 264$ \\
\hline Guo, H. et al. (2009) & 2006 & $14 / 296$ & No data & No data & Nodata & No diata \\
\hline Ma, J. \& Guo, J. (2007b) & 2006 & $62 / 433$ & No data & "ever" & Nociata & No data \\
\hline Wong, F. et al. (2008) & 2006 & No data & $60 / 208$ & "ever" & Nodata & Wrong format \\
\hline Ruan, Y. et al. (2009a) & 2007 & $13 / 507$ & $71 / 507$ & "ever" & Novatid & Wrong format \\
\hline Zou, et al. (2010); \& Zou, et al. (2008) & 2007 & $20 / 420$ & $163 / 270$ & "Ever" & Nor däto & No data \\
\hline Feng, Y. et al. (2010); \& Feng, Y. et at (2008) & 2007 & $49 / 538$ & $237 / 386$ & No data & Wrong format & No diata \\
\hline Feng, L. et al. (2009) & 2007 & $131 / 1,044$ & $551 / 1,044$ & "Ever" & Wrong format & $751 / 1,044$ \\
\hline Xiao, et at. (2009) & 2007 & $182 / 1,692$ & $873 / 1,692$ & $500 / 1,692$ & Wrong format & $1,021 / 1,692$ \\
\hline Ruan, S. et al. (2009); \& Ruan, S. et al. (2008) & 2007 & $3 / 428$ & $281 / 428$ & "ever" & Wrong format & Wrong format \\
\hline Tao (2008);\& Tao, et al. (2008) & 2007 & $18 / 1,617$ & $826 / 1,617$ & $488 / 1,617$ & No data & $1,095 / 1,617$ \\
\hline Behringer (2008) & 2007 & $4 / 468$ & $235 / 450$ & "ever" & Wrong format & $137 / 468$ \\
\hline Chen, et al. (2008) & 2007 & No data & $173 / 284$ & No data & Nodiano & No data \\
\hline Hong, et al. (2009) & 2007 & $42 / 1,146$ & No data & No data & No data & No data \\
\hline Feng, T.-J. et al. (2008) & 2007 & $46 / 1,376$ & No dati & No data & No katas & Nodata \\
\hline Liu, et al. (2009) \& Ha, et al. (2010) & 2007 & No data & $127 / 293$ & Nodala & Wrong format & Mo fata \\
\hline Guo, Y. et al. (2009) & 2007 & $12 / 204$ & $69 / 133$ & "ever" & $181 / 204$ & No data \\
\hline Guo, H. et al. (2009) & 2007 & $11 / 137$ & No data & Nodata & No data & Nosiata \\
\hline Zhong, et al. (2009) & 2008 & $20 / 379$ & $231 / 379$ & $56 / 379$ & Wrong format & $282 / 379$ \\
\hline Ruan, S. et al. (2009) & 2008 & $15 / 500$ & $170 / 500$ & Nodata & No data & Novata \\
\hline$X u$, J. et al. (2011) & 2008 & $13 / 436$ & $231 / 286$ & No ditat & $418 / 436$ & No data \\
\hline Yang, et al. (2010) & 2008 & $19 / 416$ & No data & No date? & No data & No datis \\
\hline Yang, et al. (2010) & 2008 & $7 / 286$ & $108 / 286$ & No deta & Nodata & Nodata \\
\hline Tao $(2010)$ & 2008 & $6 / 118$ & $67 / 118$ & $59 / 118$ & No data & $82 / 118$ \\
\hline \multirow[t]{2}{*}{ Cai, et al. (2010) } & 2008 & $21 / 394$ & $156 / 394$ & $174 / 394$ & $287 / 394$ & Wrong ioment \\
\hline & NED: & $3.25 \%$ & $52 \%$ & $27 \%$ & $79 \%$ & $59 \%$ \\
\hline
\end{tabular}


CHINA

Dependent Variable 1: HIV prevalence

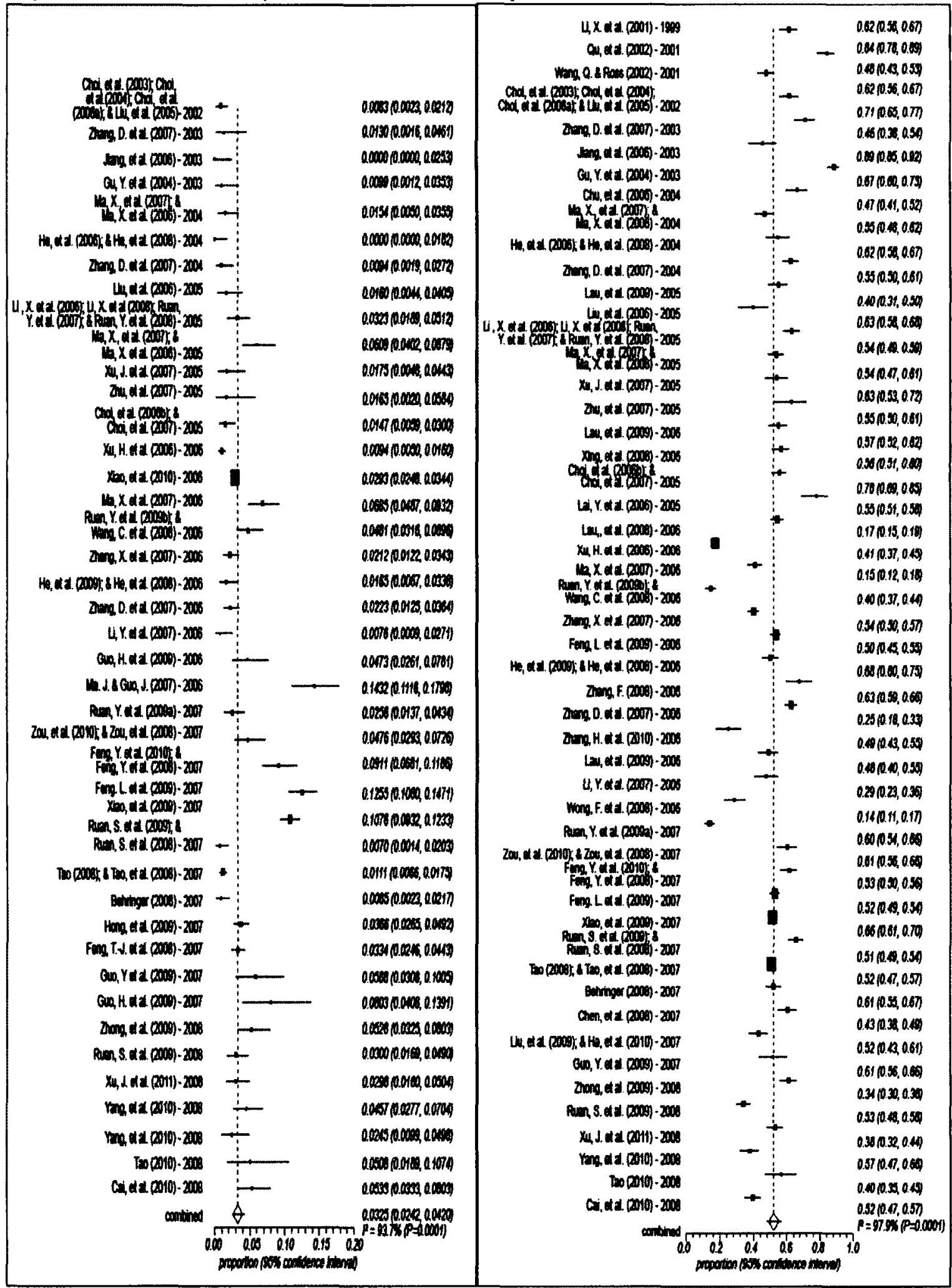

Dependent Variable 2: Inconsistent condom use 


\section{CHINA}

Dependent Variable 3: HIV testing (post year)

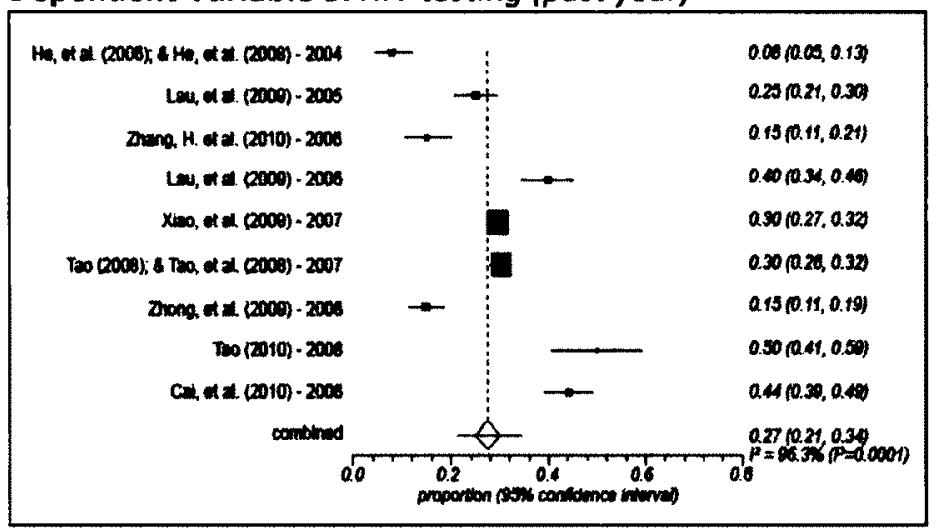

Dependent Variable 4: Adequate HIV knowledge

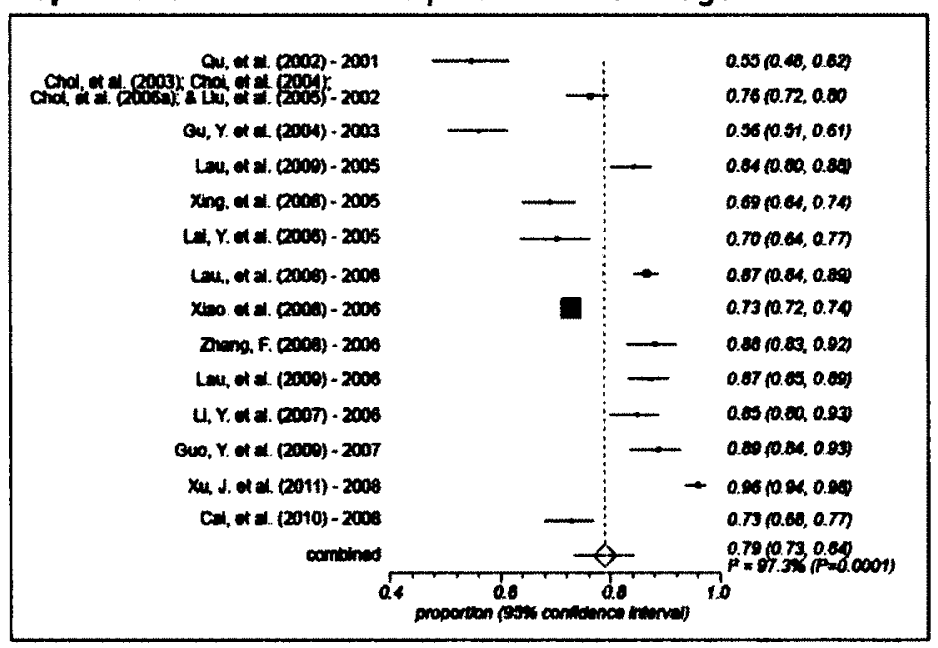

Dependent Variable 5: Exposure to HIV prevention

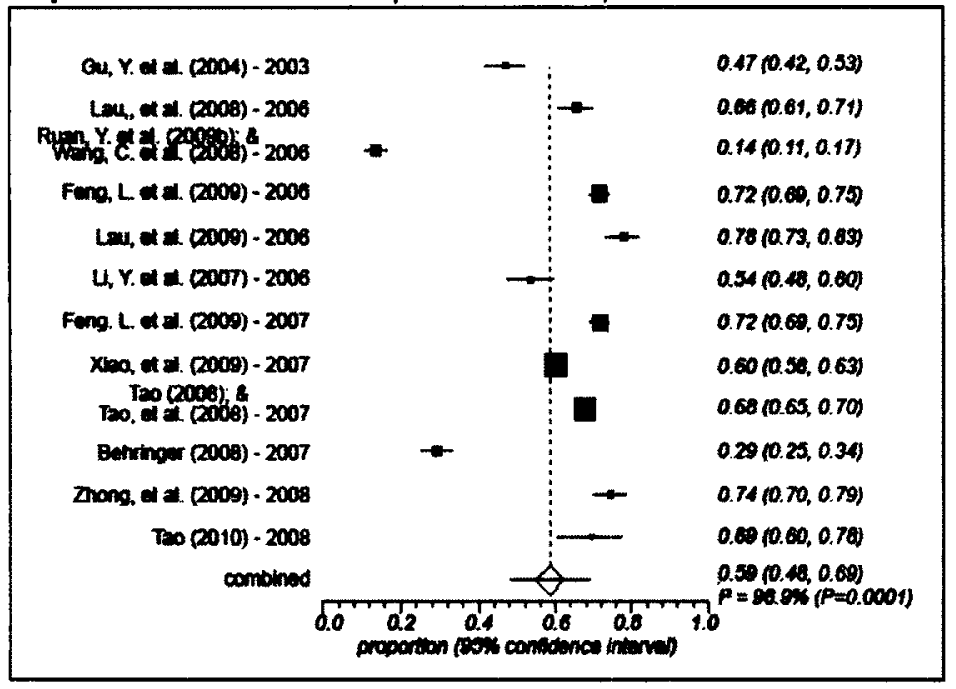




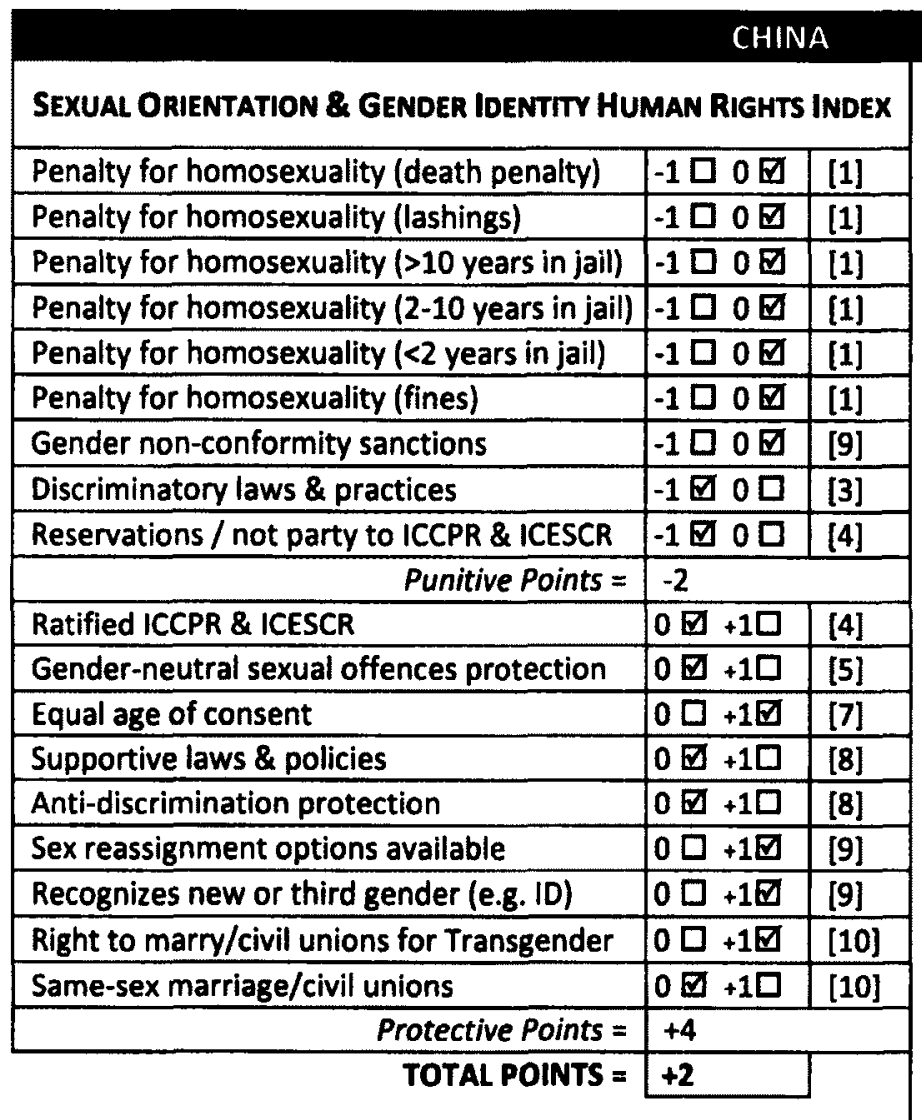

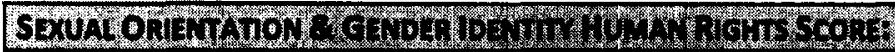

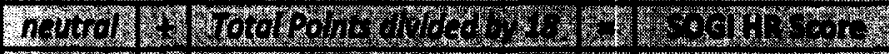

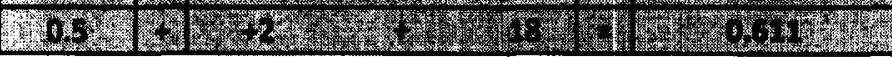

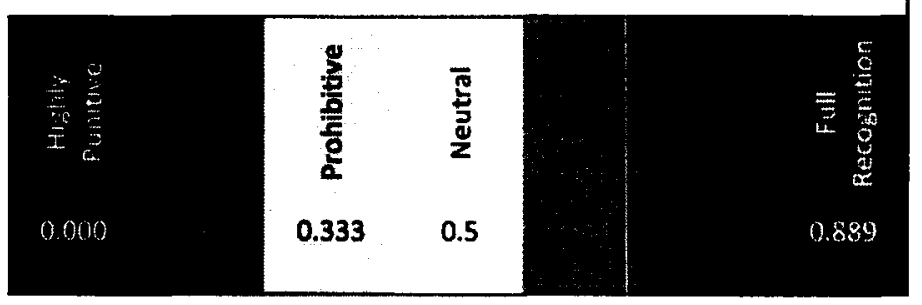

\section{REFERENCES:}

[1] Homosexuality was decriminalized in 1997 with the repeal of the "hooliganism" law.

[2] Police harass sexual minorities by using the prostitution laws and publication licensing regulations: [Mountford (2009) p. 18-22]

China tightly controls freedom of assembly and speech pertaining to sexual orientation. Art. 10.1 of the Film Censorship Regulation (1997) states that any scenes portraying homosexuality should be cut and corrected: [Godwin (2010) p. 61-62; inter alia]

"In December 2005, the police shut down Beijing's first ever gay and lesbian cultural festival.": [RRT, "China" (2007)]

In 2005, China banned foreign homosexuals from adopting. The same probably applies to domestic adoption. Artificial insemination is banned in general in China: [Mountford (2009) p. 30]

[3] Ratified the ICESCR (2001) and signed the ICCPR (1998) but has not ratified it yet: [treaties.un.org]

[4] Only women can be victims of rape (Art. 236) or sexual assault (Art. 237) according to the Criminal Law of the People's Republic of China (1997). On May 9, 2010 China had its first case of a man raping another man, but since men cannot be "rapped" the offender was only convicted of causing intentional injuries: [OneIndia News (2011)]

According to Interpol's Child Sex Abuse website, China criminalizes fingering or sodomy against minors boys and girls under fourteen (14): [interpol.int "China"]

The prostitution provision in section 8 of the Criminal Law of the People's Republic of China (1997) are gender neutral except for the provisions regarding children under 14 which apply only to girls (Arts. 358-360).

In 2004, China heard its first gay prostitution case: [China Daily (2004)]

[5] Age of consent is 14 for everyone.

[6] "China has no national laws protection people from discrimination on the grounds of sexual orientation or transgender status.": [Godwin (2010) p. 58]

[7] "In 2003, a circular issued jointly by the Supreme People's Court and the Ministry of Health established the procedure for transgender people to change their gender designation in their household registry and marry a person of their previous sex.": [Godwin (2010) p. 59-60]

[8] Sexologist, Dr. Li Yinhe submitted a draft law allowing same-sex marriage to the Chinese Parliament five times unsuccessfully in 2003, 2005, 2006, 2008, and 2011: [RRT, "China" (2007); IRB, "China (2005), inter alia] 


\section{HONG KONG}

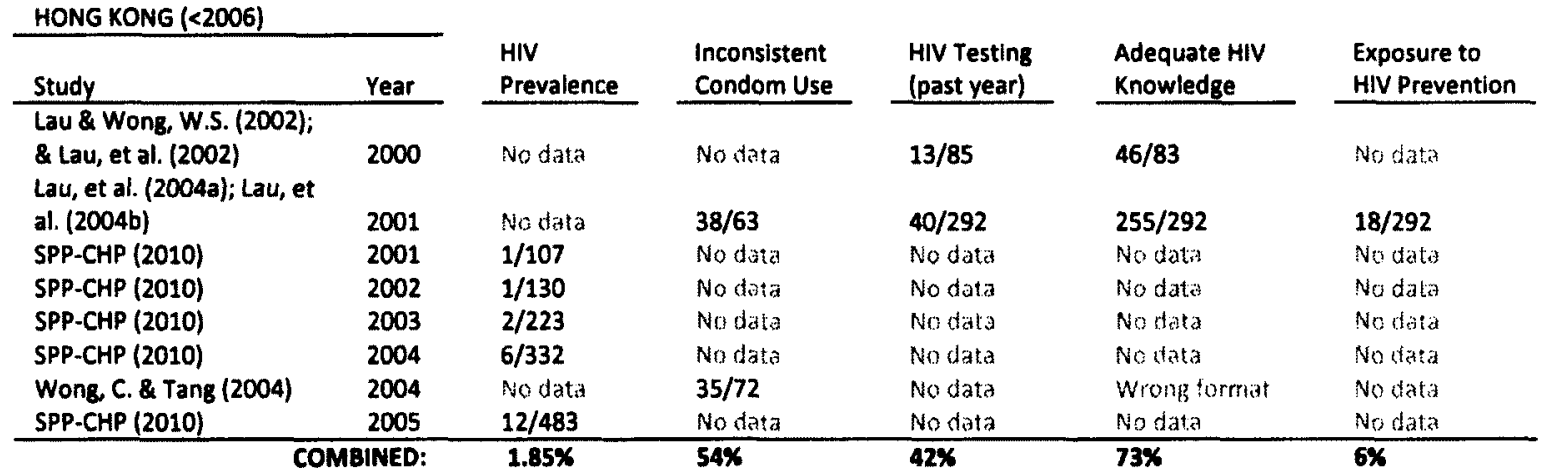

Dependent Variable 1: HIV prevalence

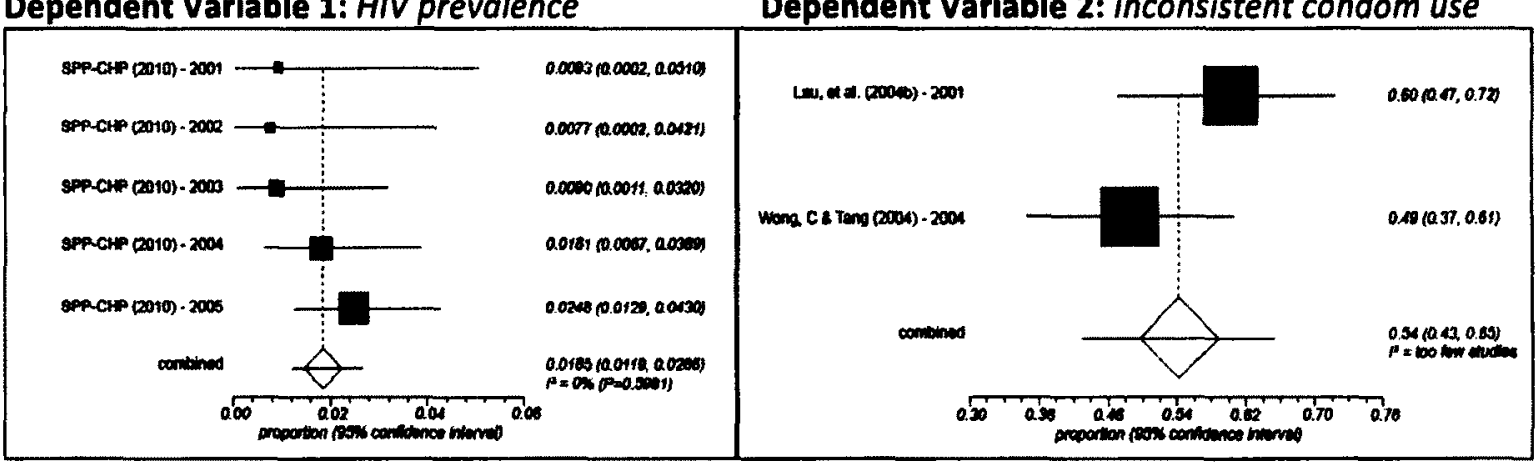

Dependent Variable 3: HIV testing (past year)

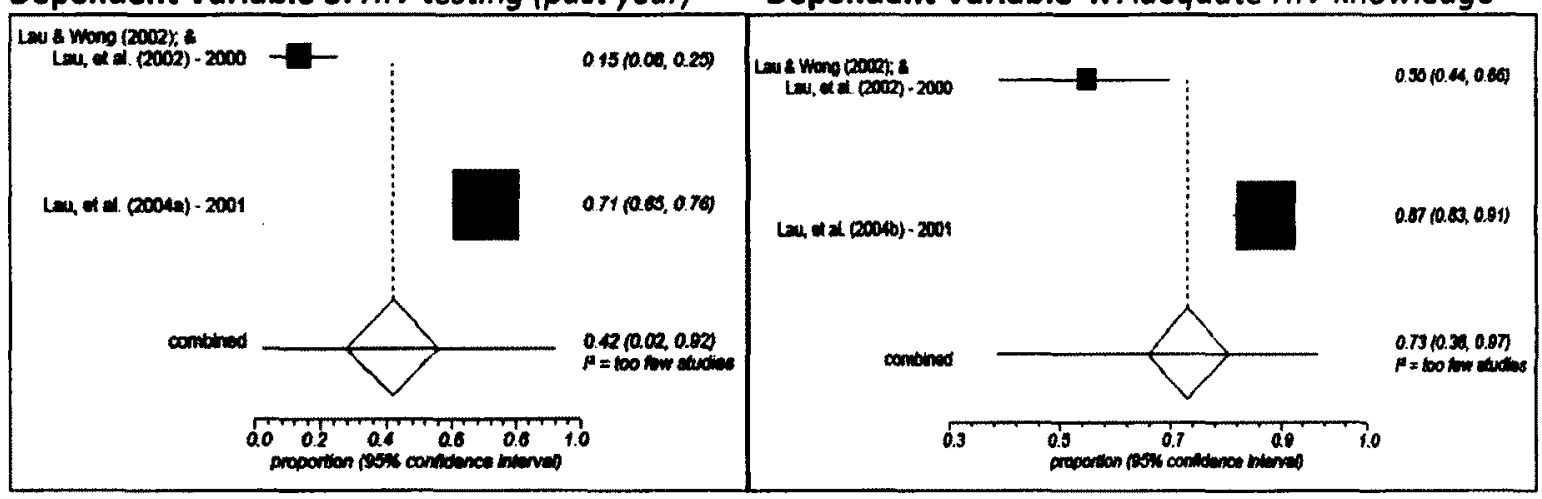

Dependent Variable 5: Exposure to HIV prevention services

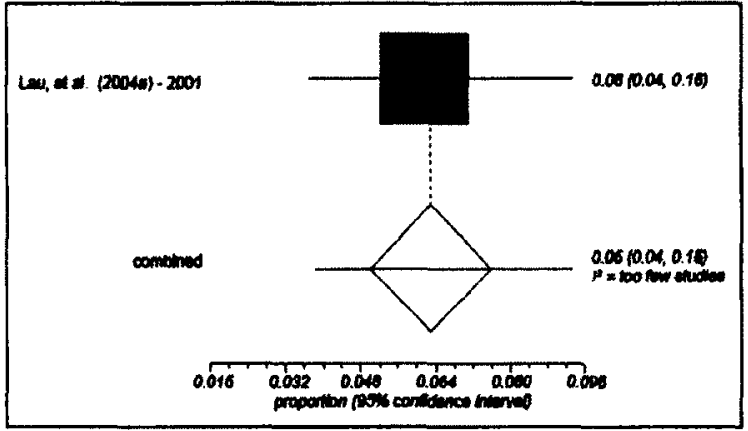




\section{HONG KONG}

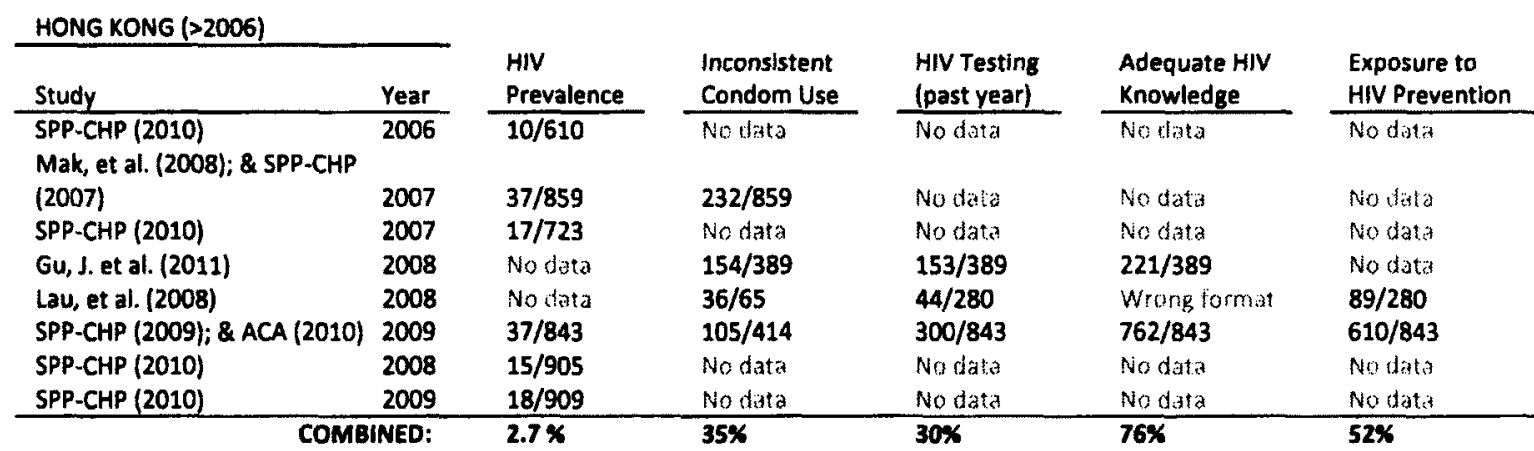

Dependent Variable 1: HIV prevalence

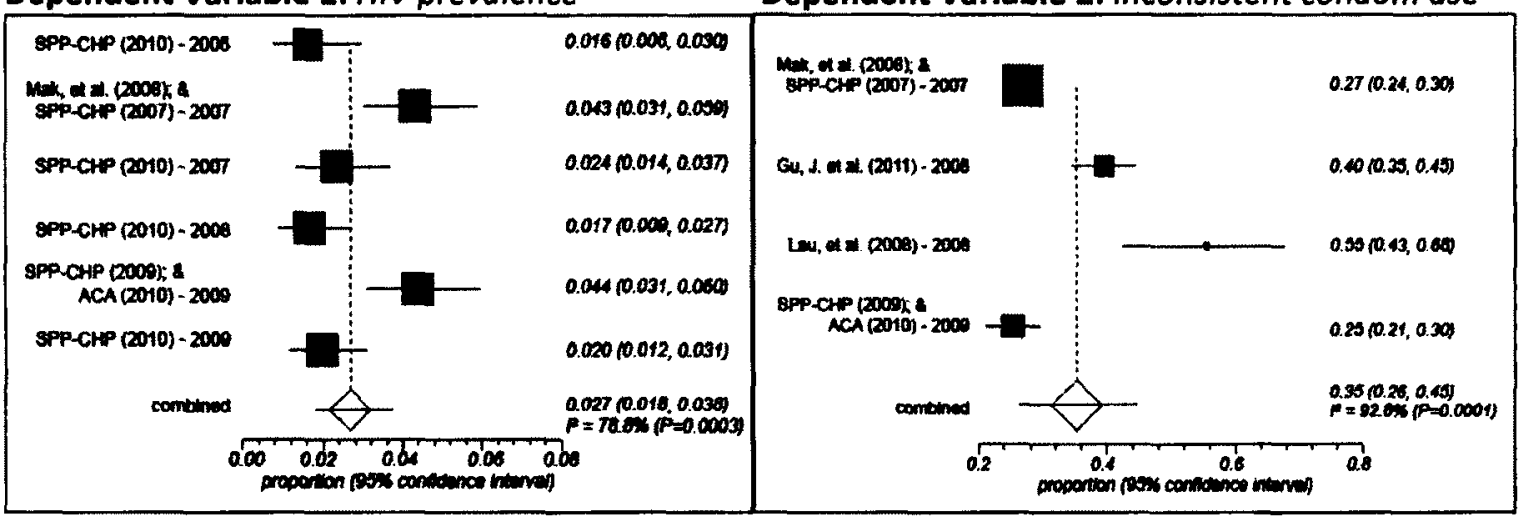

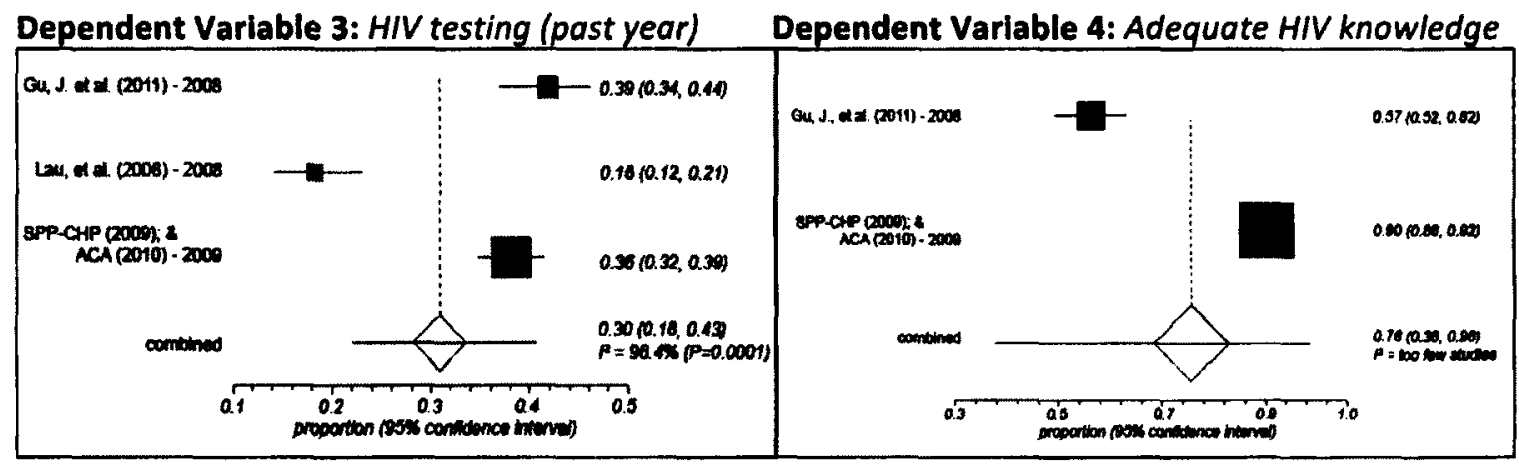

Dependent Variable 5: Exposure to HIV prevention services

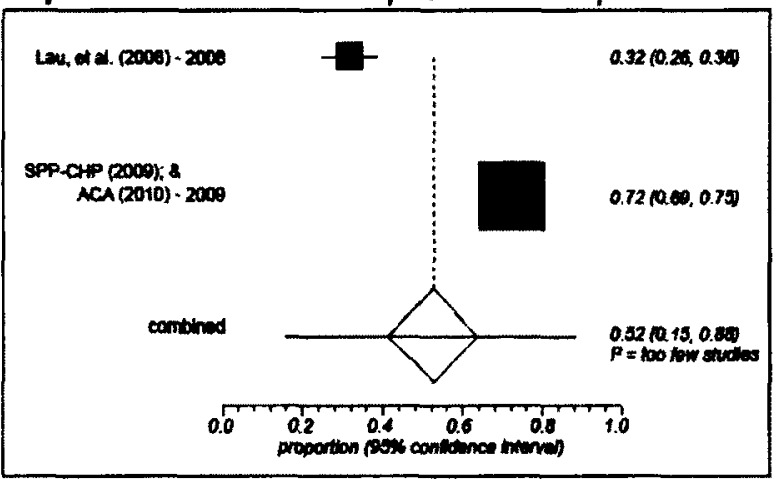


INDIA

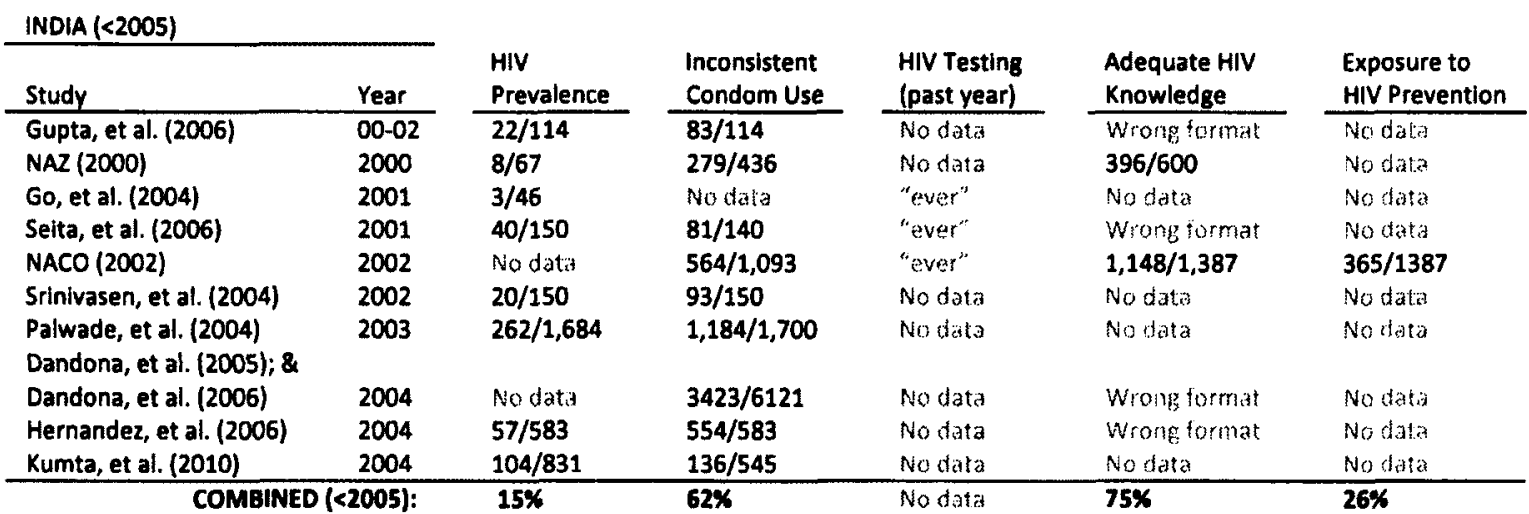

Dependent Variable 1: HIV prevalence

Dependent Variable 2: Inconsistent condom use

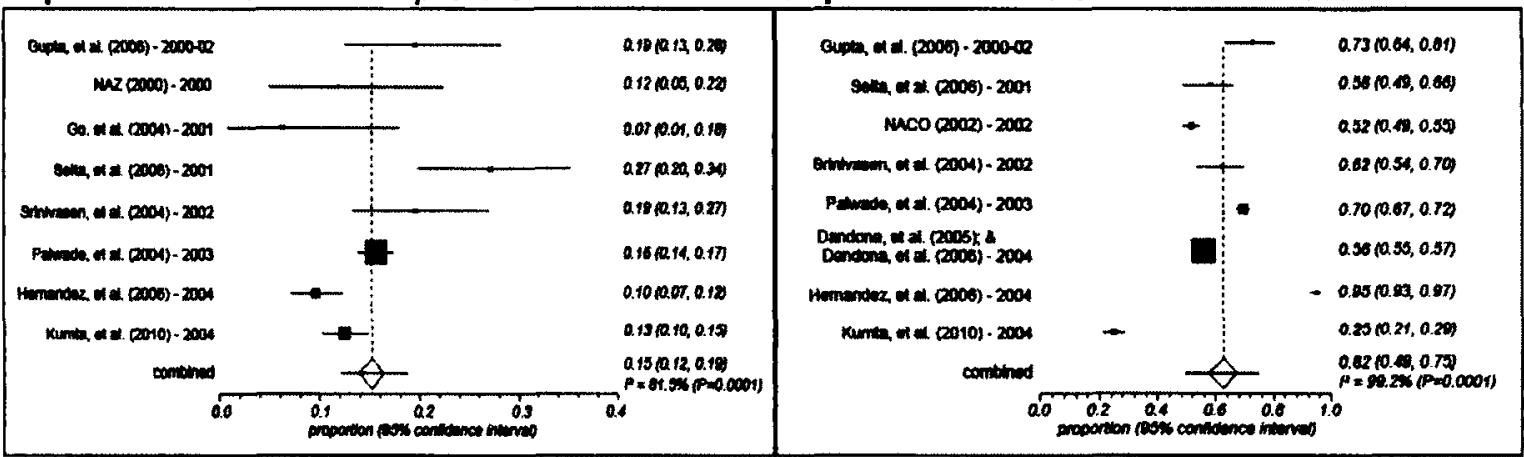

Dependent Variable 4: Adequate HIV knowledge Dependent Variable 5: Exposure to HIV prevention

(Mnz 00000 - 2000


INDIA

\begin{tabular}{|c|c|c|c|c|c|c|}
\hline \multicolumn{2}{|l|}{ INDIA (>2005) } & \multirow[b]{2}{*}{$\begin{array}{l}\text { HIV } \\
\text { Prevalence }\end{array}$} & \multirow[b]{2}{*}{$\begin{array}{l}\text { Inconsistent } \\
\text { Condom Use }\end{array}$} & \multirow[b]{2}{*}{$\begin{array}{l}\text { HIV Testing } \\
\text { (past year) }\end{array}$} & \multirow[b]{2}{*}{$\begin{array}{l}\text { Adequate HIV } \\
\text { Knowledge }\end{array}$} & \multirow[b]{2}{*}{$\begin{array}{l}\text { Exposure to } \\
\text { HIV Prevention }\end{array}$} \\
\hline Study & Year & & & & & \\
\hline \multicolumn{7}{|l|}{ Sravankumar \& Prabhakar } \\
\hline$(2006)$ & 2005 & $98 / 539$ & Wrong format & No data & No data & No data \\
\hline The Humsafar Trust (2006) & 2005 & No data & $156 / 295$ & "ever" & $268 / 278$ & No dita \\
\hline NACO (2006) & 2006 & No data & $1,184 / 1,878$ & No data & $2,327 / 2,638$ & $1,520 / 2,638$ \\
\hline \multicolumn{7}{|l|}{ Phillips, et al. (2010); \& } \\
\hline Phillips, et al. (2008) & 2006 & No data & $80 / 167$ & "ever" & No dato & No data \\
\hline Safren, et al. (2006) & 2006 & $4 / 62$ & No dato & "Ever" & Wrong tomat & No data \\
\hline Shinde, et al. $(2006)$ & 2006 & $25 / 79$ & Nodata & No data & Nodata & No bata \\
\hline $\begin{array}{l}\text { Deb, et al. (2009) } \\
\text { Brahman, et al. (2008); \& }\end{array}$ & 2007 & $1 / 108$ & $101 / 108$ & "ever" & Wrong format & No data \\
\hline Ramakrishna, et al. (2008) & 2008 & $617 / 4,597$ & $2,108 / 2,816$ & "ever" & Wrong fomat & No data \\
\hline \multicolumn{7}{|l|}{ Newman, et al. (2008a); \& } \\
\hline Newman, et al. (2008b) & 2008 & & $46 / 140$ & "ever" & Wrong format & $106 / 200$ \\
\hline Solomon, et al. (2010) & 2008 & $65 / 721$ & No dara & "ever" & No data & $321 / 721$ \\
\hline \multicolumn{7}{|l|}{ Thomas, et al. (2009a); \& } \\
\hline Thomas, et al. (2009b) & 2009 & $16 / 202$ & $46 / 210$ & No data & No ditta & $55 / 210$ \\
\hline
\end{tabular}

Dependent Variable 1: HIV prevalence

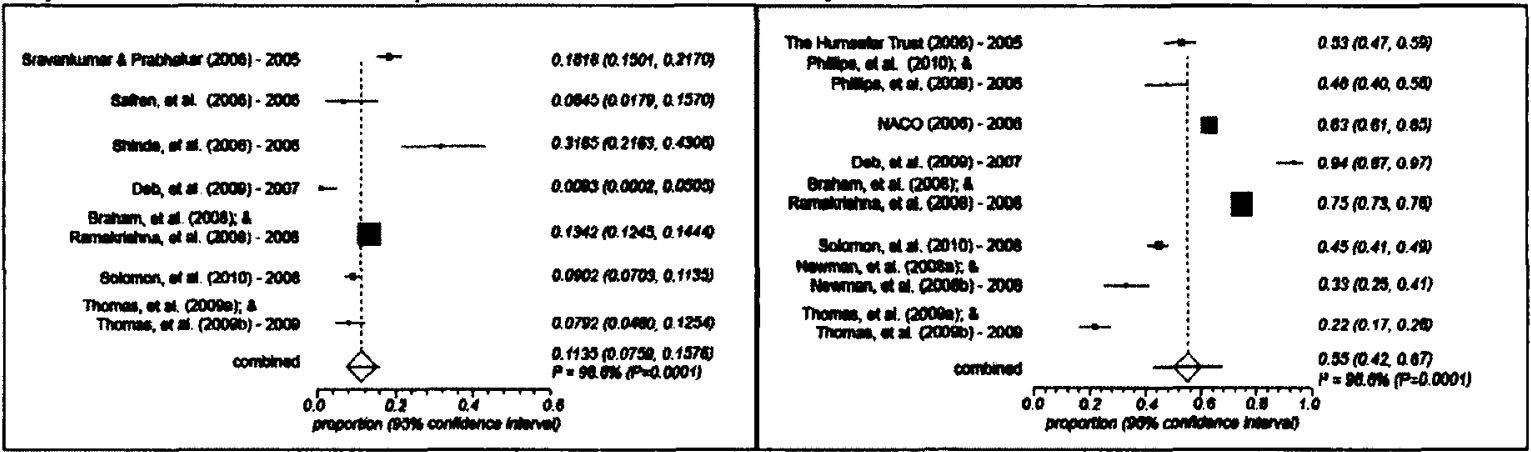

\section{Dependent Variable 4: Adequate HIV knowledge}

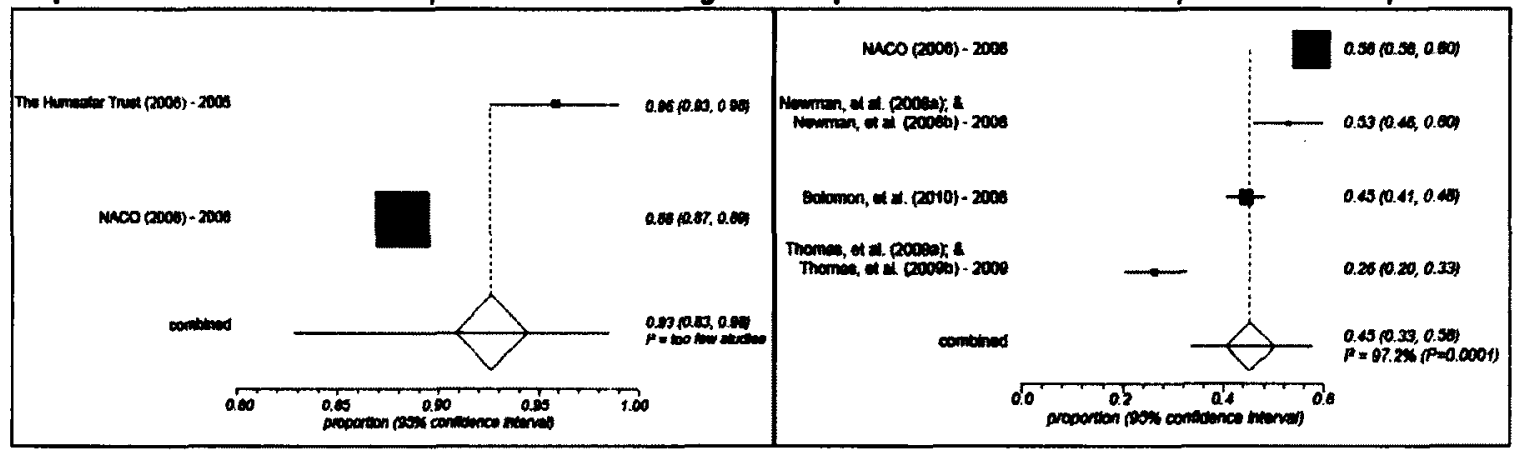


INDIA

SEXUAL ORIENTATION \& GENDER IDENTITY HUMAN RIGHTS INDEX

\begin{tabular}{|l|l|l}
\hline Penalty for homosexuality (death penalty) & $-100 \mathrm{O}$ & [1] \\
\hline
\end{tabular}

\begin{tabular}{|l|l|l}
\hline Penalty for homosexuality (lashings) & $-1 \square 0 \mathrm{~V}$ & [1]
\end{tabular}

\begin{tabular}{|l|lll}
\hline Penalty for homosexuality ( $>10$ years in jail) & -1000 & 0
\end{tabular}

Penalty for homosexuality (2-10 years in jail) -1000 [1]

Penalty for homosexuality (<2 years in jail) -1000 [1]

\begin{tabular}{|l|l|l}
\hline Penalty for homosexuality (fines) & $-100 \square$ & {$[1]$}
\end{tabular}

\begin{tabular}{|l|l|l}
\hline Gender non-conformity sanctions & $-1 \square 0 \mathrm{Q}$ & {$[7]$}
\end{tabular}

\begin{tabular}{|l|l|l}
\hline Discriminatory laws \& practices & $-1 \square 0 \square$ & (2)
\end{tabular}

\begin{tabular}{|l|l|l|}
\hline Reservations / not party to ICCPR \& ICESCR & -100 0 & [3] \\
\hline
\end{tabular}

\begin{tabular}{|l|l|l|}
\hline & Punitive Points $=$ & -5 \\
\hline Ratified ICCPR \& ICESCR & $0 \square+1[$ & [3] \\
\hline Gendersental & $0 \square+1 \square$ & {$[4]$} \\
\hline
\end{tabular}

Gender-neutral sexual offences protection $0 \square+1 \square$ [4]

Equal age of consent

Supportive laws \& policies

Anti-discrimination protection

Sex reassignment options available

Recognizes new or third gender (e.g. ID)

Right to marry/civil unions for Transgender

Same-sex marriage/civil unions

Protective Points $=$

TOTAL POINTS $=$
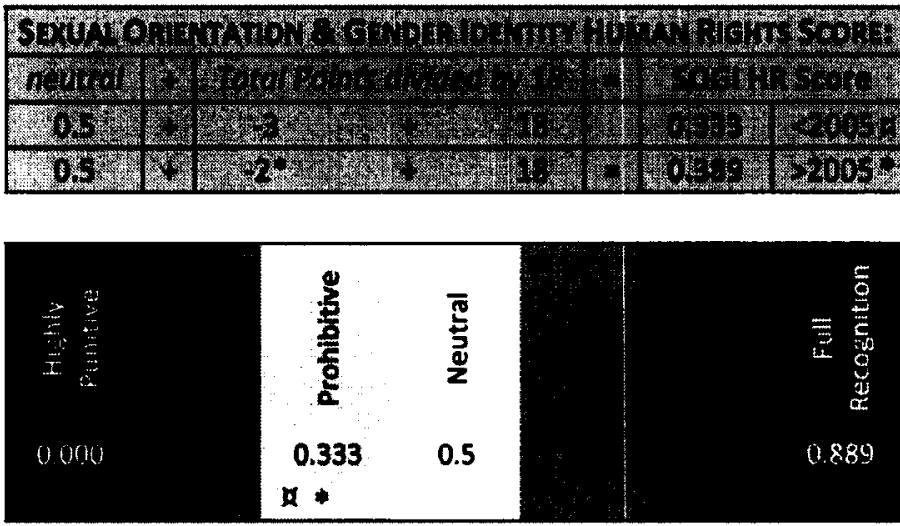

[7] Since 2005, Indian passport application forms have "male", "female" or "other". Those that have had sex reassignment surgery could make an application to change the gender on their passport (and other documents)

Throughout India's period of colonization, trasngender people were subject to registration accourding to the 1871 Criminal Tribes $A C t$, which was amended in 1897 to include Eunchs as being prone to criminality from birth, linking their behaviour to section $\mathbf{3 7 7}$ of the Indian Penal Code.

[8] Due to section 377, transgender and same-sex marriages are not permitted.

\section{REFERENCES:}

[1] Homosexuality is criminalized in Sec. 377 of the Indian Penal Code (1860): "Whoever voluntarily has carnal intercourse against the order of nature with any man, woman or animal, shall be punished with imprisonment for life, or with imprisonment of either description for a term which may extend to ten years, and shall also be liable to fine."

On July 2, 2009, the Delhi High Court ruled that Sec. 377 violated the Indian Constitution, which had the effect of decriminalizing homosexuality between consenting adults. Sec. 377 still applies to non-consensual sex between men and sex with minors. Since, this decision occurred at the end of the period of available epidemiological and behavioural data collected for India (2000-2009), there is no impact on the SOGI Human Rights Score: [Naz Foundation $v$. Govt. of NCT of Delhi]

[2] Article 33 of the Constitution allows for abrogation of human rights for members of the Armed Forces. Thus, the Naz Foundation decision does not apply to the Armed forces, where homosexuality can be punished with imprisonment: [Joshi (2009); Art. 46 of the Army Act (1950); Art. 46 of the Air Force Act (1950); and Art. 53 of the Navy Act (1957); and Art. 33 of the Constitution

Reports show that "homosexual have been detained in bospitals and forced to receive treatment against their will in India.": [IRB, "India" (2009); and IRB, "India" (2004)]

India banned surrogacy for same-sex couples in 2011, and while homosexuality was criminalized, openly-gay individuals would not be permitted to adopt.

[3] Acceded to both the ICCPR (1979) and the ICESCR (1979): [treaties.un.org]

[4] The rape provisions under section 376 of the Indian Penal Code (1860) are gender specific, where only women can be the victim. As for sexual exploitation, sections $372-373$ of the Indian Penal Code (1860) and sections 5-6 of the Immoral Traffic Prevention Act (1986) are gender-neutral and apply to all "persons".

[5] No protection against discrimination based on sexual orientation or gender identity.

[6] Since the Indian Penal Code criminalizes emasculation (e.g. castration), some doctors refuse to provide sex reassignment surgery. However, section 88 "provides an exception for action undertaken in good faith and with consent to suffer that harm." Thus, legally, transgenders can have safe sex reassignment surgery: [Godwin (2010) p.39-40]

Due to this legal situation, there is no national medical standard or guidelines for sex reassignment in India. Neverhteless, it is performed. 


\section{INDONESIA}

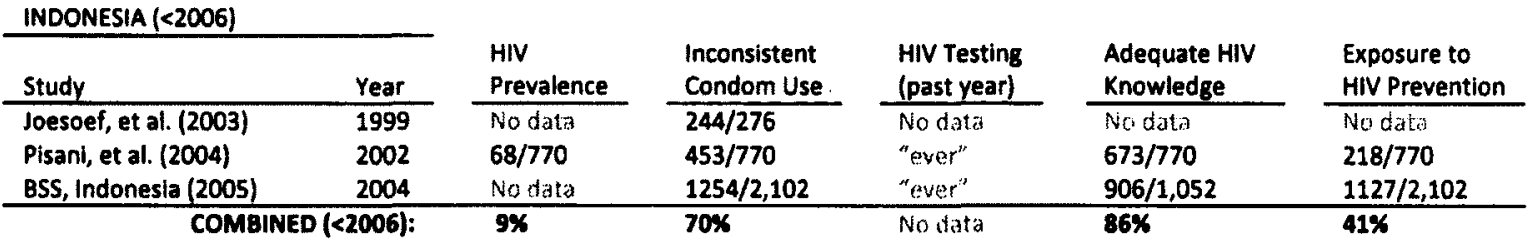

Dependent Variable 1: HIV prevalence

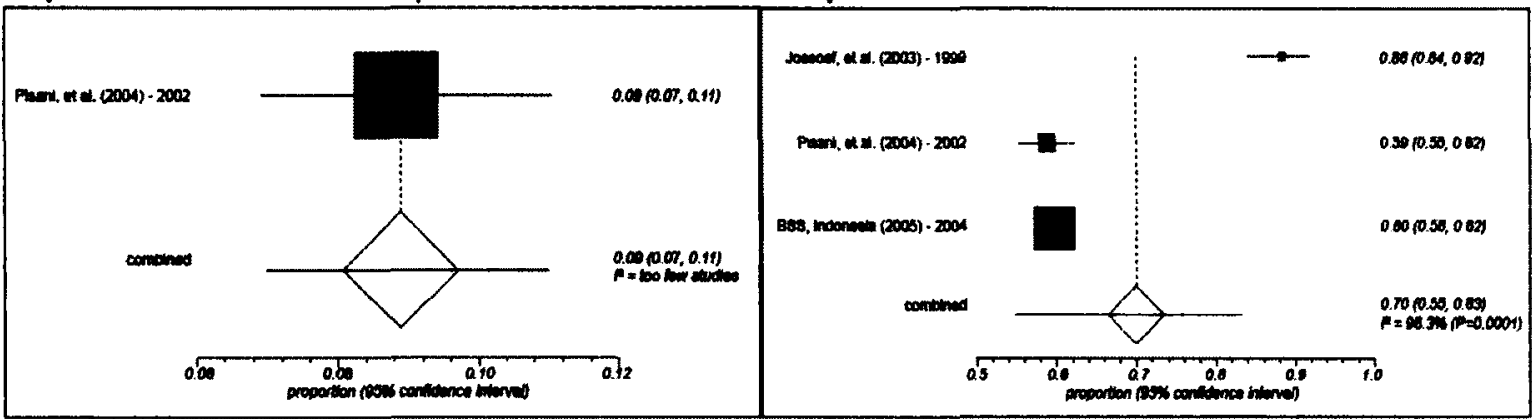

Dependent Variable 4: Adequate HIV knowledge Dependent Varlable 5: Exposure to HIV prevention

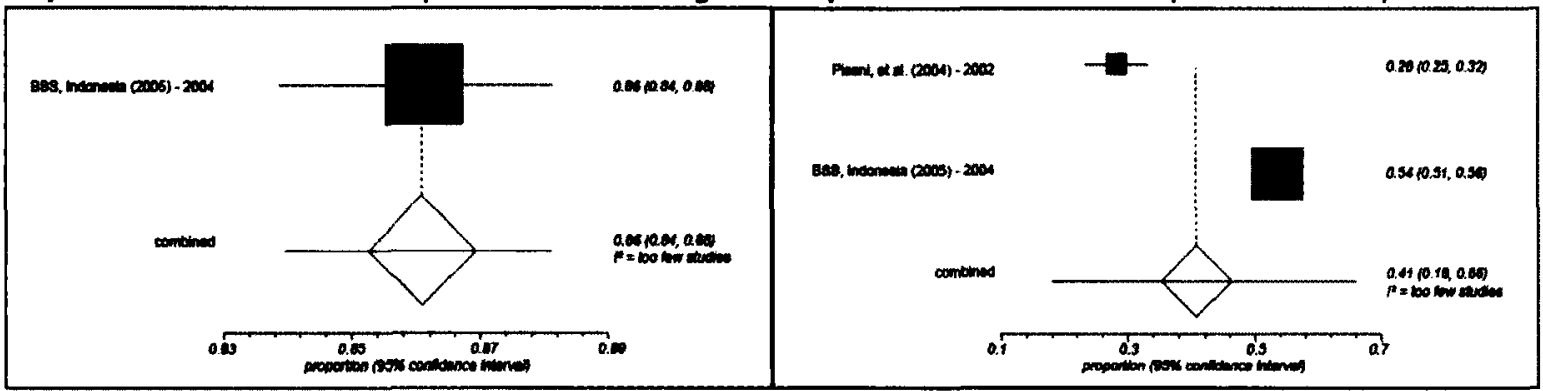


INDONESIA

\begin{tabular}{|c|c|c|c|c|c|c|}
\hline \multicolumn{7}{|l|}{ INDONESIA $(>2006)$} \\
\hline Study & Year & $\begin{array}{l}\text { HIV } \\
\text { Prevalence }\end{array}$ & $\begin{array}{l}\text { Inconsistent } \\
\text { Condom Use }\end{array}$ & $\begin{array}{l}\text { HIV Testing } \\
\text { (past year) }\end{array}$ & $\begin{array}{l}\text { Adequate HIV } \\
\text { Knowledge }\end{array}$ & $\begin{array}{l}\text { Exposure to } \\
\text { HIV Prevention }\end{array}$ \\
\hline \multicolumn{7}{|l|}{ IBBS, Indonesia (2007); \& } \\
\hline Monrieau, et al. (2009) & 2007 & $39 / 750$ & $1,146 / 1,450$ & $446 / 1,450$ & $1,160 / 1,450$ & $1,013 / 1,450$ \\
\hline Prabawanti, et al. (2010) & 2007 & $182 / 748$ & $627 / 978$ & $621 / 1,150$ & $954 / 1,150$ & Nodata \\
\hline \multicolumn{2}{|l|}{ COMBINED } & $13.3 \times$ & $72 x$ & $42 \%$ & $81 x$ & $70 \%$ \\
\hline
\end{tabular}

Dependent Variable 1: HIV prevalence

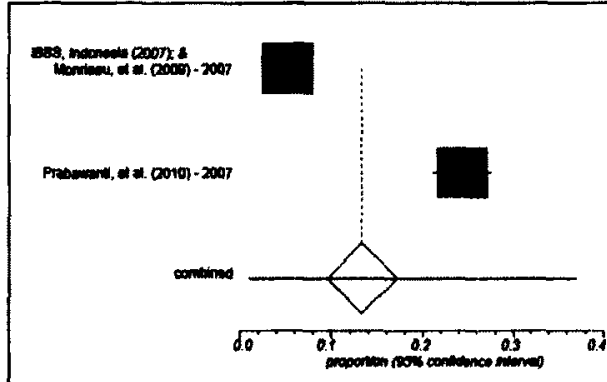

Dependent Variable 2: Inconsistent condom use

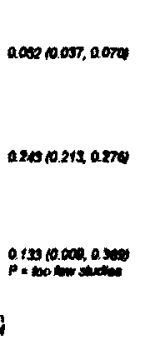

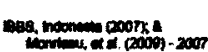

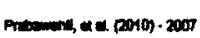

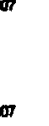

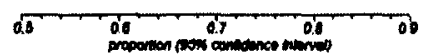

Q.7010.n, a.s

o.enger, $0.6 n$

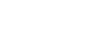

07210.000 .005

Dependent Variable 3: HIV testing (past year)

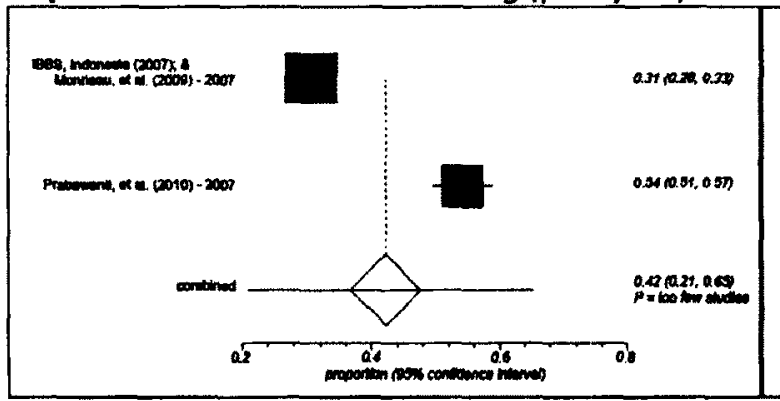

Dependent Varlable 4: Adequate HIV knowledge

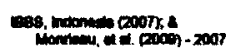

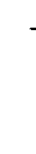

Aromentit, at a. (20010)-2000

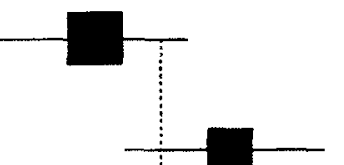

a.mo (0.7s, 0.02$)$

contion

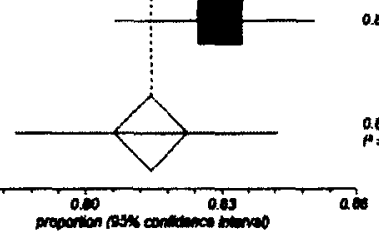

03 60.69, 0.095

Dependent Variable 5: Exposure to HIV prevention

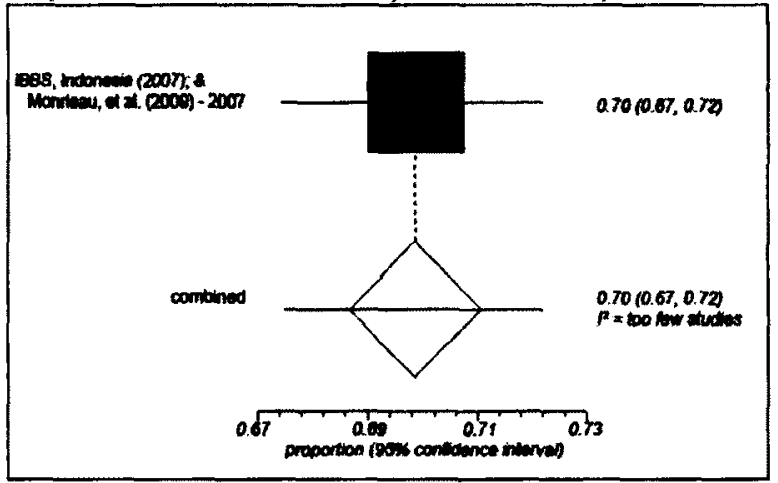


INDONESIA

SEXUAL ORIENTATION \& GENDER IDENTITY HUMAN RIGHTS INDEX

\begin{tabular}{|l|ll|l|}
\hline Penalty for homosexuality (death penalty) & -1 & 0 & 0
\end{tabular}

Penalty for homosexuality (lashings)

Penalty for homosexuality (>10 years in jail) $-1 \square 0 \square[1]$

\begin{tabular}{|l|l|l|l}
\hline Penalty for homosexuality (2-10 years in jail) & -100 0 & [
\end{tabular}

\begin{tabular}{llll}
\hline Penalty for homosexuality (<2 years in jail) & $-100 \mathrm{O}$ & {$[1$}
\end{tabular}

Penalty for homosexuality (fines)

Gender non-conformity sanctions

Discriminatory laws \& practices

Reservations / not party to ICCPR \& ICESCR

Punitive Points =

Ratified ICCPR \& ICESCR

Equal age of consent

Supportive laws \& policies

Anti-discrimination protection

Sex reassignment options available

Recognizes new or third gender (e.g. ID)

Right to marry/civil unions for Transgender

Same-sex marriage/civil unions

Protective Points =

TOTAL POINTS $=$
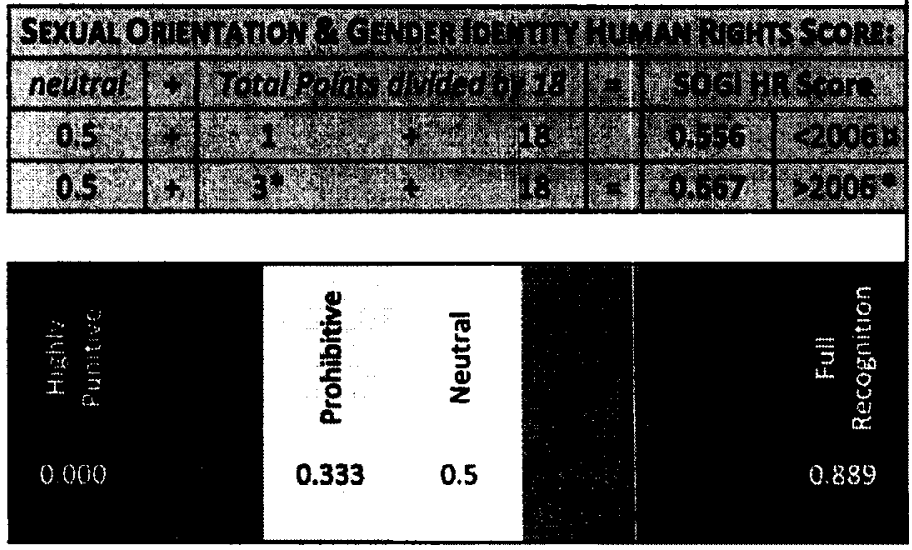

\section{REFERENCES:}

[1] The Indonesian Penal Code has never criminalized homosexuality. However, in 2004 the City of Palembang (South Sumatra) passed a bylaw criminalizing homosexuality: [Perda Kota Palembang No. 8/2004, re: Eradication of Prostitution]. In 2009, Aceh passed a law that punishes homosexuality with 100 lashes and up to 8 years in jail. Since there was no available epidemiological and behavioural data from Aceh or South Sumatra, these local laws are not included in the SOGI Human Rights Score.

[2] "The Department of Social Affairs classifies waria [transgender] as mentally handicapped under the federal 'cacat law' (Mentally Disabled Law). This effectively denies waria the right to work.": [IGLHRC (2007) p. 4]

In 2008, Indonesia passed the Pornography Bill (UU No. 44/2008), which prohibits pornography with "gay sex and lesbian sex" which is labeled "deviant sexual intercourse".

[3] Indonesia acceded to the ICCPR and ICESCR in 2006: [treaties.un.org]

(4) No protection for adult men: Secs. 285-290 of the Penal Code specifies that only women can be victims of rape. Sec. 291 criminalizes committing "obscene acts on minors of the same-sex." However the maximum penalty is only 5 years, unlike "rape" which is 12 years.

No protection for adult men: Sec. 297 of the Penal Code criminalizes trade in women and underage boys. "Trade" is not defined, but it is generally accepted to mean "trafficking". Art. 67 of the Law No. 39/1999 on Human Rights gives every child the right to be free from exploitation and sexual harassment, but does not specify any penalties.

[5] The current age of consent laws differ by gender not by sexuality. However, dreft revisions to the Penal Code would have a lower age of consent for heterosexual activity.

[6] In 2000, a wide range of human rights, including the freedom of assembly and speech, were added to the Constitution. It also included an antidiscrimination clauses "based upon any ground whatsoever", which might protect sexual minorities. Since this has not been tested, Indonesia is considered to have no antidiscrimination protection. [UNESCO (2011)]

[7] Transgender individuals can legally change their gender after completing sex reassignment, but not easily: [APF (2010) p. 48]

[8] Same-sex/transgender marriages are not permitted. "Every person shall have the right to establish a family and to procreate based upon lawful marriage.": [APF (2010) p. 48] 


\section{JAPAN}

\begin{tabular}{|c|c|c|c|c|c|c|}
\hline Study & Year & $\begin{array}{l}\text { HIV } \\
\text { Prevalence }\end{array}$ & $\begin{array}{l}\text { Inconsistent } \\
\text { Condom Use }\end{array}$ & $\begin{array}{l}\text { HIV Testing } \\
\text { (past year) }\end{array}$ & $\begin{array}{l}\text { Adequate HIV } \\
\text { Knowledge }\end{array}$ & $\begin{array}{l}\text { Exposure to } \\
\text { HIV Prevention }\end{array}$ \\
\hline Hidaka, et al. (2004) & 2000 & No da1.a & $95 / 126$ & $29 / 149$ & $145 / 149$ & No data \\
\hline Ichikawa (2010); (2007);\& (2003) & 2000 & $6 / 245$ & $73 / 146$ & $152 / 586$ & No data & No datat \\
\hline Shingae, et al. (2010a) & 2001 & $4 / 148$ & Nodata & Nodara & Ne data & No slata \\
\hline Ichlkawa (2010); (2007);\& (2003) & 2001 & $13 / 395$ & $151 / 307$ & $241 / 982$ & No data & No bata \\
\hline Shingae, et al. (2010a) & 2002 & $7 / 304$ & No data & No data & No dara & Nodabs \\
\hline Ichikawa (2010); (2007); \& (2003) & 2002 & $3 / 300$ & $149 / 399$ & $142 / 417$ & No data & No data \\
\hline Hidaka, et al. $(2006)$ & 2003 & $58 / 2,062$ & $433 / 895$ & $489 / 2,062$ & Wrong format & No data \\
\hline Shingae, et al. (2010a) & 2003 & $4 / 346$ & No date & Nodata & No data & Nothat \\
\hline Ichikawa $(2010) ;(2007) ; \&(2003)$ & 2003 & No dara & $213 / 526$ & $340 / 1,197$ & No diatla & No datid \\
\hline Inove, et al. (2006) & 2003 & AllHVt & $56 / 106$ & AllHE: & $102 / 117$ & No dala \\
\hline Takenaka \& Ichikawa (2008) & 2003 & $10 / 217$ & No data & Nodata & No data & No tata \\
\hline COMBINED / 2 & (004): & $2.6 \%$ & $50 \%$ & $26 \%$ & $93 \%$ & No data \\
\hline
\end{tabular}

Dependent Variable 1: HIV prevalence

Dependent Variable 2: Inconsistent condom use

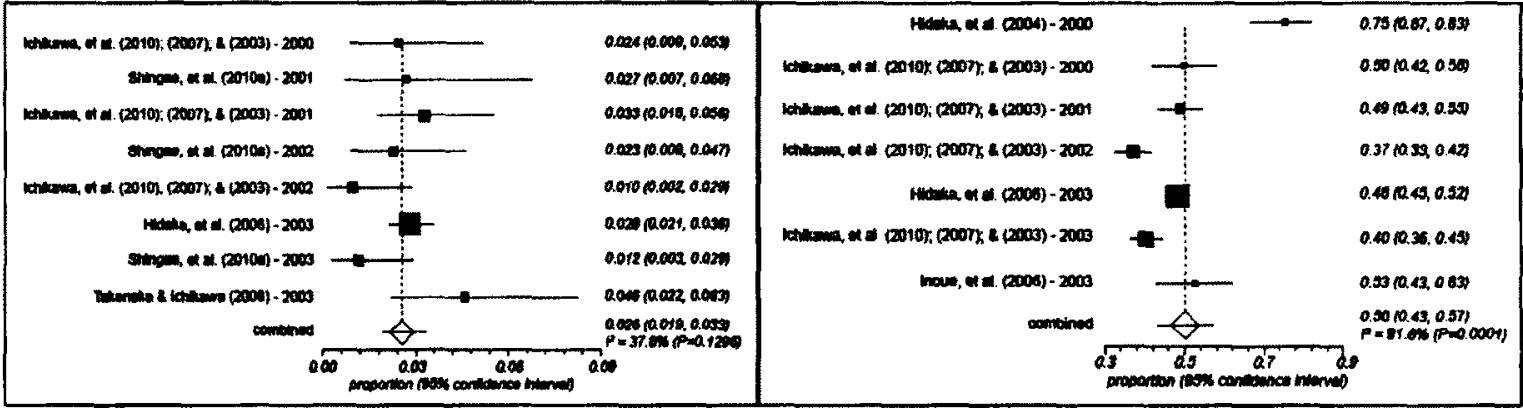

Dependent Variable 3: HIV testing (past year) Dependent Variable 4: Adequate HIV knowledge

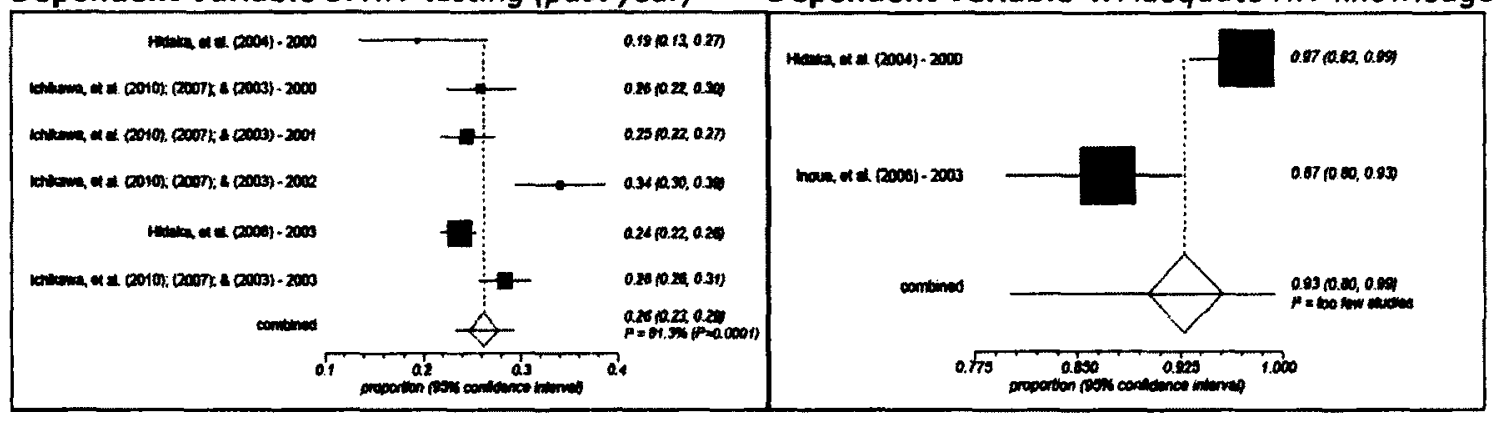


JAPAN

JAPAN (>2004)

\begin{tabular}{|c|c|c|c|c|c|c|}
\hline Study & Year & $\begin{array}{l}\text { HIV } \\
\text { Prevalence } \\
\end{array}$ & $\begin{array}{l}\text { Inconsistent } \\
\text { Condom Use }\end{array}$ & $\begin{array}{l}\text { HIV Testing } \\
\text { (past year) }\end{array}$ & $\begin{array}{l}\text { Adequate HIV } \\
\text { Knowledge }\end{array}$ & $\begin{array}{l}\text { Exposure to } \\
\text { HIV Prevention }\end{array}$ \\
\hline Shingae, et al. (2010a) & 2004 & $12 / 439$ & Ne data & No data & No data & No data \\
\hline Ichikawa, et al. (2007) & 2004 & No data & $84 / 243$ & $219 / 607$ & No data & No data \\
\hline Takenaka \& Ichlkawa (2008) & 2004 & $17 / 385$ & $128 / 212$ & $121 / 333$ & No data & Nodata \\
\hline Shingae, et al. (2010a) & 2005 & $9 / 425$ & Nodata & No data & No data & No datai \\
\hline Hidaka, et al. (2007a) & 2005 & No data & $1,847 / 2,477$ & $1,298 / 5,731$ & No data & Wrong format \\
\hline Ichikawa, et al. (2005) & 2005 & $9 / 158$ & $52 / 104$ & $150 / 532$ & Wrong format & $339 / 533$ \\
\hline Kaneko, et al. (2007a); \& (2005) & 2005 & No data & $177 / 382$ & $362 / 913$ & $192 / 223$ & $168 / 234$ \\
\hline Kimura, et al. (2005) & 2005 & No data & $154 / 405$ & $336 / 934$ & $512 / 934$ & $401 / 933$ \\
\hline Shiono, et al. (2009a) & 2005 & No data & $190 / 280$ & $135 / 496$ & Wrong format & No data \\
\hline Takenaka \& Ichikawa (2008) & 2005 & $19 / 485$ & $178 / 280$ & $160 / 430$ & No data & Nodafa \\
\hline Shingae, et al. (2010a) & 2006 & $21 / 471$ & Nodata & No data & No datit & No diata \\
\hline Kaneko, et al. (2006) & 2006 & No data & $83 / 226$ & $202 / 351$ & Wrong format & No dala \\
\hline $\begin{array}{l}\text { Kimura, et al. (2006a); (2006b) } \\
\text { Takenaka \& Ichikawa (2008); }\end{array}$ & 2006 & No data & $232 / 521$ & $256 / 674$ & $350 / 689$ & $107 / 684$ \\
\hline (2007); \& (2006) & 2006 & $20 / 422$ & $199 / 310$ & $173 / 373$ & No data & No data \\
\hline \multicolumn{7}{|l|}{ Kaneko, et al. $(2006) ;(2007 \mathrm{~b})$; } \\
\hline$\&(2007 c)$ & 2007 & $12 / 538$ & $134 / 326$ & $239 / 579$ & No datat & $266 / 577$ \\
\hline Kimura, et al. (2007) & 2007 & No data & $99 / 391$ & $384 / 1,039$ & $559 / 1,039$ & Wrone format \\
\hline Shiono, et al. (2007) & 2007 & No data & $374 / 587$ & $269 / 912$ & Wrong format & No data \\
\hline Takenaka \& Ichikawa (2008) & 2007 & $15 / 498$ & $158 / 289$ & $187 / 429$ & No data & No data \\
\hline Hidaka, et al. (2009) & 2008 & No data & $1,902 / 3,274$ & No datat & No data & No data \\
\hline Kimura, et al. (2008) & 2008 & No data & $111 / 350$ & $352 / 781$ & Nodata & Nodata \\
\hline \multicolumn{7}{|l|}{ Shingae, et al. $(2010 a)$; (2009a); } \\
\hline$(2008 a) ; \&(2008 b)$ & 2008 & $21 / 654$ & $158 / 389$ & $481 / 1,115$ & $237 / 408$ & $176 / 684$ \\
\hline $\begin{array}{l}\text { Shiono, et al. (2009a) } \\
\text { Takenaka \& Ichikawa (2010); }\end{array}$ & 2008 & No data & $49 / 99$ & $64 / 140$ & No data & $19 / 140$ \\
\hline$(2009)$ & 2008 & $19 / 374$ & $115 / 227$ & $156 / 337$ & Nodata & No data \\
\hline Kimura, et al. (2009) & 2009 & No dita & $109 / 391$ & $446 / 887$ & $559 / 942$ & Wrong format \\
\hline \multicolumn{7}{|l|}{ Shingae, et al. (2010a); (2009b); } \\
\hline $2009 c) ; 8(2009 d)$ & 2009 & $11 / 299$ & $235 / 599$ & $344 / 711$ & No dat & $59 / 170$ \\
\hline \multicolumn{7}{|l|}{ Shiono, et al. (2010b); (2009a); } \\
\hline$\&(2009 b)$ & 2009 & No data & $581 / 1,103$ & $579 / 1,959$ & Nisclata & $621 / 1,742$ \\
\hline Takenaka \& Ichikawa (2010) & 2009 & $6 / 133$ & $38 / 90$ & $56 / 123$ & Nodata & Nodata \\
\hline Kimura, et al. (2010) & 2010 & No data & $102 / 440$ & $435 / 943$ & Wrong fonat & Wrong tormat \\
\hline Shingae, et al. (2010a); \&(2010b) & 2010 & $11 / 726$ & $211 / 458$ & $308 / 1,055$ & Nodata & $49 / 173$ \\
\hline Shiono, et al. (2010a); \& (2010b) & 2010 & No data & $294 / 481$ & $268 / 786$ & Wrong Format & $250 / 581$ \\
\hline COMBINED (>2 & 1004): & $3.5 \%$ & $48 \%$ & $39 \%$ & $61 \%$ & $38 \%$ \\
\hline
\end{tabular}

\section{Dependent Varlable 1: HIV prevalence}

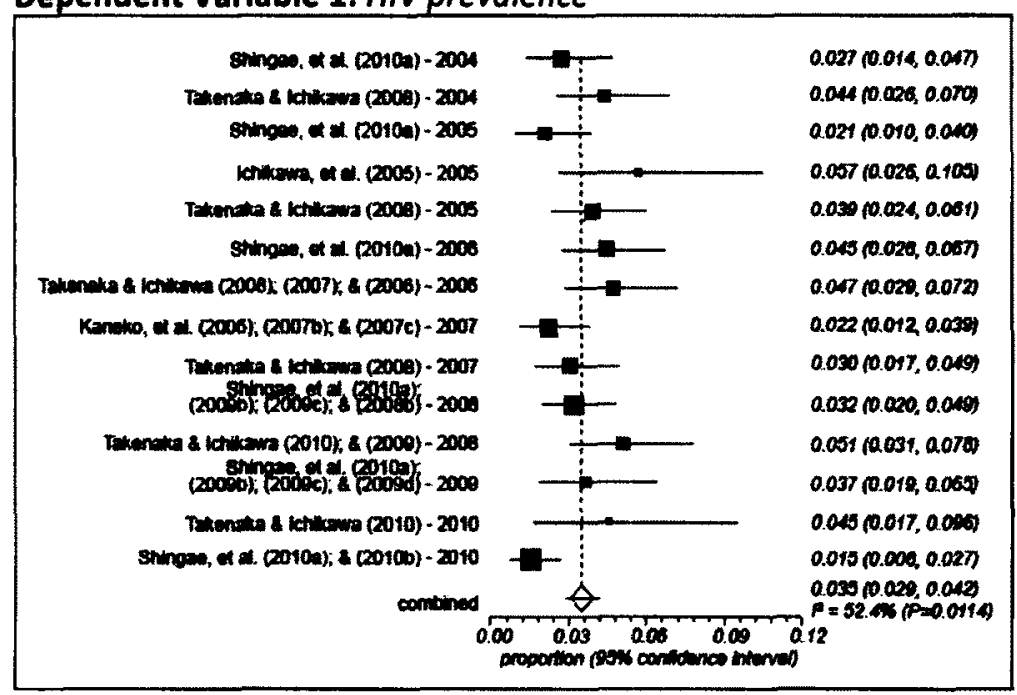




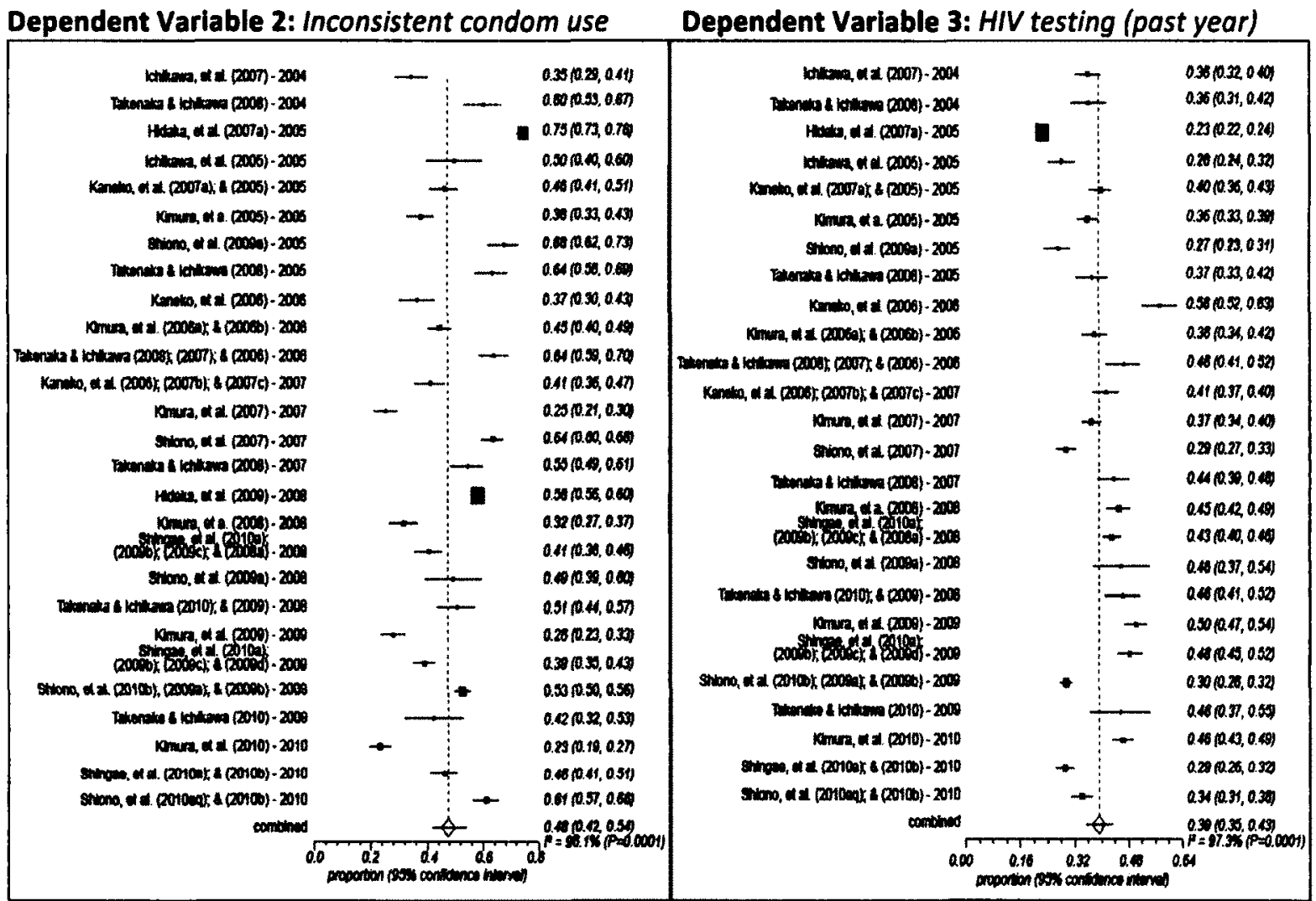

Dependent Variable 4: Adequate HIV knowledge

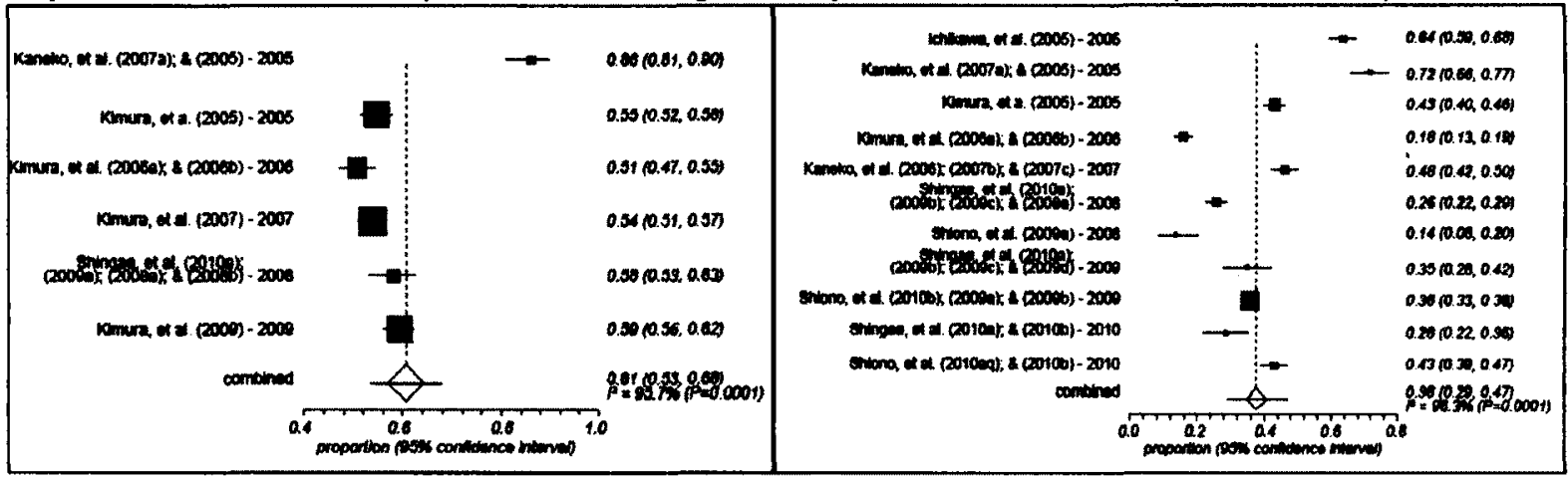


KoREA, Republic of

\begin{tabular}{|c|c|c|c|c|c|c|}
\hline \multicolumn{2}{|c|}{ KOREAN, Republic of } & \multirow[b]{2}{*}{$\begin{array}{l}\text { HIV } \\
\text { Prevalence }\end{array}$} & \multirow[b]{2}{*}{$\begin{array}{l}\text { Inconsistent } \\
\text { Condom Use }\end{array}$} & \multirow[b]{2}{*}{$\begin{array}{l}\text { HIV Testing } \\
\text { (past year) }\end{array}$} & \multirow[b]{2}{*}{$\begin{array}{l}\text { Adequate HIV } \\
\text { Knowledge }\end{array}$} & \multirow[b]{2}{*}{$\begin{array}{l}\text { Exposure to } \\
\text { HIV Prevention }\end{array}$} \\
\hline Study & Year & & & & & \\
\hline Kee, et al. (2004) & 2001 & No data & $167 / 227$ & $146 / 332$ & No data & $10 / 348$ \\
\hline
\end{tabular}

Dependent Variable 2: Inconsistent condom use Dependent Varlable 3: HIV testing (past year)

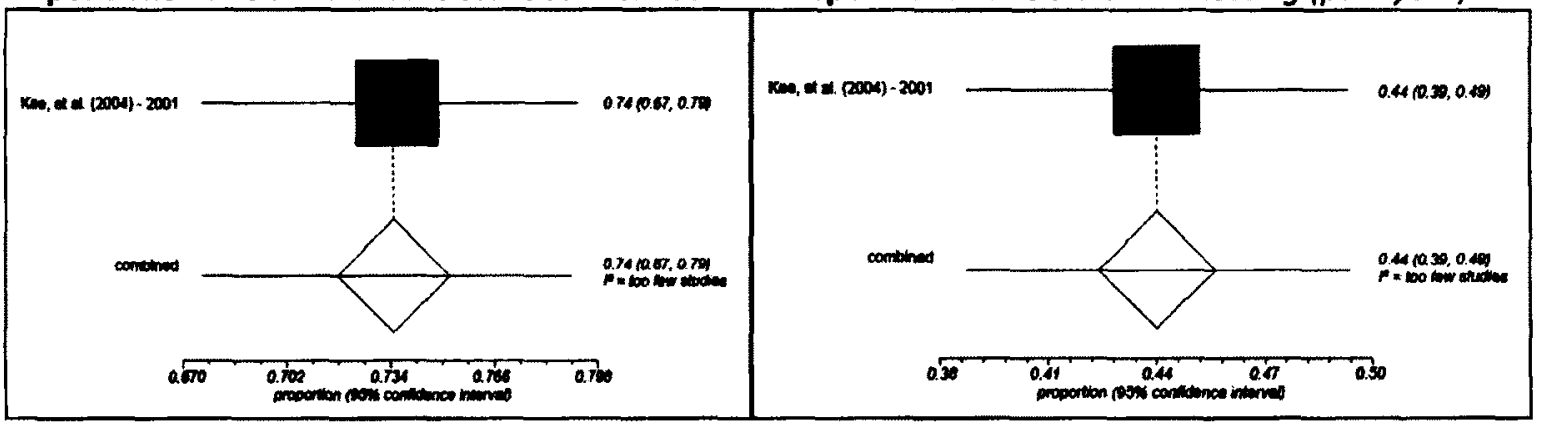

Dependent Varlable 5: Exposure to HIV prevention services

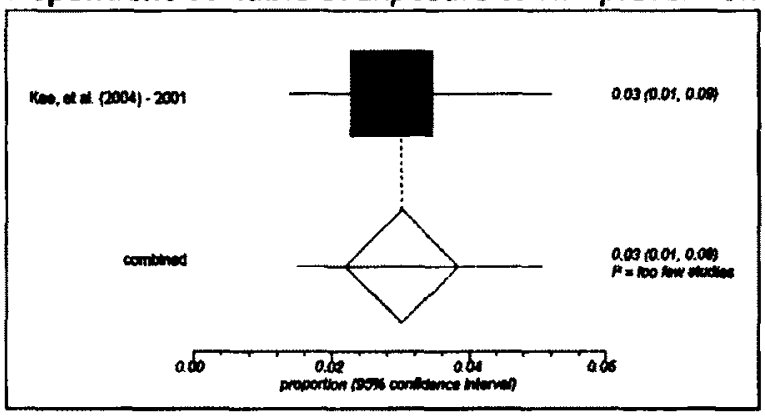




\begin{tabular}{|c|c|c|}
\hline SEXUAL ORIENTATION \& GENDER IDENTITY HUMAN RIGHTS INDEX & \multicolumn{2}{|c|}{$\begin{array}{l}\text { KOREA, REPUBLIC } \\
\text { MAN RIGHTS INDEX }\end{array}$} \\
\hline Penalty for homosexuality (death penalty) & $-1 \square 0 \square$ & [1] \\
\hline Penalty for homosexuality (lashings) & $-1 \square 0 区$ & [1] \\
\hline Penalty for homosexuality ( $>10$ years in jail) & $-1 \square 0 \square$ & [1] \\
\hline Penalty for homosexuality (2-10 years in jail) & $-1 \square 0 \square$ & [1] \\
\hline Penalty for homosexuality ( $<2$ years in jail) & $-1 \square 0 \square$ & [1] \\
\hline Penalty for homosexuality (fines) & $-1 \square 0 \square$ & [1] \\
\hline Gender non-conformity sanctions & $-1 \square 0 \square$ & [7] \\
\hline Discriminatory laws \& practices & $- 1 \longdiv { 0 0 }$ & [2] \\
\hline Reservations / not party to ICCPR \& ICESCR & $-1 \square 0$ 口 & [3] \\
\hline Punitive Points $=$ & \multicolumn{2}{|l|}{-2} \\
\hline Ratified ICCPR \& ICESCR & $0 \square+1 \square$ & [3] \\
\hline Gender-neutral sexual offences protection & 0区+1口 & [4] \\
\hline Equal age of consent & $0 \square+1 \square$ & [5] \\
\hline Supportive laws \& policies & $0 \square+1 \nabla$ & [6] \\
\hline Anti-discrimination protection & 0曰+1口 & [6] \\
\hline Sex reassignment options available & $0 \square+1 \square$ & [7] \\
\hline Recognizes new or third gender (e.g. ID) & $0 \mathrm{Q}+1 \square$ & [7] \\
\hline Right to marry/civil unions for Transgender & 0 日 +1口 & [8] \\
\hline Same-sex marriage/civil unions & 0 口+1口 & [8] \\
\hline Protective Points $=$ & \multicolumn{2}{|l|}{+4} \\
\hline TOTAL POINTS = & +2 & \\
\hline \multicolumn{3}{|c|}{ 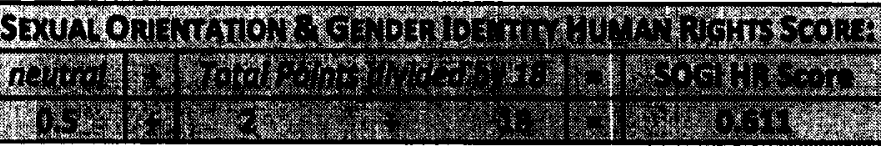 } \\
\hline $\begin{array}{l}\frac{y}{3} \\
\frac{0}{0} \\
\frac{0}{2}\end{array}$ & & 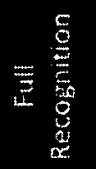 \\
\hline 0.333 & & 0.889 \\
\hline
\end{tabular}

Most of the developments in human rights for sexual minorities in the Republic of Korea occurred after 2001, which was the only year with available epidemiological and behavioural data. As such, these developments are not counted towards the SOGI Human Rights score.

\section{REFERENCES:}

[1] Homosexuality is legal in South Korea.

However, according to Art. 92 of the Military Penal Code, soldier who engage in gay sex face imprisonment of up to one year. A Military Court held this law was unconstitutional, but the Constitutional Court overturned that decision in 2011. This is very relevant since millitary service is compulsory for all men.

[2] The Youth Protection Law (1997) blocked "harmful" websites, including those with homosexual content. This law was challenged unsuccessfully in 2002. Finally, in 2004 "homosexuality" was removed from the list after the National Human Rights Commission concluded that it violated human rights: [Godwin (2010) p. 62-63]

Homosexuais are banned from the military, according to the Regulation on Physical Examinations of Recruits (Dep. of Defence Order no. 556) which defines homosexuals as a form of disease and mental disturbance: [Bong (2009) $p$. 90]

[3] Acceded to both the ICCPR (1990) and the ICESCR (1990): [treaties.un.org]

[4] Only women can be victims of rape according to Criminal Code no. 297. Non-consensual sex between men is classified as sexual assault. In 1996, the Supreme Court declared that the victim's sex is more than just biological and includes social- and self-identification. Thus, transgender victims might meet the definition of a rape victim: [Bong (2009) p. 94]

Until 2004, sex trade was defined as occurring between members of different sexes under the Prostitution Prevention Law. In 2004, the Special Law on Prostitution and the Sex-Trade Prevention Act now includes sex between men.

[5] "The age of consent is thirteen for both homo- and heterosexual acts.": [Laurent (2005) p. 206]

[6] Section 2, Clause 2 of the National Human Rights Commission Act (2001) prohibits discrimination based on sexual orientation. However, attempts to include "sexual orientation" in draft antidiscrimination bills have been unsuccessful thus far.

In 2010, a court granted refugee status to a gay man from Pakistan: [Godwin (2010) p. 63]

[7] Sex reassignment has been legal since the 1990s: [wikipedia, "legal aspects of transsexualism"].

In the case of In re Change of Name and Correction of Family Register (2004), the Supreme Court of South Korea held that the government must legally recognize the change of sex of certain transgender persons: [Godwin (2010) p. 60]

[8] Marriage is limited to opposite sex couples. In 2004 , a Court rejected a claim for alimony from a same-sex couple: [RRT, “Korea" (2008)] 
LAOS, PEOPLE'S DEMOCRATIC REPUBLIC OF

\begin{tabular}{|c|c|c|c|c|c|c|}
\hline \multicolumn{2}{|l|}{ LAO, POR } & \multirow[b]{2}{*}{$\begin{array}{l}\text { HIV } \\
\text { Prevalence }\end{array}$} & \multirow[b]{2}{*}{$\begin{array}{l}\text { Inconsistent } \\
\text { Condom Use }\end{array}$} & \multirow[b]{2}{*}{$\begin{array}{l}\text { HIV Testing } \\
\text { (past year) }\end{array}$} & \multirow[b]{2}{*}{$\begin{array}{l}\text { Adequate HIV } \\
\text { Knowledge }\end{array}$} & \multirow[b]{2}{*}{$\begin{array}{l}\text { Exposure to } \\
\text { HIV Prevention }\end{array}$} \\
\hline Study & Year & & & & & \\
\hline Longfleld, et al. (2008); \& & & & & & & \\
\hline Panyanouvong, et al. (2007) & 2004 & No data & $165 / 288$ & No data & $257 / 288$ & No data \\
\hline $\begin{array}{l}\text { Toole, et al. (2006) } \\
\text { Longfleld, et al. (2008); \& }\end{array}$ & 2004 & No data & $60 / 81$ & No data & No thata & No data \\
\hline Panyanouvong, et al. (2007) & 2006 & No datis & $227 / 324$ & No data & $404 / 415$ & $198 / 415$ \\
\hline PSI (2006) & 2006 & No data & $112 / 169$ & No data & No data & $18 / 229$ \\
\hline Sheridan, et al. (2009) & 2007 & $30 / 540$ & $223 / 294$ & "ever" & Notlata & No deta \\
\hline Morineau (2009) & 2009 & $0 / 300$ & $89 / 141$ & $48 / 300$ & $210 / 300$ & $195 / 300$ \\
\hline
\end{tabular}

Dependent Variable 1: HIV prevalence Dependent Variable 2: Inconsistent condom use

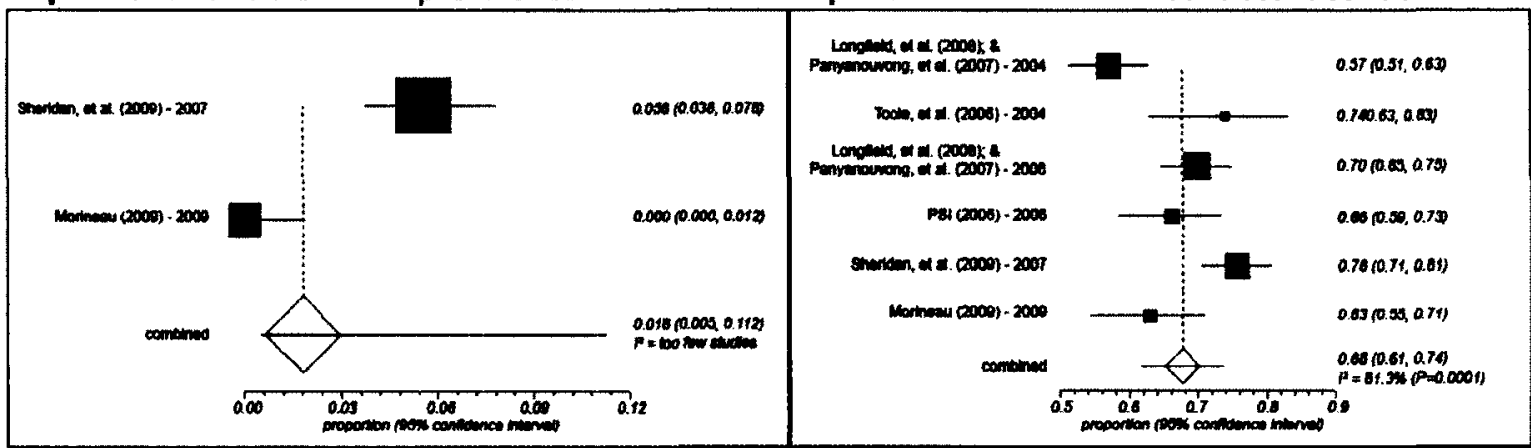

Dependent Variable 3: HIV testing (past year)

Dependent Variable 4: Adequate HIV knowledge

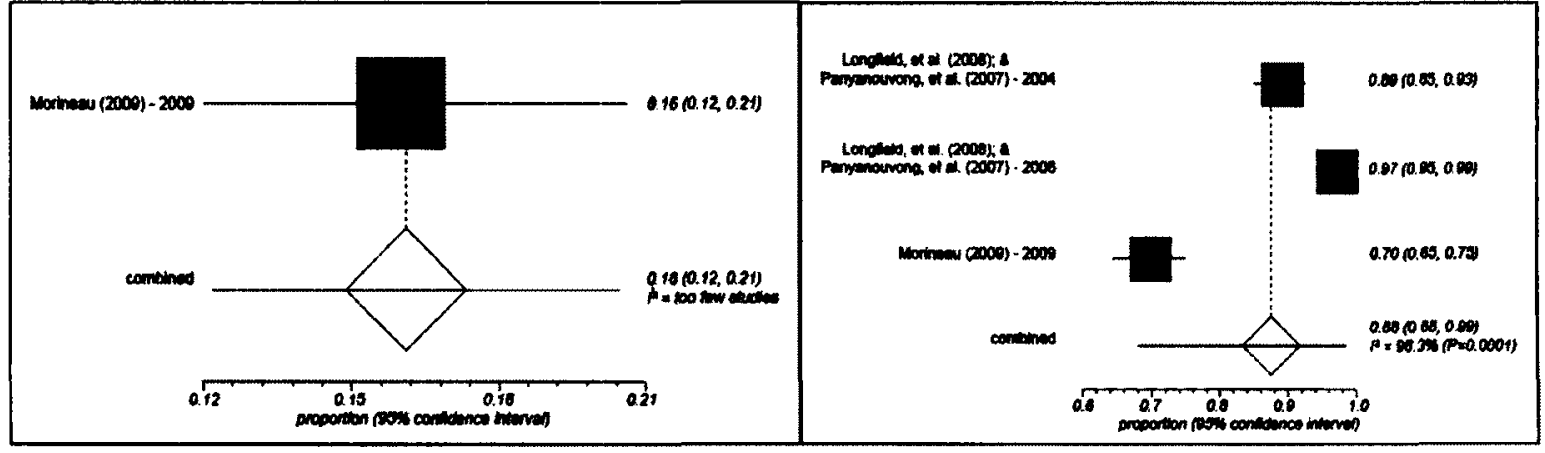

Dependent Variable 5: Exposure to HIV prevention services

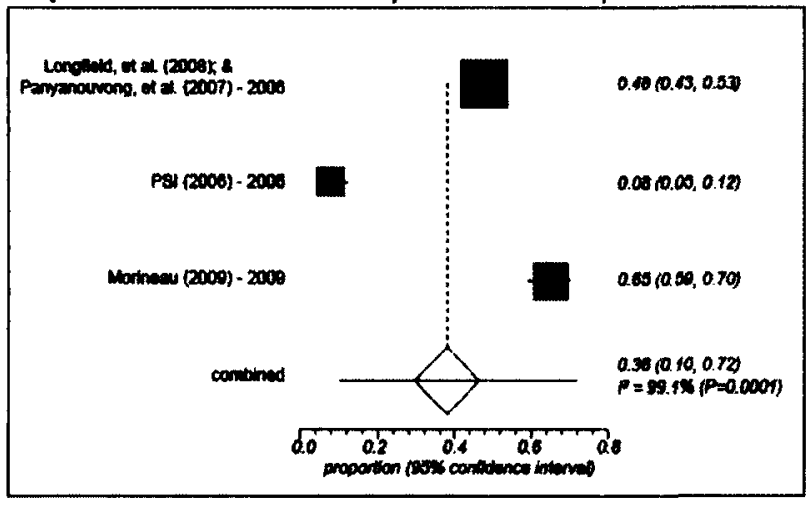


LAO, PEOPLE'S DEMOCRATIC REPUBLIC OF

\section{SEXUAL ORIENTATION \& GENDER IDENTITY HUMAN RIGHTS INDEX}

$\left.\begin{array}{|l|ll|l}\hline \text { Penalty for homosexuality (death penalty) } & -1 & 0 & 0\end{array}\right]$

Penalty for homosexuality (lashings)

$\left.\begin{array}{|l|lll}\hline \text { Penalty for homosexuality (>10 years in jail) } & -1 & 0 & 0\end{array}\right]$

Penalty for homosexuality (2-10 years in jail) $-100 \mathrm{O}$ [1]

\begin{tabular}{|l|l|l}
\hline Penalty for homosexuality ( $<2$ years in jail) & $-100 \mathrm{O}$ & [1]
\end{tabular}

\begin{tabular}{|l|l|l}
\hline Penalty for homosexuality (fines) & $-100 \mathrm{O}$ & {$[1]$} \\
\hline
\end{tabular}

\begin{tabular}{l|l|l|l}
\hline Gender non-conformity sanctions & $-100 \mathrm{O}$ & {$[1]$}
\end{tabular}

\begin{tabular}{|l|l|l|}
\hline Discriminatory laws \& practices & $-1 \square 0 \mathrm{~V}$ & $\mathrm{n} / \mathrm{d}$ \\
\hline
\end{tabular}

\begin{tabular}{|l|l|l|l|}
\hline Reservations / not party to ICCPR \& ICESCR & -1 ■ 0 口 & [2] \\
\hline
\end{tabular}

\begin{tabular}{|l|l|l|}
\hline & Punitive Points $=$ & -1 \\
\hline Ratified ICCPR \& ICESCR & $0 \mathrm{Q}+10$ & [2]
\end{tabular}

\begin{tabular}{|l|l|l}
\hline Gender-neutral sexual offences protection & $0 \mathrm{~V}+1 \square$ & {$[3]$} \\
\hline
\end{tabular}

Equal age of consent

Supportive laws \& policies

Anti-discrimination protection

Sex reassignment options available

Recognizes new or third gender (e.g. ID)

Right to marry/civil unions for Transgender

Same-sex marriage/civil unions

Protective Points =

TOTAL POINTS $=0$
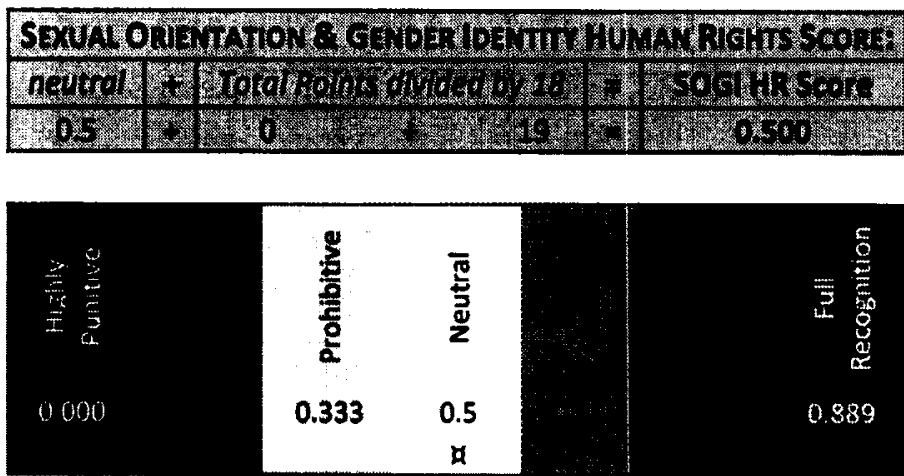

\section{REFERENCES:}

Very little data is available for Lao, since the Government strictly controls how human rights surveys are conducted. There is some suggestion that there is a growing acceptance of sexual minorities (more with gay men than with lesbian women) and low levels of discrimination towards transgender people (kathoey): [Godwin (2010) p. 70; and wikipedia, "LGBT rights in Laos"]

[1] Homosexuality is legal in Lao PDR. Kathoey (transgender) are more or less tolerated in Laos, without any formal sanctions.

[2] The available epidemiological and behavioural data collected for Lao range form 2004-2007. As such, Lao's 2000 signature to the ICCPR and ICESCR in 2000, and subsequent ratification of the ICCPR (2009) and ICESCR (2007) are deemed to have had no impact on the SOGI Human Rights score during the years under examination: [treaties.un.org]

[3] Art. 129 of the Penal Code, criminalizes sexual relations with a girl or boy whose age is under fifteen (15).

Art. 132 of the Penal Code only protects women and girls under 15 from forced prostitution.

[4] Age of consent is either 15 (art. 129 of the Penal Code) or 18 which is the "age of simple majority".

[5] No anti-discrimination protection, and no recognition of same-sex relationships: [wikjpedia, "LGBT rights in Laos"]

[n/d] no points are assigned for missing data. 
MALAYSIA

\begin{tabular}{|c|c|c|c|c|c|c|}
\hline \multicolumn{7}{|l|}{ MALAYSIA } \\
\hline Study & Year & $\begin{array}{l}\text { HIV } \\
\text { Prevalence } \\
\end{array}$ & $\begin{array}{l}\text { Inconsistent } \\
\text { Condom Use }\end{array}$ & $\begin{array}{l}\text { HIV Testing } \\
\text { (past year) }\end{array}$ & $\begin{array}{l}\text { Adequate HIV } \\
\text { Knowledge }\end{array}$ & $\begin{array}{l}\text { Exposure to } \\
\text { HIV Prevention }\end{array}$ \\
\hline \multicolumn{7}{|l|}{ Kanter, et al. (2010); \& } \\
\hline Kanter, et al. (2011) & 2008 & $20 / 517$ & $232 / 517$ & "evar" & $413 / 517$ & No data \\
\hline
\end{tabular}

Dependent Variable 1: HIV prevalence

Dependent Variable 2: Inconsistent condom use

\begin{tabular}{|c|c|c|c|c|}
\hline 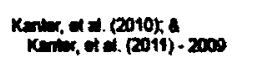 & & $0.010 .02,0.004$ & 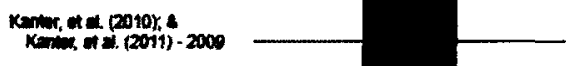 & $0.45(0.41,0.48)$ \\
\hline comomed & & $\begin{array}{l}0.0450 .02,0.009 \\
:=600\end{array}$ & conthond & 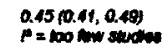 \\
\hline$a \sqrt{02}$ & 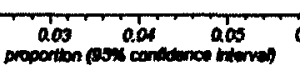 & 7.06 & 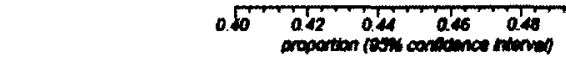 & 2.30 \\
\hline
\end{tabular}

Dependent Variable 4: Adequate HIV knowledge

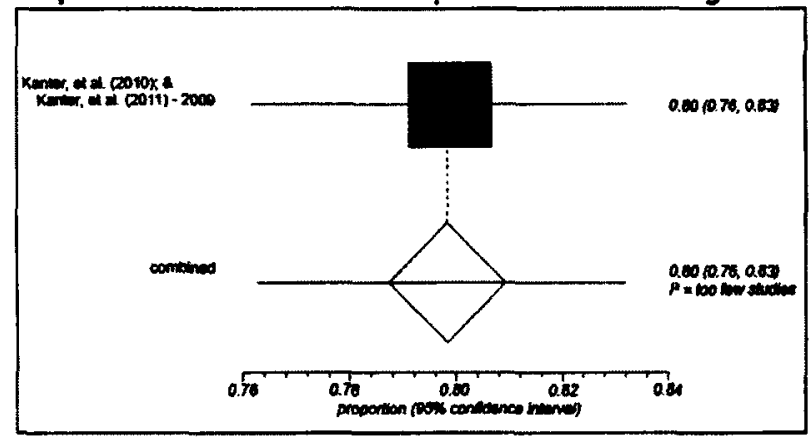


MALDIVES

\begin{tabular}{|c|c|c|c|c|c|c|}
\hline \multicolumn{2}{|l|}{ MALDIVES } & \multirow[b]{2}{*}{$\begin{array}{l}\text { HIV } \\
\text { Prevalence }\end{array}$} & \multirow[b]{2}{*}{$\begin{array}{l}\text { Inconsistent } \\
\text { Condom Use }\end{array}$} & \multirow[b]{2}{*}{$\begin{array}{l}\text { HIV Testing } \\
\text { (past year) }\end{array}$} & \multirow[b]{2}{*}{$\begin{array}{l}\text { Adequate HIV } \\
\text { Knowledge }\end{array}$} & \multirow[b]{2}{*}{$\begin{array}{l}\text { Exposure to } \\
\text { HIV Prevention }\end{array}$} \\
\hline Study & Year & & & & & \\
\hline Global Fund (2008) & 2008 & $0 / 126$ & $89 / 126$ & "ever" & $60 / 126$ & $86 / 126$ \\
\hline & BINED: & $0.00 \%$ & $71 \%$ & No dati & $48 \%$ & $68 \%$ \\
\hline
\end{tabular}

Dependent Variable 1: HIV prevalence

Dependent Variable 2: Inconsistent condom use

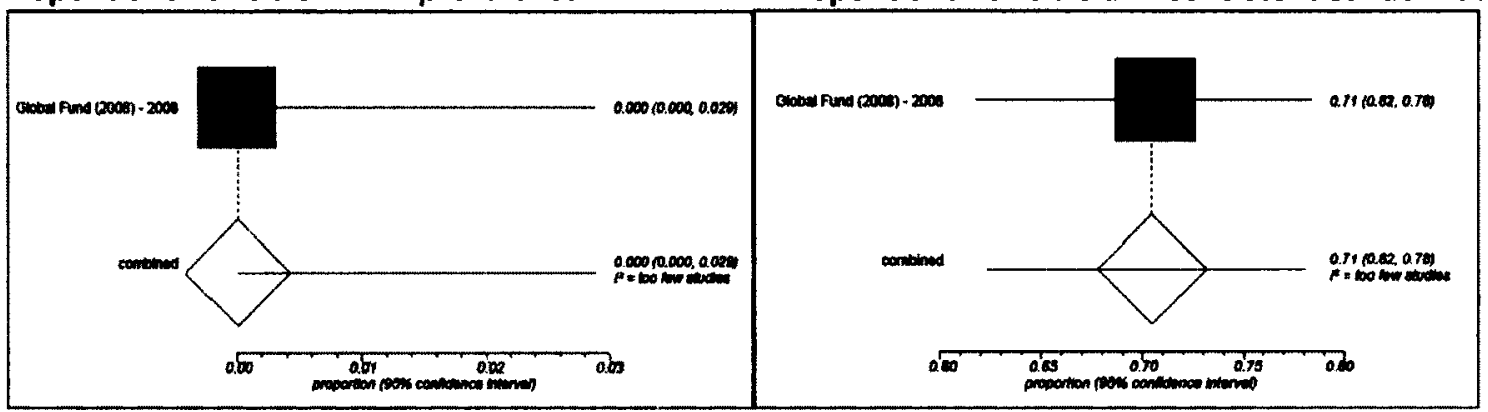

Dependent Variable 4: Adequate HIV knowledge

Dependent Variable 5: Exposure to HIV prevention

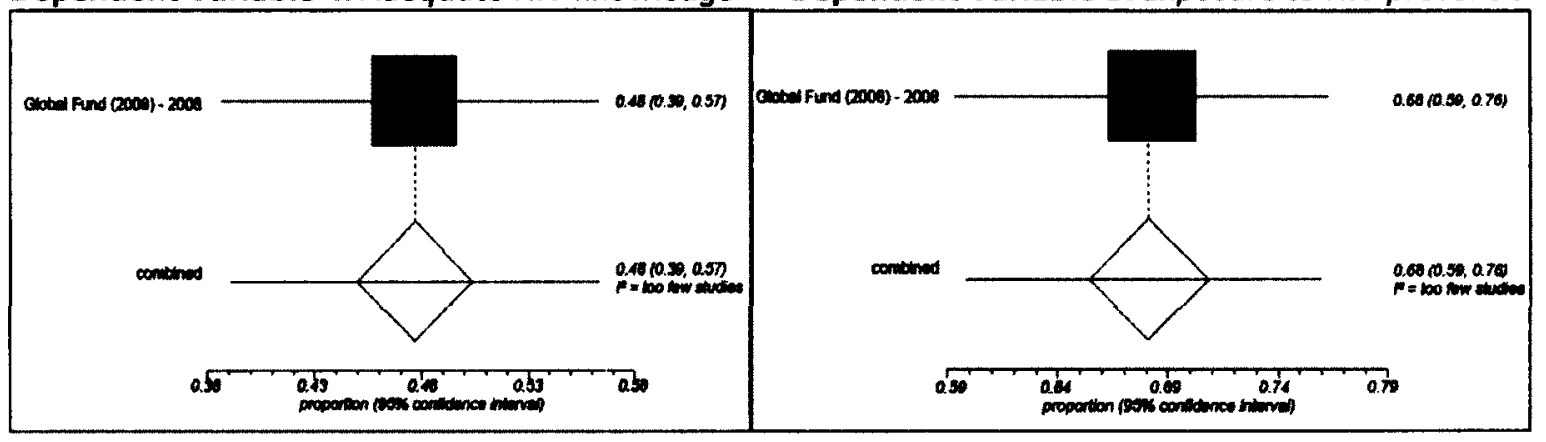




\begin{tabular}{|c|c|c|}
\hline \multirow{2}{*}{\multicolumn{3}{|c|}{$\begin{array}{l}\text { MALDIVES } \\
\text { SEXUAL ORIENTATION \& GENDER IDENTITY HUMAN RIGHTS INDEX }\end{array}$}} \\
\hline & & \\
\hline Penalty for homosexuality (death penalty) & $-1 \square 0 \square$ & [1] \\
\hline Penalty for homosexuality (lashings) & $-1 \square 0 \square$ & [1] \\
\hline Penalty for homosexuality ( $>10$ years in jail) & $-1 \square 0 \square$ & [1] \\
\hline Penalty for homosexuality (2-10 years in jail) & $-1 \square 0 \square$ & [1] \\
\hline Penalty for homosexuality ( $<2$ years in jail) & $-1 \square 0 \square$ & [1] \\
\hline Penalty for homosexuality (fines) & $-1 \square 0 \square$ & [1] \\
\hline Gender non-conformity sanctions & $-1 \square 0 \square$ & $n / d$ \\
\hline Discriminatory laws \& practices & $-1 \square 0 \square$ & {$[2]$} \\
\hline Reservations / not party to ICCPR \& ICESCR & $-1 \square 0$ 口 & [3] \\
\hline Punitive Points $=$ & \multicolumn{2}{|l|}{-3} \\
\hline Ratified ICCPR \& ICESCR & $0 \square+1 \square$ & [3] \\
\hline Gender-neutral sexual offences protection & $0 \square+10$ & [4] \\
\hline Equal age of consent & $0 \square+1 \square$ & [1] \\
\hline Supportive laws \& policies & $0 \square+1 \square$ & $n / d$ \\
\hline Anti-discrimination protection & 0 प 1 口 & [5] \\
\hline Sex reassignment options available & $0 \square+1 \square$ & [6] \\
\hline Recognizes new or third gender (e.g. ID) & $0 \square+1 \square$ & [6] \\
\hline Right to marry/civil unions for Transgender & $0 \square+1 \square$ & [7] \\
\hline Same-sex marriage/civil unions & $0 \square+1 \square$ & [7] \\
\hline Protective Points $=$ & +1 & \\
\hline TOTAL POINTS = & -2 & \\
\hline \multicolumn{3}{|c|}{ 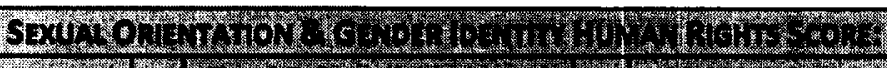 } \\
\hline \multirow{2}{*}{\multicolumn{3}{|c|}{ 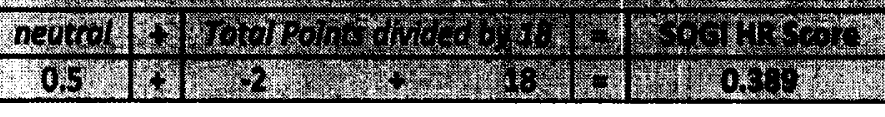 }} \\
\hline & & \\
\hline$\stackrel{2}{\frac{2}{3}}$ & & $=\frac{5}{5}$ \\
\hline $\begin{array}{c}0.333 \\
\mathrm{x}\end{array}$ & & 0.389 \\
\hline
\end{tabular}

\section{REFERENCES:}

[1] Homosexuality is illegal in Maldives through the application of Sharia Law. The penalties include lashings of 10-39 strokes, banishment of up to 1 year, house arrest for women, or imprisonment between 1-3 years: [WHO (2010) p. 83; ILGA (2011); and Godwin (2010) p. 23]

Sec. 17 (c) of the Regulation For Arrestable And Non-Arrestable Offences (2004) clearly states that "homosexual acts" is an arrestable offence.

[2] According the US Department of State, "there were no reports of official or societal discrimination based on sexual orientation in employment, housing, access to education, or health care.": [ DoS 2010) p.60]

[3] Maldives accessed to the ICCPR and ICESCR in 2006: [treaties.un.org]

[4] There appears to be no rape provisions in Maldives (even against women). These offences are prosecuted under sexual assault or misconduct: [DoS (2010) p.60].

The penalty for same-sex sexual behaviour between an adult and a minor under 16 is slightly longer than between consenting adults, (19-39 lashes and three to six years banishment or jail time).

Law No 9/91 Law on the Protection of the Rights of Children criminalizes child sex abuse and sexual exploitation. These laws were strengthened in 2008. However, there appears to be no general protection from sexual exploitation/forced prostitution.

[5] The enumerated rights and freedoms in the Constitution are limited by Article 16(a) which states: "This Constitution guarantees to all persons, in a manner that is not contrary to any tenet of Islam, the rights and freedom contain within this Chapter..." As long as homosexuality is prohibited by Maldivian Islamic interpretations, sexual minorities will have limited Constitutional rights and freedoms.

That said, in 2009 a group called Rainbow Maldives was formed. It has an on-line presence and is advocating to decriminalize male-to-male sex.

[6] "... there is no provision in the Maldivian law which allow for recognition of a third gender or for changes to gender.": [APF (2010) p. 57]

[7] No same-sex/transgender marriage recognition: [ilga.org, "MALDIVES/Law"]

[n/d] no points are assigned for missing data. 


\section{MONGOLIA}

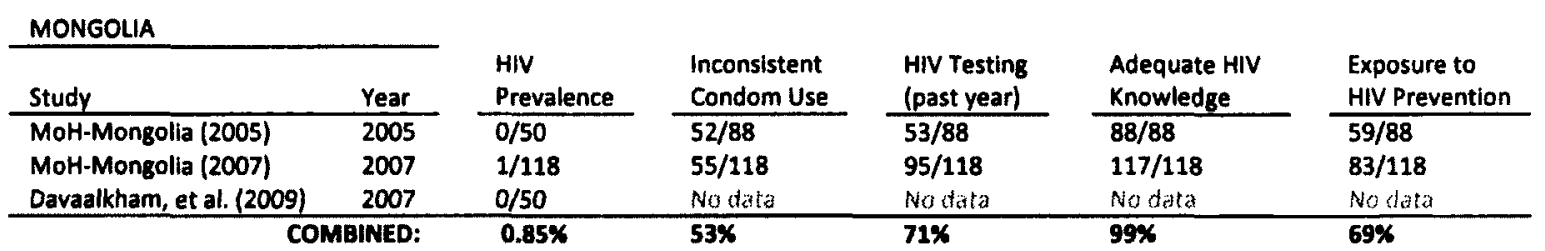

Dependent Variable 1: HIV prevalence

Dependent Variable 2: Inconsistent condom use

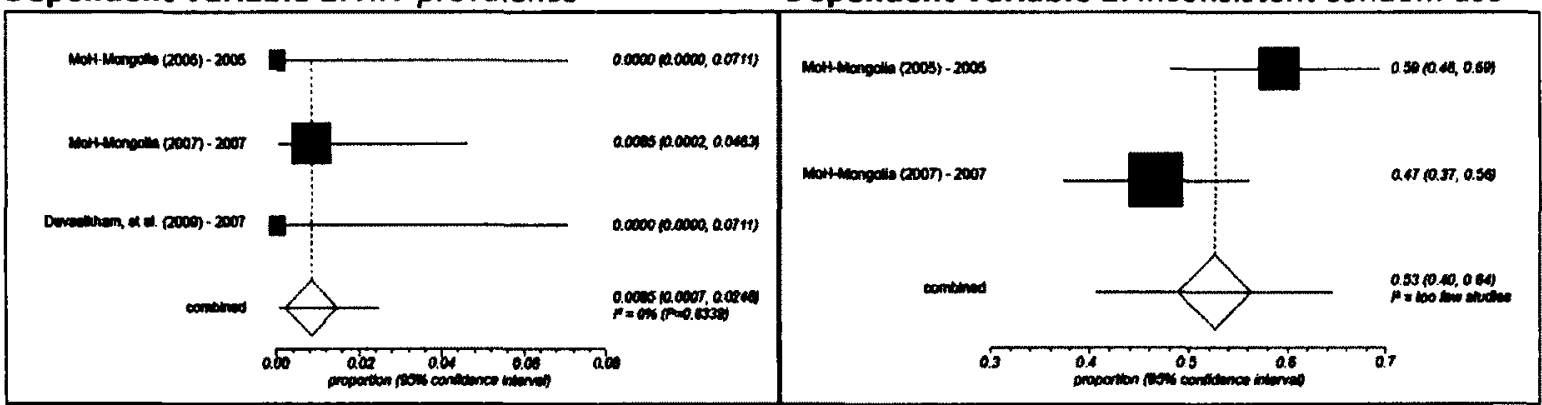

Dependent Variable 3: HIV testing (post year)

Dependent Variable 4: Adequate HIV knowledge

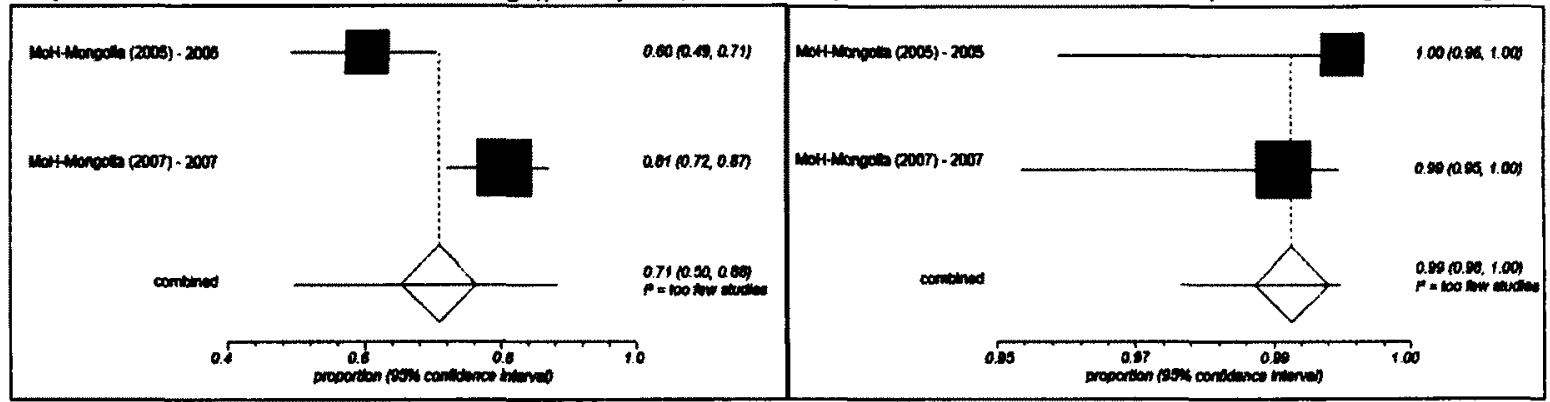

Dependent Variable 5: Exposure to HIV prevention services

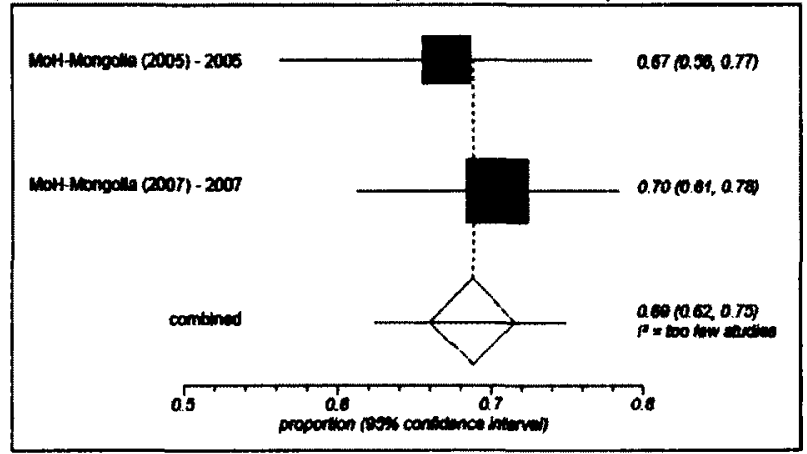




\section{MONGOLIA}

\section{SEXUAL ORIENTATION \& GENDER IOENTITY HUMAN RIGHTS INDEX}

Penalty for homosexuality (death penalty)

\begin{tabular}{|l|l|l}
\hline Penalty for homosexuality (lashings) & $-100 \mathrm{0}$ & {$[1]$}
\end{tabular}

Penalty for homosexuality (>10 years in jail) -100 ठ

Penalty for homosexuality (2-10 years in jail) -10 OV [1]

\begin{tabular}{llll}
\hline Penalty for homosexuality (<2 years in jail) & $-100 \mathrm{O}$ & {$[1]$}
\end{tabular}

\begin{tabular}{|l|l|l}
\hline Penalty for homosexuality (fines) & $-100 \mathrm{O}$ & {$[1]$}
\end{tabular}

\begin{tabular}{|l|l|l|}
\hline Gender non-conformity sanctions & $-1 \square 0 \mathrm{~V}$ & $\mathrm{n} / \mathrm{d}$ \\
\hline
\end{tabular}

\begin{tabular}{|l|l|l}
\hline Discriminatory laws \& practices & -1000 & [2]
\end{tabular}

\begin{tabular}{|l|lll}
\hline Reservations / not party to ICCPR \& ICESCR & -100 [ 0 [3] \\
\hline
\end{tabular}

\begin{tabular}{|l|l|l|}
\hline \multicolumn{2}{|c|}{ Punitive Points $=$} & \multicolumn{1}{|l|}{-1} \\
\hline Ratified ICCPR \& ICESCR & $0 \square+1 \sqrt{\square}$ & {$[3]$} \\
\hline Gender-neutral sexual offences protection & $0 \square+1[$ & {$[4]$}
\end{tabular}

\begin{tabular}{|l|l|l}
\hline Equal age of consent & $0 \square+10$ & {$[4]$} \\
\hline
\end{tabular}

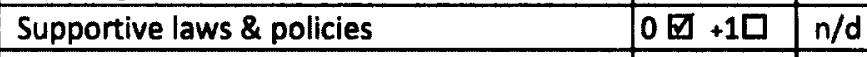

Anti-discrimination protection

Sex reassignment options available

\begin{tabular}{|l|l|l|}
\hline Recognizes new or third gender (e.g. ID) & 0 可 +1D & {$[6]$} \\
\hline
\end{tabular}

\begin{tabular}{|l|l|l|}
\hline Right to marry/civil unions for Transgender & $0 \square+1 \square$ & [5
\end{tabular}

\begin{tabular}{|l|l|l}
\hline Same-sex marriage/civil unions & $0 \mathrm{~V}+10$ & {$[5]$} \\
\hline
\end{tabular}
Protective Points $=+3$ TOTAL POINTS $=$
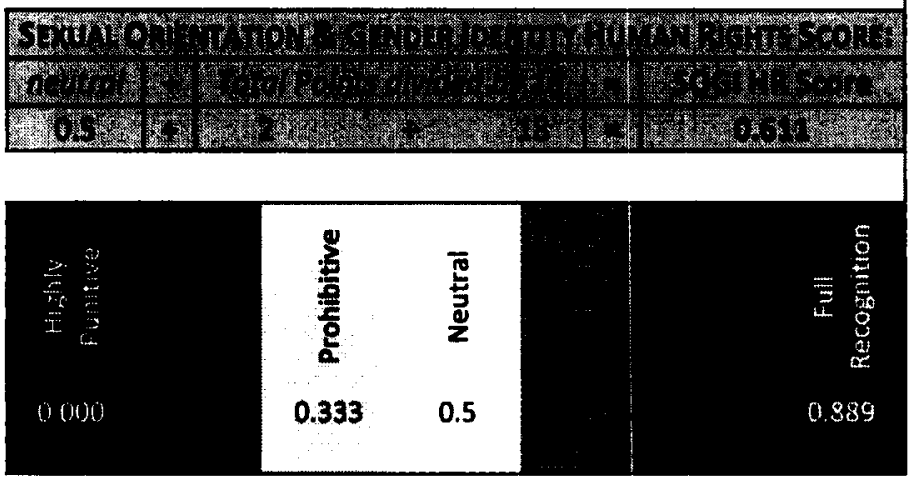

\section{REFERENCES:}

[1] Homosexuality was decriminalized in 2002.

In 2008 the Penal Code was amended, adding Section 135 which criminalizes "satisfaction of sexual desire in unnatural manner". This provision does not explicitly mention sex between men, and "the High Court of Mongolia interpreted 'unnatural manner' to be restricted to situations of force.": [APF (2010) p. 58]

However, there is some evidence that police have used this provision to harass and detain sexual minorities.

[2] “...discrimination based on sexual orientation is endemic in Mongolia, extending to the public, private and non-governmental sectors and encompassing media, police and judiciary, health care services, education and housing sector.": [APF (2010) p. 58]

The Mongolian LGBT Center has had a challenging time becoming recognized officially as an NGO. In 2007 their application was rejected "because the words 'lesbian', 'gay', 'bisexual' and 'transgender' were not Mongolian and needed to be approved." Later in 2009 their application was rejected again. This time because LGBT "has a meaning that conflicts with Mongolian customs and traditions." They were finally granted status in December 2009: [APF (2010) p. 58]

[3] Ratified both the ICCPR (1974) and the ICESCR (1974): [treaties.un.org]

[4] The rape provisions in Sec. 126 of the Penal Code are gender inclusive. The protection from sexual exploitation provisions in Sec. 124 are also gender inclusive. The legal age of consent is 16 for everyone according to Sec. 122.

[5] "There is no legal protection based on sexual orientation or gender identity" and "there is no legal recognition of same-sex marriages, civil unions or domestic partnerships.": [wikipedia, "LGBT rights in Mongolia]

[6] "Mongolian law makes no provisions for transition from one gender to another and does not recognize sex reassignment.": [APF (2010) p. 59]

[n/d] no points are assigned for missing data. 


\section{MYANMAR}

\begin{tabular}{|c|c|c|c|c|c|c|}
\hline \multicolumn{7}{|l|}{ Myanmar } \\
\hline Study & Year & $\begin{array}{l}\text { HIV } \\
\text { Prevalence }\end{array}$ & $\begin{array}{l}\text { Inconsistent } \\
\text { Condom Use }\end{array}$ & $\begin{array}{l}\text { HIV Testing } \\
\text { (past year) }\end{array}$ & $\begin{array}{l}\text { Adequate HIV } \\
\text { Knowledge }\end{array}$ & $\begin{array}{l}\text { Exposure to } \\
\text { HIV Prevention }\end{array}$ \\
\hline NAP (2007) & 2007 & $117 / 400$ & No data & No data & Nodate & Ned data \\
\hline NAP $(2009)$ & 2008 & $115 / 400$ & No data & No data & No data & No data \\
\hline & 3NED: & $29 \%$ & No data & No data & No data & Notala \\
\hline
\end{tabular}

Dependent Variable 1: HIV prevalence

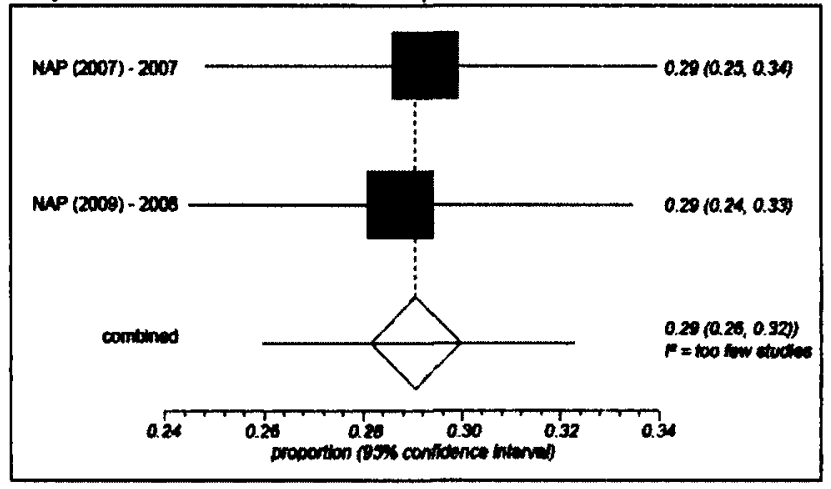




\section{MYANMAR}

\section{Sexual Orientation \& Gender loentity Human Rights IndeX}

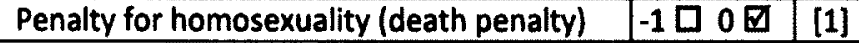

\begin{tabular}{|l|l|l}
\hline Penalty for homosexuality (lashings) & $-100 \mathrm{O}$ & {$[1]$}
\end{tabular}

Penalty for homosexuality (>10 years in jail) -1000 [1]

Penalty for homosexuality (2-10 years in jail) -1000 [1]

Penalty for homosexuality (<2 years in jail) -1000 [1]

Penalty for homosexuality (fines)

Gender non-conformity sanctions

Discriminatory laws \& practices

Reservations / not party to ICCPR \& ICESCR

\begin{tabular}{|l|l|l|}
\hline & Punitive Points $=$ & -6 \\
\hline Ratified ICCPR \& ICESCR & 0 [ $+1 \square$ & [3]
\end{tabular}

\begin{tabular}{|l|l|l|}
\hline Ratified ICCPR \& ICESCR & 0 Q $+1 \square$ & {$[3]$} \\
\hline Gender-neutral sexual offences protection & 0 曰 $+1 \square$ & {$[4]$} \\
\hline Equal age of consent & $00+10$ & {$[1]$} \\
\hline
\end{tabular}

\begin{tabular}{|l|l|l}
\hline Equal age of consent & $0 \square+1 \square$ & {$[1]$} \\
\hline Supportive laws \& policies & $0 \square+1 \square$ & {$[1,5]$} \\
\hline
\end{tabular}

Anti-discrimination protection

Sex reassignment options available

Recognizes new or third gender (e.g. ID)

Right to marry/civil unions for Transgender

Same-sex marriage/civil unions

Protective Points =

TOTAL POINTS $=-6$
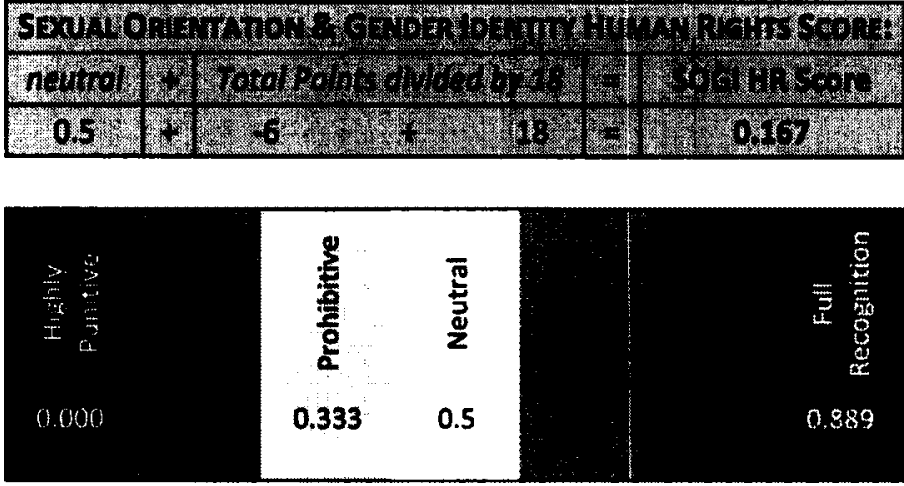

\section{REFERENCES:}

[1] Homosexuality is criminalized in section 377 of the Penal Code (1860): "Whoever voluntarily has carnal intercourse against the order of nature with any man, woman or animal, shall be punished with transportation for life, or with imprisonment of either description for a term which may extend to ten years, and shall also be liable to fine. Penetration is sufficient to constitute the sexual intercourse necessary to the offence describe in this section."

The United Kingdom used to "transport" criminals to a penal colony (c.g. Australia) for life. Most of the former British colonies revised the penalty of "transportation for life" to "imprisonment for life". It is unclear what actually happens in Myanmar, but experts believe that it is interpreted to mean imprisonment.

[2] "Under section 33A of the Law for the Student Army, any man or women engaged in same-sex relations in the military is liable to one year in prison and dismissal.": [Laurent (2005) p. 186]

[3] Not party to either the ICCPR or the ICESCR: [treaties.un.org]

[4] The rape provisions in the Penal Code are gender specific, where only women can be victims (Sec. 375). The prostitution provisions appear to be gender inclusive, since both Sections 372 and 373 use the term "of any person under 18 years with intent that such person shall at any age be employed or used for the purpose of prostitution..."

[5] According the ILGA's State-Sponsored Homophobia report, Myanmar "freedom of association and freedom of expression are strictly limited." Furthermore, there are no anti-discrimination protections for sexual orientation or gender identity, and there is no relationship recognition: [ilga.org, "MYANMAR/Law"]

[n/d] no points are assigned for missing data. 


\section{NEPAL}

\begin{tabular}{|c|c|c|c|c|c|c|}
\hline \multicolumn{7}{|l|}{ NEPAL } \\
\hline Study & Year & $\begin{array}{l}\text { HIV } \\
\text { Prevalence }\end{array}$ & $\begin{array}{l}\text { Inconsistent } \\
\text { Condom Use }\end{array}$ & $\begin{array}{l}\text { HIV Testing } \\
\text { (past year) }\end{array}$ & $\begin{array}{l}\text { Adequate HIV } \\
\text { Knowledge }\end{array}$ & $\begin{array}{l}\text { Exposure to } \\
\text { HIV Prevention }\end{array}$ \\
\hline \multicolumn{7}{|l|}{ FHI-Nepal (2005); \& } \\
\hline Acharya, et al. (2006) & 2004 & $14 / 358$ & $108 / 194$ & $24 / 358$ & $317 / 358$ & No data \\
\hline FHI-Nepal (2008) & 2007 & $13 / 400$ & 90/301 & $120 / 400$ & $319 / 400$ & $224 / 400$ \\
\hline \multicolumn{2}{|c|}{ (<2008) COMBINED: } & $3.68 \%$ & $\mathbf{4 2 \%}$ & $17 \%$ & $84 \%$ & $56 \%$ \\
\hline FHI-Nepal (2009) & 2009 & $15 / 400$ & $101 / 290$ & $170 / 400$ & $333 / 400$ & $316 / 400$ \\
\hline$(2200$ & INED: & $3.75 \%$ & $35 \%$ & 43\% & $83 \%$ & $79 \%$ \\
\hline
\end{tabular}

$<2008 \quad$ Dependent Variable 1: HIV prevalence

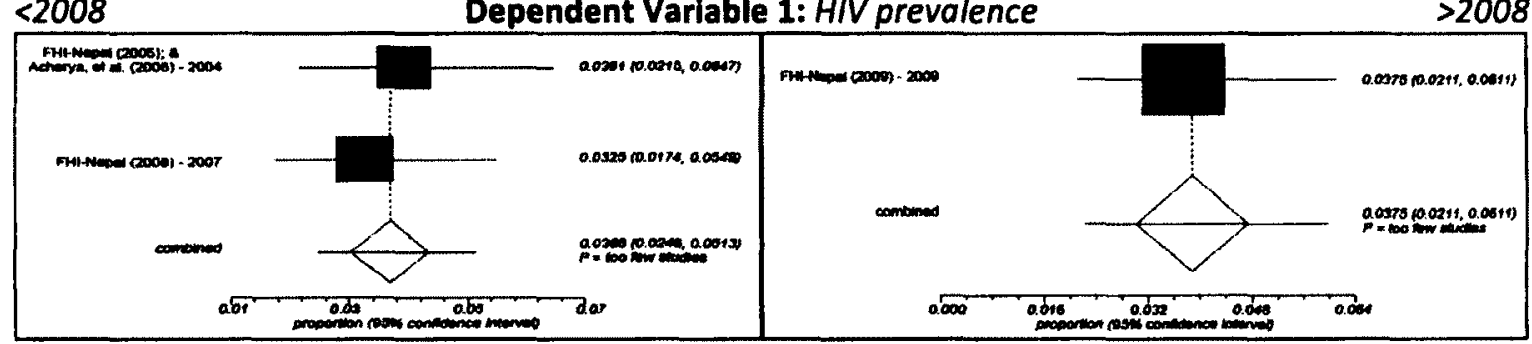

$<2008$ Dependent Variable 2: Inconsistent condom use >2008
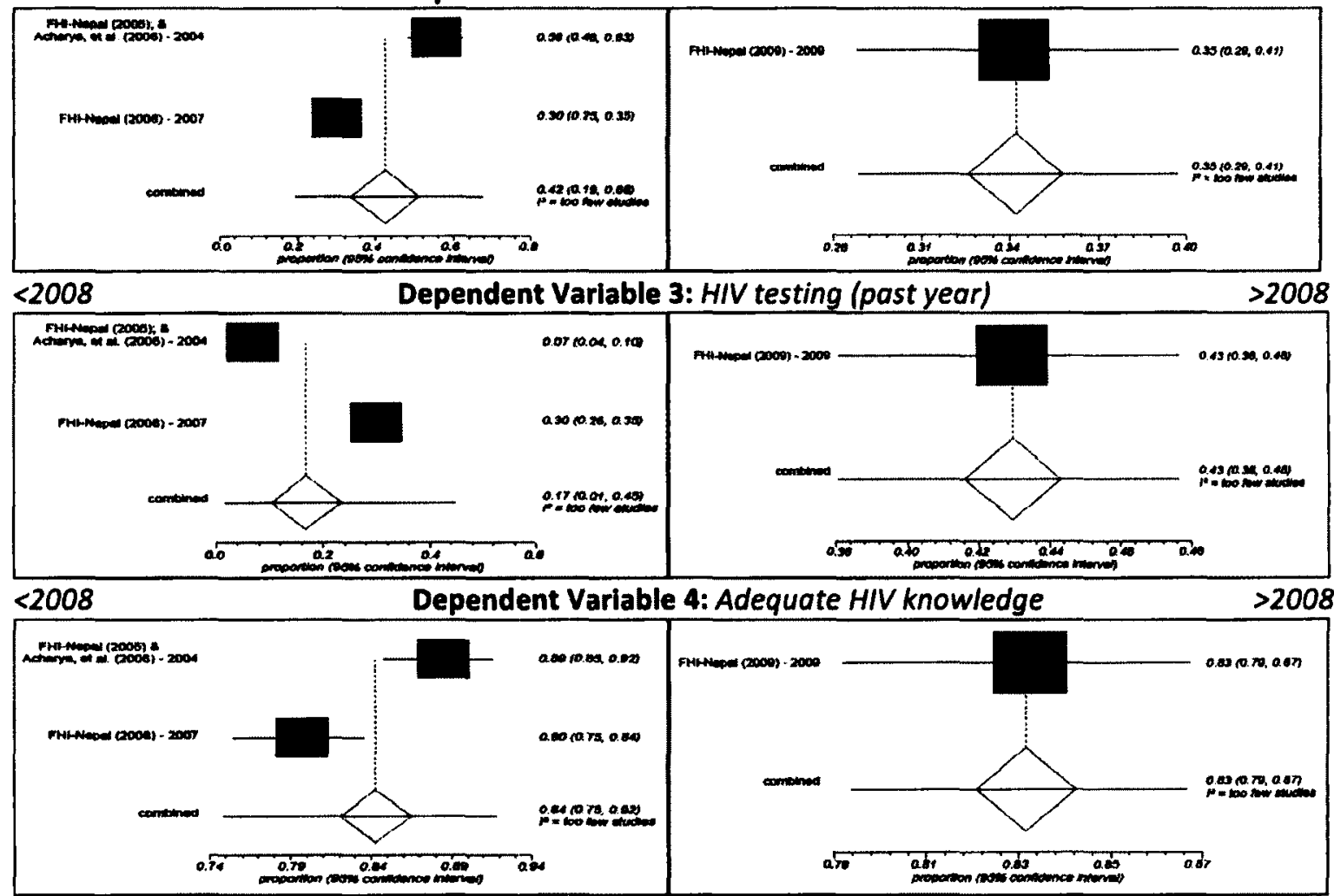

<2008 Dependent Variable 5: Exposure to HIV prevention >2008

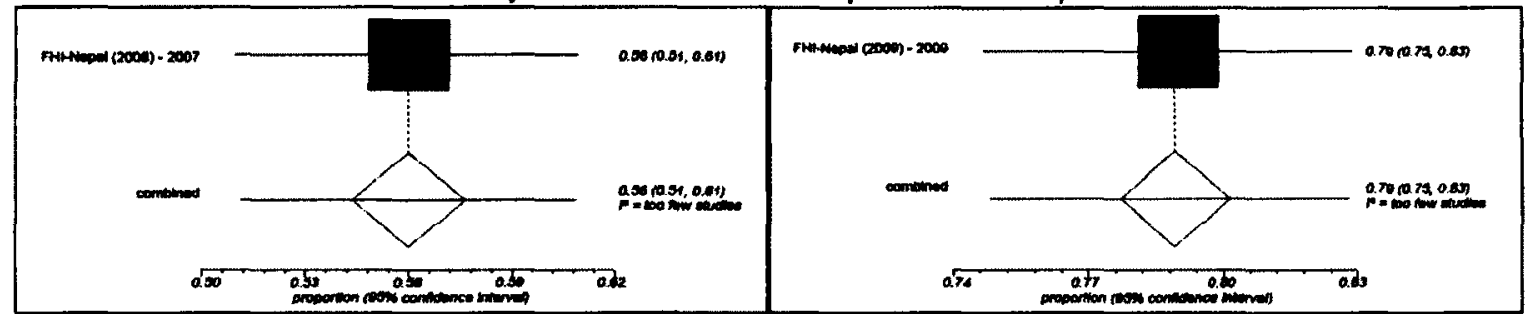


PAKISTAN

\begin{tabular}{|c|c|c|c|c|c|c|}
\hline \multicolumn{2}{|l|}{ PAKISTAN } & \multirow[b]{2}{*}{$\begin{array}{l}\text { HIV } \\
\text { Prevalence }\end{array}$} & \multirow[b]{2}{*}{$\begin{array}{l}\text { Inconsistent } \\
\text { Condom Use }\end{array}$} & \multirow[b]{2}{*}{$\begin{array}{l}\text { HIV Testing } \\
\text { (past year) }\end{array}$} & \multirow[b]{2}{*}{$\begin{array}{l}\text { Adequate HIV } \\
\text { Knowledge }\end{array}$} & \multirow[b]{2}{*}{$\begin{array}{l}\text { Exposure to } \\
\text { HIV Preventior }\end{array}$} \\
\hline Study & Year & & & & & \\
\hline NFI (2002) & 2002 & No data & $84 / 185$ & "ever" & $102 / 200$ & $10 / 200$ \\
\hline $\begin{array}{l}\text { NACP }(2005) ; \& \text { Bokhari, } \\
\text { et al. }(2007)\end{array}$ & 2004 & $20 / 1211$ & $626 / 686$ & "ever" & $542 / 1207$ & $16 / 1207$ \\
\hline NACP-CIDA (2005) & 2004 & $20 / 3248$ & $2594 / 3350$ & "ever" & $1423 / 3350$ & $78 / 3350$ \\
\hline Saleem, et al. (2004) & 2005 & No data & $195 / 202$ & No data & Wromg format & No data \\
\hline Rehan, et al. (2009) & 2007 & No data & $139 / 164$ & No data & $48 / 200$ & Nodate \\
\hline Collumblen, et al. (2008) & 2007 & Nodita & $351 / 799$ & "gver" & $322 / 889$ & No jata \\
\hline NACP-CIDA (2008) & 2008 & $84 / 2381$ & $1868 / 2391$ & "ever" & $999 / 2391$ & $319 / 2391$ \\
\hline
\end{tabular}

Dependent Variable 1: HIV prevalence

Dependent Varlable 2: Inconsistent condom use

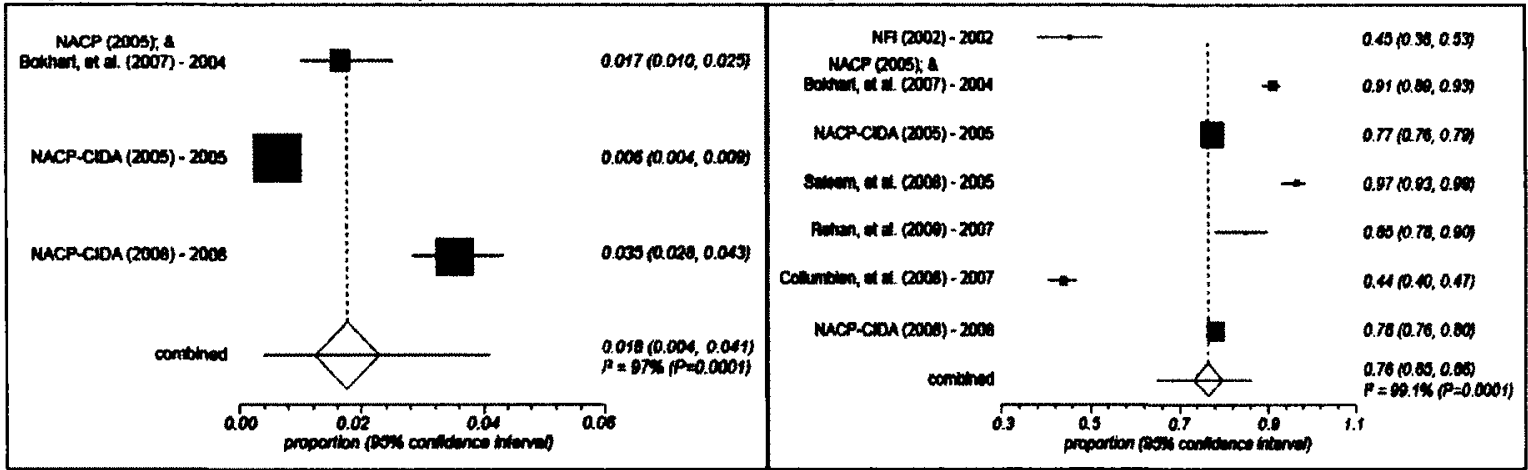

Dependent Variable 4: Adequate HIV knowledge Dependent Variable 5: Exposure to HIV prevention

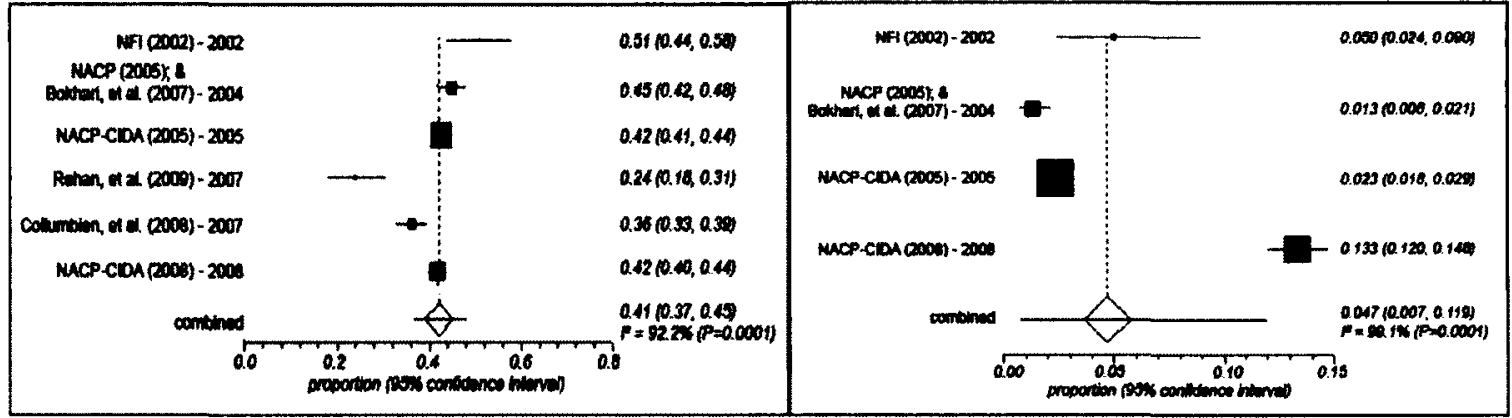


PAKISTAN

SEXUAL ORIENTATION \& GENDER IDENTITY HUMAN RIGHTS INDEX

\begin{tabular}{|l|l|l}
\hline Penalty for homosexuality (death penalty) & $(-1)$ Q 0 口 & [1]
\end{tabular}

\begin{tabular}{|l|llll}
\hline Penalty for homosexuality (lashings) & $-1 \square 0 \square$ & 0 & [1]
\end{tabular}

\begin{tabular}{ll|lll}
\hline Penalty for homosexuality (>10 years in jail) & -1 & 0 & 0 & {$[1]$}
\end{tabular}

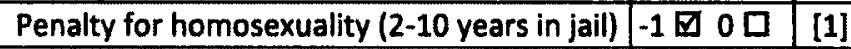

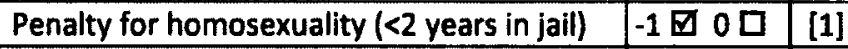

\begin{tabular}{|l|l|l|l}
\hline Penalty for homosexuality (fines) & -1000 & {$[1]$}
\end{tabular}

\begin{tabular}{l|l|l}
\hline Gender non-conformity sanctions & -1000 & [2]
\end{tabular}

\begin{tabular}{|l|l|l}
\hline Discriminatory laws \& practices & -1000 & {$[3]$}
\end{tabular}

\begin{tabular}{ll|lll}
\hline Reservations / not party to ICCPR \& ICESCR & -1 口 0 口 & [4]
\end{tabular}

\begin{tabular}{|l|l|l|}
\hline & Punitive Points $=$ & -9 \\
\hline Ratified ICCPR \& ICESCR & 0 【 $+1 \square$ & [4]
\end{tabular}

\begin{tabular}{ll|l|l}
\hline Gender-neutral sexual offences protection & 0 区 $+1 \square$ & {$[5]$}
\end{tabular}

\begin{tabular}{|l|l|l}
\hline Equal age of consent & 0 口 $+1 \square$ & [1] \\
\hline
\end{tabular}

\begin{tabular}{|l|l|l|}
\hline Supportive laws \& policies & $0 \mathrm{Q}+10$ & {$[1,3]$} \\
\hline
\end{tabular}

\begin{tabular}{l|l|l|}
\hline Anti-discrimination protection & $0 \mathrm{Q}+1 \mathrm{D}$ & {$[6]$} \\
\hline
\end{tabular}

\begin{tabular}{|l|l|l|}
\hline Sex reassignment options available & 0 Q $+1 \square$ & {$[2,7]$} \\
\hline
\end{tabular}

\begin{tabular}{|l|l|l|}
\hline Recognizes new or third gender (e.g. ID) & 0 Q $+1 \square$ & {$[2,7]$} \\
\hline
\end{tabular}

Right to marry/civil unions for Transgender

Same-sex marriage/civil unions

Protective Points $=$

TOTAL POINTS $=-9$

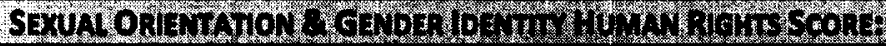

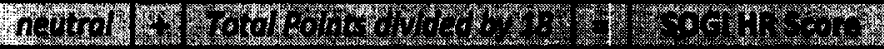
os
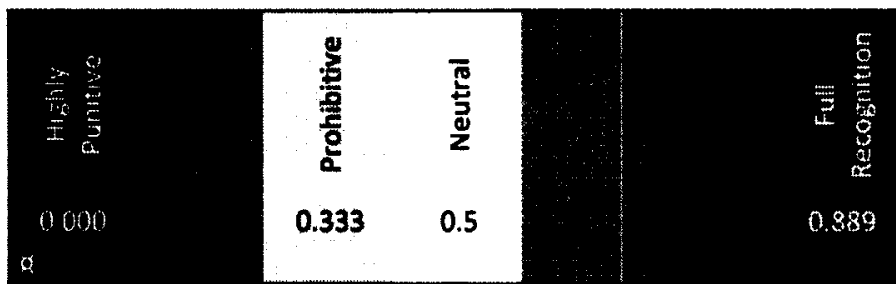

[8] Art. 496 of the Penal Code criminalizes having a marriage ceremony knowing that the marriage is unlawful, which carries a penalty of up to seven years in prison. In 2007, a married couple was imprisoned for perjury because the Court did not recognize the husband's gender (female-to-male transgender): [ilga.org, "PAKISTAN/Law"; and IRB, "Pakistan" (2007)]

\section{REFERENCES:}

[1] Article 377 of the Pakistan Penal Code (1860) criminalized "carnal intercourse against the order of nature" with penalties including "imprisonment for life, or with imprisonment of ... a term which shall not be less than two years nor more than ten years, and shall also be liable to fine."

Under Pakistani Islamic Law, referred to as the "Hudood Ordinance", homosexuality is punishable by up to 100 lashes and death by stoning (the same punishment as adultery). Islamic Law is mostly applied in tribes.

Homosexuality can be punished under secular law, Islamic law, or both.

** However, most sources reporting on sexual minority rights in Pakistan only list the penalties in Art. 377, and not the death penalty **

[2] Transvestism and sex reassignment are illegal: [RRT, "Pakistan" (2009)]

[3] Article 227 of the Constitution requires that all laws must be compatible with Islam, and Islamic law and tenets ban homosexuality. Articles 292 and 294 of the Penal Code criminalizes obscene material in print or in song. "Obscene" would probably include homosexuality due to Article 377 of the Penal Code. Despite these laws, there are organizations that work with MSM.

(4) Since the available epidemiological and behavioural data collected for Pakistan range form 1998-2008, Pakistan's ratification of the ICCPR (2010) and the ICESCR (2008) are deemed to have had no impact on the SOGl Human Rights score during the years under examination: [treaties.un.org]

[5] The rape and sexual exploitation provisions of the Pakistan Suppression of Prostitution Ordinance (1961) are gender specific and only apply to women and girls. Further more, within the Pashtun community it is common for middleaged men to have a young boyfriend: [IRB, "Pakistan" (2004)]

[6] No protection from discrimination based on sexual orientation or gender identity: [wikipedia, "LGBT rights in Pakistan]

[7] In 2008, the Lahore High Court ruled that sex change operations are permitted for individuals certified as suffering from Gender Identity Disorder. In 2009, the Supreme Court ruled that transgender people are citizens and are entitled to the benefits and protection of the law: [Godwin (2010) p. 42]

Due to their dates, these decisions are not included in the SOGI Human Rights score. 


\section{PHILIPPINES}

PHILPPINES

\begin{tabular}{|c|c|c|c|c|c|c|}
\hline Study & Year & $\begin{array}{l}\text { HIV } \\
\text { Prevalence }\end{array}$ & $\begin{array}{l}\text { Inconsistent } \\
\text { Condom Use }\end{array}$ & $\begin{array}{l}\text { HIV Testing } \\
\text { (past year) }\end{array}$ & $\begin{array}{l}\text { Adequate HIV } \\
\text { Knowledge }\end{array}$ & $\begin{array}{l}\text { Exposure to } \\
\text { HIV Prevention }\end{array}$ \\
\hline Ramos-Jimenez \& Lee (2000) & 1999 & No data & $81 / 115$ & No datat & No date & No data \\
\hline Mateo, et al. (2004) & 2000 & $0 / 784$ & No data & No tata & Nodata & No data \\
\hline Mateo, et al. (2004) & 2001 & $1 / 783$ & No data & No dala & Nodata & No data \\
\hline Mateo, et al. (2004) & 2002 & $0 / 1120$ & Nodata & No data & No data & No data \\
\hline Mateo, et al. (2004) & 2003 & $1 / 900$ & No dola & No data & No data & No datio \\
\hline UNGASS, Phillppines (2008) & 2007 & $3 / 1059$ & $147 / 216$ & $161 / 1059$ & Wromg format & $196 / 1059$ \\
\hline UNGASS, Phillppines (2010) & 2009 & $45 / 4542$ & $2001 / 2929$ & $296 / 4367$ & Wrong format & $1278 / 4367$ \\
\hline \multicolumn{2}{|c|}{ COMBINED: } & $0.22 \%$ & $68 \%$ & $11 \%$ & No data & $24 \%$ \\
\hline
\end{tabular}

Dependent Variable 1: HIV prevalence

Dependent Variable 2: Inconsistent condom use

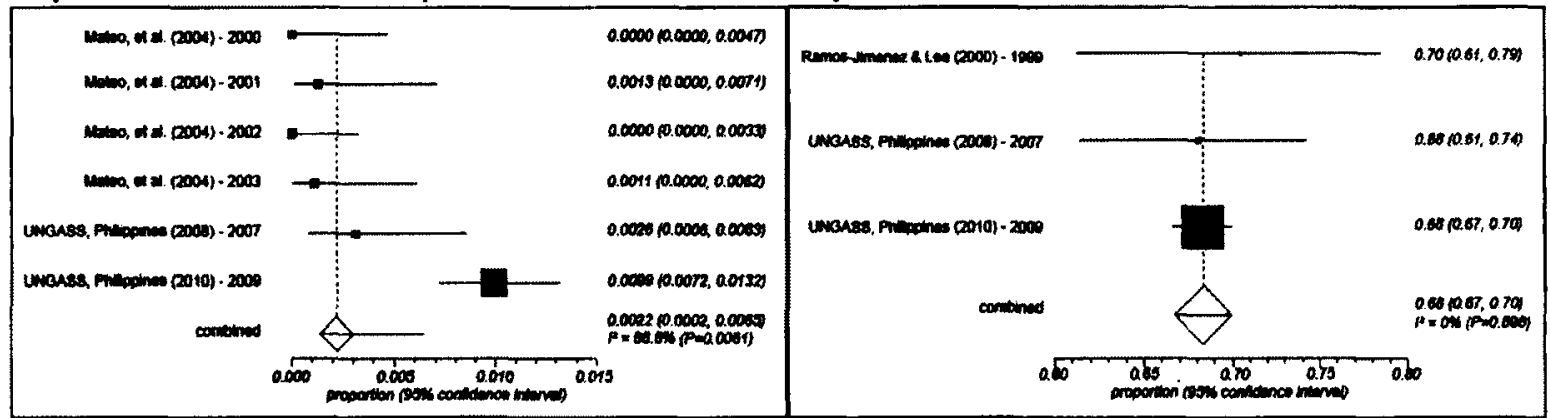

Dependent Variable 3: HIV testing (past year)

Dependent Variable 5: Exposure to HIV prevention

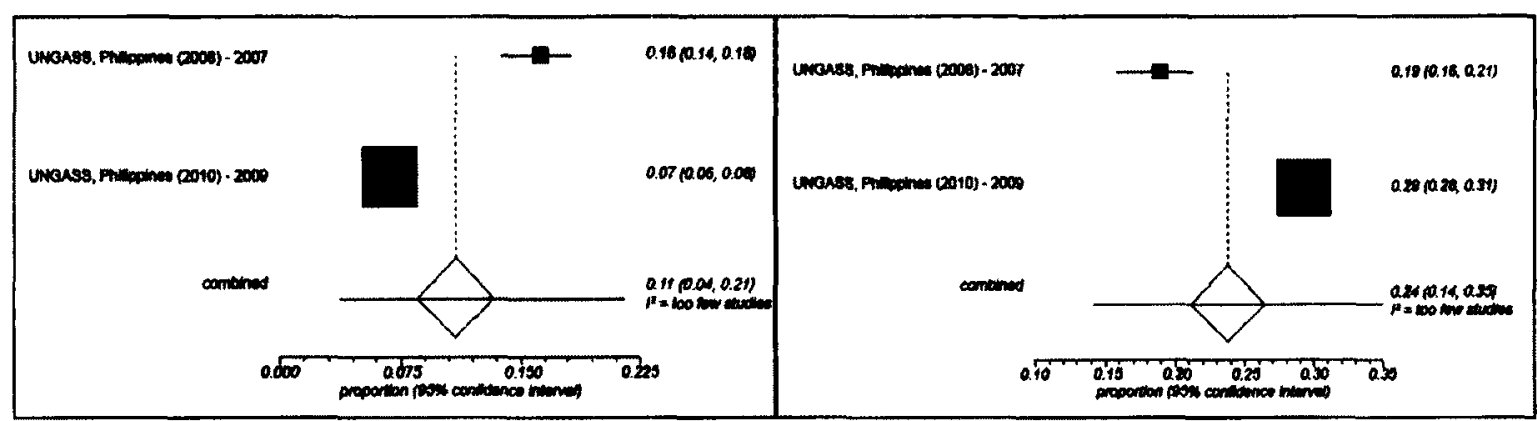




\section{SINGAPORE}

\begin{tabular}{|c|c|c|c|c|c|c|}
\hline \multicolumn{2}{|l|}{ SINGAPORE } & \multirow[b]{2}{*}{$\begin{array}{l}\text { HIV } \\
\text { Prevalence }\end{array}$} & \multirow[b]{2}{*}{$\begin{array}{l}\text { Inconsistent } \\
\text { Condom Use }\end{array}$} & \multirow[b]{2}{*}{$\begin{array}{l}\text { HIV Testing } \\
\text { (past year) }\end{array}$} & \multirow[b]{2}{*}{$\begin{array}{l}\text { Adequate HIV } \\
\text { Knowledge }\end{array}$} & \multirow[b]{2}{*}{$\begin{array}{l}\text { Exposure to } \\
\text { HIV Prevention }\end{array}$} \\
\hline Study & Year & & & & & \\
\hline Toh, et al. (2008) & 2007 & $41 / 967$ & No data & No data & Nodata & No data \\
\hline Toh (2009) & 2009 & $76 / 1994$ & $837 / 1994$ & $977 / 1994$ & Notata & No diata \\
\hline & BINED: & $3.98 \%$ & $42 \%$ & $49 \%$ & No datis & No data \\
\hline
\end{tabular}

Dependent Variable 1: HIV prevalence Dependent Variable 2: Inconsistent condom use

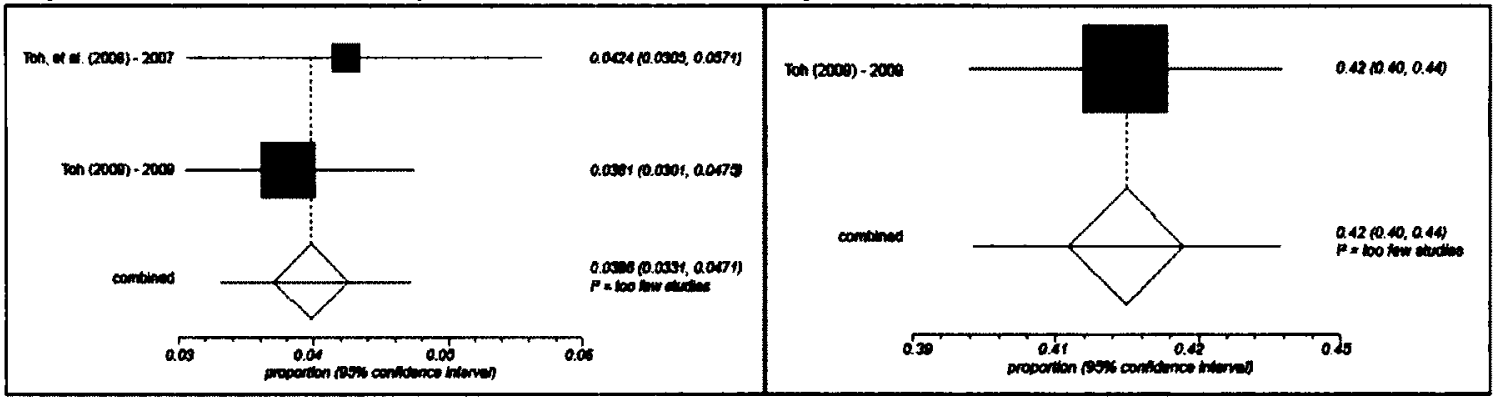

Dependent Variable 3: HIV testing (past year)

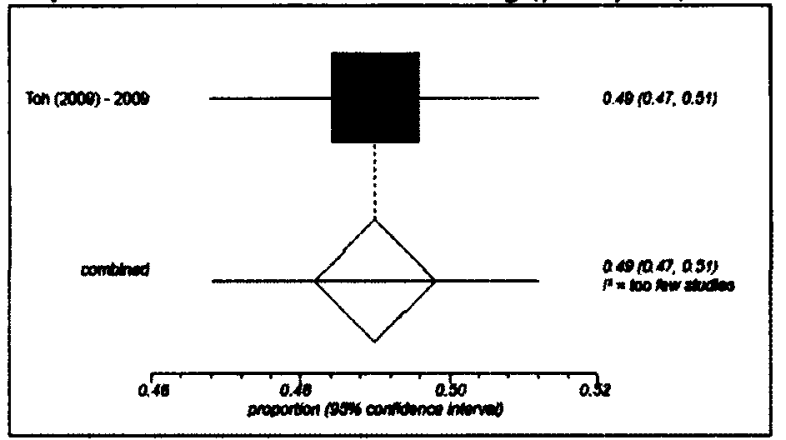


SINGAPORE

\section{Sexual Orientation \& Gender IDENTITY Human Rights Index}

\begin{tabular}{|l|lll}
\hline Penalty for homosexuality (death penalty) & -100 0 & {$[1]$}
\end{tabular}

\begin{tabular}{|l|lll}
\hline Penalty for homosexuality (lashings) & -100 0 [1]
\end{tabular}

Penalty for homosexuality (>10 years in jail) -100 O

Penalty for homosexuality (2-10 years in jail) -1000 [ 00

Penalty for homosexuality (<2 years in jail) -1000 [1]

\begin{tabular}{|l|l|l}
\hline Penalty for homosexuality (fines) & $-100 \square$ & {$[1]$}
\end{tabular}

\begin{tabular}{llll}
\hline Gender non-conformity sanctions & $-100 \mathrm{O}$ & {$[6]$}
\end{tabular}

\begin{tabular}{|l|l|l}
\hline Discriminatory laws \& practices & $-100 \square$ & [2]
\end{tabular}

Reservations / not party to ICCPR \& ICESCR -10 O 0 口 [3]

\begin{tabular}{|l|l|l|}
\hline \multicolumn{1}{|c|}{ Punitive Points $=$} & -5 \\
\hline Ratified ICCPR \& ICESCR & $0 \square+1 \square$ & {$[3]$} \\
\hline Gender-neutral sexual offences protection & $0 \square+1 \bar{\square}$ & {$[4]$}
\end{tabular}

Equal age of consent

Supportive laws \& policies

Anti-discrimination protection

Sex reassignment options available

Recognizes new or third gender (e.g. ID)

Right to marry/civil unions for Transgender

Same-sex marriage/civil unions

Protective Points $=$

TOTAL POINTS $=-1$

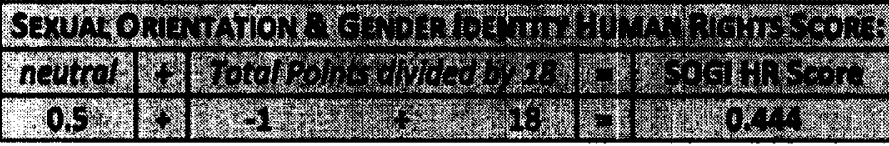
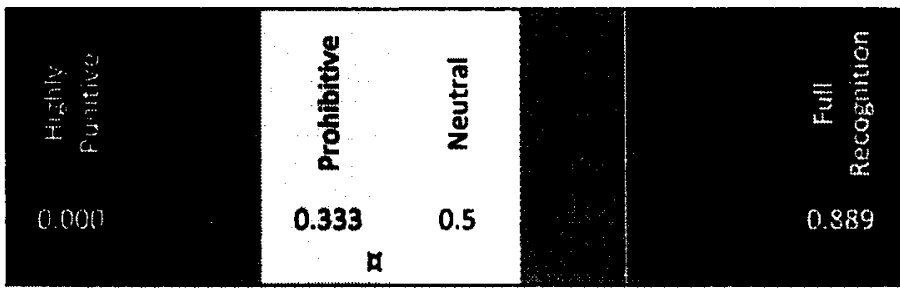

[5] The Prime Minister said in 2007 that s.377A would not be actively enforced, allowing homosexuals to live their private lives without harassment, though not the same as an official repeal: [UNESCO (2011) p.36]

Since 2009, people participated in Pink Dot (a public rally to support the GLBT community). This happened after the years for which there is epidemiological data.

[6] No anti-discrimination protection based on sexual orientation or gender identity exists.

(7) Sex reassignment has been legal since 1973. Identity documents (except for birth certificates) can be change after sex reassignment: [Godwin (2010) p.78]

[8] The Women's Charter was amended in 1996, prohibiting (and voiding) same-sex marriages in Article 12(1), while recognizing marriages between post-operative transgenders and someone of their previous sex in Article 12(2): [UNESCO (2011), p. 38]

\section{REFERENCES:}

[1) Section 377A of the Singapore Penal Code: "Any male person who, in public or private, commits, or abets the commission of, or procures or attempts to procure the commission by any male person of, any act of gross indecency with another male person. shall be punished with imprisonment for a term which may extend to 2 ycars."

Like all the former British colonies in Asia, the Singapore Penal Code had a section 377 (camal knowledge against the order of nature). In 2007, section 377 was repealed and replaced with the crime of necrophilia. According to the rule against redundancies, the prohibited acts in sections 377 and 377A were not the same. Therefore, when the repeal took effect in 2008, anal and oral intercourse were legalized for heterosexuals and maybe for homosexuals as well as. It is believed that the offences covered in section 377A are for nonpenetrative acts: [UNESCO (2011) p.37]

Sexual minorities are charged and harassed under Sec. 354 "outrage of modesty" and Sec. 294(a) "doing an obscene act in public" of the Penal Code, and "indecent behaviour" in Art. 20 of the Miscellaneous Offences Act.

[2] Sexual minorities in the Armed Forces are medically downgraded as a Category 302 (a medical code given to personnel who have sexual disorders, such as homosexuality and gender confusion): [UNESCO (2011) p.39]

Section 5.2 of the Free-to-Air Television Programme Code (2004) prohibits broadcasting any program that "promotes, justifies or glamorizes" gay lifestyles. Associations need to be approved and registered in order to be legal. According to Sec. 4(2) of the Societies Act, groups are prohibited if they are likely to be used for unlawful purposes or would be contrary to the national interest for society.

Although in 2003, homosexuals were allowed to hold sensistive civil servant positions, openly gay homosexuals are still barred from a Foreign Affairs appointment involving classified/sensitive information: [UNESCO (2011) p.40]

[3] Not party to the ICCPR or the ICESCR: [treaties.un.org]

[4] Section 376 criminalizes non-consensual sexual assault by penetration. Section $376 \mathrm{~A}$ criminalizes sexual assault by penetration with a minor under the age of 16 . Sections 363 and 374 protect people under 21 from sexual exploitation. All of these provisions are gender inclusive. 
SRI LANKA

\begin{tabular}{|c|c|c|c|c|c|c|}
\hline Study & Year & $\begin{array}{l}\text { HIV } \\
\text { Prevalence } \\
\end{array}$ & $\begin{array}{l}\text { Inconsistent } \\
\text { Condom Use }\end{array}$ & $\begin{array}{l}\text { HIV Testing } \\
\text { (past year) }\end{array}$ & $\begin{array}{l}\text { Adequate HIV } \\
\text { Knowledge }\end{array}$ & $\begin{array}{l}\text { Exposure to } \\
\text { HIV Prevention }\end{array}$ \\
\hline NASP (2007) & 2006 & No data & $240 / 446$ & $93 / 854$ & $607 / 846$ & No dato \\
\hline Arlyaratne, et al. (2007) & 2007 & No data & $282 / 311$ & "ever" & $428 / 494$ & $161 / 494$ \\
\hline $\operatorname{NASP}(2010)$ & 2009 & $2 / 413$ & No dala & No data & No dota & No data \\
\hline
\end{tabular}

Dependent Variable 1: HIV prevalence

Dependent Varlable 2: Inconsistent condom use

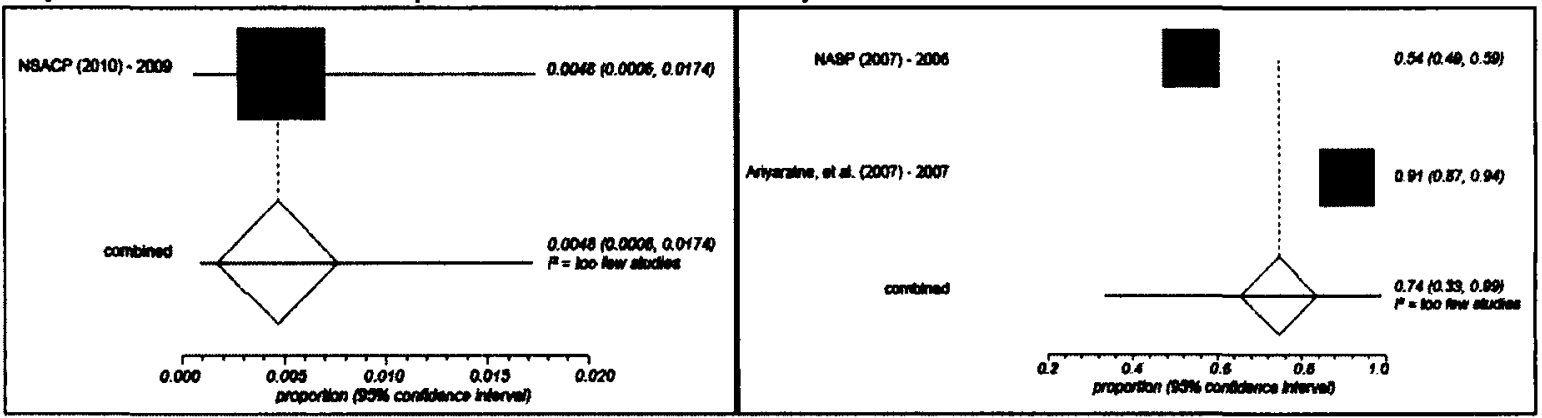

Dependent Varlable 3: HIV testing (past year) Dependent Variable 4: Adequate HIV knowledge

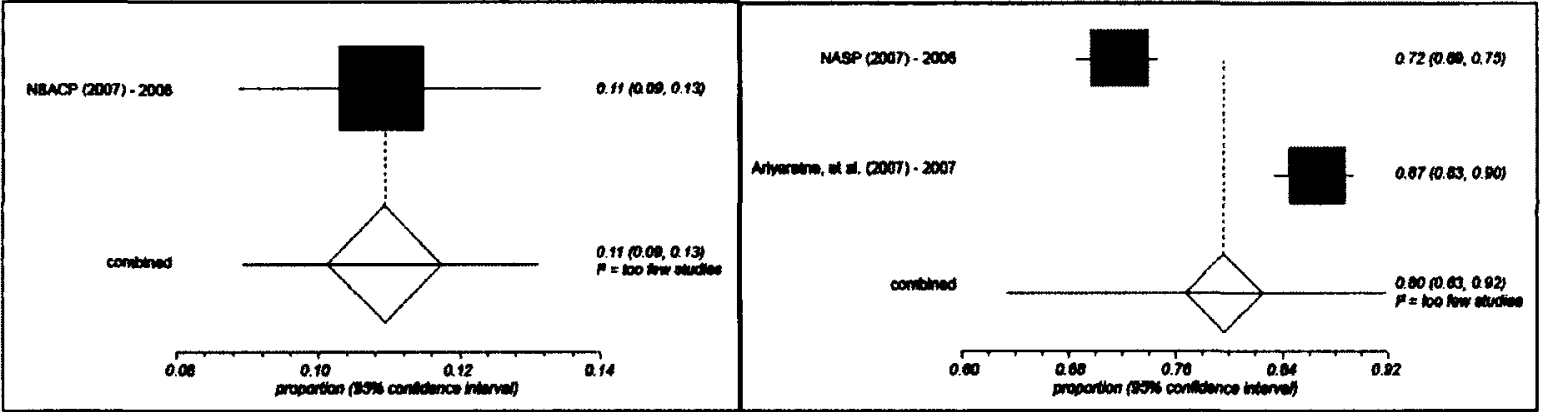

Dependent Variable 5: Exposure to HIV prevention services

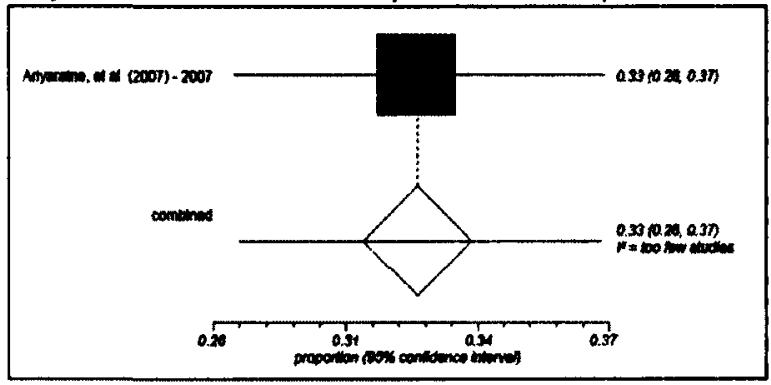




\section{SRI LANKA \\ SEXUAL ORIENTATION \& GENDER IDENTITY HUMAN RIGHTS INDEX}

$\left.\begin{array}{|l|ll|l}\hline \text { Penalty for homosexuality (death penalty) } & -1 & 0 & 0\end{array}\right]$

\begin{tabular}{|l|l|l}
\hline Penalty for homosexuality (lashings) & -1000 & [2]
\end{tabular}

\begin{tabular}{llll}
\hline Penalty for homosexuality ( $>10$ years in jail) & -1000 & {$[1]$}
\end{tabular}

Penalty for homosexuality (2-10 years in jail) -100 口 0 [1]

Penalty for homosexuality (<2 years in jail) $1-1000$ [ 0 [1]

\begin{tabular}{|l|l|l|}
\hline Penalty for homosexuality (fines) & -1000 & [1] \\
\hline
\end{tabular}

\begin{tabular}{ll|l|l|}
\hline Gender non-conformity sanctions & $-100 \square$ & $\mathrm{n} / \mathrm{d}$ \\
\hline
\end{tabular}

\begin{tabular}{|l|l|l|}
\hline Discriminatory laws \& practices & $-100 \mathrm{Q}$ & $\mathrm{n} / \mathrm{d}$ \\
\hline
\end{tabular}

\begin{tabular}{|l|l|l|}
\hline Reservations / not party to ICCPR \& ICESCR & -100 0 [2] \\
\hline
\end{tabular}

\begin{tabular}{|c|c|c|}
\hline Punitive Points = & -5 & \\
\hline Ratified ICCPR \& ICESCR & $0 \square+1 \square$ & [2] \\
\hline Gender-neutral sexual offences protection & $0 \square+1 \square$ & [3] \\
\hline
\end{tabular}

\begin{tabular}{|l|l|l}
\hline Equal age of consent & $0 \square+1 \square$ & {$[1]$}
\end{tabular}

\begin{tabular}{|l|l|l|}
\hline Supportive laws \& policies & $0 \mathrm{Q}+1 \square$ & $\mathrm{n} / \mathrm{d}$ \\
\hline
\end{tabular}

\begin{tabular}{|l|l|l|}
\hline Anti-discrimination protection & 0 日 $+1 \square$ & {$[4$} \\
\hline
\end{tabular}

\begin{tabular}{|l|l|l|}
\hline Sex reassignment options available & 0 日 +10 & {$[5]$} \\
\hline
\end{tabular}

\begin{tabular}{|l|l|l|}
\hline Recognizes new or third gender (e.g. ID) & $0 \mathrm{~V}+1 \mathrm{I}$ & [5 \\
\hline
\end{tabular}

\begin{tabular}{|l|l|l}
\hline Right to marry/civil unions for Transgender & $0 \mathrm{Q}+1 \mathrm{D}$ & {$[1]$}
\end{tabular}

\begin{tabular}{|l|l|l|}
\hline Same-sex marriage/civil unions & 0 甘 $+1 \square$ & {$[1]$} \\
\hline
\end{tabular}

Protective Points $=$ TOTAL POINTS =
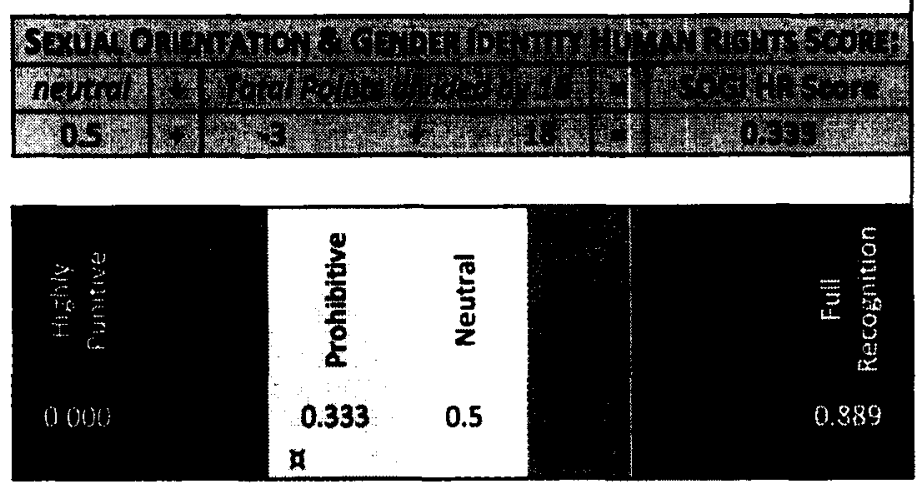

\section{REFERENCES:}

[1] Like Section 377 of the Indian Penal Code, Section 365 of the Sri Lankan Penal Code (1883) criminalizes "carnal intercourse against the order of nature" which carries a penalty of up to 10 years in prison. Section 365A criminalizes "gross indecency", which carries penalties of up to 2 years in prison, fines, or both. The 1995 amendment to the Penal Code changed the word "males" to "persons" in section $365 \mathrm{~A}$, making the offence applicable to lesbians.

Section 9 of the Vagrants Ordinance prohibits systematically procuring persons for the purposes of illicit or unnatural sexual intercourse. The penalties include up to 2 years in prison, fines and whipping (for men only).

[2] Acceded to both the ICCPR (1980) and the ICESCR (1980): [treaties.un.org]

[3] Section 363 "Rape" is defined in such a way that only women can be victims. However, section $365 \mathrm{~B}$ provides an equal penalty for nonconsensual sexual acts of gross indecency. Furthermore, the 1995 amendment to the Penal Code added protection for children from sexual crimes. Sections 365 and $365 \mathrm{~A}$ were changed to add a larger penalty for those over 18 who commit unnatural sexual intercourse or gross indecency against a person under 16 . The new penalties are the same as those for "rape" against girls under 16 . Finally, section $360 \mathrm{~A}$ "procuring" protects men and women from sexual exploitation.

[4] No anti-discrimination protection based on sexual orientation or gender identity exists.

According to the NGO Shadow Report to the Committee on the Elimination of All Forms of Discrimination Against Women, there is a loophole in the law that allows doctors to perform sex reassignment to bring a person's gender in line with their identity documents (putting the "cart before the horse" [WSG Sri Lanka (2011) p.5]

Doctors risk losing their medical license if the change a person's gender to the opposite of what the identity document says. Since this area is largely unregulated and taboo, it is not really practical for transgender people to have sex reassignment or change their documents: [WSG Sri Lanka (2011)]

[n/d] no points are assigned for missing data. 
TAIWAN

TAIWAN

\begin{tabular}{|c|c|c|c|c|c|c|}
\hline Study & Year & $\begin{array}{l}\text { HIV } \\
\text { Prevalence }\end{array}$ & $\begin{array}{l}\text { Inconsistent } \\
\text { Condom Use }\end{array}$ & $\begin{array}{l}\text { HIV Testing } \\
\text { (past year) }\end{array}$ & $\begin{array}{l}\text { Adequate HIV } \\
\text { Knowledge }\end{array}$ & $\begin{array}{l}\text { Exposure to } \\
\text { HIV Prevention }\end{array}$ \\
\hline Hseih, et al. (2006) & 2000 & $24 / 273$ & No data & No datat & Nodata & No data \\
\hline Lai, S., et al. (2004) & 2000 & $33 / 348$ & No data & No dota & No data & No data \\
\hline Hseih, et al. (2006) & 2001 & $6 / 139$ & No datio & No data & No data & No tiata \\
\hline Hseih, et al. (2006) & 2001 & $12 / 178$ & No data & No data & No data & No data \\
\hline Lai, S., et al. (2004) & 2001 & $16 / 307$ & No dota & No data & No data & No data \\
\hline Hseih, et al. (2006) & 2002 & $19 / 213$ & No dota & No data & No data & No data \\
\hline Hselh, et al. (2006) & 2002 & $13 / 265$ & No data & Nodata & Nodota & No diata \\
\hline Lal, S., et al. (2004) & 2002 & $15 / 260$ & Nodata & No data & No data & No data \\
\hline Lal, S., et al. (2004) & 2003 & $38 / 549$ & $281 / 466$ & "ever" & No vata & No data \\
\hline \multicolumn{7}{|l|}{ Ko, et al. (2006); \& NCK } \\
\hline University (2006) & 2004 & $38 / 372$ & $121 / 370$ & "ever" & No dala & $269 / 451$ \\
\hline Yaoming University (2004) & 2004 & $71 / 983$ & $449 / 755$ & "ever" & $91 / 95$ & $458 / 774$ \\
\hline Yaoming University (2005) & 2005 & $36 / 459$ & $171 / 273$ & "ever" & No data & $171 / 273$ \\
\hline NCK University (2006) & 2006 & $6 / 107$ & $33 / 109$ & "over" & No data & $115 / 131$ \\
\hline
\end{tabular}

Dependent Variable 1: HIV prevalence

\begin{tabular}{|c|c|c|c|}
\hline 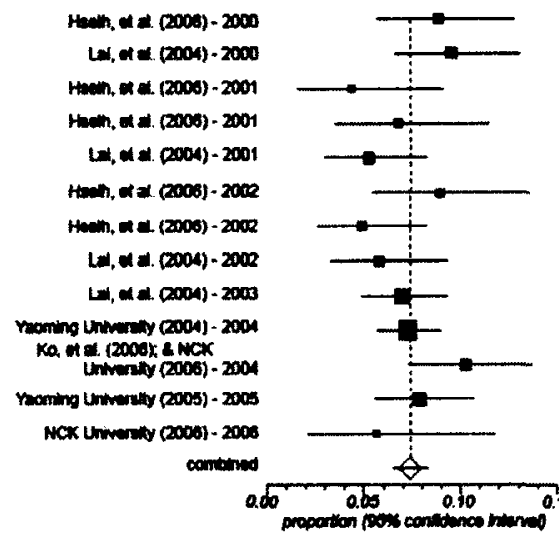 & 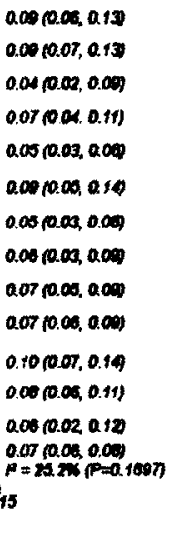 & 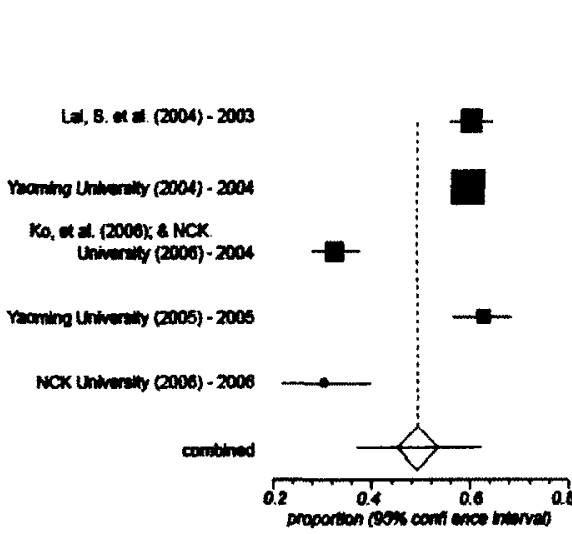 & $\begin{array}{l}0.63(0.57,0.60 \\
0.30(0.22,0.00 \\
0.00(0.37,0.62) \\
P=96.75,(P=0.0000)\end{array}$ \\
\hline
\end{tabular}

\section{Dependent Variable 4: Adequate HIV knowledge}

Dependent Variable 5: Exposure to HIV prevention

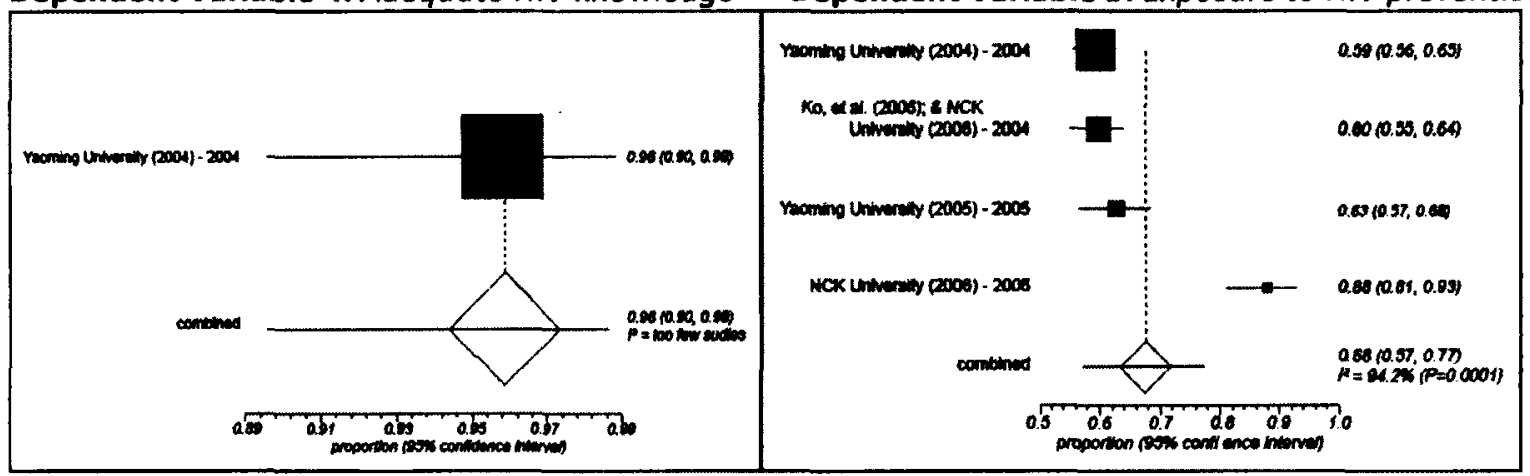


TAIWAN

SEXUAL ORIENTATION \& GENDER IOENTITY HUMAN RIGHTS INDEX

\begin{tabular}{|l|l|l}
\hline Penalty for homosexuality (death penalty) & $-100 \mathrm{O}$ & [1] \\
\hline
\end{tabular}

\begin{tabular}{|l|l|l}
\hline Penalty for homosexuality (lashings) & -100 [1]
\end{tabular}

Penalty for homosexuality (>10 years in jail) $-1000[1]$

\begin{tabular}{llll}
\hline Penalty for homosexuality (2-10 years in jail) & -100 Q & [1]
\end{tabular}

Penalty for homosexuality (<2 years in jail) $-100 \mathrm{Q}$ [1]

\begin{tabular}{|l|l|l}
\hline Penalty for homosexuality (fines) & $-100 \mathrm{O}$ & {$[1]$} \\
\hline
\end{tabular}

\begin{tabular}{ll|l}
\hline Gender non-conformity sanctions & $-100 \mathrm{D}$ & $\mathrm{n} / \mathrm{d}$ \\
\hline
\end{tabular}

\begin{tabular}{|l|l|l|}
\hline Discriminatory laws \& practices & $-100 \square$ & $\mathrm{n} / \mathrm{d}$ \\
\hline
\end{tabular}

\begin{tabular}{|l|lll}
\hline Reservations / not party to ICCPR \& ICESCR & -1 口 00 & [2] \\
\hline
\end{tabular}

\begin{tabular}{|l|l|l|}
\hline \multicolumn{1}{|c|}{ Punitive Points $=$} & \multicolumn{1}{|l}{} \\
\hline Ratified ICCPR \& ICESCR & 0 Q $+1 \square$ & [2]
\end{tabular}

\begin{tabular}{ll|l} 
Gender-neutral sexual offences protection & $0 \square+10$ & {$[3]$}
\end{tabular}

\begin{tabular}{l|l|l}
\hline Equal age of consent & $0 \square+10]$ & {$[4]$}
\end{tabular}

Supportive laws \& policies

Anti-discrimination protection

Sex reassignment options available

Recognizes new or third gender (e.g. ID)

Right to marry/civil unions for Transgender

Same-sex marriage/civil unions Protective Points $=$

TOTAL POINTS =
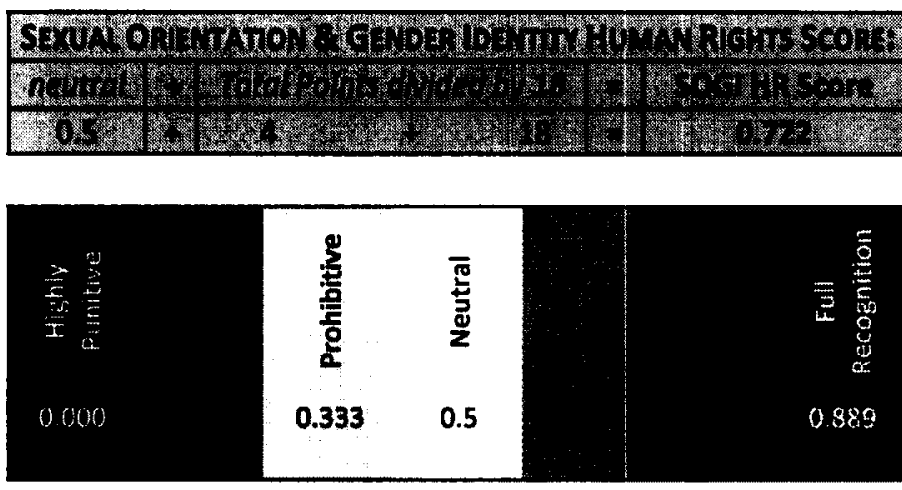

[8] In 2001 (or 2003), the Minister of Justice introduced the Basic Law On The Guarantees of Human Rights, which would have included a provision for sexual minorities to form families: "All people are entitled to the rights to get married and form families based on their free wills. The families formed by gays and lesbians can adopt children based on the law." However, the draft bill was eventually abandoned: [GayTimes, "Gay Taiwan"; Laurent (2005) p.185]

In 2003, the government introduced same-sex marriage legislation, but it proved to be too controversial. Thus, same-sex marriages are not recognized in Taiwan: [GayLawNet, "Tajwan"; wikipedia, "LGBT rights in the Republic of China"]

[n/d] no points are assigned for missing data.

\section{REFERENCES:}

[1] Homosexuality has been legal since 1896: [ILGA (2011) p. 8)]

[2] The available epidemiological and behavioural data collected for Taiwan range form 20002006. As such, Taiwan's 2009 "ratification" of the ICCPR and ICESCR (which was rejected by the UN due to the UN's "one-China policy") is deemed to have had no impact during the years under examination: [treaties.un.org]

[3] "Until a 1999 amendment that included samesex intercourse without consent as one type of rape, rape only applied to acts between members of the opposite sex.": [Laurent (2005) p. 185]

Section 296 and 296-1 of the Criminal Code prohibits sex slavery, with a penalty of up to 7 years. This law appears to be gender neutral, and effective at preventing sexual exploitation.

[4] Avert.org reports that the age of consent in Taiwan is 16 for heterosexual and homosexual acts: [GayTimes, "Gay Taiwan"]

[5] In 2008, the Gender Equality in Employment Act was amended to include protection from discrimination based on gender and sexual orientation. In 2004, the Gender Equality in Education Act added protection for student from discrimination based on gender and sexual orientation, and mandated that school take positive steps to improve their situation. In 2011, the Ministry of Education announced that textbooks will teach GLBT human rights: [Godwin (2010) p. 59]

In 2009 Taiwan passed implementing legislation for the ICCPR and ICESCR.

Since the available epidemiological and behavioural data collected for Taiwan range form 2000-2006, these recent developments do not impact the SOGI Human Rights score.

[6] Sex reassignment has been legal since 1986 (or 1988). Changing identity documents is only available to those who have completed their surgery. However, in 2008, the Health Department relaxed the regulation by allowing transgender to change their documents without genital reconstruction.

[7] "Under Taiwan's Civil Code, a marriage must 'not involve fraud or coercion,' but only a dozen or so transsexuals are currently married in Taiwan, and most of them have been with their partners since before their sex change operations. Thus no one here has ever married a transsexual unknowingly and then sued him or her for the deception." "unconfirmed* [Taiwan Panorama] 


\section{THAILAND}

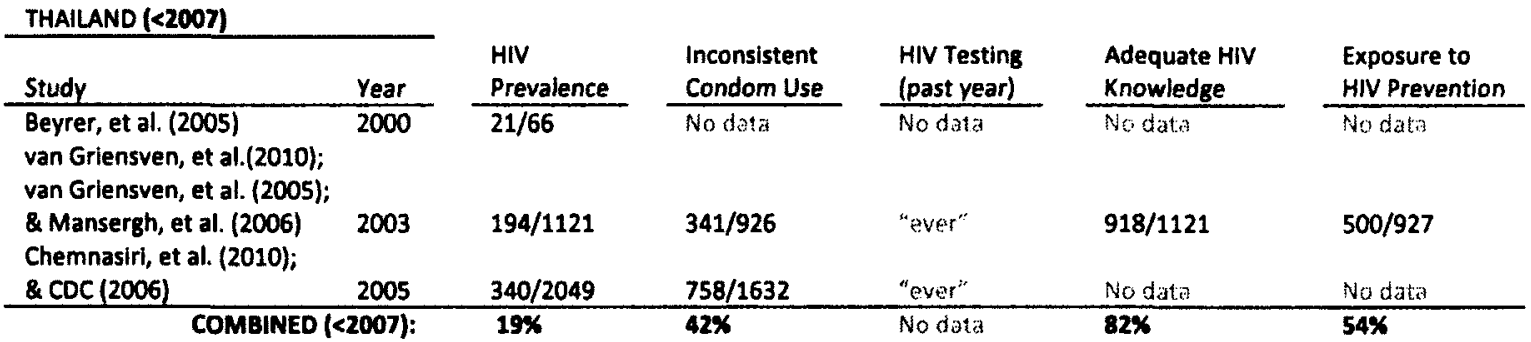

Dependent Variable 1: HIV prevalence

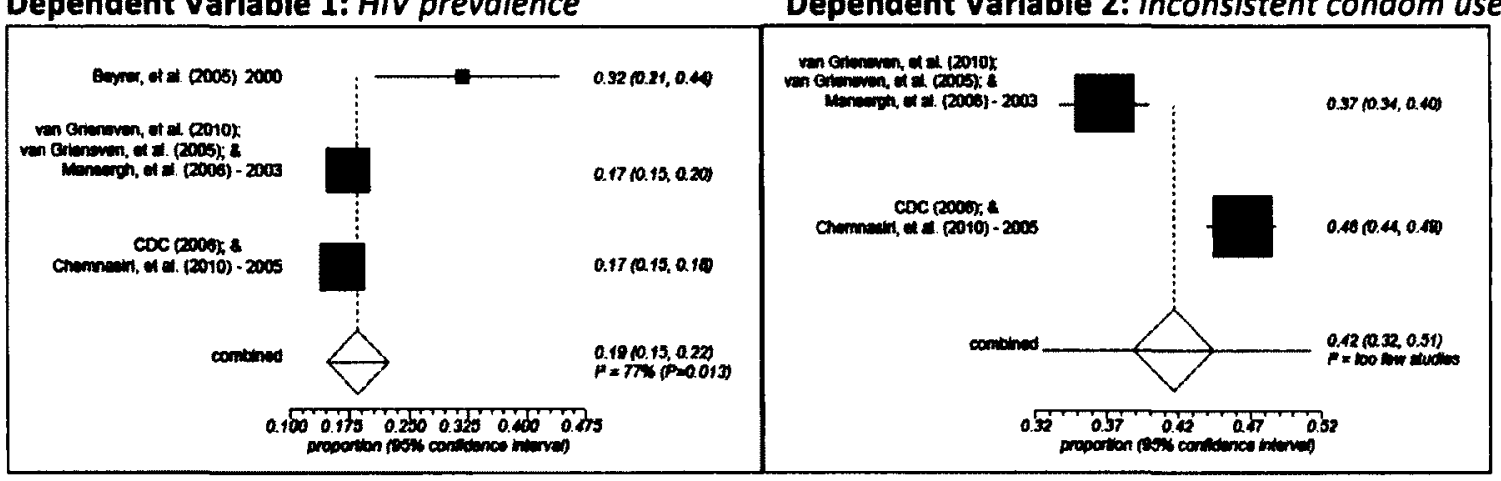

Dependent Variable 4: Adequate HIV knowledge

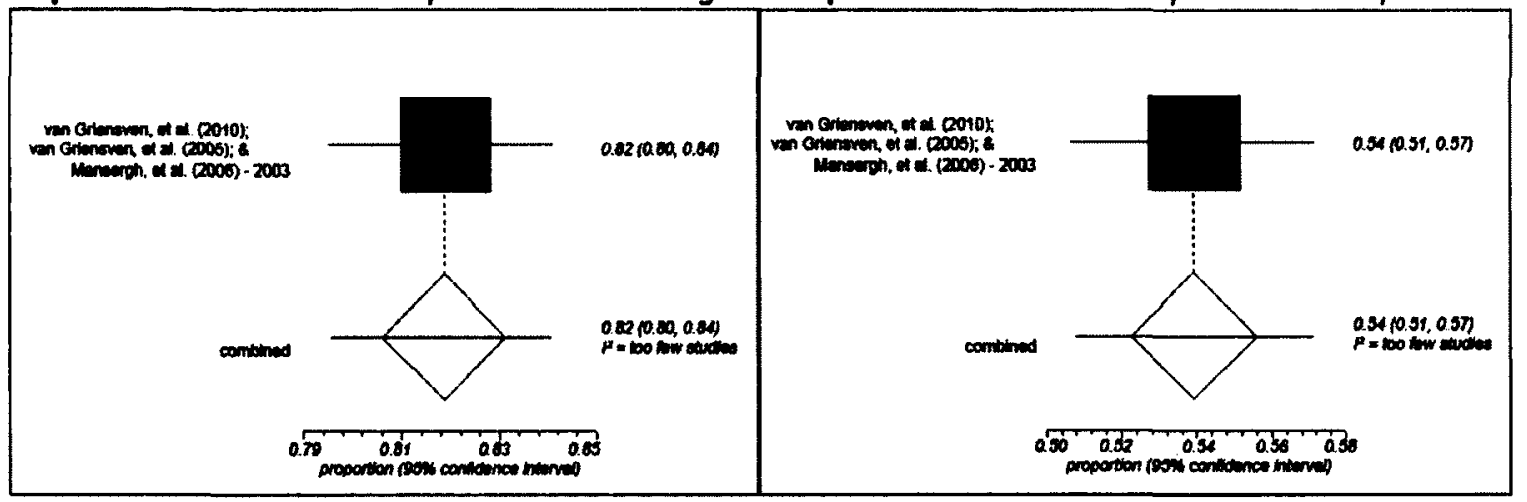


THAILAND

THAILAND $(>2007)$

\begin{tabular}{|c|c|c|c|c|c|c|}
\hline Study & Year & $\begin{array}{l}\text { HIV } \\
\text { Prevalence }\end{array}$ & $\begin{array}{l}\text { Inconsistent } \\
\text { Condom Use }\end{array}$ & $\begin{array}{l}\text { HV Testing } \\
\text { (past year) }\end{array}$ & $\begin{array}{l}\text { Adequate HIV } \\
\text { Knowledge }\end{array}$ & $\begin{array}{l}\text { Exposure to } \\
\text { HIV Prevention }\end{array}$ \\
\hline van Griensven, et al. (2010) & 2007 & $123 / 400$ & $65 / 189$ & "ever" & No data & Nodata \\
\hline UNGASS Thailand (2008) & 2007 & 223/906 & $28 / 237$ & $317 / 906$ & $747 / 906$ & No data \\
\hline van Griensven, et al. (2009) & 2008 & $361 / 1292$ & $566 / 1002$ & No datla & Nodata & No data \\
\hline CPHO (2010) & 2010 & $35 / 300$ & $92 / 208$ & No data & $251 / 300$ & No datia \\
\hline \multicolumn{2}{|c|}{ COMBINED (>2007): } & $24 \%$ & $57 \%$ & $35 \%$ & $83 \%$ & No data \\
\hline
\end{tabular}

Dependent Varlable 1: HIV prevalence

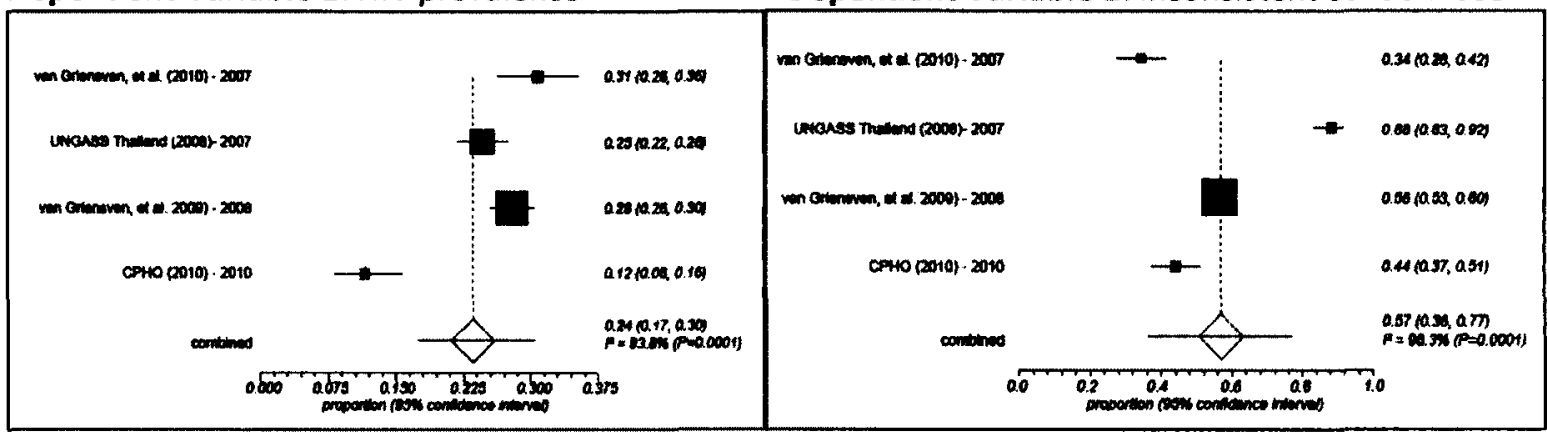

Dependent Variable 3: HIV testing (past year)

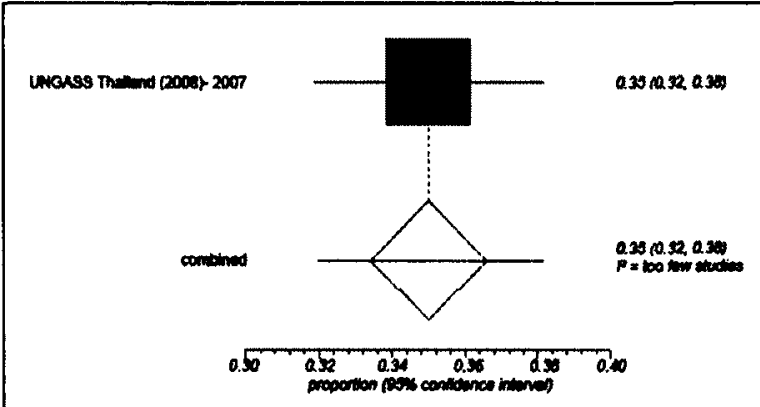

Dependent Variable 4: Adequate HIV knowledge

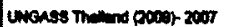

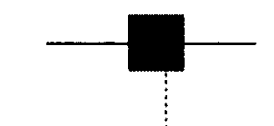

$0.0010 .00,0.004$

CN10 (2010) 2010

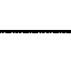

comanom

0.03 0.05, 0.0.45 $\mu=100$ inim thend consing

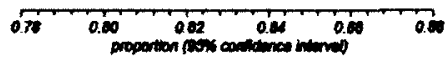


TIMOR LESTE

\begin{tabular}{|c|c|c|c|c|c|c|}
\hline Study & Year & $\begin{array}{l}\text { HIV } \\
\text { Prevalence }\end{array}$ & $\begin{array}{l}\text { Inconsistent } \\
\text { Condom Use }\end{array}$ & $\begin{array}{l}\text { HIV Testing } \\
\text { (past year) }\end{array}$ & $\begin{array}{l}\text { Adequate HIV } \\
\text { Knowledge }\end{array}$ & $\begin{array}{l}\text { Exposure to } \\
\text { HIV Prevention }\end{array}$ \\
\hline Pisani, et al. (2006) & 2003 & $1 / 110$ & $72 / 77$ & No data & $69 / 110$ & No data \\
\hline Lee, et al. (2008) & 2008 & No data & $187 / 228$ & "ever" & $49 / 52$ & $204 / 267$ \\
\hline
\end{tabular}

Dependent Variable 1: HIV prevalence Dependent Variable 2: Inconsistent condom use

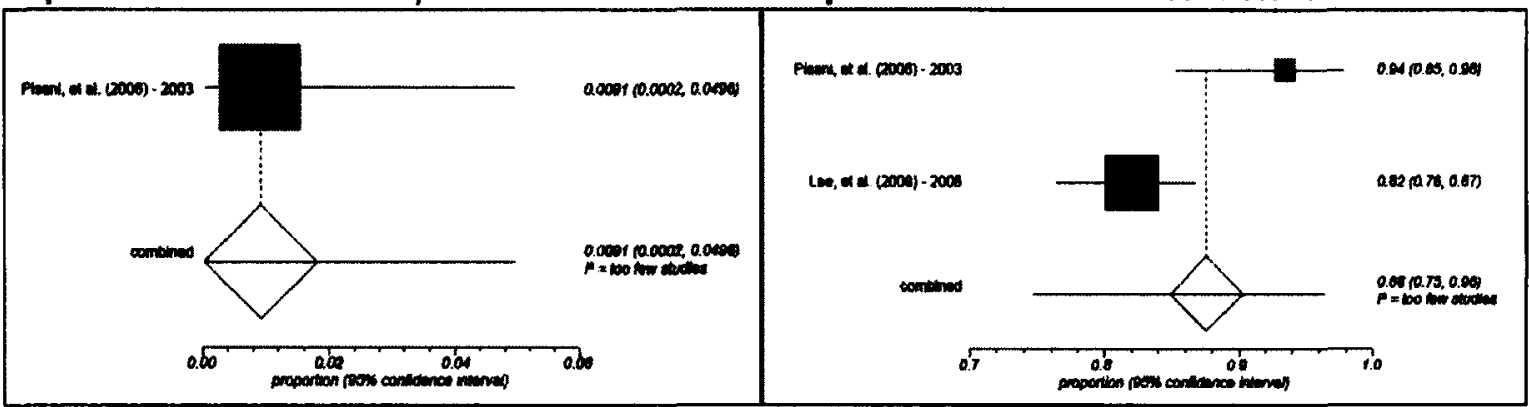

Dependent Variable 4: Adequate HIV knowledge

Dependent Variable 5: Exposure to HIV prevention

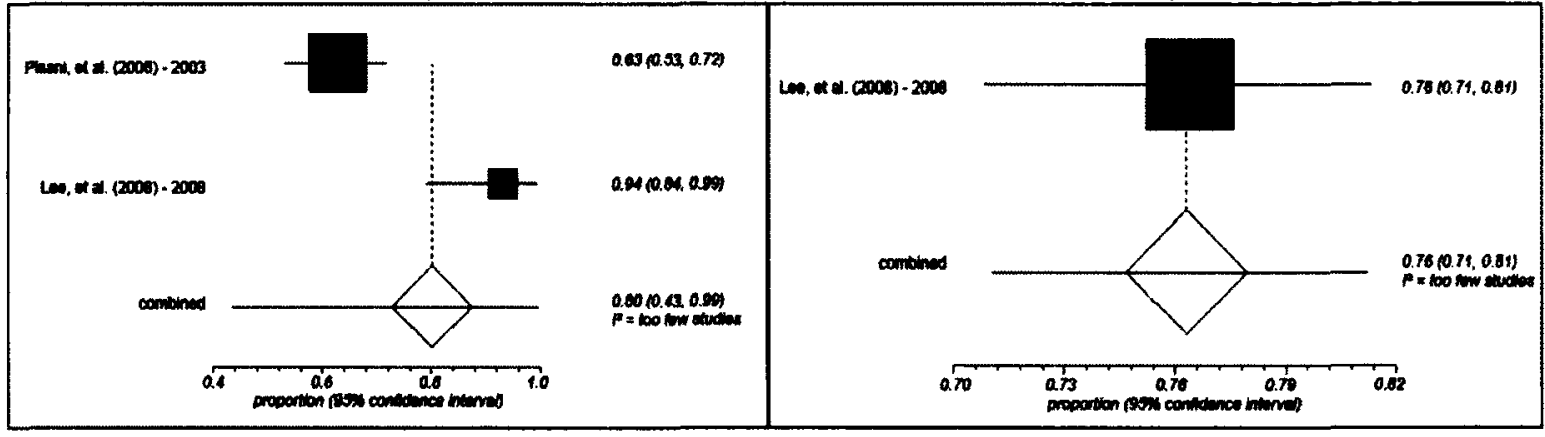




\section{VIETNAM}

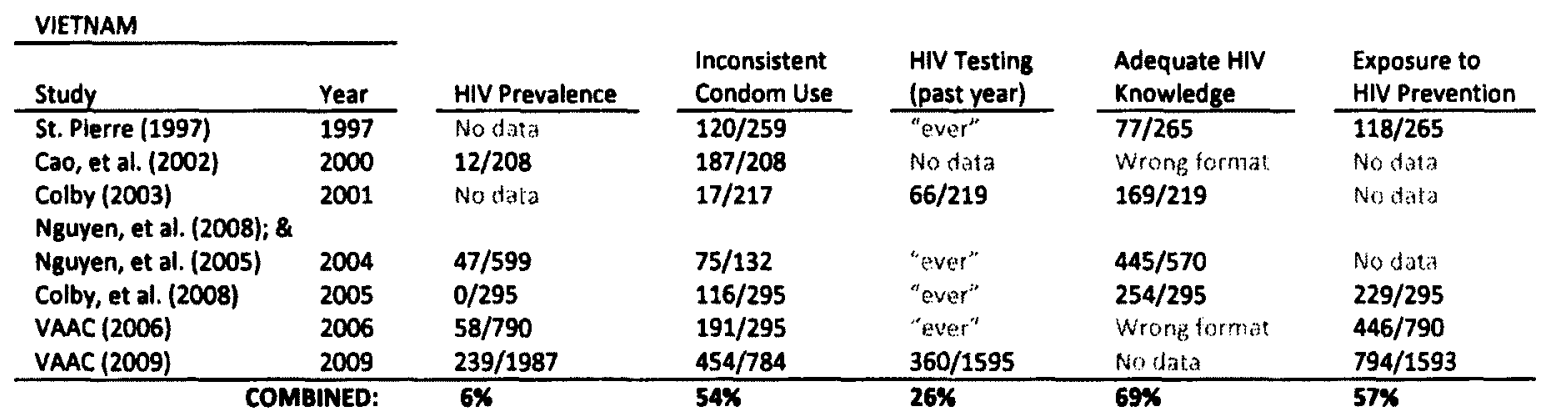

Dependent Variable 1: HIV prevalence Dependent Variable 2: Inconsistent condom use

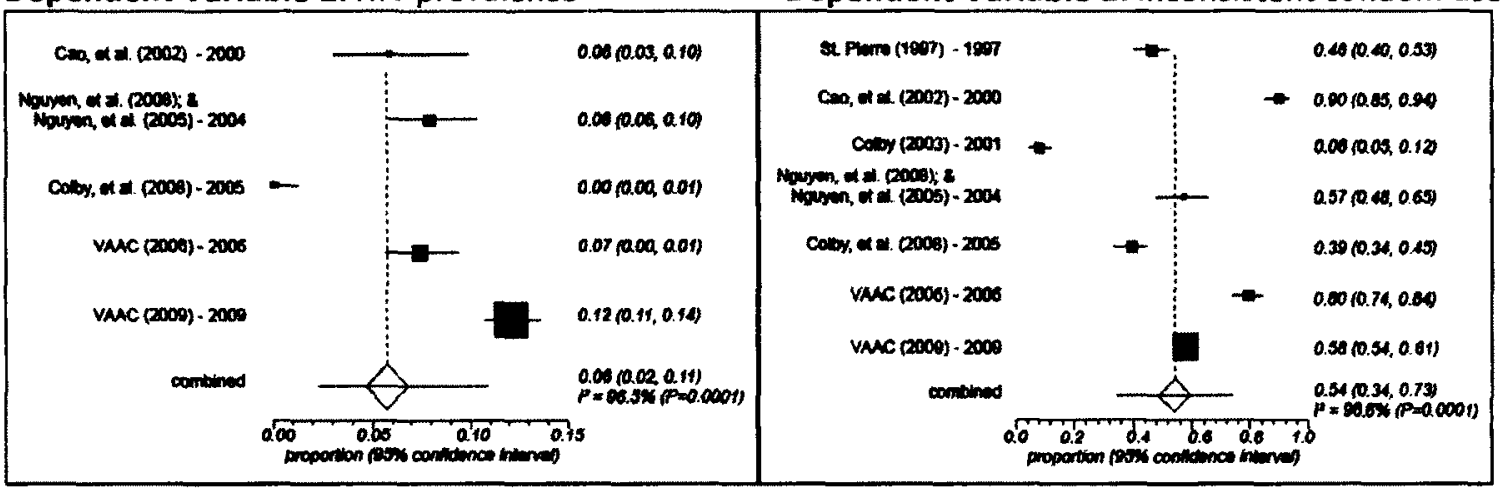

Dependent Variable 3: HIV testing (past year)

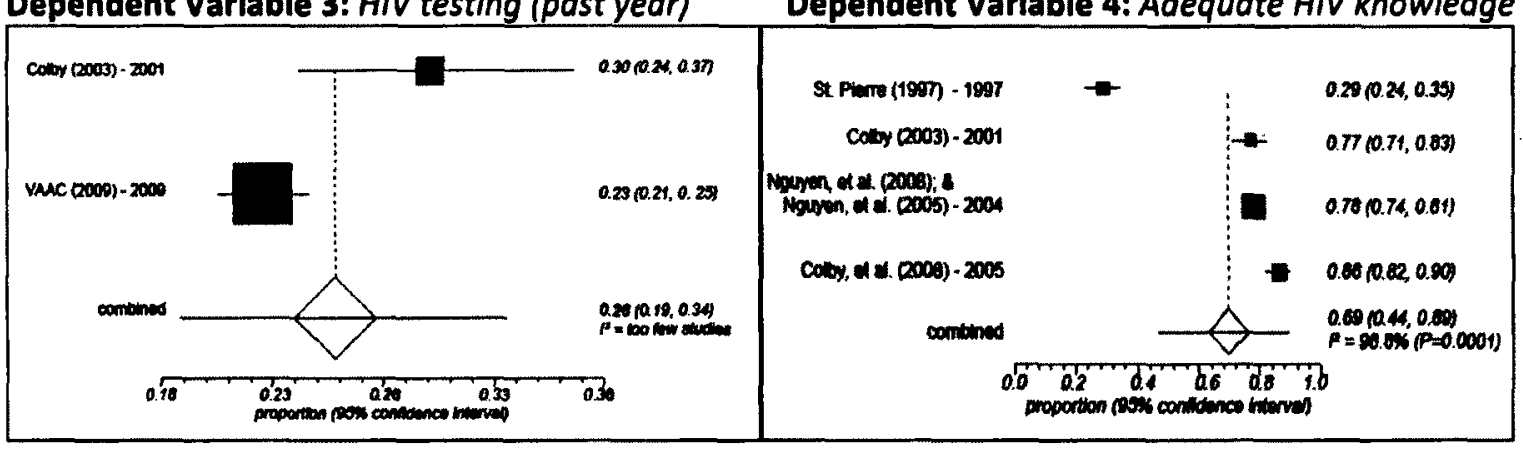

\section{Dependent Variable 5: Exposure to HIV prevention services}

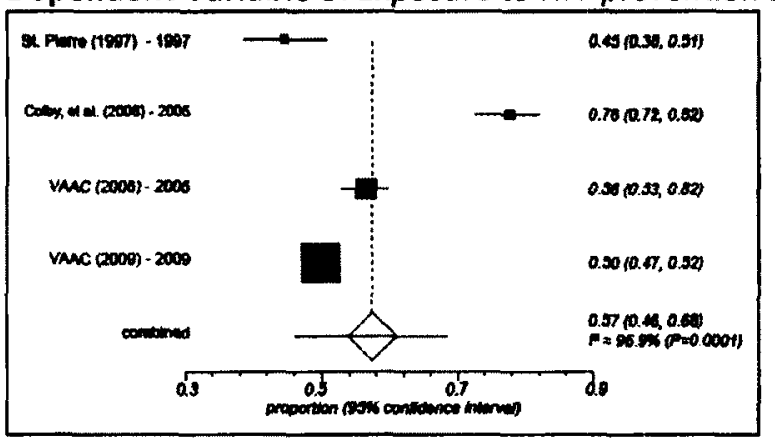


VIETNAM

\section{SEXUAL ORIENTATION \& GENDER IDENTTY HUMAN RIGHTS INDEX}

\begin{tabular}{|l|lll|l}
\hline Penalty for homosexuality (death penalty) & -10 & 0 & $\square$ & {$[1]$}
\end{tabular}

\begin{tabular}{|l|l|l}
\hline Penalty for homosexuality (lashings) & $-1 \square 0 \square$ & [1]
\end{tabular}

Penalty for homosexuality (>10 years in jail) $-100 \square[1]$

Penalty for homosexuality $(2-10$ years in jail) $-100 \mathrm{O}$

Penalty for homosexuality ( $<2$ years in jail) $-1 \square 0$ 口 $[1$

\begin{tabular}{l|l|l}
\hline Penalty for homosexuality (fines) & $-100 \mathrm{O}$ & [1
\end{tabular}

\begin{tabular}{|l|l|l}
\hline Gender non-conformity sanctions & $-100 \mathrm{Q}$ & {$[1]$}
\end{tabular}

\begin{tabular}{l|l|l}
\hline Discriminatory laws \& practices & -1 口 0 [2]
\end{tabular}

\begin{tabular}{|l|l|l}
\hline Reservations / not party to ICCPR \& ICESCR & -1000 & [3] \\
\hline
\end{tabular}

\begin{tabular}{|l|l|l|}
\hline & Punitive Points $=$ & -1 \\
\hline Ratified ICCPR \& ICESCR & $0 \square+1 \mathbb{Q}$ & {$[3]$} \\
\hline
\end{tabular}

\begin{tabular}{|l|l|l|}
\hline Gender-neutral sexual offences protection & $0 \square+10$ & {$[4]$}
\end{tabular}

Equal age of consent

Supportive laws $\&$ policies

Anti-discrimination protection

Sex reassignment options available

Recognizes new or third gender (e.g. ID)

Right to marry/civil unions for Transgender

Same-sex marriage/civil unions

Protective Points $=$

TOTAL POINTS $=+2$
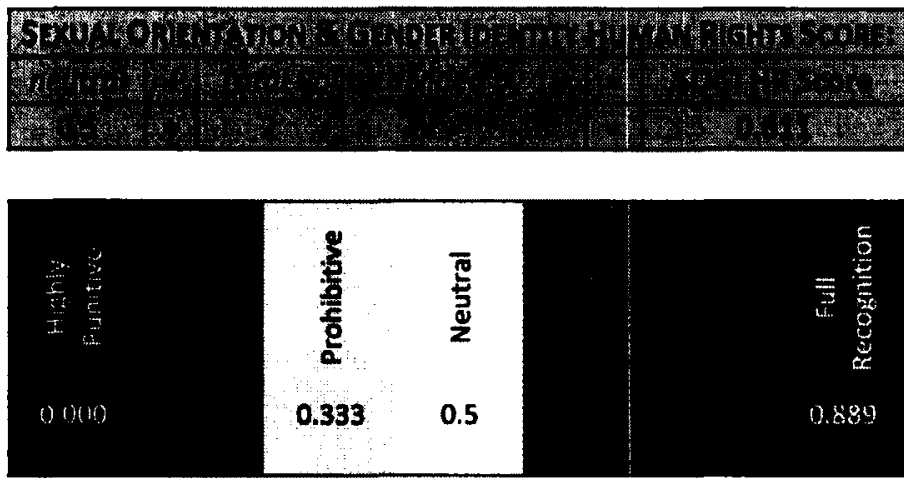

(8) Article 10(5) of the 2000 Marriage and Family Law expressly prohibits same-sex marriage.

Following a 1997 'marriage' between an Australian man and his boyfriend, two Vietnamese woman 'married' in 1998 . The Justice Minister decided to "put an end to the marrige", and had the two woman sign a documet promsing not ot live together: [RRT, "Vietnam" (2010)]

\section{REFERENCES:}

[1] Homosexuality has never been criminalized in Vietnam. Vietnam did not follow China when they criminalized sodomy during the Ching Dynasty $\left(18^{\text {th }}\right.$ century). France also did not impose any laws against sodomy, since it was not in their Napoleonic Code.

[2] "Vietnam does not allow the adoption of a child by a gay or lesbian person.": [adoptvietnam.org] The criminal code does prohibit "undermining public morality". This vague law could be used to harass gay people or gay rights organizations: [IRB, "Vietnam" (2010); Laurent (2005) p.192]

Police tend to turn a blind eye to crimes involving gay victims: [RRT, "Vietnam" (2010)]

[3] Acceded to both the ICCPR (1982) and the ICESCR (1982): [treaties.un.org]

14] The "rape" (sec. 111), "rape against children" (sec. 112), "forcible sexual intercourse" (sec. 113 , and "forcible sexual intercourse with children" of the Penal Code are all genderneutral: [worldlii.org/vn/legis/pc66]

With respect to sexual exploitation, section 119(2)(a) of the Penal Code criminalizes "trafficking" in women (not men) for the purpose of prostitution. Section 120(2)(g) criminalizes the trade in children for the purpose of prostitution, which is gender-neutral.

15] Age of consent appears to be 16 for both men and women, based on the provisions on "rape against children" and "forcible sexual intercourse with children" in the Penal Code.

[6] "There are no official records in the books of law to support sexual minorities. Under the guise of public health, and NGO funding, MSM are free to meet, to support, to receive HIV/AIDS info." [Alex Hoa; DoS (2010) p.25]

Homosexuals are not protected against discrimination: [IRB, "Vietnam" (2010)]

(7) In 2008, by Government Decree, sex reassignment procedures are only legal for "hermaphrodites and people born with certain genital abnormalities, but not for people who are physically of one sex and request sex reassignment surgery.": [Godwin (2010) p. 78].

Those who do qualify for sex reassignment (i.e. intersex people) can change all of their documents, including their birth certificate. 


\section{Bibliography}

\subsection{In-text references}

\section{Primary Sources: International Treatien}

Bangkok Declaration, March 29-April 3, 1993.

Cairo Declaration of Human Rights in Islam, adopted by and proclaimed by Organization of Islamic Conference resolution 217 A (III) on 5 August 1990.

Charter of the United Nations and Statute of the International Court of Justice, June 26, 1945, 59 Stat. 1031, TS No. 993, 3 Bevans 1153.

International Covenant on Economic, Social and Cultural Rights, 16 December 1966, 993 UNTS 3.

Terms of References for the ASEAN Intergovernmental Commission on Human Rights, adopted at the 42nd ASEAN Foreign Ministers Meeting on July 20, 2009, held in Phuket, Thailand.

Treaty of Amsterdam amending the Treaty on European Union, the Treaties establishing the European Communities and certain related acts, October 2, 1997, entered into force May 1, 1999.

\section{Primary Sources: Jurisprudence}

Colombia: Report $N^{\circ} 71 / 99$ Marta Lucía Álvarez Giraldo, IACHR Admissibility, Case 11.656, May 4, 1999.

Dudgeon $v$ The United Kingdom, 4 Eur HR Rep 149 (1981).

Joslin v New Zealand, Communication No 902/1999, UN Doc CCPR/C/75/D/902/1999 (1999).

Lustig-Prean v United Kingdom, 29 Eur HR Rep 548 (1999).

Modinos $v$ Cyprus, 16 Eur HR Rep 485 (1993).

Norris $v$ Republic of Ireland, 13 Eur HR Rep 186 (1989).

Toonen v Australia, Communication No 488/1992, UN Doc CCPR/C/50/D/488/1992 (1994).

Young v Australia, Communication No 941/2000, UN Doc CCPR/C/78/D/941/2000 (2003).

\section{Primary Sources: Official Documents of International Organizations}

Commission on Human Rights, General Comment 24(52), on issues relating to reservations made upon ratification or accession to the Covenant or the Optional Protocols thereto, or in relation to declarations under article 41 or the Covenant, UN Doc CCPR/C/21/Rev.1/Add.6 (1994).

-.----, Report of the Rapporteur on the right of everyone to the highest attainable standard of physical and mental health, Paul Hunt, UN Doc E/CN.4/2004/49, Feb. 16, 2004.

The Global Fund to Fight AIDS, TB, and Malaria. The Global Fund Strategy in Relation to Sexual Orientation and Gender Identities (SOGI), proceedings of the 19th Board Meeting of the Global Fund to Fight AIDS, TB, and Malaria (Geneva) May 5-6, 2009.

Human Rights Council, Report of the Rapporteur on the right of everyone to the highest attainable standard of physical and mental health, Anand Grover, UN Doc A/HRC/13/20, April 27, 2010. 
Joint United Nations Programme on HIV/AIDS (UNAIDS), Global Report: UNAIDS Report on the Global AIDS Epidemic 2010, (Geneva: UNAIDS, 2010).

-----, Monitoring the Declaration of Commitment on HIV/AIDS: guidelines on construction of core indicators: 2010 reporting, (2009) UN Doc UNAIDS/09.10E.

Organization of American States, "Human Rights, Sexual Orientation, and Gender Identity”, AG/RES. 2435 (XXXVIII-O/08).

-.--.-, "Human Rights, Sexual Orientation, and Gender Identity", AG/RES. 2504 (XXXIX-O/09).

-----, "Human Rights, Sexual Orientation, and Gender Identity", AG/RES. 2600 (XL$\mathrm{O} / 10$ ).

UN Committee on Economic, Social and Cultural Rights (CESCR), General Comment No. 14 (2000): The right to the highest attainable standard of health (article 12 of the International Covenant on Economic, Social and Cultural Rights), August 11, 2000, UN Doc E/ C.12/2000/4.

-----, General Comment No. 14: The right to the highest attainable standard of health, August 11, 2000, UN Doc E/C.12/2000/4.

-----, General Comment No. 20: Non-Discrimination in Economic, Social and Cultural Rights (art. 2, para. 2), June 10, 2009, UN Doc E/C.12/2GC/20.

-----, General Comment No. 3 (1990): The nature of States parties'obligations (Art 2, Para.1, of the Covenant), December 14, 1990, UN Doc E/1991/23.

UN Committee on the Elimination of Discrimination against Women, Concluding Observations of the Committee on the Elimination of Discrimination Against Women: Kyrgyzstan, January 27, 1999, UN Doc CEDAW/A/54/38.

UN Committee on the Rights of the Child, General Comment No 3 (2002): HIV/AIDS and the Rights of the Child, March 17, 2003, UN Doc CRC/GC/2003/3.

------, General Comment No. 4 (2003): Adolescent health and development in the context of the Convention on the Rights of the Child, July 1, 2004, UN Doc CRC/ $\mathrm{GC} / 2003 / 4$.

------, General Comment No. 4 (2003): Adolescent health and development in the context of the Convention on the Rights of the Child, July 1, 2004, UN Doc $\mathrm{CRC} / \mathrm{GC} / 2003 / 4$.

UN Economic and Social Council, "Communications concerning human rights", Resolution 1235 (XLII) of the Economic and Social Council, UN Doc E/4393 (1967).

UN General Assembly, Annex to the letter dated 18 December 2008 from the Permanent Representatives of Argentina, Brazil, Croatia, France, Gabon, Japan, the Netherlands and Norway to the United Nations addressed to the President of the General, UN Doc A/63/635 (22 December 2008).

-----, Declaration of Commitment on HIV/AIDS. "Global crisis - global action", August 2, 2001, UN Doc A/Res/S-26/2.

------, Official Records, UN Doc A/63/PV.71 (18 December 2008): Holy See.

-..---, Political Declaration of HIV/AIDS, June 15, 2006, UN Doc A/Res/60/262.

------, Political Declaration of HIV/AIDS: Intensifying our Efforts to Eliminate HIV/AIDS, June 10, 2011, UN Doc A/Res/65/277.

UN Development Programme (UNDP), 2010 Report: HDI Trends 1980-2010, online: $<$ http://hdr.undp.org/en/media/HDI-trends-1980-2010.xls $>$. 
Secondary Sources: Monographs

Commission on AIDS in Asia, Redefining AIDS in Asia: Crafting an Effective Response, (Oxford University Press: New Delhi, India, 2008).

Borenstein, et al, Introduction to Meta-Analysis, (Chichester, UK: John Wiley \& Sons, Ltd., 2009).

Donnelly, "Human Rights and Asian Values: A Defense of "Western" Universalism", in Joanne R. Bauer and Daniel A. Bell, eds, The East Asian Challenge for Human Rights (Cambridge: Cambridge University Press, 1999) 60.

Evans and Murray, eds, The African Charter on Human and Peoples' Rights: The System in Practice, 1986-2006, 2d ed, (Cambridge: Cambridge University Press, 2008).

Godwin, Legal environments, human rights and HIV responses among men who have sex with men and transgender people in Asia and the Pacific: An agenda for action, (Bangkok: APCOM-UNDP, 2010).

Rehman, International Human Rights Law: A Practical Approach, (Harlow: Pearson Education Limited, 2003).

Remis and Liu, "The Epidemiology of HIV infection among Men who have sex with other men in Ontario: The situation in 2005" in Ontario Gay Men's HIV Prevention Strategy: Gay, Bi, MSM Situation Report (Toronto: Ontario Ministry of Health and Long-Term Care, 2006) 107.

Rothschild, Written Out: How sexuality is used to attack women's organizing, (New York: International Gay and Lesbian Human Rights Commission and the Center for Women's Global Leadership, 2005).

Rubin, Multiple imputation for nonresponse in surveys, (New York: John Wiley, 1987).

Surin, Shin, "Republic of Korea," in Tadashi Yamamoto and Satoko Itoh, eds, Fighting a Rising Tide: The Response to AIDS in East Asia, (Tokyo: Japan Center for International Exchange, 2006) 156.

World Health Organization (WHO), Prevention and Treatment of HIV and other Sexually Transmitted Infections Among Men Who Have Sex with men and Transgender Populations: Report of a technical consultation, (Geneva, Switzerland: WHO, 1517 September 2008).

Secondary Sources: Peer-Revlewed Articles

Adams, et al, "Estimating Levels of HIV Testing, HIV Prevention Coverage, HIV Knowledge, and Condom Use Among Men Who Have Sex With Men (MSM) in Low-Income and Middle-Income Countries" (2009) 52:Sup 2 J. AIDS s143.

Agoramoorthy and Hsu, "Can India abolish the anachronistic homosexuality law to battle HIV/AIDS?" (2006) 20:10 AIDS 1469.

Ayala, et al, "Social Discrimination Against Men who have sex with Men (MSM): Implications for HIV Policy and Programs" (2010) The Global Forum on MSM and HIV.

Baral, et al, "HIV Prevalence, Risks for HIV Infection, and Human Rights among Men Who Have Sex with Men (MSM) in Malawi, Namibia, Botswana" (2009) 4:3 PloS ONE 1.

------, "Elevated risk for HIV infection among men who have sex with men in low- and middle-income countries 2000-2006: a systematic review" (2007) 4:12 PLoS Med. e339

Bernstein, "Paths to Homophobia" (2004) 1:2 Sexuality Research \& Social Policy 41. Beyrer, "Hidden yet happening: the epidemics of sexually transmitted infections and HIV 
among men who have sex with men in developing countries" (2008) 84:6 Sex. Transm. Infect. 410.

------, "Global Prevention of HIV Infection for Neglected Populations: Men Who Have Sex with Men" (2010) 50: Sup 3 Clinical Infect. Dis. s108.

Beyrer, et al, "The Expanding Epidemic of HIV Type 1 Among Men Who Have Sex With Men in Low- and Middle-Income Countries: Diversity and Consistency" (2010) 32:1 Epidemiological Rev. 137.

Blake, et al, "Preventing Sexual Risk Behaviors Among Gay, Lesbian, and Bisexual Adolescents: The Benefits of Gay-Sensitive HIV Instruction in Schools" (2001) 91:6 American J. Public Health 940.

Burris, "Law as a Structural Factor in the Spread of Communicable Disease" (1999) 36 Hous. L. Rev. 1755.

Caceres, et al, "Epidemiology of male same-sex behaviour and associated sexual health indicators in low- and middle-income countries: 2003-2007 estimates" (2008) 84: Sup 1 Sex. Transm. Infect. 149.

-..-.-., "Estimating the number of men who have sex with men in low and middle income countries" (2006) 82: Sup 3 Sex. Transm. Infect. iii3.

-----, "Sexual diversity, social inclusion and HIV/AIDS" (2008) 22: Sup 2 AIDS s45.

Celentano, "Undocumented epidemics of HIV continue to persist in the twenty-first century" (2005) 19:5 AIDS 527.

Chakrapani, et al, "Structural violence against Kothi-identified Men who have Sex with Men in Chennai, India: A Qualitative Investigation" (2007) 19:4 AIDS Ed. \& Prev. 346.

Chatterjee, "AIDS in India: police power and public health" (2006) 367 Lancet 805.

Cheng, "Asian countries urged to address HVI/AIDS in MSM" (2009) 373 Lancet 707.

Chew, "Human Rights in Singapore: Perceptions and Problems" (1994) 34:11 Asian Survey 933.

Csete, "HIV/AIDS and human rights: we've only just begun" (2005) 10:1 HIV/AIDS Pol'y \& L. Rev. 7.

------, "Indian NGO challenges penal code prohibition of 'unnatural offences"' (2002) 7:1 HIV/AIDS Pol'y \& L. Rev. 58.

Ehlers, et al, "The well-being of gays, lesbians and bisexuals in Botswana" (2001) 35:6 J. Adv. Nursing 848.

Frye, et al, "The Urban Environment and Sexual Risk Behavior among Men who have Sex with Men" (2006) 83:2 J. Urban Health 308.

Gabel, et al, "A global assessment of the role of law in the HIV/AIDS pandemic" (2009) 123:2 Public Health 260.

Garmaise, "Senegal: Growing intolerance towards gay men" (2009) 14:1 HIV/AIDS Pol'y \& L. Rev. 31.

Glasier, et al, "Sexual and Reproductive Health: a matter of life and death" (2006) 368:9547 Lancet 1595.

Griensven and Wijngaarden, "A review of the epidemiology of HIV infection and prevention responses among MSM in Asia" (2010) 24: Sup 3 AIDS s30.

Griensven, et al, "Evidence of a previously undocumented epidemic of HIV infection among men who have sex with men in Bangkok, Thailand" (2005) 19:5 J. AIDS 521.

-.---., "The global epidemic of HIV infection among men who have sex with men" (2009) 4 Current Opinion in HIV \& AIDS 300. 
Gruskin and Ferguson, "Government regulation of sex and sexuality in their own words" (2009)17:34 Reproductive Health Matters 108.

Gruskin, et al, "Beyond the numbers: using rights-based perspectives to enhance antiretroviral treatment scale-up" (2007) 21: Sup 5 AIDS s1.

------, "Human Rights in the Global Response to HIV: Findings From the 2008 United Nations General Assembly Special Session Reports" (2009) 52:Sup 2 J. AIDS s104.

Hergest, "India: UNAIDS claims law criminalizing homosexuality hinders HIV prevention" (2006) 11:1 HIV/AIDS Pol'y \& L. Rev. 35;

------, "Namibia: Anti-homosexuality law undermines HIV prevention in prisons", (2006) 11:1 HIV/AIDS Pol'y \& L. Rev. 34.

Johnson, et al, "Internalized Heterosexism Among HIV-Positive, Gay-Identified Men: Implications for HIV Prevention and Care" (2008) 76:5 J. Consulting \& Clinical Psych. 829.

Khan, "Bangkok 2004: A human rights crisis in need of a human rights response" (2004) 9:3 HIV/AIDS Pol'y \& L. Rev. 75.

Kraft, "Human Rights, ASEAN and Constructivism: Revisiting the "Asian Values" Discourse" (2001) 22:45 Philippine Pol. Sci. J. 33.

Lau, "Sexual Orientation: Testing the Universality of International Human Rights Law" (2004) 71 U. Chicago L. Rev. 1689.

Mayer, et al, "Out of the Closet and Into Public Health Focus: HIV and STDs in Men Who Have Sex With Men in Middle Income and Resource-Limited Countries" (2010) 37:4 Sex. Transm. Dis. 205.

McFarland and Caceres, "HIV surveillance among men who have sex with men" (2001) 15: Sup 3 AIDS s23.

Meyer, "Prejudice, Social Stress, and Mental Health in Lesbian, Gay, and Bisexual Populations: Conceptual Issues and Research Evidence" (2003) 129:5 Psych. Bull. 674.

Mistra, "Decriminalising homosexuality in India" (2009) 17:34 Reproductive Health Matters 20.

Moody, "Ensuring human and sexual rights for men who have sex with men living with HIV" (2009) 87:11 Bull. of the WHO 875.

Muntarbhorn, "Asia, Human Rights and the New Millennium: Time for a Regional Human Rights Charter?" (1998) 8 Transn'l L. \& Contemp. Prob. 408.

Mykhalovskiy, et al, "XVII International AIDS Conference: From Evidence to Action Social, behavioural and economic science and policy and political science" (2009) 12: Sup $1 \mathrm{~J}$. Intl. AIDS Society s5.

O'Flaherty and Fisher, "Sexual Orientation, Gender Identity and International Human Rights Law: Contextualising the Yogyakarta Principles" (2008) 8:2 Human Rights L. Rev. 207.

Pant, "Vulnerable populations in Nepal face hostile environment" (2006) 11:2-3 HIV/AIDS Pol'y \& L. Rev. 87.

Pappas, et al, "Males Who Have Sex with Males (MSM) and HIV/AIDS in India: The Hidden Epidemic" (2001) 16:1-2 AIDS \& Pub. Pol'y J. 1.

Phillips, et al, "Serosorting is Associated with a Decreased Risk of HIV Seroconversion in the EXPLORE Study Cohort" (2010) 5:9 PLOS ONE e12662.

Piot, et al, "Coming to terms with complexity: a call to action for HIV prevention" (2008) 372 Lancet 845. 
Ramasubban, "Political intersections between HIV/AIDS, sexuality and human rights: A history of resistance to the anti-sodomy law in India" (2008) 3: Sup 2 Global Public Health 22.

Roehr, "The invisible epidemic" (2008) 337 British Medical Journal 1262.

Ross, et al, "The relationship of internalized homonegativity to unsafe sexual behavior in HIV seropositive men who have sex with men"(2008) 20:6 AIDS Ed. \& Prev. 547.

Saavedra, et al, "Sex between men in the context of HIV: The AIDS 2008 Jonathan Mann Memorial Lecture in health and human rights" (2008) 11:9 J. Intl. AIDS Society.

Schafer, "Multiple Imputation: a primer" (1999) 8 Statistical Methods in Medical Research 3

Senior, "HIV, human rights, and men who have sex with men" (2010) 10: 7 Lancet 448.

Stall and Hart, "The continuing evolution of research on sexually transmitted infections among men who have sex with men" (2008) 84:6 Sex Transm. Infect. 407.

Stemple, "Health and human rights in today's fight against HIV/AIDS" (2008) 22: Sup 2 J. AIDS $\mathrm{s} 113$.

Wilcoxon, "Individual comparisons by ranking methods" (1945) 1:6 Biometrics Bul. 80.

Wohfeiler, "Structural and environmental HIV prevention for gay and bisexual men" (2000) 14: Sup 1 AIDS s52.

Wright, "Homosexuality and HIV/AIDS prevention: the challenge of transferring lessons learned from Western European to Central and Eastern European Countries" (2005) 20:1 Health Promotion International 91.

\section{Secondary Sourcese Miscellaneous}

"CIRI Human Rights Data Project", online: <http://ciri.binghamton.edu>.

"Commonwealth Secretariat - Member States", online: $<\mathrm{http}$ ://www.thecommonwealth.org/Internal/ 191086/142227/members/>.

"Global Commission on HIV and the Law", online: <http://www.hivlawcommission.org/>.

"Organisation of Islamic Cooperation", online: <http://www.oicoci.org/member_states.asp>.

"Stigma and Discrimination: Hindering Effective HIV Responses", NGO Delegation Annual Report to the UNAIDS Board, Presented at the 26th UNAIDS Board Meeting, Geneva, Switzerland, 22-24 June 2010.

"Transrespect versus Transphobia Worldwide" online: <http://www.transrespecttransphobia.org/>.

Amnesty International, "Indonesia (Aceh): Torture of gay men by the Banda Raya police", 20 June 2007.

Australian Federation of AIDS Organisations, "HIV risk reduction strategies among gay men", April 2011, online: <http://www.afao.org.au/_data/assets/pdf_file/0012/ 5601/LR_APrill1_risk_reduction.pdf $>$.

Caceres, et al, "Review of Legal Frameworks and the Situation of Human Rights related to Sexual Diversity in Low and Middle Income Countries", (2008) Commissioned by UNAIDS.

Immigration and Refugee Board of Canada, "Malaysia: Treatment of sexual minorities (August 2004 - August 2005)" August 30, 2005, MYS100434.E.

International Coalition on AIDS and Development, "Gender Based Violence and HIV \& AIDS: Affecting Everyone" (May 2008). 
International Commission of Jurists, Submission to the Supreme Court of the State of Nepal, Providing the Basis in International Human Rights Law for the Prohibition of Discrimination Based on Sexual Orientation and Gender Identity and Other Connected Matters, January 9, 2008.

International Gay and Lesbian Human Rights Commission (IGLHRC), "Civil Society Pressures Governments to Successfully Reverse Discriminatory Vote at UN" (December 12, 2010) online: <http://www.iglhrc.org/cgi-bin/iowa/article/ pressroom/pressrelease/1291.html $>$.

-----, "United Nations Grants Official Status to U.S.-based International LGBT Rights Group" (July 19, 2010) online: <http://www.iglhrc.org/cgi-bin/iowa/article/ pressroom/pressrelease/1169.html>.

International Lesbian, Gay, Bisexual, Trans and Intersex Association (IGLA), online: $<$ http://ilga.org/>.

International Panel of Experts in International Human Rights Law and on Sexual Orientation and Gender Identity, The Yogyakarta Principles: Principles on the Application of International Human Rights Law in Relation to Sexual Orientation and Gender Identity, March 2007, online: <www.yogyakartaprinciples.org/>.

Johnson, Cary Alan, "Diverse sexualities/Disparate laws: Sexual minorities, the State and International Law" (April 3, 2010), Keynote address at the Harvard Law School.

Monitoring the AIDS Pandemic Network, Male-Male Sex and HIV/AIDS in Asia (2005).

Office of the High Commissioner of Human Rights, "International Human Rights", online: $<\mathrm{http}: / / \mathrm{www}$.ohchr.org/en/professionalinterest/Pages/InternationalLaw.aspx>.

-----, "Laws criminalizing homosexuality are incompatible with international human rights standards and fuel homophobia", online: $<$ http://www.ohchr.org/EN/NewsEvents/Pages/Homophobia.aspx > .

Ottosson, "State-Sponsored Homophobia: A world survey of laws prohibiting same sex activity between consenting adults, an ILGA report" (May 2010).

Personal communication from Douglas Sanders, professor emeritus, Faculty of Law, University of British Columbia, and professor, Chulalongkorn University, Bangkok, Thailand (February 27, 2012).

Polity IV Project, Political Regime Characteristics and Transitions, 1800-2010, online: <http://www.systemicpeace.org/inscr/p4v2010.xls>.

Sanders, The Role of the Yogyakarta Principles, February 8, 2009, online: <http://sxpolitics. org/wp-content/uploads/2009/03/yogyakarta-principles-2-douglas-sanders.pdf $>$.

SAS, version 9.2 (Cary, North Carolina: SAS Institute Inc, 2009).

StatsDirect Ltd., StatsDirect statistical software, (England: StatsDirect Ltd., 2008), online: <http://www.statsdirect.com>.

United States Holocaust Memorial Museum, "Nazi Persecution of Homosexuals 19331945" online: <http://www.ushmm.org/museum/exhibit/online/hsx/>.

Wikipedia, "List of country by Human Development Index", online: $<\mathrm{http}$ //en.wikipedia.org/wiki/List_of_countries_by_Human_Development_Inde>.

Williams, Jurisprudential Annotations to the Yogyakarta Principles (November 2007), online: <http://www.yogyakartaprinciples.org/yogyakarta-principlesjurisprudential-annotations.pdf $>$.

Weidlich, "AIDS taking toll among prison inmates and staff" (April 20, 2007), The Namibian, online: <http://www.namibian.com.na/index.php?id $=28 \& t x$ ttnews [tt_news] $=31217 \&$ no_cache $=1>$. 
National AIDS/STD Programme (NASP), Ministry of Health and Family Welfare, National HIV Serological and Behavioural Surveillance, 2002 Bangladesh: 4th Round Technical Report (Dahka: NASP, 2003).

-----, National HIV Serological and Behavioural Surveillance, 2003-2004 Bangladesh: 5 th Round Technical Report (Dahka: NASP, 2004).

-.----, National HIV Serological Surveillance, 2004-2005 Bangladesh: 6th Round Technical Report (Dahka: NASP, 2005).

------, National HIV Serological Surveillance, 2006 Bangladesh: 7th Round Technical Report (Dahka: NASP, 2007).

-.----, National HIV Serological Surveillance, 2007 Bangladesh: 8th Round Technical Report (Dahka: NASP, 2008a).

-----, Behavioural Surveillance Survey 2006-07: Technical Report (Dahka: NASP, 2008b).

Naz Foundation International (NFI), "Situational Assessments of Sexual health Among Males who have Sex with Males and their Sexual Partners in South Asia" (2000) available online: <www.nfi.net>.

-----, "Situational Assessments Among Men who have Sex with Men in Mymensingh, Bangladesh" (2001) available online: <www.nfi.net>.

-----, "Situational Assessments of Sexual health Among Males who have Sex with Males and their Sexual Partners in Comilla and Rajbari, Bangladesh, 2002" (2003) available online: <www.nfi.net>.

\section{Chingm}

Catalla, et al, Out of the Shadows: Male to Male Sexual Behaviour in Cambodia (Phnom Penh: KHANA, 2003).

Chhorvann, National Center for HIV, Dermatology and STDs, "Behavioral Sentinel Surveillance 2007", presented by Chhea Chhorvann, April 28, 2008.

Chhorvann and Liu, Cambodia 2005 Behavioral Sentinel Surveillance: HIV/AIDS Related Sexual Behaviors among Sentinel Groups, (Phnom Penh: National Center for HIV/AIDS, Dermatology and STDs, Ministry of Health, 2007).

Girault, et al, "HIV, STI, and Sexual Behaviors Among Men Who Have Sex With Men in Phnom Penh, Cambodia" (2004) 16:1 AIDS Ed \& Prev 31.

Phalkun, et al, "HIV, sexually transmitted infections, and related risk behavior among Cambodian men who have sex with men", Presented at the XVI International AIDS Conference, Toronto, Canada, August 13-18, 2006, Abstract no CDC0618.

Sophead, et al, 2005 Cambodia STI Prevalence Survey - Integrated Biological and Behavioral Survey, (National Center for HIV, Dermatology, and STDs, 2008).

Behringer, HIV/AIDS Prevention: Factors Affecting Risky Sexual Behaviors among MSM in Shenzhen, China, (2008) MA Thesis, University of Connecticut.

Cai, et al, "HIV prevalence and related risk factors among male sex works in Shenzhen, China: Results from a time-location sampling survey" (2010) 86 Sex. Transm. Infect. 15. 
Chen, et al, "HIV sentinel surveillance for men who have sex with men in Shenzhen in 2007" Presented at the XVII International AIDS Conference, Mexico City, Mexico, August 3-8, 2008, Abstract no THPE0381.

Choi, et al, "Emerging HIV-1 epidemic in China in men who have sex with men" (2003) 261 Lancet 2125.

-----, "High levels of unprotected sex with men and women among men who have sex with men: A potential bridge of HIV transmission in Beijing, China" (2004) 16:1 AIDS Ed \& Prev 19.

-.---., "Lack of HIV testing and awareness of HIV infection among men who have sex with men, Beijing, China" (2006a) 18:1 AIDS Ed \& Prev 33.

-.----, "Social and sexual network characteristics are associated with HIV risk among men who have sex with men (MSM) in Shanghai, China", Presented at the XVI International AIDS Conference, Toronto, Canada, August 13-18, 2006b, Abstract no TUPE0470.

-----, "The Influence of Social and Sexual Networks in the Spread of HIV and Syphilis Among Men Who Have Sex With Men in Shanghai, China" (2007) 45:1 J. AIDS 77.

Chu, et al, "Investigation of condom use in man who have sex with man (MSM) in a provincial city of the northeast" (2006) 12:4 Chin. J. AIDS STD 330 [in Simplified Chinese: translated by Cory Wong].

Feng, L. et al, "High HIV Prevalence Detected in 2006 and 2007 Among Men Who Have Sex With Men in China's Largest Municipality: An Alarming Epidemic in Chongqing, China" (2009) 52:1 J. AIDS 79.

Feng, Y., et al, "HIV STD prevalence among MSM in Chengdu, China and associated risk factors for HIV infection", Presented at the XVII International AIDS Conference, Mexico City, Mexico, August 3-8, 2008, Abstract no CDC0088.

-.-.-., "HIV/STD Prevalence Among Men Who Have Sex With Men in Chengdu, China and Associated Risk Factors for HIV Infection" (2010) 53: Sup 1 J. AIDS s74.

Feng, T.-J., et al, "Prevalence of Syphilis and Human Immunodeficiency Virus Infections Among Men Who Have Sex With Men in Shenzhen, China- 2005 to 2007" (2008) 35:12 Sex. Transm. Dis. 1022.

Gu, Y., et al, "Survey of knowledge, attitude, behavior and practice related to STI / HIV among male homosexuals in Shenyang" (2004) 20:5 Chin. J. Public Health 573 [in Simplified Chinese: translated by Cory Wong].

Guo, Y., et al, "Study on HIV/syphilis infections among men who have sex with men and their behavioral feature" (2009) 15:1 Chin. J. AIDS STD 50 [in Simplified Chinese: translated by Cory Wong].

Guo, H., et al, "Rapidly Increasing Prevalence of HIV and Syphilis and HIV-1 Subtype Characterization Among Men Who Have Sex With Men in Jiangsu, China" (2008) 36:2 Sex. Transm. Dis. 120.

$\mathrm{Ha}$, et al, "Concurrent Sexual Partnerships Among Men Who Have Sex With Men in Shenzhen, China" (2010) 37:8 Sex. Transm. Dis. 506.

$\mathrm{He}$, et al, "High prevalence of risk behaviour concurrent with links to other high-risk populations: a potentially explosive HIV epidemic among men who have sex with men in Guangzhou, China" (2009) 85 Sex. Transm. Infect. 383.

-----, "Accessing Men Who Have Sex with Men Through Long-Chain Referral Recruitment, Guangzhou, China" (2008) 12 AIDS Behav. s93.

-...-.., "Potential Bridges for HIV Infection to Men Who Have Sex With Men in 
Guangzhou, China" (2006) 10: Sup 1 AIDS Behav. s17.

Hong, et al, "Prevalence of syphilis and HIV infections among men who have sex with men from different settings in Shenzhen, China: implications for HIV/STD surveillance" (2009) 85 Sex. Transm. Infect. 42.

Jiang, et al, High Prevalence of Sexually Transmitted Diseases Among Men Who Have Sex With Men in Jiangsu, China" (2006) 33:2 Sex. Transm. Dis. 118.

Lai, Y., et al, "STD/HIV Hish Risk Behavior Survey among Men Who Have Sex with Men in Shenzhen" (2006) 13:2 Southern China J. of Dermato-Venereology 146 [in Simplified Chinese: translated by Cory Wong].

Lau, et al, "HIV-related behaviors among men who have sex with men in China, 20052006" (2009) 21:4 AIDS Ed. \& Prev. 325.

-.---., "Prevalence of Bisexual Behaviors Among Men Who Have Sex with Men (MSM) in China and Associations Between Condom Use in MSM and Heterosexual Behaviors" (2008) 35:4 Sex. Trans. Dis. 406.

$\mathrm{Li}, \mathrm{X} .$, et al, "HIV and syphilis infection among men who have sex with men in Beijing, China: potential for HIV rapid transmission", Presented at the XVI International AIDS Conference, Toronto, Canada, August 13-18, 2006, Abstract no CDC0093.

------, "Predictors of Unprotected Sex Among Men Who Have Sex With Men in Bejing, China" (2008) 39:1 Southeast Asian J. Trop. Med. Public Health 99.

$\mathrm{Li}$, Y., et al, "Survey of HIV/SY Infection and KABP Related to AIDS among MSM in Lanzhou" (2007) 8 Chin. Medical Science \& Health 1 [in Simplified Chinese: translated by Cory Wong].

Liu, et al, "A survey of the knowledge, attitude, and behaviors on STD/AIDS in men who have sex with men in Beijing" (2005) 11:4 Chin J. AIDS STD 268 [in Simplified Chinese: translated by Cory Wong].

-.-.-., "HIV prevalence and the risk behaviors amongst MSM in Beijing, China", Presented at the XVI International AIDS Conference, Toronto, Canada, August 1318,2006 , Abstract no CDC1698.

-----, "Money boys, HIV risks, and the Association between Norms and Safer Sex: A Respondent-Driven Sampling Study in Shenzhen, China" (2009) 13 AIDS Behav. 652.

$\mathrm{Ma}, \mathrm{X}$., et al, "Possible rise in HIV prevalence among men who have sex with men (MSM) in Beijing", Presented at the XVI International AIDS Conference, Toronto, Canada, August 13-18, 2006, Abstract no MOPE0526.

-----., "Trends in Prevalence of HIV, Syphilis, Hepatitis C, Hepatitis B, and Sexual Risk Behavior Among Men Who Have Sex With Men" (2007) 45:5 J. AIDS 581.

$\mathrm{Ma}$, J., and Guo, "Internet survey of high risk sexual behaviors and sexually transmitted diseases among male homosexuals in Tianjin" (2007) 34:20 Modern Preventive Medicine 3928 [in Simplified Chinese: translated by Cory Wong].

$\mathrm{Qu}$, et al, "A survey of knowledge, attitude and practice relate to HIV/AIDS among men who have sex with men in a northeast city of China" (2002) 8:6 Chin. J. STD/AIDS Prev. Cont. 338 [in Simplified Chinese: translated by Cory Wong].

Ruan, S., et al, "HIV Prevalence and Correlates of Unprotected Anal Intercourse Among Men Who Have Sex with Men, Jinan, China" (2008) 12 AIDS Behav. 469.

------, "Rising HIV Prevalence Among Married and Unmarried Among Men Who Have Sex with Men - Jinan, China" (2009) 13 AIDS Behav. 671.

Ruan, Y., et al, "Changes of HIV and syphilis infection among men who have sex with 
men in Beijing China" Presented at the XVII International AIDS Conference, Mexico City, Mexico, August 3-8, 2008, Abstract no CDC0153.

-----, "Incidence of HIV-1, Syphilis, Hepatitis B, and Hepatitis C Virus Infections and Predictors Associated With Retention in a 12-Month Follow-Up Study Among Men Who Have Sex With Men in Beijing, China" (2009a) 52 J. AIDS 604.

-.---, "Relationship Between Syphilis and HIV Infections Among Men Who Have Sex With Men in Beijing, China" (2007) 34:8 Sex. Transm. Dis. 592.

, "Risk factors for syphilis and prevalence of HIV, Hepatitis B and C, among Men Who Have Sex with Men in Beijing, China: Implications for HIV prevention" (2009b) 13 AIDS Behav. 663.

Tao, "A survey of the related health services require of STD/AIDS in men who have sex with men" Presented at the XVII International AIDS Conference, Mexico City, Mexico, August 3-8, 2008, Abstract no CDC0109.

Tao, et al, "HIV Infection and Mental Health of 'Money Boys': A Pilot Study in Shandong Province, China" (2010) 41:2 Southeast Asian J. Trop. Med. Public Health 358.

------, "Prevalence of HIV infection an HIV-related sex risk behaviors in men who have sex with men in Shandong Province, China" (2008) 2:3 BioScience Trends 97

Wang, C., et al, "A survey of HIV infections and related factors among men who have sex with men in Beijing" (2008) 14:6 Chin. J. AIDS STD 552 [in Simplified Chinese: translated by Cory Wong].

Wang, Q. and Ross, "Difference Between Chat Room and E-mail Sampling Approaches in Chinese Men Who Have Sex With Men" (2002) 14:5 AIDS Ed. \& Prev. 361.

Wong, F., et al, "HIV risks among gay- and non-gay identified migrant money boys in Shanghai, China" (2008) 20:2 AIDS Care 170.

Xiao, et al, "Prevalence and Correlates of HIV and Syphilis Infections Among Men Who Have Sex With Men in Seven Provinces in China with Historically Low HIV Prevalence" (2010) 53: Sup 1 J. AIDS s66.

------, "Prevalence and Correlates of HIV and Syphilis Infections Among Men Who Have Sex With Men in Chongqing Municipality, China" (2009) 36:10 Sex. Transm. Dis. 647

Xing, et al, "A cross-section study among men who have sex with men: a comparison of online and offline samples in Hunan Province, China" (2008) 121:22 Chinese Med. J. 2342.

$\mathrm{Xu}, \mathrm{H} .$, et al, "HIV epidemic status and behavioral surveillance among MSM in China", Presented at the XVI International AIDS Conference, Toronto, Canada, August 1318, 2006, Abstract no WEAC0304.

$\mathrm{Xu}$, J., et al, "A cross-sectional study of HIV and syphilis infections among male students who have sex with men (MSM) in northeast China: implications for implementing HIV screening and intervention programs" (2011) 11:287 BMC Pub. Health.

--.--, "Demand and use of VCT service among MSM" (2007) 23:9 Chin. J. Public Health 1040 [in Simplified Chinese: translated by Cory Wong].

Yang, et al. "HIV Incidence and Associated Factors in a Cohort of Men Who Have Sex With Men in Nanjing, China" (2010) 37:4 Sex. Trans. Dis. 208.

Zhang, D., et al, "Changes in HIV prevalence and sexual behavior among men who have sex with men in a northern Chinese city 2002-2006" (2007) $55 \mathrm{~J}$. Infect. 456.

------, "Risk factors of HIV infection and prevalence of co-infections among men who 
have sex with men in Beijing, China", (2007) 21: Sup 8 AIDS s53.

Zhang, F, "Survey on Knowledge, Attitude, and Behavior of MSM Toward AIDS in Handan" (2008) 15:2 Practical Preventive Medicine 424 [in Simplified Chinese: translated by Cory Wong].

Zhang, H., et al, "A Pilot Intervention to Increase Condom Use and HIV Testing and Counseling Among Men Who Have Sex With Men in Anhui, China" (2010) 53: Sup $1 J$. AIDS s88.

Zhang, X, et al, "Risk factors of HIV infection and prevalence of co-infections among men who have sex with men in Beijing, China" (2007) 21: Sup 8 AIDS s53.

Zhong, et al, "Possible Increase in HIV and Syphilis Prevalence Among Men Who Have Sex with Men in Guangzhou, China: Results from a Respondent-Driven Sampling Survey" (2009) AIDS Behav.

Zhu, et al, "High risk sexual behavior and HIV/STD infection rate among $122 \mathrm{MSM}$ from students" (2007) 13:4 Chin. J. AIDS STD 350 [in Simplified Chinese: translated by Cory Wong].

Zou, et al, "Sexual Risk Behaviors and HIV Infection Among Men Who Have Sex with Men Who Use the Internet in Beijing and Urumqi, China" (2010) 53:Sup $1 \mathrm{~J}$ AIDS s81.

Gu, J., Lau and Tsui, "Psychological factors in association with uptake of voluntary counseling and testing for HIV among men who have sex with men in Hong Kong" (2011) 30 Public Health.

Hong Kong Advisory Council on AIDS (ACA), Department of Health, Hong Kong, Third Set of Core Indicators for Monitoring Hong Kong's AIDS Programme, (Hong Kong: ACA, Department of Health, 2010).

Lau and Wong, W.S., "HIV antibody testing among male commercial sex networkers, men who have sex with men and the lower-risk male general population in Hong Kong" (2002) 14:1 AIDS Care 55.

Lau, et al, "A randomized controlled study to evaluate the efficacy of an Internet-based intervention in reducing HIV risk behaviors among men who have sex with $\mathrm{m}$ en in Hong Kong" (2008) 20:7 AIDS Care 820.

------, "Prevalence and Risk Behaviors of Hong Kong Males who seek cross-border samesex partners in mainland China" (2004b) 31:9 Sex. Trans Dis. 568. , "A Study of the STD/AIDS Related Attitudes and Behaviors or Men Who Have Sex With Men in Hong Kong" (2002) 31:4 Archives of Sex. Behav. 367.

-.---, "HIV related behaviours and attitudes among Chinese men who have sex with men in Hong Kong - A population based study" (2004a) 80 Sex. Trans. Infect. 459.

Mak, et al, "The first integrated seroprevalence and behavioural survey for men who have sex with men (MSM) in Hong Kong - Prism", Presented at the XVII International AIDS Conference, Mexico City, Mexico, August 3-8, 2008, Abstract no MOPE0407.

Special Preventive Programme (SPP) - Center for Health Protection (CHP), Department of Health, Hong Kong (AIDS Office) "PRiSM - HIV Prevalence and Risk behavioural Survey of Men who have sex with men in Hong Kong 2006" Factsheet, April 2007.

......., "PRiSM - HIV Prevalence and Risk behavioural Survey of Men who have sex with 
men in Hong Kong 2008" Factsheet, July 2009.

-----, HIV Surveillance Report - 2009 Update, (Hong Kong: CHP, 2010)

Wong, C., and Tang, "Sexual Practices and Psychosocial Correlates of Current Condom Use Among Chinese Gay Men in Hong Kong" (2004) 33:2 Archives Sex. Behov. 159.

Brahmam, et al, "Sexual practices, HIV and sexually transmitted infections among selfidentified msm in four high HIV prevalence states of India" (2008) 22: Sup 5 AIDS s45.

Dandona, et al, "How much attention is needed towards men who sell sex to men for HIV prevention in India?" (2006) 6:31 BMC Pub. Health.

-----, "Sex behaviour of men who have sex with men and risk of HIV in Andhra Pradesh, India" (2005) 19:6 AIDS 611.

Deb, et al, "Sexual Practice and Perception of HIV/AIDS Amongst men Who Have Sex With Men in Kolkata" (2009) 34:3 Indian J. Community Medicine 206.

Go, et al, "High HIV Prevalence and Risk Behaviors in Men Who Have Sex With Men in Chennai, India" (2004) 35:3 J. AIDS 314.

Gupta, et al, "Same-Sex Behavior and High Rates of HIV Among Men Attending Sexually Transmitted Infection Clinics in Pune, India (1993-2002)" (2006) 43:4 J. AIDS 483.

Hernandez, et al, "Sexual Behavior Among Men Who Have Sex With Women, Men, and Hijras in Mumbai, India - Multiple Sexual Risks" (2006) 10 AIDS Behav. s5.

Humsafar Trust, the, 2005 - 4th baseline study [First Draft Report].

Kumta, et al, "Bisexuality, Sexual Risk Taking, and HIV Prevalence Among Men Who Have Sex With Men Accessing Voluntary Counseling and Testing Services in Mumbai, India" (2010) 52:2 J. AIDS 227.

National AIDS Control Organization (NACO), Ministry of Health and Family Welfare, National Behavioural Surveillance Survey (BSS): Men who have sex with men (MSM) and Injecting Drug Users (IDUs), (Delhi, NACO, 2006).

-.----, HIV Sentinel Surveillance And HIV Estimation in India, 2007- A Technical Brief, (Delhi: NACO, 2008).

-----, National Baseline High risk and Bridge Population Behavioural Surveillance Survey: Report - Part II (Men who have sex with men and injecting drug users) (Delhi: NACO. 2002).

Naz Foundation International, "Situational Assessments Among MSM in South Asia" (2000) online: <www.nfi.net>.

Newman, et al, "Determinants of Sexual Risk Behavior Among Men Who Have Sex with Men Accessing Public Sex Environments in Chennai, India" (2008b) 4:2-3 J. LGBT Health Research 81.

------, "Correlates of paid sex among men who have sex with men in Chennai, India", (2008a) 84 Sex. Trans. Infect. 434.

Palwade, et al, "Prevalence of HIV infection and sexually transmitted diseases amongst MSM population in Mumbai, India", Presented at the XVth International AIDS Conference, Bangkok, Thailand, July 11-16, 2004, Abstract no C10822.

Phillips, et al, "Men who have sex with men and women in Bangalore, South India, and potential impact on the HIV epidemic" (2010) 86 Sex. Trans. Infect. 187. 
------, "Sexual Identity and Its Contribution to MSM Risk Behavior in Bangaluru (Bangalore), India: The Results of a Two-Stage Cluster Sampling Survey" (2008) 4:2-3 J. LGBT Health Research 111.

Ramakrishnan, et al, "High HIV STI prevalence among self-identified men who have sex with men in South India", Presented at the XVII International AIDS Conference, Mexico City, Mexico, August 3-8, 2008, Abstract no CDC0264.

Safren, et al, "A survey of MSM HIV prevention outreach workers in Chennai, India" (2006) 14:4 AIDS Ed. \& Prev. 323.

Setia, et al, "Men who have sex with men and transgenders in Mumbai, India: An emerging risk group for STIs and HIV" (2006) 72:6 Indian J. Dermatology, Venereology and Leprology 425.

Shinde, et al, "Socio-demographic characteristics of male sex workers (MSW) in Mumbai, India", Presented at the XVI International AIDS Conference, Toronto, Canada, August 13-18, 2006, Abstract no CDC0861.

Solomon, et al, "The Emerging HIV Epidemic among Men Who have Sex with Men in Tamil Nadu, India- Geographic Diffusion and Bisexual Concurrency" (2010) 14 AIDS Behav. 1001.

Sravankumar and Prabhakar, "High risk behaviors among HIV positive and negative men having sex with men (MSM) attending Mythri clinics in Andhra Pradesh, India", Presented at the XVI International AIDS Conference, Toronto, Canada, August 1318,2006 , Abstract no MOPE0582.

Srinivasan, et al, "Sexual behavior, STD and HIV prevalence among men who have sex with men (MSM) attending a government STD clinic in Chennai, India" Poster exhibition at the XV International AIDS Conference, Bangkok, Thailand, July 11 16, 2004, Abstract no WePeC6092.

Thomas, et al, "HIV Prevention Interventions in Chennai, India: Are Men Who Have Sex With Men Being reached?" (2009a) 23:11 AIDS Patient Care \& STDs 1.

-.---., "Unseen and Unheard: Predictors of sexual risk behaviour and HIV infection among men who have sex with men in Chennai, India" (2009b) 21:4 AIDS Ed. \& Prev. 372

Heriawan, et al, Behavioral Surveillance Survey (BSS) Results in Indonesia 2004-2005, (Jakarta: Ministry of Health and Statistics-Indonesia, 2005).

Joseoef, et al, "High rate of sexually transmitted diseases among male transvestites in Jakarta, Indonesia" (2003) 14:9 Intl J STD AIDS 609, reprinted in Susami, et al, eds, Indonesia: HIV/AIDS Research Inventory 1995-2009, (National AIDS Commission, 2009).

Ministry of Health, Republic of Indonesia, HIV/STI Integrated Biological Behavioral Surveillance (IBBS) among Most-At-Risk Groups (MARG) in Indonesia, 2007, reprinted in Susami, et al, eds, Indonesia: HIV/AIDS Research Inventory 19952009, (National AIDS Commission, 2009).

Morineau, et al, "Sexual Risk Taking, STI and HIV Prevalence Among Men Who Have Sex with Men in Six Indonesian Cities" (2009) AIDS Behav.

Pisani, et al, "HIV, syphilis infection, and sexual practices among transgenders, male sex workers, and other men who have sex with men in Jakarta, Indonesia" (2004) 80 Sex. Trans. Infect. 536. 
Prabawatani, et al, "HIV, Sexually Transmitted Infections, and Sexual Risk Behavior Among Transgenders in Indonesia" (2010) AIDS Behav.

Hidaka, et al, "Substance use and sexual behaviours of Japanese men who have sex with men: A nationwide internet survey conducted in Japan" (2006) 6 BMC Pub. Health 239.

-----, インターネットによるMSMのHIV感染予防に関する行動疫学研究

[Epidemiological studies of MSM with HIV prevention activities on the Internet] (2007) AIDS Prevention Research Project Health and Labour Sciences Research Grants [in Japanese: translated by Author and Yoshikazu Kono].

-----, インターネットによるMSMのHIV感染予防に関する行動疫学研究ーREACH Online 2008 [Epidemiological studies of MSM with HIV prevention activities on the Internet-REACH Online 2008] (2008) AIDS Prevention Research Project Health and Labour Sciences Research Grants [in Japanese: Translated by Minako Yashiro].

-..---, グイ・バイセクシュアル男性の健康レポート2 [Gay and Bisexual Men's Health Report 2] (2007) AIDS Prevention Research Project Health and Labour Sciences Research Grants [in Japanese: Translated by Minako Yashiro].

-..--., "Sexual HIV Risk Behaviors, Mental Health and Milestone Events among Japanese Gay and Bisexual Men" (2004) 6:3 J. AIDS Res. 165 [in Japanese: translated by Jordan Bernick].

Ichikawa, "A Review of Prevention Activity of Gay Non Government Organization (NGO) to HIV Infection among Men who have sex with men (MSM) in Japan" (2007) 9:1 J. AIDS Res. 23 [in Japanese: translated by Jordan Bernick].

...-.-, "Prevention Intervention of HIV Infection among Men who have sex with men (MSM) - Project MASH Osaka" (2003) 5:3 J. AIDS Res. 174 [in Japanese: translated by Jordan Bernick].

-..--., "The HIV/AIDS epidemic among MSM in Japan: Background and gay NGO response", Presented at the Asian Administrators Meeting on HIV/AIDS, Tokyo, Japan, February 3-4, 2010.

Ichikawa, et al, 大阪地域の予防介入プログラムの評価と

HIV感染予防行動の関連要因に関する研究 [Research on behavioral factors associated with HIV prevention interventions and evaluate prevention programs in the region of Osaka] (2005) AIDS Prevention Research Project Health and Labour Sciences Research Grants [in Japanese: translated by Author and Yoshikazu Kono].

Kaneko, et al, "Cell phone survey using RDS to investigate MSM's social networks and HIV risk behavior in Japan", Presented at the 8th International Congress on AIDS in Asia and the Pacific, Colombo, Sri Lanka, August 19-23, 2007a.

-----, "HIV Testing and HIV Prevention Behavior Among Gay and Bisexual Men in Central Japan", Presented at the 6th International Nursing Conference, Seoul, Korea, November 6-8, 2007.

-----, 2006年NLGR・HIV抗体検査会の受検者の概要

一受検者への質問紙調査結果から[Summary of NLGR · HIV antibody test in 2006 - the results of a questionnaire to the examinees] (2006) AIDS Prevention Research Project Health and Labour Sciences Research Grants [in Japanese: 
translated by Author and Yoshikazu Kono].

-.----, 2007年NLGR・HIV抗体検査会の受検者の概要-

受検者への質問紙調查結果から [Summary of NLGR · HIV antibody test in 2007

- the results of a questionnaire to the examinees] (2007) AIDS Prevention Research

Project Health and Labour Sciences Research Grants [in Japanese: translated by Minako Yashiro].

-----, NLGR・HIV抗体検査会の受検者の概要 -アンケート調査結果から [A summary of NLGR HIV test examinees: results from questionnaire] (2005) AIDS Prevention Research Project Health and Labour Sciences Research Grants [in Japanese: translated by Minako Yashiro].

-.---, RDS法を用いた'hidden population'に対する調査法の開発 ゲイコミュニティーのソーシャルネットワーク内での介入の浸透度の評価 [Development of a survey of 'hidden population' Method for RDS - Evaluation of penetration of the intervention in the gay community social network] (2007) AIDS Prevention Research Project Health and Labour Sciences Research Grants [in Japanese: translated by Author and Yoshikazu Kono].

------, 行動ステージを用いたコミュニティーでのHIV予防啓発活動の評価大阪地域でのグイ向け商業施設利用者一の質問紙調查から [Evaluation of HIV prevention educational activities at the community stage for action - from the questionnaire to users for commercial gain in the Osaka area] (2007) AIDS Prevention Research Project Health and Labour Sciences Research Grants [in Japanese: translated by Author and Yoshikazu Kono].

Kimura, et al, 大阪の予防啓発の評価に関するクラブ調查による研究 [Survey research on the evaluation of educational prevention clubs in Osaka] (2006b) AIDS Prevention Research Project Health and Labour Sciences Research Grants [in Japanese: translated by Minako Yashiro].

------, 大阪の予防啓発の評価に関する研究ー2008年大阪クラブ調査報告 [Evaluation of prevention education in Osaka: Osaka 2008 Club Survey] (2008) AIDS Prevention Research Project Health and Labour Sciences Research Grants [in Japanese: translated by Minako Yashiro].

------, 大阪地域における予防行動調查の分析 -2010年クラブイベント調査 [Analysis of survey research - 2010 Club Event year preventive action in the Osaka area] (2010) AIDS Prevention Research Project Health and Labour Sciences Research Grants [in Japanese: translated by Author and Yoshikazu Kono].

-..---, 平成18年度大阪における予防啓発の評価に関する研究:

大阪クラブイベント参加者調査2006の結果 [Evaluation of prevention education in Osaka in 2006: Results of 2006 Survey Participants club event in Osaka] (2006a) AIDS Prevention Research Project Health and Labour Sciences Research Grants [in Japanese: translated by Minako Yashiro].

------, 東京における予防啓発の評価に関するクラブ調査による研究 [Survey research on the evaluation of educational prevention clubs in Tokyo] (2007) AIDS Prevention Research Project Health and Labour Sciences Research Grants [in Japanese: translated by Author and Yoshikazu Kono].

-.-.-, 東京の予防啓発の評価に関する研究一2009年東京クラブ調査報告 [Tokyo Club survey-2009 Evaluation of prevention education in Tokyo] (2009) AIDS 
Prevention Research Project Health and Labour Sciences Research Grants [in Japanese: translated by Author and Yoshikazu Kono].

--.---, 東京地区のクラブイベント参加者に対する質問票調查結果の概要 [A summary on the results of survey targeted to participants in club events in Tokyo] (2005) AIDS Prevention Research Project Health and Labour Sciences Research Grants [in Japanese: translated by Minako Yashiro].

Okuda, et al, "A Survey investigating HIV Optimism, HIV Risk Behavior and Psychological Factors of Japanese Gay and Bisexual Men Living in the Tokyo and Kanto Area" (2008) 10:3 J. AIDS Res. 191 [in Japanese: translated by Jordan Bernick].

Onitsuka, et al, "The HIV/AIDS epidemic among MSM in Japan: Background \& gay NGO responses", Presented at the IX International Congress on AIDS in Asia and the Pacific, Bali, Indonesia, August 9-13, 2009.

Shingae, et al, "Sexual Behavior and Self-reported Sexual Identity among MSM (Men who have Sex with Men) Participating in HIV Testing Evnets at Nagoya City, Tokai Area" (2009a) 11:3 J. AIDS Res. 255 [in Japanese: translated by Jordan Bernick].

-----, 名古屋市で開催されたMSMを対象としたHIV検査会受検者質問紙調查 -2008年実施のNLGR2008とM検における受検者の特性に関して [M test takers about the properties of the questionnaire NLGR2008 implementation of 2008 examinees and HIV testing for MSM meeting was held in Nagoya] (2008b) AIDS Prevention Research Project Health and Labour Sciences Research Grants [in Japanese: translated by Author and Yoshikazu Kono].

-..-..., 名古屋市の保健所で実施されたMSM (Men who have Sex with Men) を対象とした HIV抗体検査会参加者の特性に関する研究 [MSM was conducted in Nagoya City Public Health Center (Men who have Sex with Men) Study on the characteristics of the participants were meeting for HIV testing] (2009b) AIDS Prevention Research Project Health and Labour Sciences Research Grants [in Japanese: translated by Author and Yoshikazu Kono].

-----, 東北地域におけるRDS法を用いた萼帯電話調査 [Mobile telephone survey using RDS methods in Tohoku region] (2009c) AIDS Prevention Research Project Health and Labour Sciences Research Grants [in Japanese: translated by Author and Yoshikazu Kono].

-----, 東北地域のゲイ・バイセクシュアル男性を対象とした行動科学的調查 [Behavioral science research aimed at gay bisexual men in the Tohoku region] (2009d) AIDS Prevention Research Project Health and Labour Sciences Research Grants [in Japanese: translated by Author and Yoshikazu Kono].

-----, 福岡地域のMSM におけるHIV 予防に関する質問紙調査の経年比較一バー顧客調查とスポーツ大会参加者 調査の結果か ら [Yearly comparison questionnaire about HIV prevention among MSM in the Fukuoka area - the results of the survey participants and sports bar, a customer survey] (2010) AIDS Prevention Research Project Health and Labour Sciences Research Grants [in Japanese: translated by Author and Yoshikazu Kono]. -..--.-, 福岡地域のMSMにおけるHIV予防に関する質問紙調查

一2008年実施のバー顧客調査より [Conducted a customer survey of 2008 bars 
questionnaire on HIV prevention among MSM in the Fukuoka area] (2008a) AIDS Prevention Research Project Health and Labour Sciences Research Grants [in Japanese: translated by Author and Yoshikazu Kono].

Shiono, et al, 大阪地域の予防介入プログラムの評価とHIV感染予防行動の関連要因に関 する研究 -バー顧客調査2009年の結果 [Research on behavioral factors associated with HIV prevention interventions and evaluate prevention programs in the region of Osaka: Customer Survey Results for 2009 Bar] (2009b) AIDS Prevention Research Project Health and Labour Sciences Research Grants [in Japanese: translated by Minako Yashiro].

-----, 東北地域のMSMにおけるHIV 感染に関連した行動に関する研究行動疫学調查の結果から [Research on behavior related to HIV infection among MSM in the Tohoku region - from the results of epidemiological research activities] (2010a) AIDS Prevention Research Project Health and Labour Sciences Research Grants [in Japanese: translated by Author and Yoshikazu Kono].

-----, 東海地域におけるMSMの予防行動に関する研究 -NLGR (Nagoya Lesbian \& Gay Revolution）来場者調查から [Research on preventive behavior of MSM in the Tokai region: NLGR (Nagoya Lesbian \& Gay Revolution) Visitors survey](2009a) AIDS Prevention Research Project Health and Labour Sciences Research Grants [in Japanese: translated by Jordan Bernick].

--.--, 東海地域のMSMにおける性行動と予防介入プログラムの評価に関する研究 [Evaluation of intervention programs and prevention sexual behavior among MSM in the Tokai region] (2010b) AIDS Prevention Research Project Health and Labour Sciences Research Grants [in Japanese: translated by Author and Yoshikazu Kono].

Takenaka and Ichikawa, HIV検査機関におけるMSMの受検動向 [Examination of trends in MSM HIV testing organizations (2005 2007)] (2007a) AIDS Prevention Research Project Health and Labour Sciences Research Grants [in Japanese: translated by Minako Yashiro].

-----, HIV検查機関におけるMSMの受検動向 [Examination of trends in MSM HIV testing organizations (2007)] (2007b) AIDS Prevention Research Project Health and Labour Sciences Research Grants [in Japanese: translated by Minako Yashiro].

------, 大阪地域のHIV検査機関におけるMSMの受検動向 [Examination of trends in HIV testing of MSM in the Osaka area agencies (2008)] (2008) AIDS Prevention Research Project Health and Labour Sciences Research Grants [in Japanese: translated by Minako Yashiro].

-.---., 大阪地域のHIV検查機関におけるMSMの受検動向 [Examination of trends in HIV testing of MSM in the Osaka area agencies (2009)] (2009) AIDS Prevention Research Project Health and Labour Sciences Research Grants [in Japanese: translated by Minako Yashiro].

--.---, 大阪地域のHIV検查機関におけるMSMの受検動向 [Examination of trends in HIV testing of MSM in the Osaka area agencies (2010)] (2010) AIDS Prevention Research Project Health and Labour Sciences Research Grants [in Japanese: translated by Minako Yashiro]. 
Kee, et al, "Sexual Behavioral Characteristics and the Knowledge of HIV/AIDS among Men who have Sex with Men in Republic of Korea", (2004) 37:3 J. of Prev. Med. and Pub. Health, 220 [in Korean].

Surin, "Republic of Korea" in Yamamoto and Itoh, eds, Fighting a Rising Tide: The Response to AIDS in East Asia (Tokyo: Japan Center for International Exchange, 2006) $156-171$.

Longfield, et al, "HIV Prevention Programming among Transgenders: Lesson from Laos" (2008) PSI Research \& Metrics, Working Paper No. 76.

Morineau, Center for HIV/AIDS/STI (CHAS), Ministry of Health, Lao PDR 2009 Surveillance surveys: Behavioral survey among service woman and Integrated biological and behavioral surveillance survey among men who have sex with men in Luang Prabang, (Vientiane: CHAS, 2009).

Panyanouvong, et al, "Interpersonal Communication Activities of PSI/Laos Associated with Trends toward Safer Sexual Behavior among Transgender in Laos" Presented the 135th annual meeting of the American Public Health Association, Washington DC, November 3-7, 2007, Abstract No 156422.

Population Services International (PSI), Laos (2006): HIV/AIDS TRaC Study among Transgenders in Luang Prabang, Vientiane, and Savannakhet - Second Round, (Vientiane: PSI, 2006).

Sheridan, et al, "HIV prevalence and risk behaviour among men who have sex with men in Vientiane Capital, Lao People's Democratic Republic, 2007" (2009) 23:3 AIDS 409 ,

Toole, et al, "Understanding male sexual behavior in planning HIV prevention programmes: lessons from Laos, a low prevalence country" (2006) 82 Sex. Trans. Infect. 135.

Kanter, et al, "Risk Behavior and HIV Prevalence among MSM in a Multi-Ethnic Society: A Venue-Based Study in Kuala Lumpur, Malaysia" (2011) 22 Intl. J. STD AIDS 30.

-----, "Risk behaviour and HIV Prevalence among Men who have Sex with Men in a Predominantly Muslim and Multi-Ethnic Society: A venue-based study in Kuala Lumpur, Malaysia", Presented at the 17th Conference on Retrovinuses and Opportunistic Infections, San Francisco, United States, February 16-19, 2010, Poster no 973.

Global Fund, The, Biological and Behavioural Survey on HIV/AIDS - 2008 Republic of Maldives (2008).

Davaalkham, et al, "High-risk status of HIV-1 infection in the very low epidemic country, Mongolia, 2007" (2009) 20 Intl. J. STD \& AIDS 391.

Ministry of Health of Mongolia, Second Generation HIV Surveillance: Mongolia, 2005 
(Ulaanbaatar: Ministry of Health of Mongolia, 2005).

-----, Second Generation HIV/STI Surveillance report, 2007 Mongolia (Ulaanbaatar: Ministry of Health of Mongolia, 2007).

WE Wh:

National AIDS Programme (NAP), Report of the HIV Sentinel Sero-surveillance Survey 2007 (Yangon: NAP, 2007).

------, Report of the HIV Sentinel Sero-surveillance Survey 2008 (Yangon: NAP, 2009).

10.

Acharya, et al, "HIV and STI prevalence among MSM in Kathmandu, Nepal", Presented at the XVI International AIDS Conference, Toronto, Canada, August 13-18, 2006, Abstract no MOPE0558.

Family Health International/Nepal (FHI/N), Integrated Bio-behavioral Survey (IBBS) among Men who have Sex with Men in the Kathmandu Valley: Round III - 2009, Summary Report (Kathmandu: FHI/N, 2008).

---.--, Integrated Bio-behavioral Survey (IBBS) among Men who have Sex with Men in the Kathmandu Valley - 2007 (Kathmandu: FHI/N, 2008).

-----, Integrated Bio-behavioral Survey (IBBS) among Men who have Sex with Men in the Kathmandu Valley: Final Report (Kathmandu: FHI/N, 2005).

Bokhari A, et al, "HIV risk in Karachi and Lahore, Pakistan: an emerging epidemic in injecting and commercial sex networks" (2007) 18:7 Intl. J. STD \& AIDS 486.

Collumbien, et al, "Multiple Risk Among Male and Transgender Sex Workers in Pakistan" (2008) 4:2-3 J. LGBT Health Research 71.

National AIDS Control Programme (NACP) - Canadian International Development Agency (CIDA), HIV Second Generation Surveillance in Pakistan: National Report Round 1, 2005, (Islamabad: NACP-CIDA, 2005).

-.---, HIV Second Generation Surveillance in Pakistan: National Report Round III, 2008, (Islamabad: NACP-CIDA, 2008).

National AIDS Control Programme (NACP) National Study of Reproductive Tract and Sexually Transmitted Infections: Survey of High Risk Groups in Lahore and Karachi, 2005 (Islamabad: NACP, 2005).

Naz Foundation International (NFI), "Social Assessment and Mapping of MSM in Lahore, Pakistan" (2002) online: <www.nfi.net>.

Rehan, et al, "Socio-sexual Behaviour of Hijras of Lahore" (2009) 59:6 J. Pak. Med. Assoc. 380.

Saleem, et al, "Risky Sexual Behavior, Knowledge of Sexually Transmitted Infections and Treatment Utilization Among a Vulnerable Population in Rawalpindi, Pakistan" (2008) 39:4 Southeast Asian J. Trop. Med. Public Health 642.

Mateo, et al, "HIV/AIDS in the Philippines" (2004) 43: Sup A AIDS Ed. \& Prev. 43.

National Epidemiology Center (NEC), Department of Health, Philippines, 2005

Integrated HIV Behavioral and Serologic Surveillance Findings: Summary Report, (Manila: NEC, Department of Health, 2005). 
-----, "This is it! Integrated HIV Behavioral and Serologic Surveillance" Presented at the IHBSSS National Dissemination Forum, Manila, December 11, 2009.

Philippines National AIDS Council (PNAC) Country Report of the Philippines January 2008 to December 2009: Follow-up to the Declaration of Commitment on HIV and AIDS United Nations General Assembly Special Session, (Manila, PNAC, 2010).

------, Follow-up to the Declaration of Commitment on HIV and AIDS United Nations General Assembly Special Session (UNGASS): Country Report of the Philippines January 2006 to December 2007, (Manila, PNAC, 2008).

Ramos-Jimenez and Lee, Male Sexual Risk Behavior and HIV/AIDS: A Survey in Three Philippine Cities (Manila: Family Health International, 2002).

Toh, et al, "Men having sex with men HIV sero-prevalence study in Singapore, a community based project to protect the MSM community", Presented at the XVII International AIDS Conference, Mexico City, Mexico, August 3-8, 2008.

Toh, "Country Report - Singapore", Presented at the Insular Southeast Asia Consultation on Male-to-Male Transmission of HIV, Bali, Indonesia, August 4-6, 2009.

Sig.

Ariyaratne, et al, (Companions on a Journey), Knowledge, Attitude and Practice in the gay community, gay identified men, and Men who have Sex with men in Sri Lanka, (Colombo: NSACP, 2007).

National STD/AIDS Control Program (NSACP), Ministry of Healthcare and Nutrition, Sri Lanka Behavioural Surveillance Survey: First Round Survey Results 20062007, (Colombo: NSACP, 2007).

-----, HIV Sentinel Sero-Surveillance Survey - Report on the Study of 2009 (Colombo: NSACP, 2010).

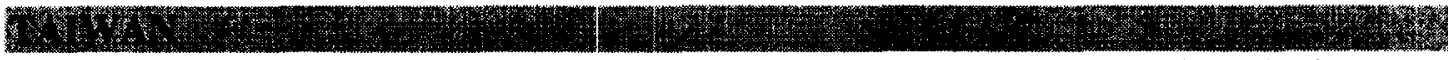

Hsieh, et al, "Estimating the Number of HIV-infected gay sauna patrons in Taipei area" (2006) 362 Physica A 495.

Ko, et al, "Prevalence of Human Immunodeficiency Virus and Sexually Transmitted Infections and Risky Sexual Behaviors Among Men Visiting Gay Bathhouses in Taiwan" (2006) 33:8 Sex. Trans. Dis. 467.

Lai, et al, "Molecular epidemiology of HIV-1 in men who have sex with men from gay saunas in Taiwan from 2000 to 2003", Presented at the XVth International AIDS Conference, Bangkok, Thailand, July 11-16, 2004, Abstract no WePeC6097.

National Cheng Kung University, "Evaluation of structural intervention of STI and HIV prevention at gay sauna" (2006) [in Traditional Chinese: translated by Cory Wong].

Yaoming University (HIV Research Center), "HIV and Syphilis prevention among MSM patrons in Taiwanese gay saunas" (2005) [in Traditional Chinese: translated by Cory Wong].

----- "Sexual behaviour and HIV prevalence among patrons of gay saunas in north and central Taiwan" (2004) [in Traditional Chinese: translated by Cory Wong]. 
Beyrer, et al, "High HIV, hepatitis C, and sexual risks among drug-using men who have sex with men in northern Thailand" (2005) 19:14 AIDS 1535.

Center for Disease Control (CDC), "HIV Prevalence Among Populations of Men Who Have Sex with Men - Thailand, 2003 and 2005" (2006) 55 Morb. Mortal Wkly. Rep 844.

Chemnasiri, et al, "Inconsistent condom use among young men who have sex with men, male sex workers, and transgenders in Thailand" (2010) 22:2 AIDS Ed. \& Prev. 100.

Chonburi Provincial Health Office (CPHO), Surveillance for HIV Prevalence and HIV Related Behaviors in Men Who Have Sex with Men (MSM), (Chonburi: CPHO, 2010).

Guadamuz, et al, "HIV Prevalence, Risk Behavior, Hormone Use and Surgical History Among Transgender Persons in Thailand" (2010) AIDS Behav.

Li, et al, "Sexual Behavior and Risk Factors for HIV Infection Among Homosexual and Bisexual Men in Thailand" (2009) 13 AIDS Behav. 318.

Mansergh, et al, "Inconsistent Condom Use with Steady and Casual Partners and Associated Factors among Sexually-Active Men who Have Sex with Men in Bangkok, Thailand" (2006) 10 AIDS Behav. 743.

National AIDS Prevention and Alleviation Committee, UNGASS Country Progress Report - Thailand: Reporting period January 2006 - December 2007 (Bangkok: Department of Disease Control, Ministry of Public Health, 2008).

van Griensven, et al, "Continuing High HIV Incidence in a Cohort of Men Who Have Sex With Men (MSM) in Bangkok, Thailand", Presented at the 16th Conference on Retroviruses and Opportunistic Infections, Montreal, Canada, February 8-11, 2009, Abstract no W-1007.

-----, "Evidence of a previously undocumented epidemic of HIV infection among men who have sex with men in Bangkok, Thailand" (2005) 19:5 AIDS 521.

------, "Trends in HIV Prevalence, Estimated HIV Incidence, and Risk Behavior Among Men Who Have Sex With Men in Bangkok, Thailand, 2003-2007" (2010) 53:2 J. AIDS 234.

Wimonsate, et al, "Factors Associated with HIV Testing History and Returning for HIV Test Results Among Men Who Have Sex with Men in Thailand" (2011) 15 AIDS Behav. 693.

Lee, et al, "Behavioural Surveillance Survey in Timor-Leste, 2008: First Round Results for Men who have Sex with Men (MSM)" (2008) International HIV Research Group, University of New South Wales.

Lee, "Country Update: Timor-Leste", Presented at the Insular Southeast Asia Consultation on Male-to-Male Transmission of HIV, Bali, Indonesia, August 4-6, 2009 [unpublished].

Pisani, et al, "Basing policy on evidence: low HIV, STIs, and risk behaviour in Dili, East Timor argue for more focused interventions" (2006) 82 Sex. Trans. Infect. 88. 
Cao, et al, "Knowledge, attitudes and practices on HIV/AIDS among men who had sex with men (MSM) and visited the Consultation Unit of the Pasteur Institute in Hochiminh City (PIHCMC) Vietnam", Poster Exhibition at the XIV International AIDS Conference, Barcelona, Spain, July 7-12, 2002, Abstract no MoPeC3447.

Colby, "HIV knowledge and risk factors among men who have sex with men in Ho Chi Minh City, Vietnam" (2003) 32 J. AIDS 80.

Colby, et al, "Down on the farm: homosexual behaviour, HIV risk and HIV prevalence in rural communities in Khanh Hoa province, Vietnam" (2008) 84 Sex. Trans. Infect. 439.

Nguyen, et al, "Prevalence and Risk Factors Associated with HIV infection among men who have sex with men in Ho Chi Minh City, Vietnam" (2008) 12 AIDS Behav. 476.

-----, "Risk Factors for HIV Transmission Among Men Having Sex With Men in Vietnam" Presented at the VII International Congress on AIDS in Asia and the Pacific, Kobe, Japan 1-5 July, 2005.

St-Pierre, Evaluation of SCF (UK) HIV/AIDS Prevention Programme For Men Who Have Sex With Men (MSM): Final Report (1997).

Tan, et al, "HIV prevalence and risk factors among MSM in Khanh Hoa province", Presented at the XVI International AIDS Conference, Toronto, Canada, August 1318, 2006, Abstract no CDC1659.

Vietnam Administration of HIV/AIDS Control (VAAC), et al, "HIV/STI Integrated Behavioral and Biological Surveillance in Vietnam (IBBS) 2009 (Round 2)" [unpublished Excel data tables and PowerPoint presentation].

-.----, Results from the HIV/STI Integrated Biological and Behavioural Surveillance (IBBS) in Viet Nam 2005-2006, (Hanoi: Ministry of Health, 2006).

\subsection{SOGI Human Rights references}

Asia Pacific Forum, ACJ Reference: Human Rights, Sexual Orientation and Gender Identity - Background Paper, presented at the $15^{\text {th }}$ annual meeting of the Asia Pacific Forum of National Human Rights Institutions, Bali, Indonesia August 3-5, 2010.

Bruce-Jones, Eddie, and Itaborahy, Lucas, State-sponsored Homophobia: A world survey of laws prohibiting same sex activity between consenting adults, (ILGA, 2011).

Godwin, John, Legal environments, human rights and HIV responses among men who have sex with men and transgender people in Asia and the Pacific: An agenda for action, (Bangkok: UNDP-APCOM, 2010).

Laurent, Erick, "Sexuality and Human Rights: An Asian Perspective" (2005) 48:3/4 J. Homosexuality 163.

Ottoson, Daniel, State-sponsored Homophobia: A world survey of laws prohibiting same sex activity between consenting adults, (ILGA, 2007).

-.----, State-sponsored Homophobia: A world survey of laws prohibiting same sex activity between consenting adults, (ILGA, 2008).

-----, State-sponsored Homophobia: $A$ world survey of laws prohibiting same sex activity between consenting adults, (ILGA, 2009). 
-----, State-sponsored Homophobia: A world survey of laws prohibiting same sex activity between consenting adults, (ILGA, 2010).

United Nations, "United Nations Treaty Collection", online: <http://treaties.un.org>.

United Nations Educational, Scientific and Cultural Organizations (UNESCO) Bangkok, Human Rights Protections for Sexual Minorities in Insular Southeast Asia: Issues and Implications for Effective HIV Prevention, (Bangkok: UNESCO Bangkok, 2011).

United States of America, Department of State (DoS), "2009 State Department Human Rights Reports: Sexual Orientation/Gender Identity References "(March 11, 2010).

Waaldijk, Kees, "Legal recognition of homosexual orientation in the countries of the world: A chronological overview with footnotes", (draft February 22, 2009), presented at The Global Arc of Justice - Sexual Orientation Law Around the World conference, Los Angeles, March 11-14, 2009.

World Health Organization (WHO), HIV/AIDS among men who have sex with men and transgender populations in South-East Asia: The current situation and national responses, (New Delhi: WHO Regional Office for South-East Asia, 2010).

Bangladesh Penal Code (1860).

Criminal Code of Procedure (1898).

Charman, Rachel, "Transgender Bangladeshis to Vote Today" (December 29, 2008)

PinkNews, online: <http://www.pinknews.co.uk/news/articles/2005-10095.html/>.

GayLawNet, "Bangladesh", online: <http://www.gaylawnet.com/laws/bd.htm>.

Imaan, Najrana and Alam, A T M Morshed, "Review Paper Analyzing the Existing Legal and Policy Provisions and Practices with respect to Human Rights in relation to People Living with HIV and AIDS in Bangladesh" (April 2008), online: $<\mathrm{http}: / /$ aidsdatahub.org/en/reference-librarycols2/human-rights/item/11700-theexisting-legal-and-policy-provisions-and-practices-with-respect-to-human-rightsimaan-n-and-alam-am-2008>.

Immigration and Refugee Board of Canada (IRB), "Bangladesh: Treatment of homosexuals including legislation, availability of state protection and support services", July 19,2010 , online:

$<$ http://www.unhcr.org/refworld/docid/4ddl 122f2.html>.

-.---, "Bangladesh: Treatment of homosexuals; legislation on homosexuality and its enforcement (2000-2003)", July 30, 2003, IRB Doc BGD41822.FE.

International Human Rights Program - Sexual Orientation and Gender Identity Project, University of Toronto, Faculty of Law, "Bangladesh: Country Report for use in refugee claims based on persecution relating to sexual orientation and gender identity" (March 27, 2011), online: < http://utorontoihrp.com/index.php/sogiresources/doc_download/77-bangladesh-report-2011>.

Personal communication from Premangshu Sarkar, senior legal officer for Bandhu Social Welfare Society (July 20, 2011).

Pudasaini, "Against the Order of Nature?" (March 2008) Himal Southasia, online: $<$ http://www.himalmag.com/component/content/article/4058-a-fillip-to-queerrights--reading-down-section-377.html>.

Wikipedia, "LGBT rights in Bangladesh" online:

<http://en.wikipedia.org/wiki/LGBT_rights_in_Bangladesh>. 
Law on Suppression of the Kidnapping. Trafficking and Exploitation of Human Persons (1996).

The Law on Aggravating Circumstances of Crimes (2001).

Abbot, Dr. Jason, "No Longer 'In the Bottle'? LGBT Rights in Malaysia and Southeast Asia" (April 26, 2011), Aid Netherlands Blog and News Agency, online: $<\mathrm{http} / / / \mathrm{www} . n \mathrm{l}$-aid.org/continent/south-east-asia/no-longer-\%E2\%80\%98in-thebottle\%E2\%80\%99-lgbt-rights-in-malaysia-and-southeast-asia/>.

Cambodian Center for Human Rights (CCHR), Coming Out in the Kingdom: Lesbian, Gay, Bisexual and Transgender People in Cambodia, (December 2010) online: $<$ www.sithi.org/admin/upload/media/\%5B2010-1209\%5DCOMING/2010_12_09_CCHR Report - Coming out in the Kingdom Lesbian, Gay, Bisexual and Transgender People in Cambodia (ENG).pdf $>$.

Immigration and Refugee Board of Canada (IRB), "Cambodia: Treatment of homosexuals in Cambodia; legislation regarding homosexuality; existence of gay rights organizations" August 14, 2003, IRB Doc KHM41863.FE.

Personal communication with Robert Finch, Legal Consultant for the Cambodian Center for Human Rights (CCHR), (August 9, 2011).

Sovan, Nguon, "Cambodia: Transsexual triumphs over gender adversity" Phnom Penh Post (September 25, 2008), reposted on TransGriot online: <http://transgriot.blogspot.com/2008/09/transsexual-triumphs-over-gender.html>.

Wikipedia, "LGBT rights in Cambodia" online: $<$ http://en.wikipedia.org/wiki/LGBT_rights_in_Camboida>.

Criminal Law of the People's Republic of China (1997).

Film Censorship Regulation (1997).

China Daily, "China court hears homosexual prostitution case", (February 8, 2004) China Daily, online: <http://www.chinadaily.com.cn/english/doc/200402/08/content_304163.htm>.

GayLawNet, "China", online: <http://gaylawnet.com/laws/cn.htm>.

Immigration and Refugee Board of Canada (IRB), "China: The situation and treatment of homosexuals 2003-2005)", September 26, 2005, IRB Doc CHN100544.E.

INTERPOL, "Sexual Offences Laws - China", online: <https://www.interpol.int/Public /Children/SexualAbuse/NationalLaws/csaChina.asp>.

Mountford, Tom, "The Legal Status and Position of Lesbian, Gay, Bisexual and Transgender People in the People's Republic of China" (2009), online: $<$ http://www.iglhrc.org/binary-data/ATTACHMENT/file/000/000/395-1.pdf>.

OneIndia News, "China can't punish man for raping man" (January 5, 2011) OneIndia News, online: <http://news.oneindia.in/2011/01/05/china-can-t-punish-man-forraping-man.html $>$.

Refugee Review Tribunal of Australia (RRT), “China, keywords: China-lesbians”, July 23, 2007, RRT Doc CHN32103.

Basic Law of the Hong Kong Special Administrative Region (1990, China).

Crimes Ordinance (Cap. 200, 1972). 
Hong Kong Bill of Rights Ordinance (Cap. 383, 1991).

Marriage Ordinance (Cap. 181, 1950).

Leung TC William Roy v. Secretary of Justice [2006] 4 HKLRD 211 (C.A.).

$W v$. Registrar of Marriages [2010] $6 \mathrm{HKC} 359$.

Chan, Peter, "The Lack of Sexual Orientation Anti-Discrimination Legislation in Hong

Kong: Breach of International and Domestic Legal Obligations" (2005) 9: 1 Intl. J. Human Rights 69.

Immigration and Refugee Board of Canada (IRB), "Hong Kong: Situation and treatment of homosexuals; availability of state protection and support services (2005 - May 2008)", May 15, 2008, IRB Doc HKG1028.40.E.

INTERPOL, "Sexual Offences Laws: China (Hong Kong)", online:

$<$ https://www.interpol.int/Public/Children/SexualAbuse/NationalLaws/ csaChinaHK.asp>.

Lau, Holning and Stotzer, Rebecca, "Employment Discrimination Based on Sexual Orientation: A Hong Kong Study" (2010) Employ Respons Rights J DOI 10.1007/s10672-010-9150-2.

Personal communication with Christine Line, Legal Director for the Hong Kong Refugee Advocacy Center (HKRAC), (August 29, 2011).

Immoral Traffic Prevention Act (1986).

Indian Penal Code (1860).

Naz Foundation v. Govt. of NCT of Delhi, 160 Delhi Law Times 277 (Delhi High Court 2009).

GayLawNet, "India" online: <http://www.gaylawnet.com/laws/in.htm>.

Immigration and Refugee Board of Canada (IRB), "India: Situation of homosexuals; availability of state protection (June 2004 - April 2009)", April 29, 2009, IRB Doc IND103130.E.

-----, "India: Update to IND32120.E of 25 June 1999 on the situation of homosexuals (June 1999 - April 2004)", May 13, 2005, IRB Doc IND42507.E.

INTERPOL, "Sexual Offences Laws: India", online: <https://www.interpol.int/Public/ Children/SexualAbuse/NationalLaws/csaIndia.asp $>$.

Joshi, Saurabh, "Being gay still a crime in the military" (2009)" online: $<\mathrm{http}: / /$ www.stratpost.com/being-gay-still-a-crime-in-the-military>.

Wikipedia, "Homosexuality in India" online: $<\mathrm{http} / / /$ en.wikipedia.org/wiki/Homosexuality_in_India>.

Constitution of the Republic of Indonesia, UUD, 1945.

Indonesian Penal Code.

Law No. 39/1999 on Human Rights.

Perda Kota Palembang No 8/2004 re: Eradication of Prostitution.

Pornograpi (Anti-Pornography Act) UU No. 44/2008.

GayLawNet, "Indonesia", online: <http://www.gaylawnet.com/laws/id.htm>.

Immigration and Refugee Board of Canada (IRB), "Indonesia: The situation of homosexuals; state protection and availability of support groups", July 3, 2008, IRB Doc IDN102828.E. 
------, "Indonesia: Treatment of Muslim homosexuals in Indonesia, both by the Muslim community and the authorities, especially the police; available state protection (1999-2000)", July 19, 2000, IRB Doc IDN34972.E.

------, "Indonesia: Update to IDN34972 of 19 July 2000 regarding the treatment of Muslim homosexuals in Indonesia, both by the Muslim community and the authorities, especially the police; available state protection", 28 May 2004, IRB Doc IDN42668.E.

International Gay and Lesbian Human Rights Commission (IGLHRC), "Human Rights Abuses Against Sexual Minorities in Indonesia" (November 2007) report submitted to the United Nations Human Rights Council fro its 2008 Universal Periodic Review on November 19, 2007.

INTERPOL, "Sexual Offences Laws: Indonesia", online: <https://www.interpol.int/ Public/Children/SexualAbuse/NationalLaws/csaIndonesia.asp>.

Wikipedia, "LGBT rights in Indonesia" online: $<$ http://en.wikipedia.org/wiki/LGBT_rights_in_Indonesia>.

Japanese Penal Code (1907).

Law Concerning Special Cases in Handling Gender for People with Gender Identity Disorder (Law No. 111 or 2003).

Tokyo High Court, Case no H6-Ne-1580, 16 September 1997.

Associated Foreign Press, "Japan allows its citizens same-sex marriage abroad" (March 28, 2009) The Japan Times, online: $<$ http://www.japantimes.co.jp/text/nn20090328a2.html>.

GayJapanNews, et al "The Violations of the Rights of Lesbian, Gay, Bisexual and Transgender Persons in JAPAN: A Shadow Report" report submitted to the Human Rights Committee, October 2008.

-----, "Joint Submission of the Universal Period Review on: Japan" (February 8, 2008)

GayLawNet, "Japan", online: <http://www.gaylawnet.com/laws/jp.htm>.

International Gay and Lesbian Human Rights Commission (IGLHRC), "Japan:

Psychiatrists Remove Homosexuality from List of Disorders" (June 1, 1995) online: $<$ http://www.iglhrc.org/cgi-bin/iowa/article/takeaction/resourcecenter/53.html $>$.

-----, "Japan: Victory in Japan" December 16, 2000, online: <http://www.iglhrc.org/cgibin/iowa/article/takeaction/globalactionalerts/755.html $>$.

INTERPOL, "Sexual Offences Laws: Japan", online: <https://www.interpol.int/Public/ Children/SexualAbuse/NationalLaws/csaJapan.asp>.

Lunseng, Wim, "LGBT Rights in Japan" (2005) 17 Peace Review: A Journal of Social Justice 143.

Taniguichi, Hiroyuki, "The Legal Situation Facing Sexual Minorities in Japan" (2006) 12 Intersections: Gender, History and Culture in the Asian Context, online: $<\mathrm{http}$ ://intersections.anu.edu.au/issue 12/taniguchi.html>.

Wikipedia, "LGBT rights in Japan", online: <http://en.wikipedia.org/wiki/LGBT_rights_in_Japan>.

-----, "Same-sex marriage in Japan", online: <http://en.wikipedia.org/wiki/Samesex_marriage_in_Japan>. 


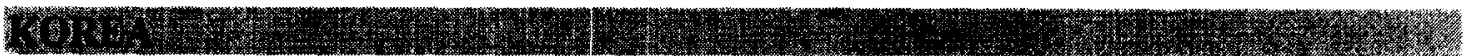

Military Penal Code.

Regulation on Physical Examinations of Recruits (Department of Defence Order no. 556). Special Law on Prostitution and the Sex-Trade Prevention Act.

Youth Protection Law (1997).

In re Change of Name and Correction of Family Register (2004) Seu 42, delivered on June 22, 2006.

Bong, Youngshik, "The Gay Rights Movement in Democratizing Korea" (2009) 32 Korean Studies 86.

GayLawNet, "Korea", online: <http://www.gaylawnet.com/laws/kr.htm>.

Immigration and Refugee Board of Canada (IRB), "Korea, Republic of: Treatment of homosexuals, including legislation, availability of state protection and support services" November 30, 2009, IRB Doc KOR103306.E.

-.---., "Korea, Republic of: Compulsory military service including the length of service, possibility of conscientious objection and grounds for exemption; consequences for draft evaders; policy on military service of homosexuals; impact that revealing sexual orientation before entering the military or while serving would have on the person's military service, post-military employment, ability to travel and social and economic status" February 26, 2007, IRB Doc KOR102151.E.

-..---, "Korea: Policy on military service of homosexuals; impact that revealing sexual orientation before entering the military or while serving would have on the person's military service, post-military employment, ability to travel and social and economic status (2002-2004)" November 8, 2004, IRB Doc KOR43093.E.

-.---., "Republic of Korea: Current situation of, and protection available to, homosexual, lesbian, bisexual, and transgender citizens" May 27, 2002, IRB Doc KOR39176.E.

Refugee Review Tribunal of Australia (RRT), "South Korea, keywords: South Korea Homosexuals - Transgender People - Transsexuals - Legal provisos - Military Marriage - HIV/AIDS" November 26, 2008, RRT Doc KOR34062.

Wikipedia, "Legal aspects of transsexualism", online: $<\mathrm{http}: / /$ en.wikipedia.org/wiki/Legal_aspects_of_transsexualism>.

-----, "LGBT rights in South Korea", online: <http://en.wikipedia.org/wiki/LGBT_rights_in_South_Korea>.

Penal Code.

GayLawNet, "Laos", online: <http://www.gaylawnet.com/laws/la.htm>.

INTERPOL, "Sexual Offences Laws: Laos", online: <https://www.interpol.int/Public /Children/SexualAbuse/NationalLaws/csaLaos.pdf $>$.

Wikipedia, "LGBT rights in Laos", online: $<$ http://en.wikipedia.org/wiki/LGBT_rights_in_Laos>.

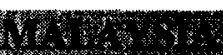

Film Censorship Guidelines.

Minor Offences Act (1955).

Penal Code, the Laws of Malaysia, 1936 (revised 1997, Act 574) current to January 1, 2006.

Sharia Criminal Offences Enactment (1995).
} 
$J-G$ v. Pengarah Jabatan Pendaftaran Negara [2005] 4 CLJ 710

Wong Chiou Yong v. Pendaftar Besar/Ketua Pengarah Jabatan Pendaftaran Negara [2005] 1 CLJ 622.

AsiaNews/Agencies, "In Malaysia fatwa condemns tomboy"(October 24, 2008) AsiaNews, online: <http://www.asianews.it/index.php?l=en\&art=13569>.

International Human Rights Program - Sexual Orientation and Gender Identity Project, University of Toronto, Faculty of Law, "Malaysia: Country Report for use in refugee claims based on persecution relating to sexual orientation and gender identity" (February 12, 2009), online: <http://utorontoihrp.com/index.php/sogiresources/doc_download/24-malaysia-report-2009>.

Immigration and Refugee Board of Canada (IRB), "Malaysia: The situation of sexual minorities (January 2002 - August 2005)" August 13, 2004, IRB Doc MYS42857.E.

------, "Malaysia: Treatment of sexual minorities (August 2004 - August 2005)" August 30, 2005, IRB Doc MYS100434.E.

------, "Malaysia: Update to MYS41879.E of 25 August 2003; arrests, conviction or charges against Islamic and non-Islamic lesbians, gays, and/or bisexuals; sentences imposed on these individuals; whether non-Muslim homosexual or bisexuals are targeted by the religious police (August 2003-June 2004)" June 21, 2004, IRB Doc MYS42734.E.

------, "Malaysia: Updates to MYS20281.E, MYS20097.E, and MYS31072.E on the treatment of homosexuals in Malaysia; penalties, if any applied to persons accused of homosexuality, including role of Islamic Council, and frequency of penalties being applied" January 18, 2002, IRB Doc MYS38131.E.

International Lesbian, Gay, Bisexual, Trans, and Intersex Associations (ILGA), "Malaysia (laws)", online: <http://ilga.org/ilga/en/countries/MALAYSIA/Law>.

Personal communication with Stuart Shaw, Second Secretary of the High Commission of Canada in Kuala Lumpur, Malaysia, (August 10, 2011).

Refugee Review Tribunal of Australia (RRT), "Country Advice Malaysia: Homosexuals - Legal Provisions - Religious Groups - State protection” June 29, 2010, RRT Doc MYS36927.

------, "Country Advice Malaysia: Johor - Homosexual Men - Homosexual organisations and venues - Ethnic Chinese" April 7, 2010, RRT Doc MYS36378. "Malaysia - keywords: Homosexuals", February 2, 2007, RRT Doc MYS31228

------, "Malaysia - keywords: Transsexuals - Treatment", June 15, 2009, RRT Doc MYS34932.

Regulation for Arrestable and Non-Arrestable Offences (2004).

Law on the Protection of the Rights of Children, Law No 9/91.

International Lesbian, Gay, Bisexual, Trans, and Intersex Associations (ILGA), "Maldives (laws)", online: <http://ilga.org/ilga/en/countries/MALDIVES/Law>.

Wikipedia, "LGBT rights in the Maldives", online: $<\mathrm{http}$ ://en.wikipedia.org/wiki/LGBT_rights_in_the_Maldives>.

GayLawNet, "Mongolia", online: <http://www.gaylawnet.com/laws/mn.htm>. Immigration and Refugee Board of Canada (IRB), "Mongolia: The treatment of 
homosexuals by authorities and by society in general; recourse available to those who have been harassed based on their sexual orientation (2004 - March 2007)"' March 16, 2007, IRB Doc MNG10216.E.

-----, "Mongolia: Update to MNG31446.E of 26 March 1999 on the current treatment of homosexuals by the authorities" December 5, 2004, IRB Doc MNG42200.E.

INTERPOL, "Sexual Offences Laws: Mongolia", online: <https://www.interpol.int/ Public/Children/SexualAbuse/NationalLaws/csaMongolia.asp>.

Refugee Review Tribunal of Australia (RRT), "Country Advice Mongolia: Homosexuals - Hospitals - Sexual Minorities" July 9, 2010, RRT Doc MNG36914.

-----, "Mongolia - keywords: Homosexuals - Attitudes towards homosexuals - Police protections - GLBT groups", May 20, 2008, RRT Doc MNG33314.

-----, "Mongolia - keywords: Homosexuals - Police protection", April 10, 2008, RRT Doc MNG33121.

--.--, "Mongolia - keywords: Homosexuals - Universities", February 4, 2008, RRT Doc MNG32859.

-----, "Mongolia - keywords: Lesbians - LGBT - State protection - Societal attitudes Support groups", September 4, 2009, RRT Doc MNG35228.

Wikipedia, "LGBT rights in Mongolia", online: $<$ http://en.wikipedia.org/wiki/LGBT_rights_in_Mongolia >

Penal Code (1860).

International Lesbian, Gay, Bisexual, Trans, and Intersex Associations (ILGA), "Myanmar (laws)", online: <http://ilga.org/ilga/en/countries/MYANMAR/Law>.

INTERPOL, "Sexual Offences Laws: Myanmar", online: <https://www.interpol.int/ Public/Children/SexualAbuse/NationalLaws/csaMyanmar.asp>.

Wikipedia, "LGBT rights in Burma", online: $<$ http://en.wikipedia.org/wiki/LGBT_rights_in_Burma>.

\section{Mins}

Criminal Code.

Sunil Babu Pant v. Government of Nepal, Writ No. 917 of the year 2064 (BS) (2007). GayLawNet, "Nepal", online: <http://www.gaylawnet.com/laws/np.htm>.

International Human Rights Program - Sexual Orientation and Gender Identity Project, University of Toronto, Faculty of Law, "Nepal: Country Report for use in refugee claims based on persecution relating to sexual orientation and gender identity" (November 5, 2011), online: <http://utorontoihrp.com/index.php/sogiresources/doc_download/94-nepal-report->.

INTERPOL, "Sexual Offences Laws: Nepal", online: <https://www.interpol.int/Public/ Children/SexualAbuse/NationalLaws/csaNepal.pdf $>$.

Rai, Neetij, "Rape: With Reference to Nepalese Legal Provisions" Paper prepared for Kathmandu School of Law, (May 11, 2010).

Refugee Review Tribunal of Australia (RRT), "Country Advice Nepal: Sexual minorities - Homosexuals - Blue Diamond Society", November 24, 2010, RRT Doc NPL37600.

Times of India, "New law threatens to crush Nepal's gays" (June 9, 2011) Times of India, online: <http://m.timesofindia.com/PDATOI/articleshow/8789293.cms>. 
Wikipedia, "LGBT rights in Nepal", online:

$<$ http://en.wikipedia.org/wiki/LGBT_rights_in_Nepal>.

Hudood Ordinance (Islamic Law).

Pakistan Suppression of Prostitution Ordinance (1961).

Penal Code (Act XLV of 1860).

GayLawNet, "Pakistan", online: <http://www.gaylawnet.com/laws/pk.htm>.

Immigration and Refugee Board of Canada (IRB), "Pakistan: Information regarding Muslim law on homosexuality", November 1, 1991, IRB Doc PAK9462.

-----, "Pakistan: Situation of homosexuals in urban centers, particularly in Islamabad, Karachi and Lahore (December 2007 - November 2009)", November 18, 2009, IRB Doc PAK103285.E.

.-.--, "Pakistan: Situation of homosexuals, including the application of laws towards homosexuals, the number of prosecution of homosexuals and their outcomes; whether any regions have an open and active gay community", November 29, 2007, IRB Doc PAK102660.E.

--.---, "Pakistan: Update to PAK42114.E of 17 October 2003 on the situation of homosexuals, including the availability of state protection (October 2003 - July 2004)", July 27, 2004, IRB Doc PAK42801.E.

International Gay and Lesbian Human Rights Commission (IGLHRC), "Human Rights and Transgender People in Pakistan" (February 2008), report submitted to the UN Human Rights Council for the 2008 Universal Periodic Review, online: <www.iglhrc.org/binary-data/ATTACHMENT/file/000/000/73-1.pdf >.

International Human Rights Program - Sexual Orientation and Gender Identity Project, University of Toronto, Faculty of Law, "Homosexuality in Pakistan: Persecution, Fundamentalist Opposition, and Lack of State Protection" (October 7, 2008), online: <http://utorontoihrp.com/index.php/sogi-resources/doc_download/28pakistan-report-2008>.

International Lesbian, Gay, Bisexual, Trans, and Intersex Associations (ILGA), "Pakistan (laws)", online: <http://ilga.org/ilga/en/countries/PAKISTAN/Law>.

INTERPOL, "Sexual Offences Laws: Pakistan", online: <https://www.interpol.int/Public/ Children/SexualAbuse/NationalLaws/csaPakistan.pdf $>$.

Refugee Review Tribunal of Australia (RRT), "Pakistan - keywords: Transsexuals Cross-dressing - Hijras - Homosexuality - Legal provisions - Sharia law - State protection", May 20, 2009, RRT Doc PAK34794.

Wikipedia, "LGBT rights in Pakistan", online:

$<$ http://en.wikipedia.org/wiki/LGBT_rights_in_Pakistan>.

An Act Providing for a Magna Carta of Social Workers (2007) Act no. 9432.

Anti-Trafficking in persons Act of 2003 (2003).

Military Code of Ethics.

Revised Penal Code of the Philippines (1997) Act no. 8353.

Ang Ladlad v. Comelec, GR. No. 190582, 8 April 2010.

People of the Philippines v. Alvin J. Ignacio, G.R. No. 114849, 24 August 1998.

Republic of the Philippines v. Jennifer B. Cagandahan, G.R. No. 166676, September 12, 
2008.

Silverio v. Republic, GR No. 174689, October 22, 2007.

Chan Robles, Virtual Law Library, "Philippines Laws, Statutes and Codes", online: $<\mathrm{http} / / / \mathrm{www} . c h a n r o b l e s . c o m /$ republicactno8353.htm>.

Immigration and Refugee Board of Canada (IRB), "Philippines: treatment of homosexuals and state protection available (2000-2005)", September 15, 2005, IRB Doc PHL100477.E.

INTERPOL, "Sexual Offences Laws: Philippines", online: <https://www.interpol.int /Public/Children/SexualAbuse/NationalLaws/csaPhilippines.pdf>.

Personal communication with Ging Cristobal of LAGABLAB, (March 25, 2009).

Wikipedia, "LGBT rights in the Philippines", online: $<$ http://en.wikipedia.org/wiki/LGBT_rights_in_the_Philippines>.

Free-to-Air Television Programme Code (2004).

Miscellaneous Offences Act.

Singapore Penal Code (Cap. 224, 2008 Revised Edition).

Societies Act.

Women's Charter (Cap. 353, 1996 Revised Edition).

Lim Ying v. Hiok Kian Ming Eric, 1 SLR: 184-196; 1992.

P.P. v. Tan Kuan Meng, 30 January 1996); C.C. No. 62 of 1994 (H.C.).

GayLawNet, "Singapore", online: <http://www.gaylawnet.com/laws/sg.htm>.

Immigration and Refugee Board of Canada (IRB), "Singapore: Treatment of homosexuals and people living with HIV/AIDS (1999-2003)", February 14, 2003, IRB Doc SGP40800.E.

Leong, Laurence Wai-Teng, "Singapore" in D. West and R. Green, eds, Sociolegal Control of Homosexuality: A Multi-Nation Comparison (New York: Plenum Press, 1997).

United States Bureau of Citizenship and Immigration Services, "Singapore: Human Rights Situation of Homosexuals", December 20, 1999, SGP00001.ZNK.

Wikipedia, "LGBT rights in Singapore", online: $<$ http://en.wikipedia.org/wiki/LGBT_rights_in_Singapore>.

Penal Code (1883).

Vagrants Ordinance.

GayLawNet, "Sri Lanka", online: <http://www.gaylawnet.com/laws/lk.htm>.

INTERPOL, "Sexual Offences Laws: Sri Lanka", online: <https://www.interpol.int /Public/Children/SexualAbuse/NationalLaws/csaSriLanka.asp >.

Women's Support Group (WSG) Sri Lanka, "The Status of Lesbians, Bisexual Women and Transgendered Persons in Sri Lanka: NGO Shadow Report to the Committee on the Elimination of All Forms of Discrimination Against Women" January 2011, online: $<\mathrm{http} / / / \mathrm{www}$.ohchr.org/english/bodies/cedaw/docs/ngos/WSG_SriLanka48.pdf>.

Wikipedia, "LGBT rights in Sri Lanka", online: $<$ http://en.wikipedia.org/wiki/LGBT_rights_in_Sri_Lanka>. 
GayLawNet, "Taiwan", online: <http://www.gaylawnet.com/tw.html>.

GayTimes, "Gay Taiwan - Gaytimes" online: <http://www.gaytimes.co.uk/Hotspots/ GayGuide-action-Country-countryid-924.html $>$.

Tsai Wen-ting, translation by David Mayer, "Taiwan Panorama - Transsexual Rights", (November 2002) online: <http://www.taiwan-panorama.com/en/show_issue.php? id $=2002119111073 \mathrm{e}$.txt\&table1=2\&h1=About Taiwan\&h2=Gender Issues $>$.

Wikipedia, "LGBT rights in the Republic of China", online: $<$ http://en.wikipedia.org/wiki/LGBT_rights_in_Taiwan>.

Constitution (2007).

Criminal Code Amendment Act (No. 19) B.E. 2550 (2007).

Prostitution Prevention and Suppression Act.

365Gay.com, "Thailand OKs Gay, Transsexual Soldiers" (August 10, 2005), online: $<$ http://www.365gay.com/newscon05/08/08/1005thaiArmy.htm>.

GayLawNet, "Thailand", online: <http://www.gaylawnet.com/th.html>.

Immigration and Refugee Board of Canada (IRB), "Thailand: Situation and treatment of homosexuals, transsexuals and transgender persons; whether the government updated the constitution to provide rights to homosexuals, transsexuals and transgender persons (2005-2007", January 7, 2008, IRB Doc THA102695.E.

Wikipedia, "LGBT rights in Thailand", online: $<\mathrm{http}: / /$ en.wikipedia.org/wiki/LGBT_rights_in_Thailand $>$.

Constitution (2002).

Immigration and Asylum Act (Law No. 9/2003).

Indonesian Penal Code.

Labour Code (UNTAET/REG/2002/5).

Timorese Penal Code (2009).

Marriage and Family Law (2000).

Penal Code, online: <http://www.worldlii.org/vn/legis/pc66>.

Adopt Vietnam, "Vietnam Adoption Agency Program: Plan Loving Adoption Now (PLAN)", online: <http://www.adoptvietnam.org/adoptionagencydirectory/ planadoptionagency.htm $>$.

GayLawNet, "Vietnam", online: <http://www.gaylawnet.com/laws/vn.htm>.

Frank, "On the Legality of Homosexuality in Vietnam" reposted from the VN-GBLF Email forum, online: $<$ http://www.utopia-asia.com/vietlaw.htm>.

Immigration and Refugee Board of Canada (IRB), "Vietnam: Treatment of homosexuals by the society and the government, particularly those who are HIV-positive, whether the government provides social assistance or medical coverage to HIVpositive individual, and whether the results of HIV testing remain confidential or can be released to the public", July 1, 1998, IRB Doc VNM29783.E.

------, "Viet Nam: Treatment of homosexuals, including legislation, availability of state protection and support services", January 8, 2010, IRB Doc VNM103323.E. 
Personal communication with Alex Hoa, co-founding member of the Gay Vietnamese Alliance, (August 13, 2011).

Refugee Review Tribunal of Australia (RRT), "Country Advice Vietnam - Treatment of Lesbians”, February 22, 2010, RRT Doc VNM36120.

-.---., "Vietnam - keywords: Homosexuals - Lesbians - Discrimination - Violence Legislation - State protection", January 25, 2008, RRT Doc VNM32852.

Wikipedia, "LGBT rights in Vietnam", online: $<h t t p: / / e n . w i k i p e d i a . o r g / w i k i / L G B T$ rights_in_Vietnam>. 